Universidade de São Paulo

InSTITUTO DE FÍ́SICA

\title{
Processos Eletro-Induzidos em Complexos de Timina e Uracila
}

\author{
Lucas Medeiros Cornetta
}

Orientador: Prof. Dr. Márcio Teixeira do Nascimento Varella

Tese de doutorado apresentada ao Instituto de Física da Universidade de São Paulo, como requisito parcial para a obtenção do título de Doutor(a) em Ciências.

Banca Examinadora:

Profa. Dra. Kaline Coutinho - Presidente (IF-USP)

Prof. Dr. Filipe Ribeiro Ferreira da Silva (FCT-NOVA - Externo)

Prof. Dr. Marco Aurelio Pinheiro Lima (IF-UNICAMP(ESALQ))

Prof. Dr. Antonio Carlos Borin (IQ-USP)

Profa. Dra. Lucy Vitoria Credidio Assali (IF-USP) 


\section{FICHA CATALOGRÁFICA}

\section{Preparada pelo Serviço de Biblioteca e Informação}

do Instituto de Física da Universidade de São Paulo

Cornetta, Lucas Medeiros

Processos eletro-induzidos em complexos de timina e uracila. São Paulo, 2019.

Tese (Doutorado) - Universidade de São Paulo. Instituto de Física.

Orientador: Prof. Dr. Marcio Teixeira do Nascimento Varella Departamento: Física Geral

Área de Concentração: Espalhamento de Elétrons por Biomoléculas em Solução

Unitermos: 1. Espalhamento; 2. Elétrons; 3. Solvatação; 4. DNA. 
University of São Paulo

Physics Insitute

\title{
Electro-Induced Processes in Thymine and Uracil Complexes
}

\author{
Lucas Medeiros Cornetta
}

Supervisor: Prof. Dr. Márcio Teixeira do Nascimento Varella

Thesis submitted to the Physics Institute of the University of São Paulo in partial fulfillment of the requirements for the degree of Doctor of Science.

Examining Committee:

Profa. Dra. Kaline Coutinho - Presidente (IF-USP)

Prof. Dr. Filipe Ribeiro Ferreira da Silva (FCT-NOVA - Externo)

Prof. Dr. Marco Aurelio Pinheiro Lima (IF-UNICAMP(ESALQ))

Prof. Dr. Antonio Carlos Borin (IQ-USP)

Profa. Dra. Lucy Vitoria Credidio Assali (IF-USP) 



\section{Agradecimentos}

Não serei capaz de expressar minha gratidão a todos que, direta ou indiretamente, foram responsáveis por possibilitar a realização deste trabalho ao longo dos últimos anos. Porém, aqui me dedico a tentar reconhecer e agradecer os grandes pilares em que tive a oportunidade e a honra de me apoiar. Assim, primeiramente, agradeço ao Instituto de Física da Universidade de São Paulo, que desde 2009 vem sendo o principal lar do meu desenvolvimento científico, técnico, profissional e pessoal. Agradeço a todos os meus professores e professoras, que ao longo de tantas disciplinas, ensinamentos e discussões durante minha graduação e pós-graduação, sequer sabem o papel que desempenharam em minha formação.

Agradeço à Fundação de Amparo à Pesquisa do Estado de São Paulo (FAPESP) pelo fomento do meu projeto de doutorado desde 2015 (processo 2015/17273-5), e por ter proporcionado a realização de diversas atividades de valor inestimável, dentre elas um intercâmbio na Universidade de Stanford (CA) em 2018 (processo 2018/022572), participação em vários congressos nacionais e internacionais, e consequentemente o contato com diversos pesquisadores importantes da comunidade científica. Nesse contexto agradeço também ao Conselho Nacional de Desenvolvimento Científico e Tecnológico $(\mathrm{CNPq})$ e à Coordenação de Aperfeiçoamento de Pessoal de Nível Superior (CAPES), por terem fomentado os primeiros meses do meu projeto.

A meus pais, Victor Cornetta Júnior e Simone Medeiros Cornetta, e a minha irmã, Mariana Medeiros Cornetta, por sempre acreditarem em mim, me motivarem e me apoiarem. Vocês foram e ainda são os principais responsáveis pela minha condição de bem suceder.

Ao prof. Dr. Márcio Teixeira do Nascimento Varella, primeiramente pela con- 
fiança, oportunidade e orientação. Obrigado por acreditar diversas vezes no Lucas de 2012, no Lucas de 2013, no de 2014, e assim, sucessivamente, por acreditar em mim até os dias de hoje. Agradeço pela amizade, pelos conselhos, pela tutoria, pelas discussões valiosas sobre física, ciência e sobre a nossa profissão.

À Vanessa França Pegoraro, dedico um agradecimento especial. Agradeço toda a força, todo o carinho e todos os conselhos durante os últimos anos. Obrigado pelo amparo, por ser um exemplo diário e por acreditar em mim, muitas vezes mais do que eu mesmo. Além disso, obrigado por aturar minha personalidade excessivamente científica e metódica em assuntos do nosso dia-a-dia.

A todos os alunos de pós-graduação do Grupo de Física Molecular e Modelagem, pelo alto nível das discussões diárias, pelas recomendações, interações e trocas de experiências. Obrigado pela força e pela união. Nesse contexto, agradeço também ao prof. Dr. Sylvio Canuto e à profa. Dra. Kaline Coutinho por todas as orientações, aulas e ensinamentos. Também faço um agradecimento especial ao Dr. Fábris Kossoski pela amizade altamente produtiva, pelas discussões sobre ciência, futuro e sobre a vida.

Por fim agradeço ao prof. Dr. Todd Martinez, da Universidade de Stanford, que durante seis meses me recebeu em seu grupo como um estudante visitante. O período em que estive lá foi extremamente enriquecedor em diversos sentidos. Agradeço a todos os alunos e pós-doutorandos de seu grupo por me receberem, e por todas as dicussões engrandecedoras.

A todos muito obrigado, Lucas Medeiros Cornetta. 
"New truths become evident when new tools become available"

(Rosalin Sussman Yallow) 



\section{Resumo}

Os danos causados em biomoléculas devido a colisões de elétrons de baixas energias são alvos de muitos estudos teóricos e experimentais. Uma classe de interesse particular dessas biomoléculas são unidades de fitas simples de DNA e RNA. Nesse contexto, podemos estudar o problema da colisão através de um modelo mínimo, adotando nucleotídeos (ou subunidades) como alvo do processo colisional. Além da capacidade que as bases nitrogenadas possuem de capturar o elétron e desencadear fenômenos dissociativos, as mesmas também podem atuar como sensitizadoras em processos radioterapêuticos, devido a alta capacidade de gerarem radicais livres altamente reativos.

A partir disso, muitos esforços vêm sendo aplicados para se investigar possíveis novos sensibilizadores em processos radioterápicos, como 5-halouracilas ou outras uracilas modificadas. Nesse contexto, o trabalho realizado por Bowen et al. [1] aponta os compostos 5-OCNU e 5-SCNU como sendo possíveis candidatos. O projeto se propõe a caracterizar os estados aniônicos que iniciam os processos dissociativos nos dois compostos, usando técnicas de espalhamento e técnicas de estados ligados.

As motivações acerca do problema de espalhamento entre elétrons e classes particulares de biomoléculas são de natureza biológica. Sendo assim, alguns resultados obtidos para moléculas em fase gasosa podem ser um primeiro passo para o estudo das mesmas propriedades físicas em solução aquosa, mimetizando o ambiente biológico no qual se desencadeiam processos físicos de interesse. Portanto, em seguida, propomos um novo modelo para a inclusão de efeitos de solvente nas descrições da captura eletrônica em baixas energias. Nosso estudo se baseia na combinação de simulções clássicas de Monte Carlo e técnicas de espalhamento eletrônico. 
Por último, apresento também uma abordagem dependente do tempo baseada em técnicas MQC (mixed quantum-classical dynamics) para a dinâmica do ânion temporário da 5-bromouracila, um radiossensibilizador já bem conhecido. A dinâmica nuclear de estados ressonantes constitui um problema em aberto, e os desenvolvimentos realizados significam um novo passo em direção a novas metodologias.

Palavras-chave: Radiossensibilizadores, elétrons, espalhamento, ressonâncias, solvatação. 


\section{Abstract}

The damage to biomolecules due to low-energy electron collisions is the subject of many theoretical and experimental studies. A particular interesting class of biomolecules are single stranded units of DNA and RNA. In this context, we can study the collisional problem through a minimal model, considering nucleotides (or subunits) as the target of the scattering process. In addition to their ability to capture the electron and trigger dissociative phenomena, they also act as sensitizers in radiotherapeutic processes due to the high capacity of generating reactive free radicals.

Many efforts have been applied to investigate possible new sensitizers in radiotherapeutic processes, such as 5-halouracils or another modified uracils. In this context, the work by Bowen et al. [1] points to 5 -OCNU and 5-SCNU compounds as potential candidates. The work proposed the characterization of the anion states related to the dissociative processes in this two compounds, employing both scattering and bound states techniques.

The main motivations about the scattering problem between electrons and particular classes of biomolecules are related to biological interests. Thus, some results obtained for gas phase molecules can be a first step to the study of the same physical properties in aqueous solution, describing the biological environment in which physical processes are triggered. Therefore, we present a new methodology to include the solvent effects in the characterization of the electron attachment at low energies. Our study is based on the combination of classical Monte Carlo simulations and electron scattering techniques.

Finally, we also present a new novel on the time-dependent dynamics of the low lying negative ions of 5-bromouracil, a well stablished radiosensitizer. Nuclear dyna- 
mics of resonant states are an open problem, and our developments based on MQC (mixed quantum-classical dynamics) mean a new step toward new methodologies.

Keywords: Radiosensitizers, electrons, scattering, ressonances, solvation. 


\section{Sumário}

1 Introdução 1

1.1 Interação elétron-molécula e captura eletrônica dissociativa . . . . . . 2

1.2 Motivações e relevância biológica . . . . . . . . . . . . . . . 4

1.3 Radiossensibilizadores . . . . . . . . . . . . . . 7

1.4 Objetivos do Projeto . . . . . . . . . . . . . . . . 9

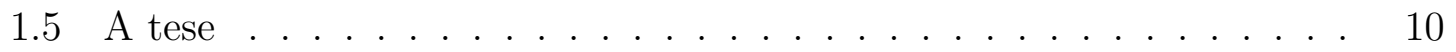

2 Métodos teóricos I: Estados ligados de moléculas isoladas 13

2.1 Estrutura eletrônica de estados ligados . . . . . . . . . . . . . . . 14

2.2 Funções Base . . . . . . . . . . . . . . . . . . . . . . . . . . . . 18

3 Métodos teóricos II: O espalhamento de elétrons e estados resso$\begin{array}{ll}\text { nantes } & 21\end{array}$

3.1 Aspectos gerais do problema de espalhamento . . . . . . . . . . . . 21

3.2 O método SMC . . . . . . . . . . . . . . . . . . . . 25

3.3 Implementação . . . . . . . . . . . . . . . . . . . . . . 28

3.4 As aproximações estático-troca e estático-troca mais polarização . . . 31

3.5 Seções de choque integral e caracterização de ressonâncias . . . . . 32

3.6 Considerações finais . . . . . . . . . . . . . . . . . 33

4 Espectro de ânions transientes da 5-SCNU e 5-OCNU 35

4.1 Resultados e discussão . . . . . . . . . . . . . . . . . . . . . . . . . 38

5 Métodos teóricos III: Modelos de solvatação 51 
5.1 Solvatação implícita - Modelos contínuos . . . . . . . . . . . . . . 52

5.2 Simulação Computacional . . . . . . . . . . . . . . . 55

5.2.1 Análise da simulação - Erros e distribuição radial de pares . . 61

$5.2 .2 \mathrm{O}$ método $\mathrm{QM} / \mathrm{MM}$ e s-QM/MM . . . . . . . . . 62

5.2 .3 Micro-solvatação . . . . . . . . . . . . . . . . . . . 64

6 Efeitos do solvente no espectro de estados aniônicos transientes de $\begin{array}{ll}\text { algumas biomoléculas } & 69\end{array}$

6.1 Uracila . . . . . . . . . . . . . . . . . . . . . . . . 71

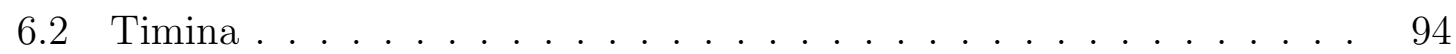

6.3 Halouracilas . . . . . . . . . . . . . . . . . . . . . . . 103

7 Métodos teóricos IV: Dinâmica nuclear dos ânions transientes $\quad 119$

7.1 O método ab initio multiple spawning . . . . . . . . . . . . . . . . . . 120

7.2 Adaptação do método AIMS para TNIs e seção de choque de DEA 126

8 A dinâmica dos ânions transientes da 5-BrU

8.1 Alguns cálculos e modelagens preliminares . . . . . . . . . . . . 135

8.2 Resultados da dinâmica . . . . . . . . . . . . . . . . . . 138

9 Conclusões 147

A Separação e aproximação de Born-Oppenheimer 151

$\begin{array}{lll}\text { B Funções de onda multi-eletrônicas } & 157\end{array}$

C O método Hartree-Fock e os métodos pós Hartree-Fock 161

$\begin{array}{ll}\text { D Teoria do Funcional da Densidade } & 169\end{array}$

E DFT: Modelos para o termo de correlação e troca e funcionais híbridos

F Quadratura utilizada nas integrais dos cálculos de espalhamento $\mathbf{1 7 5}$ 


\section{Lista de Figuras}

1.1 Esquema das superfícies de energia potencial ao longo de uma determinada coordenada de reação, separadas em quatro casos. No painel superior esquerdo, a curva preta $\left(\mathrm{S}_{0}\right)$ denota a energia eletrônica do estado fundamental da molécula neutra e a curva pontilhada verde representa a energia eletrônica do estado antiligante $\sigma^{*}$. No painel superior direito, dois estados do ânion estão mostrados, e nesse caso a curva pontilhada azul denota um estado $\pi^{*}$ do ânion. O painel inferior esquerdo é semelhante ao superior direito, com a diferença que o estado do ânion representado se encontra a energias mais baixas do que do neutro $\mathrm{S}_{0}$ (curva pontilhada vermelha). Por último, no painel inferior direito mostro três estados do ânion, rotulados $\pi_{1}^{*}, \pi_{2}^{*}$ e o estado antiligante $\sigma^{*} \ldots \ldots \ldots \ldots \ldots \ldots \ldots$

1.2 Geometrias das moléculas de (a) uracila, (b) timina e (c) uracila modificada. Na estrutura (c) X está ligado ao carbono C5 e representa o grupo associado à modificação. Os átomos de carbono estão representados em preto, os nitrogênios em azul, os oxigênios em vermelho e os hidrogênios em azul. . . . . . . . . . . . . . . . . .

4.1 Estruturas da 5-OCNU (à esquerda) e 5-SCNU (à direita). O painel superior mostra os sistemas em suas geometrias planares (grupo $C_{s}$ de mais baixa energia, enquanto que as geometrias otimizadas (grupo $C_{1}$ ) estão mostradas nos painéis inferiores. Os átomos de enxofre estão representados em amarelo, os oxigênios em vermelho, nitrogênios em azul, carbonos em cinza e hidrogênios em branco. Os ângulos diedrais entre os planos C6-C5-X e C5-X-C, onde $\mathrm{X}=\mathrm{O}, \mathrm{S}$, estão indicados nas estruturas $C_{1}$, e a nomenclatura dos sítios atômicos do anel estão indicados no painel superior esquerdo. . . . . . . . . . . . . 
4.2 Seções de choque integral para o espalhamento eletrônico pela 5-OCNU calculadas nas aproximações ET e ETP. As componentes de simetria $A^{\prime}$ e $A^{\prime \prime}$ obtidas a partir do cálculo da estrutura $C_{s}$ estão mostradas juntamente com as curvas obtidas para a estrutura $C_{1}$ As assinaturas das ressonâncias também estão indicadas. . . . . . . . . . . . . . . .

4.3 Orbitais virtuais HF obtidos com a base $6-31 \mathrm{G}(\mathrm{d})$ na geometria $C_{s}$ da 5-OCNU. Os painéis foram nomeados de acordo com a natureza das ressonâncias. . . . . . . . . . . . . . . . . . .

4.4 Orbitais virtuais HF obtidos com a base $6-31 \mathrm{G}(\mathrm{d})$ na geometria $C_{1}$ da 5-OCNU. Os painéis foram nomeados de acordo com a natureza das ressonâncias. . . . . . . . . . . . . . . . . . . . .

4.5 Seções de choque integral para o espalhamento eletrônico pela 5-SCNU calculadas nas aproximações ET e ETP. As componentes de simetria $A^{\prime}$ e $A^{\prime \prime}$ obtidas a partir do cálculo da estrutura $C_{s}$ estão mostradas juntamente com as curvas obtidas para a estrutura $C_{1}$ As assinaturas das ressonâncias também estão indicadas. . . . . . . . . . . . . . . .

4.6 Orbitais virtuais HF obtidos com a base $6-31 \mathrm{G}(\mathrm{d})$ na geometria $C_{s}$ da 5-SCNU. Os painéis foram nomeados de acordo com a natureza das ressonâncias. . . . . . . . . . . . . . . . . .

4.7 Orbitais virtuais $\mathrm{HF}$ obtidos com a base $6-31 \mathrm{G}(\mathrm{d})$ na geometria $C_{1}$ da 5-SCNU. Os painéis foram nomeados de acordo com a natureza das ressonâncias. . . . . . . . . . . . . . . . . . . . . .

5.1 Geometria e cargas da molécula de água no modelo SPC/E. O oxigênio está disposto em vermelho e os hidrogênios em branco. As cargas $q_{\mathrm{O}}$ e $q_{\mathrm{H}}$ indicam os valores dos parâmetros de carga utilizados no campo de força. . . . . . . . . . . . . . . . . . . .

5.2 Exemplo de distribuição radial de pares $G(r)$, à esquerda (linha contínua roxa), e sua integral $N(r)$, à direita (linha contínua laranja). No painel à esquerda, a linha tracejada vermelha indica o mínimo local correspondente à camada de micro-solvatação, e no painel à direita o número de moléculas de água presente nessa camada. As linhas tracejadas em verde e azul indicam a primeira e a segunda camada de solvatação, respectivamente. . . . . . . . . . . . . . .

5.3 Exemplos de agregados da uracila micro-solvatada, com o número de moléculas de água compatíveis (a) com a camada de micro-solvatação e (b) com a primeira camada de solvatação. . . . . . . . . . . . .

5.4 Esquema da combinação s-QM/MM com a seleção de clusters empregado para estudar os sistemas micro-solvatados. . . . . . . . . . . 
6.1 MDDF, à esquerda, e o número médio de moléculas obtido pela integral da distribuição $G(r)$, à direita, da simulação da uracila. A camada de micro-solvatação pode ser obtida através do primeiro mínimo local na distribuição $G(r)$, indicada pela linha tracejada em vermelho. O número de moléculas a primeira camada de solvatação, por sua vez, é obtido pela curva $N(r)$ uma vez que a distância $r$ foi estabelecida. . .

6.2 Os gráficos apresentam a distribuição radial de pares $G(r)$ referentes às distâncias entre átomos que realizam ligações de hidrogênio solutosolvente. Abaixo um painel mostrando, como legenda, a numeração adotada para o estudo das distribuições. Os números entre parêntesis indicam se o átomo pertence ao soluto (1) ou ao solvente (2) . . . . . 74

6.3 Estrutura da uracila (à esquerda) e de um cluster $\mathrm{U}-\left[\mathrm{H}_{2} \mathrm{O}\right]_{6}$ (à direita). $\quad 76$

6.4 Seção de choque integral dos cinco clusters C1-C5 da uracila- $\left[\mathrm{H}_{2} \mathrm{O}\right]_{6}$, na aproximação ET. As posições das duas ressonâncias $\pi_{1}^{*}$ e $\pi_{2}^{*}$ estão indicadas. Além disso, as linhas tracejadas em rosa indicam a posição das ressonâncias $\pi_{1}^{*}$ e $\pi_{2}^{*}$ da uracila isolada (gas), para comparação.

6.5 Estrutura do cluster $\overline{\mathrm{C}}$. Os VO's correspondentes aos estados $\pi_{1}^{*}$ e $\pi_{2}^{*}$, assim como suas energias $\mathrm{HF} / 6-31 \mathrm{G}^{*}$, estão mostrados na esquerda e direita, respectivamente. . . . . . . . . . . . .

6.6 Esquerda: Gráficos mostrando as posições das ressonâncias $\pi_{1}^{*}$ e $\pi_{2}^{*}$ $\left(E_{\mathrm{res}}\right)$, obtidas na aproximação ET para os cinco clusters C1-C5, em função das energias dos orbitais virtuais correspondentes, calculadas no nível HF /6-31G*. As linhas retas mostram as regressões lineares em cada caso. Direita: Distribuição térmica das energias dos VO's sobre o conjunto das 133 configurações estatisticamente descorrelacionadas geradas pela amostragem MC . . . . . . . . . . . . . . . .

6.7 Seção de choque integral para o espalhamento eletrônico pelo cluster $\overline{\mathrm{C}}$ obtida tanto na aproximação ET (linha laranja tracejada) quanto na aproximação ETP (linha preta sólida). . . . . . . . . . . . . . .

6.8 Seção de choque integral para o espalhamento eletrônico pela molécula de uracila isolada, na aproximação ETP, onde foi utilizado a mesma estratégia para a construção do espaço de configurações. As ressonâncias $\pi_{1}^{*}$ e $\pi_{2}^{*}$ estão indicadas. . . . . . . . . . . . . . . . . .

6.9 Estimativas das posições das ressonâncias $\pi^{*}$ na aproximação ETP em função das estimativas ET para uracila (Ura), para o cluster $\overline{\mathrm{C}}$ $\left(\mathrm{U}\left[\mathrm{H}_{2} \mathrm{O}\right]_{6}\right)(\mathrm{Clu})$, glicina (Gly) [2], fenol (Phe) [3] e guaiacol (Gua) [3]. A linha sólida preta indica a regressão linear baseada apenas nos nossos resultados para a uracila e para o cluster $\overline{\mathrm{C}}$, enquanto que a linha tracejada leva em consideração todos os pontos. 
6.10 Distribuições térmicas de VAEs $\pi_{1}^{*}$ e $\pi_{2}^{*}$ obtidas sobre o conjunto de 133 configurações $\mathrm{U}\left[\mathrm{H}_{2} \mathrm{O}\right]_{6}$ estatisticamente descorrelacionadas à temperatura $T=298 \mathrm{~K}$. O Modelo I (à esquerda) foi obtido das equações 6.5 e 6.6, enquanto que o Modelo II (à direita) das equações 6.7 e 6.8.

6.11 Largura de auto-ionização $(\Gamma)$ como uma função da posição em energia das ressonâncias $\pi^{*}\left(E_{\text {res }}\right)$ da uracila, assim como também da ressonância $\pi_{2}^{*}$ do cluster $\overline{\mathrm{C}}$ obtida no presente trabalho. Também foram incluídos dados apresentados por Kossoski et al. [4], Winstead et al. [5], Tonzani et al. [6], Dora et al.[7] e Gianturco et al.[8]. . . . . . . . . .

6.12 Distribuição térmica das larguras de auto-ionização $(\Gamma)$ dos estados aniônicos $\pi_{1}^{*}$ e $\pi_{2}^{*}$ calculados sobre o conjunto de 133 configurações estatisticamente descorrelacionadas, à temperatura $T=298 \mathrm{~K}$. Os dois painéis à esquerda e os dois painéis à direita foram obtidos com os Modelos I e II, respectivamente. . . . . . . . . . . . . . . .

6.13 Distribuição de VOEs dos estados $\pi_{1}^{*}$ para o conjunto completo de 133 configurações, à esquerda, e para o subconjunto representativo de 101 configurações que apresentam o padrão médio de ligações de hidrogênio, à direita. O valor do $\mathrm{VOE} \pi_{1}^{*} \mathrm{HF} / 6-31 \mathrm{G}^{*}$ para a uracila em fase gasosa também está indicado (rosa) para comparação. . . . .

6.14 Distribuição de VOEs dos estados $\pi_{1}^{*}$ para o conjunto completo de 133 configurações, à esquerda, e para o subconjunto representativo de 101 configurações que apresentam o padrão médio de ligações de hidrogênio, à direita. O valor do $\operatorname{VOE} \pi_{1}^{*} \mathrm{HF} / 6-31+\mathrm{G}(\mathrm{d})$ para a uracila em fase gasosa também está indicado (rosa) para comparação. . . . .

6.15 Gráficos de dispersão entre as energias dos orbitais virtuais $\pi_{1}^{*}$ (à esquerda) e $\pi_{2}^{*}$ (à direita) em função dos momentos de dipolo dos clusters $\mathrm{U}\left[\mathrm{H}_{2} \mathrm{O}\right]_{6}$ neutros, $\mu_{\text {cluster }}$, calculados no nível DFT/B3LYP/augcc-pVDZ, em D. . . . . . . . . . . . . . . . . .

6.16 Energias dos orbitais virtuais $\mathrm{HF} / 6-31 \mathrm{G}^{*} \pi_{1}^{*}$ como função das energias dos VOs $\pi_{2}^{*}$ para a uracila em fase gasosa (vermelho) e para os 133 clusters estatisticamente descorrelacionados $\mathrm{U}\left[\mathrm{H}_{2} \mathrm{O}\right]_{6}$ (roxo). . . . . .

6.17 MDDF, à esquerda, e o número médio de moléculas obtido pela integral da distribuição $G(r)$, à direita, da simulação da timina. . . . . . . . .

6.18 Distribuição térmica de VOEs referentes aos estados $\pi_{1}^{*}$ e $\pi_{2}^{*}$ sobre o conjunto de 133 agregados de $\mathrm{T}\left[\mathrm{H}_{2} \mathrm{O}\right]_{6}$ à temperatura $T=298.15 \mathrm{~K}$. Os orbitais virtuais e suas energias foram obtidas no nível $\mathrm{HF} / 6-31 \mathrm{G}^{*}$.

6.19 Estrutura do cluster $\overline{\mathrm{C}}$ do sistema $\mathrm{T}\left[\mathrm{H}_{2} \mathrm{O}\right]_{6}$. Os VOs correspondentes aos estados $\pi_{1}^{*}$ e $\pi_{2}^{*}$, assim como suas energias $\mathrm{HF} / 6-31 \mathrm{G}^{*}$, estão mostrados na esquerda e direita, respectivamente. . . . . . . . . . . 
6.20 Seção de choque integral para o espalhamento eletrônico elástico pelo cluster $\overline{\mathrm{C}}$ da $\mathrm{T}\left[\mathrm{H}_{2} \mathrm{O}\right]_{6}$, na aproximação ET. As duas estruturas na curva sólida representam as ressonâncias $\pi_{1}^{*}$ e $\pi_{2}^{*}$, como indicado. As linhas tracejadas correspondem a resultados ET para a timina em fase gasosa reportados por Winstead et al[5] (linha tracejada rosa) e Tonzani et al[6] (linha tracejada marrom). . . . . . . . . . . . . .

6.21 Distribuições térmicas de VAEs $\pi_{1}^{*}$ e $\pi_{2}^{*}$ obtidas sobre o conjunto de 133 configurações $\mathrm{T}\left[\mathrm{H}_{2} \mathrm{O}\right]_{6}$ estatisticamente descorrelacionadas à temperatura $T=298 \mathrm{~K}$. O Modelo I (à esquerda) foi obtido das equações 6.5 e 6.6, enquanto que o Modelo II (à direita) das equações 6.7 e 6.8. 101

6.22 Distribuição térmica das larguras de auto-ionização $(\Gamma)$ dos estados aniônicos $\pi_{1}^{*}$ e $\pi_{2}^{*}$ calculados sobre o conjunto de 133 configurações estatisticamente descorrelacionadas, à temperatura $T=298 \mathrm{~K}$. Os dois painéis à esquerda e os dois painéis à direita foram obtidos com os Modelos I e II, respectivamente.

6.23 Os gráficos apresentam a distribuição radial de pares $G(r)$ referentes às distâncias entre os halogênios, em cada um dos casos 5-XU $(\mathrm{X}=\mathrm{F}, \mathrm{Cl}, \mathrm{Br}, \mathrm{I})$, e os átomos do solvente. Os números (2) entre parêntesis indicam que o átomo pertence ao solvente. . . . . . . . . . . . . 107

6.24 Distribuições térmicas das energias HF/6-31G* (HF/LANL2DZP-ECP para o iodo) dos orbitais virtuais $\pi_{1}^{*}, \pi_{2}^{*}$ e $\sigma_{\mathrm{CX}}^{*}$, em eV, para cada um dos conjuntos de agregados de $5-\mathrm{XU}\left[\mathrm{H}_{2} \mathrm{O}\right]_{6}$, para $\mathrm{X}=\mathrm{F}, \mathrm{Cl}, \mathrm{Br}, \mathrm{I}$. O sistema correspondente a dada histograma está indicado em cada um dos quartro painéis. Os histogramas referentes às distribuições dos VOEs $\sigma_{\mathrm{CX}}^{*}$ só estão presentes no caso da 5-ClU, 5-BrU e 5-IU, enquanto que no primeiro dos três casos o orbital só foi apreciado em 33 configurações.

6.25 Painel de VOs $\pi^{*}$ e $\sigma^{*}$ dos clusters representativos $\overline{\mathrm{C}}$ associados aos quatro sistemas $5-\mathrm{XU}\left[\mathrm{H}_{2} \mathrm{O}\right]_{6}$, para $\mathrm{X}=\mathrm{F}, \mathrm{Cl}, \mathrm{Br}, \mathrm{I}$, esquematizados em colunas.

6.26 Seções de choque integral para o espalhamento eletrônico elástico pelos quatro agregados $\overline{\mathrm{C}}$ dos sistemas $5-\mathrm{XU}\left[\mathrm{H}_{2} \mathrm{O}\right]_{6}(\mathrm{X}=\mathrm{F}, \mathrm{Cl}, \mathrm{Br}, \mathrm{I})$, na aproximação ET. As duas estruturas em cada curva sólida preta representam as ressonâncias $\pi_{1}^{*}$ e $\pi_{2}^{*}$. As linhas tracejadas laranjas correspondem a resultados ET para as respectivas halouracilas em fase gasosa reportados por Kossoski et al[9]. . . . . . . . . . . . . . . . . . 112 
6.27 Distribuições térmicas dos VAEs $\pi^{*}$ das quatro halouracilas microsolvadas, em eV, segundo o Modelo II, à temperatura $T=298.15 \mathrm{~K}$. As distribuições foram obtidas sobre o conjunto das 133 configurações estatisticamente descorrelacionadas, em cada caso. A fração de estados ligados descritas pelas distribuições dos VAEs $\pi_{1}^{*}$ estão indicados em azul.

6.28 Distribuições térmicas das larguras $\Gamma$, das ressonâncias $\pi^{*}$, das quatro halouracilas micro-solvadas, em eV, segundo o Modelo II, à temperatura $T=298.15 \mathrm{~K}$. As distribuições das larguras das ressonâncias $\pi_{1}^{*}$ foram obtidas apenas sobre as parcelas ressonante das distribuições. Quanto às larguras das ressonâncias $\pi_{2}^{*}$, as distribuições foram obtidas sobre todo o conjunto das 133 configurações estatisticamente descorrelacionadas, em cada caso.

7.1 (Adaptado da referência [10])Esquema da propagação do pacote de ondas nuclear na metodologia AIMS. Nesse esquema mostro dois estados eletrônicos envolvidos (digamos, $J=0,1$ ). O pacote de onda, no caso, se encontra inicialmente sobre o estado eletrônico $J=1$ e é submetido a uma divisão (spawning) ao atravessar a região de alto acoplamento.

8.1 Orbitais SOMO/FOMO-CASCI/6-31G(d) associados aos estados (a) $\pi_{1}^{*}$, (b) $\sigma_{\mathrm{CBr}}^{*}$ e (c) $\pi_{2}^{*}$ do ânion 5 - $\mathrm{BrU}^{-}$, na geometria otimizada da molécula neutra. Os orbitais foram gerados com o isovalor 0.4 . . . .

8.2 SEPs adiabáticas do estado fundamental $\mathrm{D}_{0}$ (vermelho) e dos dois primeiros estados excitados $\mathrm{D}_{1}$ (verde) e $\mathrm{D}_{2}$ (azul) em função da distância C-Br. As curvas foram levantadas no nível FOMO-CASCI $(3,4) / 6$ $31 \mathrm{G}(\mathrm{d}) . \ldots \ldots \ldots \ldots \ldots \ldots$

8.3 Painéis das distribuições Lorentzianas $f_{l}\left(\mathbf{R}_{0}^{j}, E\right)$ obtidas para as 21 configurações, à esquerda, e as respectivas somas normalizadas, à direita. Os valores do parâmetro $\eta$ estão indicados em cada caso. . . . . . . .

8.4 Painel esquemático da propagação e divisões (spawnings) da função de onda nuclear referente a uma única condição incial. Inicialmente $(t=0)$ a função de onda nuclear era dada por um único pacote de onda sobre o estado eletrônico $\mathrm{D}_{2}\left(\pi_{2}^{*}\right)$. A primeira divisão da TBF ocorre em cerca de $t=24.5$ fs e corresponde a um decaimento $\mathrm{D}_{2} \rightarrow \mathrm{D}_{1}$ (acoplamento $\pi_{2}^{*} / \sigma_{\mathrm{CBr}}^{*}$ ). Seguindo adiante, podemos acompanhar duas TBFs percorrendo caminhos independentes e atingido regiões de diferentes acoplamentos. Nesse exemplo, há divisões em 28.2fs (acoplamento $\sigma_{\mathrm{CBr}}^{*} / \pi_{1}^{*}$ ), 32.5fs (acoplamento $\sigma_{\mathrm{CBr}}^{*} / \pi_{1}^{*}$ ), 47.0fs (acoplamento $\pi_{2}^{*} / \sigma_{\mathrm{CBr}}^{*}$ ) and $48.4 \mathrm{fs}$ (acoplamento $\left.\sigma_{\mathrm{CBr}}^{*} / \pi_{1}^{*}\right) \ldots \ldots \ldots$ 
8.5 População $P_{I}(t)$ dos estados eletrônicos $I=0,1,2$ obtidos sobre as 122 TBFs originadas a partir de 21 condições iniciais. O ponto de partida das TBFs iniciais foi o estado $\mathrm{D}_{2}$ (curva azul), e pode-se observar a maneira como a população é transferida para os estados $D_{1}$ (verde) e $\mathrm{D}_{0}$ (vermelho). As linhas mais finas representam a evolução das populações de cada condição inicial, enquanto que as linhas grossas (uma de cada cor) mostram a média obtida diretamente da equação $7.13 \ldots \ldots \ldots \ldots \ldots \ldots \ldots$

8.6 Análise dos valores da coordenada reativa $R_{\mathrm{CBr}}$ em função do tempo para cara trajetória. As cores indicam o cada estado eletrônico em que se encontram a TBF. . . . . . . . . . . . . . . . . . . . . . . . . 142

8.7 Análise dos valores da coordenada reativa $R_{\mathrm{N} 1 \mathrm{H}}$ em função do tempo para cara trajetória. As cores indicam o cada estado eletrônico em que se encontram a TBF. . . . . . . . . . . . . . . . . . . . . 143

8.8 Evolução temporal das energias e larguras dos estados $D_{1}$ e $D_{2}$ ao longo da dinâmica de uma trajetória. As geometrias inicial, durante o acoplamento e a em $t=20$ fs estão dispostas na parte superior dos painéis. A linha tracejada cinza no painel superior representa a energia do estado fundamental do neutro, e fornece o instante em que o estado $\mathrm{D}_{2}$ passa a ser um estado ligado. . . . . . . . . . . . . . . . . . . . 144

8.9 Seções de choque de DEA para os canais dissociativos $\mathrm{Br}^{-}$(à esquerda), (U-H) ${ }^{-}$(ao centro) e $\mathrm{H}$ (à direita). As curvas do nosso modelo foram obtidas da expressão 7.24. Os resultados experimentais[11] para a dissociação do $\mathrm{Br}^{-}$e (U-H) ${ }^{-}$estão dispostos para comparação em seus respectivos painés. . . . . . . . . . . . . . . . . .

F.1 Seção de choque integral da componente $A^{\prime \prime}$ da 5-SCNU plana, na aproximação ET. A curva vermelha foi obtida com a quadratura de $32+32$ pontos radiais com $32 \times 32$ pontos angulares para cada ponto radial,já a curva verde foi obtida com a quadratura de $48+48$ pontos radiais com $48 \times 48$ pontos angulares para cada ponto radial. . . . . . 176

F.2 Seção de choque integral da componente $A^{\prime \prime}$ da 5-SCNU plana, na aproximação ET. A curva vermelha foi obtida com a quadratura de $32+32$ pontos radiais com $32 \times 32$ pontos angulares para cada ponto radial, já a curva verde foi obtida com a quadratura de $32+8$ pontos radiais com $32 \times 32$ pontos angulares para cada um desses pontos radiais mais 24 pontos radiais com $48 \times 48$ pontos angulares para cada um desses pontos radiais. 



\section{Lista de Tabelas}

4.1 Expoentes das gaussianas cartesianas pertencentes ao conjunto de base utilizado para os átomos de carbono, nitrogênio, oxigênio e enxofre. .

4.2 Estimativas da VAE e momentos de dipolo da 5-OCNU em sua geometria plana (grupo de simetria $C_{s}$ ) e em sua geometria otimizada $\left(C_{1}\right) \ldots \ldots \ldots \ldots \ldots \ldots \ldots \ldots$

4.3 Estimativas da VAE, em eV, e momentos de dipolo, em D, da 5-SCNU em sua geometria plana $\left(C_{s}\right)$ e em sua geometria otimizada $\left(C_{1}\right) \ldots$.

4.4 Energia dos estados aniônicos, em eV, obtidas através da seção de choque calculada na aproximação ETP para a 5-OCNU e 5-SCNU nas geometrias $C_{s}$ e $C 1 \ldots \ldots \ldots \ldots \ldots$

4.5 Limiares de energia, entalpia e energia livre de dissociação, em eV, para $T=298.15 \mathrm{~K}$. Os valores foram obtidos com o método G4(MP2), implementado no software gaussian09.

6.1 Posições (e larguras) das ressonâncias, em eV, dos cinco clusters C1 - C5 e do cluster $\overline{\mathrm{C}}$, assim como os resultados para a uracila em fase gasosa. Os resultados obtidos nas aproximações ET e ETP estão dispostos separadamente. A largura da ressonância $\pi_{1}^{*}$ do cluster $\overline{\mathrm{C}}$ não pôde ser obtida a partir da seção de choque. . . . . . . . . . . . .

6.2 Médias e desvios padrão das distribuições térmicas dos VOEs HF/6$31 \mathrm{G}^{*}$ (HF/LANL2DZP-ECP para o iodo), em eV. Os valores dos respectivos VOEs das moléculas em fase gasosa também estão disposto (segundo bloco). . . . . . . . . . . . . . . .

6.3 Posição das ressonâncias $\pi^{*}$ dos clusters representativos $\overline{\mathrm{C}}$ associados aos quatro sistemas $5-\mathrm{XU}\left[\mathrm{H}_{2} \mathrm{O}\right]_{6}(\mathrm{X}=\mathrm{F}, \mathrm{Cl}, \mathrm{Br}, \mathrm{I})$, em eV, na aproximação ET. Também estão dispostos os resultados ET para as ressonâncias $\pi^{*}$ das quatro halouracilas isoladas, obtidas com o método SMCPP e reportadas por Kossoski et al[9], para comparação. . . . . . 



\section{Capítulo 1}

\section{Introdução}

Muitos processos relevantes podem ser desencadeados pela interação entre elétrons livres e a matéria. Em um processo colisional entre um elétron e uma molécula, a natureza físico-química do processo é diferente dependendo do regime de energias da colisão. Em baixas energias, por exemplo, essa interação é capaz de ocasionar a formação de estados ressonantes. No contexto do espalhamento eletrônico, ressonâncias são estados do ânion cujas energias estão acima do limiar de ionização do sistema aniônico. Sendo assim, correspondem a estados discretos não-ligados embebidos num contínuo de estados, possuem um acoplamento com esse contínuo e por isso possuem uma probabilidade não-nula para o processo de auto-ionização. Descrevo os estados ressonantes com detalhes nas seções a seguir, mas por ora menciono que a formação de ressonâncias representa um processo de múltiplos interesses, como em ciências atmosféricas, na física de plasmas de processamento e, particularmente, em processos deletérios em biomoléculas.

O presente trabalho refere-se ao estudo de processos induzidos pela captura eletrônica a baixas energias pela uracila, derivados de uracila, e aglomerados envolvendo as moléculas de timina e uracila. Nesse capítulo introdutório, apresento uma visão dos aspectos gerais do problema da captura eletrônica e de possíveis processos subsequentes. 


\subsection{Interação elétron-molécula e captura eletrônica dissociativa}

O espalhamento elétron-molécula é entendido por via de um processo colisional resultante da interação entre um projétil (elétron) e um alvo (molécula). Em uma visão clássica do espalhamento o projétil incide sobre o alvo e ambos interagem, efetivamente, em uma certa região finita, associada ao alcance da interação, e em seguida emerge, sendo caracterizado por uma configuração projétil+alvo no limite assintótico, e denomina-se canal qualquer possível configuração final. Há canais de diferentes naturezas, podendo ser elásticos, inelásticos ou canais dissociativos. Canais inelásticos usualmente referem-se a estados excitados do alvo no limite assintótico. Uma determinada configuração assintótica do alvo só é permitida se a energia do elétron incidente for suficiente para que, ao possivelmente ser transferida para o alvo, o alvo consiga acessar tal configuração. A nomenclatura usual é dizer que o canal é aberto caso seja energeticamente permitido, enquanto que ele é dito fechado caso contrário. Como exemplo, é intuitivo perceber que em uma colisão elástica o único canal relevante é aquele no qual o alvo permanece, após a colisão, no mesmo estado em que se encontrava antes[12].

Experimentalmente, podemos fazer incidir feixes de elétrons com energia cinética inicial bem definida sobre uma determinada amostra, e assim investigar o número de eventos de espalhamento que ocorrem para elétrons com aquela energia préestabelecida. Essa propriedade é retratada através da seção de choque, sendo ela o objeto central de um processo colisional. Uma vez que a seção de choque é conhecida, temos acesso a certas propriedades do alvo.

Como já mencionado, uma das propriedades que podemos investigar ao ter acesso à seção de choque do problema a baixas energias $(<15 \mathrm{eV})$ é a existência de estados ressonantes da espécie aniônica do alvo. Novamente, a ressonância é definida como um estado do sistema total (projétil+alvo) cuja energia está acima da soma das energias do projétil e do alvo, caso não houvesse interação entre eles. Fundamentalmente, um estado ressonante é um estado com tempo de vida finito, e assim pode caracterizado 
por uma energia complexa da forma $E=E_{r}-i \Gamma / 2$, onde $E_{r}$ representa a energia, ou posição, da ressonância e $\Gamma$ é a largura de autoionização do estado, e está associada a seu tempo de vida $\tau=\hbar / \Gamma$. Assim, o ânion formado pela captura eletrônica é dito transiente (ou metaestável) (do inglês transient negative ion - TNI), por apresentar um tempo de vida finito frente a auto-ionização.

Dependendo da circunstância, a dinâmica de um TNI pode mediar uma dissociação, caso o tempo de vida e a energia transferida para os graus de liberdade vibracionais sejam suficientes e caso haja um estado de caráter dissociativo facilmente acessível. Chamamos esse processo de dissociação induzida pela captura eletrônica (do inglês dissocative electron attachment - DEA). Alguns processos de DEA são ditos diretos, caso a captura eletrônica promova um ânion de caráter antiligante. No painel superior esquerdo da Fig. 1.1 represento um esquema das superfícies de energia potencial eletrônica ${ }^{1}$, em termos de uma determinada coordenada reativa, suficiente para ilustrar o processo direto. Assumimos que o estado fundamental do sistema neutro pode ser bem descrito por uma curva de energia potencial $\left(\mathrm{S}_{0}\right)$. A captura eletrônica pode transferir o sistema ao estado representado pela curva verde, que na região de Franck-Condon é um estado ressonante do ânion de caráter antiligante $\left(\sigma^{*}\right)$. A relaxação vibracional do TNI deve rumar à dissociação caso o processo seja mais eficiente do que a autoionização. Há também os processos indiretos, cujo esquema das superfícies de energia potencial enolvidas é ilustrado no painel superior direito da mesma figura. No caso indireto a captura eletrônica leva à formação de uma ressonância de caráter ligante $\pi^{*}$ (linha azul), e a dinâmica do pacote de ondas nuclear subsequente pode promover o acoplamento entre o estado $\pi^{*}$ e o estado dissociativo $\sigma^{*}$, só então favorecendo a dissociação. Os painéis inferiores representam circustâncias similares, porém ilustrando um sistema que admite um estado ligado do ânion (linha vermelha). Nesse caso, a relaxação vibracional da ressonância pode conduzir o sistema a um acoplamento entre o estado dissociativo e o ânion ligado,

\footnotetext{
${ }^{1}$ As superfícies esquematizadas correspondem às energias eletrônica no contexto da aproximação de Born-Oppenheimer (ver apêndice A), em que o auto-valor da equação de Schrödinger eletrônica - que descreve todos os elétrons do sistema - é resolvida para um dado conjunto fixo de coordenadas nucleares.
} 


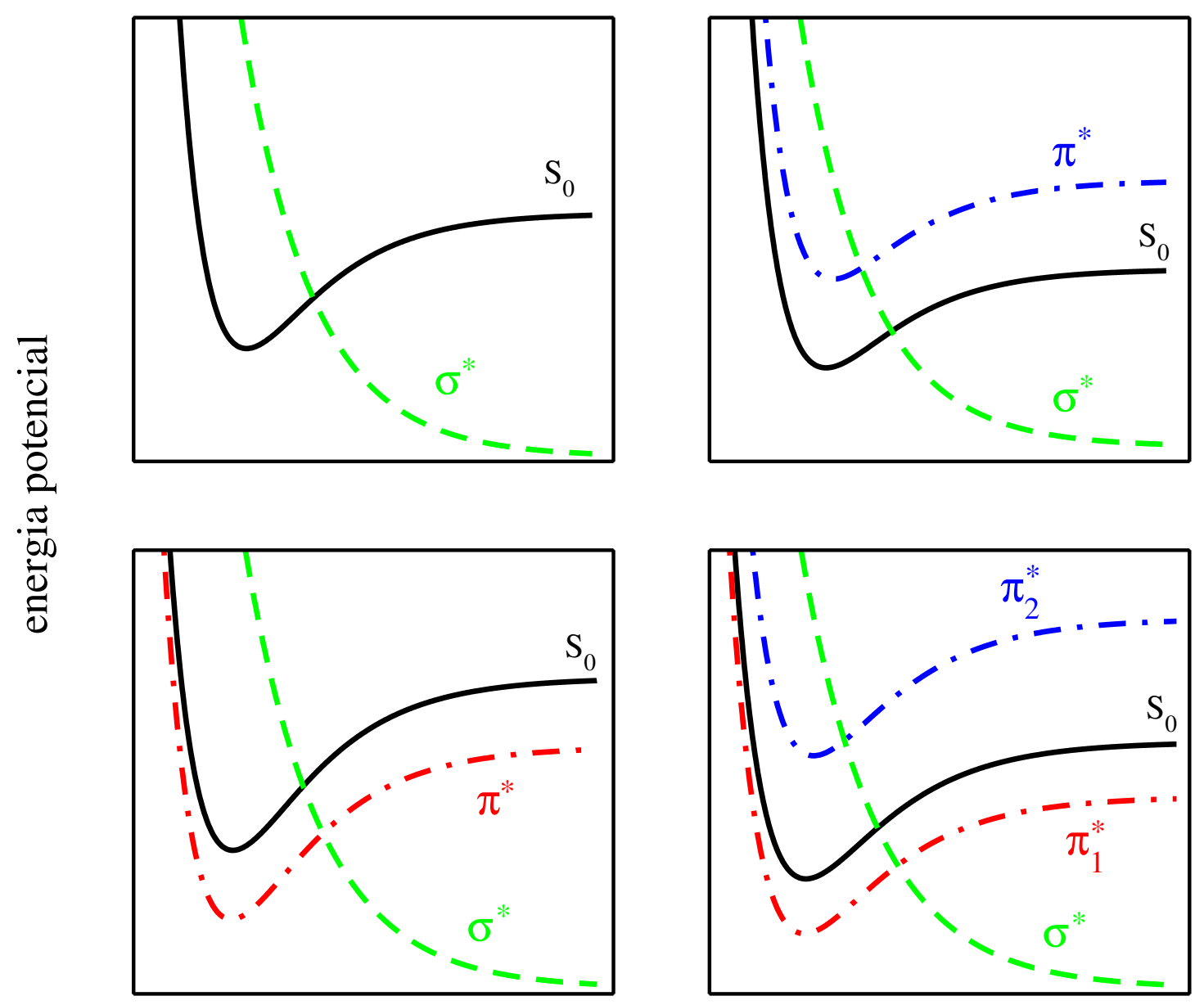

\section{coordenada reativa}

Figura 1.1: Esquema das superfícies de energia potencial ao longo de uma determinada coordenada de reação, separadas em quatro casos. No painel superior esquerdo, a curva preta $\left(\mathrm{S}_{0}\right)$ denota a energia eletrônica do estado fundamental da molécula neutra e a curva pontilhada verde representa a energia eletrônica do estado antiligante $\sigma^{*}$. No painel superior direito, dois estados do ânion estão mostrados, e nesse caso a curva pontilhada azul denota um estado $\pi^{*}$ do ânion. O painel inferior esquerdo é semelhante ao superior direito, com a diferença que o estado do ânion representado se encontra a energias mais baixas do que do neutro $\mathrm{S}_{0}$ (curva pontilhada vermelha). Por último, no painel inferior direito mostro três estados do ânion, rotulados $\pi_{1}^{*}, \pi_{2}^{*}$ e o estado antiligante $\sigma^{*}$.

formando um estado estável do ânion ao final do processo.

\subsection{Motivações e relevância biológica}

Considera-se que TNI's estão associados direta ou indiretamente a lesões e outros efeitos deletéreos em biomoléculas que residem no meio celular, como cadeias ou subu- 
nidades de DNA ou RNA. Ao incidir no meio biológico, a radiação eletromagnética de altas energias (raios- $\gamma$, raios-X, radiação ultra-violeta ou radiação proveniente de espécies carregadas aceleradas) pode interagir com o ambiente e ocasionar uma série de lesões, como mutação, perda de informações genéticas ou inclusive a morte celular[13, 14]. Dentre essas lesões, as que são consideradas mais letais e interessantes no contexto celular são as relacionadas os efeitos deletérios no material genético. Esse danos incluem quebras de fita simples ( single-strand breaks SSBs), quebras de fita dupla (double-strand breaks DSBs) e fenômenos como a fragmentação de bases nitrogenadas, liberação de radicais altamente reativos, entre outros. Sabe-se que os danos da radiação eletromagnética no $\mathrm{DNA}(\mathrm{RNA})$ podem ser diretos ou indiretos, sendo que o primeiro é resultado da interação direta da radiação com a matéria enquanto que o segundo é resultado da ação de espécies secundárias, que surgem da interação entre a radiação e moléculas que residem na vizinhança dos ácidos nucleicos, i. e., moléculas de água, íons, proteínas e sais. Há hoje em dia uma extensa discussão sobre a relação de ocorrência entre danos diretos e indiretos, e hoje acredita-se que danos indiretos causados pela radiação é entre um terço e dois terços do dano total[14, 15].

Dentre as espécies secundárias que surgem da interação direta da radiação com o meio, acredita-se que as de maior interesse são originadas a partir da interação com as moléculas de água. Ao colidir com a água $\left(\mathrm{H}_{2} \mathrm{O}\right)$, o fóton altamente energético pode promover uma dissociação, produzindo $\mathrm{H}^{+}$e uma hidroxila $\mathrm{OH}^{-}$, como também pode ocasionar a ionização da água, segundo a reação[15] $\mathrm{H}_{2} \mathrm{O} \rightarrow \mathrm{H}_{2} \mathrm{O}^{+}+e^{-}$, que se torna significativa mediante a fótons com energias $>15 \mathrm{eV}$. Assim, atinge-se um estágio do processo onde elétrons secundários (do inglês secondary electrons - SEs) são o produto em maior abundância (cerca de $5 \times 10^{4} / \mathrm{MeV}$ de radiação incidente), ao lado de radicais hidroxilas, íons e outros radicais livres. Devido às sucessivas colisões inelásticas com os constituintes do meio, os SEs atingem energias tipicamente menores que $30 \mathrm{eV}$, à temperatura ambiente, em intervalos de tempo da ordem de ps, e acabam por se amostrarem segundo uma distribuição que apresenta um pico em torno de $9 \sim 10 \mathrm{eV}$. Esse traço de elétrons em equilíbrio térmico torna-se então o 
que se chama de elétrons pré-hidratados[16], que podem permanecer no meio aquoso e termalizar, sofrendo um processo de solvatação tornando-se elétrons hidratados, uma espécie pouco reativa, ou podem atingir energias suficientemente baixas para sofrerem eventuais capturas em regiões de alta eletroafinidade de biomoléculas que ali residem.

O primeiro e pioneiro trabalho experimental que sugere que elétrons de baixas energias podem causar danos em fitas simples e duplas de DNA foi realizado por Boudaïffa et al.[17] e publicado no ano 2000. O experimento dispunha de um arranjo onde ocorriam colisões entre elétrons livres com energia cinética entre 0 e 20 eV e segmentos de DNA plasmídico absorvido em filme, e os resultados mostram que elétrons de baixas energias $(4 \sim 10 \mathrm{eV})$ podem de fato causar DSBs e SSBs[18, 19]. Após a publicação desse trabalho uma série de estudos sobre o dano causado por elétrons de baixas energias (do inglês low-energy electrons - LEEs) vem sendo realizados, com o objetivo de compreendermos a natureza dos LEEs no meio biológico e o seu papel detalhado no mecanismo deletério mediado pela interação com biomoléculas.

\section{Captura eletrônica dissociativa por biomoléculas}

O estudo experimental realizado por Wang et al.[20] observou a dissociação de nucleotídeos (dXMP) quando submetidos à captura eletrônica em meio aquoso. A reação que buscou-se observar foi $e_{p r e}^{-}+\mathrm{dXMP} \rightarrow \mathrm{dXMP}^{*-} \rightarrow$ dissociação de dXMP. As medidas apontam que o elétron pode, de fato, ser capturado pelas bases nitrogenadas dTMP e dGMP formando ânions transientes, que podem dissociar em um intervalo de $\sim 5$ ps. Assim, o que foi proposto sobre o fenômeno[18] é que o LEE, ao colidir com a biomolécula com energias particulares, pode ser aprisionado em um TNI localizado sobre um segmento específico da cadeia. Isto é, o dano é local.

A título de menção, um dos progressos mais significativos ocorridos na área foi a realização de experimentos de excitação e prova para monitoramento da dinâmica dissociativa da uracila $[21,22]$ e timina [22] induzida por transferência eletrônica. Nas técnicas tradicionais baseadas em colisões, tais como Espectroscopia de Transmissão 
Eletrônica (Electron Transmission Spectroscopy - ETS), Espectroscopia de Perda de Energia Eletrônica (Electron Energy Loss - EEL), medidas de seções de choque ou de fragmentos de dissociação, não há possibilidade de resolução temporal. A alternativa proposta por Neumark e colaboradores foi produzir complexos $\mathrm{I}^{-}-\mathrm{X}$ em fase gasosa, onde $\mathrm{X}=\mathrm{U}, \mathrm{T}$ denota as bases. A dinâmica nesses sistemas é iniciada pelo pulso de excitação, que transfere um elétron do ânion iodeto para a base $\left(\mathrm{I}^{-}-\mathrm{X} \stackrel{h \nu}{\longrightarrow} \mathrm{I} \cdots \mathrm{X}^{-}\right)$, enquanto o pulso de prova, com atraso temporal bem definido em relação ao pulso anterior, fotoioniza o ânion $\mathrm{X}^{-}$, permitindo obter assinaturas da dinâmica vibracional no espectro fotoeletrônico.

\subsection{Radiossensibilizadores}

Os processos deletéreos induzidos por elétrons em biomoléculas podem ser benéficos para a terapia do câncer. São denominadas radiossensibilizadoras as drogas que, introduzidas quimioterapicamente, aumentam a eficiência da radioterapia[23]. Um dos mecanismos de sensibilização considerados é a formação de radicais por mecanismos de captura eletrônica dissociativa, sendo uracilas substituídas, em particular halouracilas, exemplos clássicos dessa classe de compostos. Seu mecanismo de ação consiste em substituir uma unidade de timina nas cadeias de DNA durante a replicação celular, processo que ocorre preferencialmente em células tumorais devido à grande velocidade de duplicação. As pirimidinas substituídas introduzem mecanismos eficientes de dissociação mediada por captura eletrônica, tais como a quebra de ligações carbono-halogênio, resultando na produção do radical uracila $\left(\mathrm{U}^{\bullet}\right)$, que ataca o DNA em etapas subsequentes. Vale mencionar que o termo radiossensibilizador não se limita à classe de moléculas que podem incorporar a fita de DNA/RNA, mas em outros contextos também se referem a qualquer molécula capaz de gerar radicais livres ao serem introduzidas no meio celular.

A investigação sobre formação de ânions transientes e suas consequências geralmente explora protótipos e modelos mínimos, tais como bases nitrogenadas, nucleosídeos e nucleotídeos. Isso se deve principalmente a dois fatores: o primeiro é o 
fato de que a captura eletrônica por macromoléculas ocorre localmente, isto é, em pequenas regiões das cadeias poliméricas; o segundo é a complexidade do meio biológico, que motiva a utilização de sistemas mais simples tanto nos estudos teóricos quanto nos experimentais. Nesse contexto as bases de timina e uracila têm papel destacado, seja pelo mecanismo de ação radiossensibilizadora descrito acima, ou pelo fato de que constituem protótipos mais simples que as purinas (adenina e guanina).

Como dito na seção anterior, a relevância das bases para os mecanismos de DEA reside no passo inicial, isto é, a formação de ânions transientes. Esses compostos insaturados favorecem a formação de ressonâncias $\pi^{*}$, as quais, em primeira aproximação, podem ser entendidas pela ocupação de um orbital virtual com caráter $\pi^{*}$ pelo elétron adicional. Esses ânions têm por característica longos tempos de vida, que permitem significativa relaxação vibracional, favorecendo não apenas sua estabilização mas também o acoplamento a estados aniônicos de caráter dissociativo, tal como descrito na seção 1.1.

A busca por novos compostos com potencial ação sensibilizadora tem constituído área de intensa pesquisa, sendo particularmente interessante a investigação teórica de Chomicz et al.[1] sobre a quebra da ligação X-C5 em diversas uracilas substituídas (X=SCN, NCS, SH, CN, OCN, NCO, NNN, NOO), mostradas na Fig. 1.2. Utilizando teoria do funcional da densidade (ver capítulo 2 e apêndice D) os autores apontaram, com base nas barreiras de energia para os processos

$$
\mathrm{XU}^{-} \rightleftharpoons \mathrm{XU}_{\mathrm{TS}}^{-} \rightleftharpoons \mathrm{X}^{-}+\mathrm{U}^{\bullet}
$$

onde $\mathrm{XU}_{\mathrm{TS}}^{-}$denota o estado de transição, os compostos 5-cianatouracila (5-OCNU) e 5-tiocianatouracil (5-SCNU) como principais alternativas à 5-bromouracila (5-BrU). Entretanto, o estudo esteve limitado ao estado fundamental dos ânions, modelados com técnica de estado ligado (DFT), levantando questões sobre o papel das ressonâncias na dinâmica dissociativa desses compostos. 


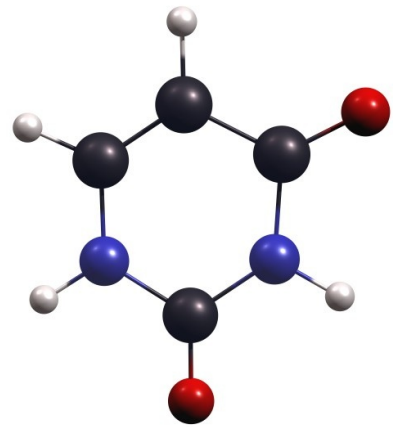

(a)

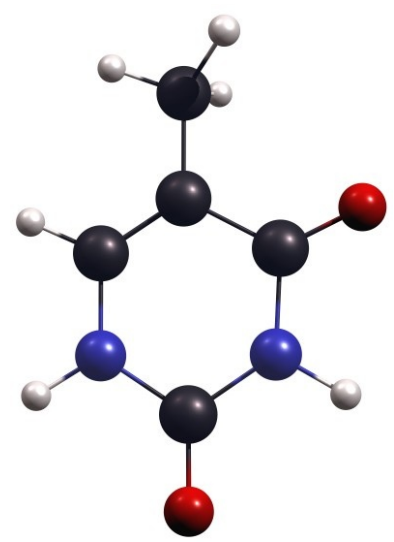

(b)

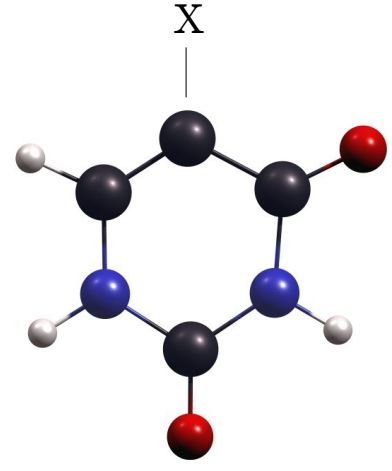

(c)

Figura 1.2: Geometrias das moléculas de (a) uracila, (b) timina e (c) uracila modificada. Na estrutura (c) X está ligado ao carbono C5 e representa o grupo associado à modificação. Os átomos de carbono estão representados em preto, os nitrogênios em azul, os oxigênios em vermelho e os hidrogênios em azul.

\subsection{Objetivos do Projeto}

O trabalho foi dividido em três partes. A primeira parte diz respeito à caracterização dos estados aniônicos das moléculas 5-OCNU e 5-SCNU, apontadas como possíveis novos candidatos a radiossensibilizadores. O estudo dos estados aniônicos foram realizados por meios de técnicas de espalhamento eletrônico pelas moléculas neutras. As técnicas de espalhamento fornecem meios de investigar energias dos estados ressonantes, relacionados com ânions transientes de grande interesse para o problema da dissociação induzida pela captura eletrônica.

Em seguida, o outro objetivo é o desenvolvimento de uma metodologia para incluir os efeitos do solvente nas propriedades de captura eletrônica a baixas energias. A ideia se baseou na investigação de como o ambiente influencia o, buscando refazer os cálculos de espalhamento incorporando a solução aquosa na descrição do alvo. Esse processo foi empregado para as moléculas de uracila, timina e de quatro halouracilas 5-XU, com $\mathrm{X}=\mathrm{F}, \mathrm{Cl}, \mathrm{Br}, \mathrm{I}$.

Por fim, durante a última parte do projeto buscou-se empregar técnicas de dinâmica 
não-adiabática no estudo da dissociação do ânion da 5-bromouracila (5-BrU). O problema da dinâmica nuclear sobre diferentes estados eletrônicos requer uma abordagem dependente do tempo da mecânica quântica, e atualmente é uma ferramenta extremamente útil na descrição de proccessos fotoquímicos. Entretanto, o tratamento da dinâmica de TNIs é um problema ainda em fase de desenvolvimento, e a proposta se desenvolve na direção de um protótipo para um futuro tratamento mais sofisticado.

\subsection{A tese}

Em razão das diferentes naturezas dos três objetivos do projeto, o texto está organizado de uma forma incomum, e a ordem dos capítulos é esclarescida como segue. No capítulo 2 apresentaremos os métodos teóricos utilizados no projeto para a descrição de estados ligados. Farei uma breve discussão sobre os métodos de estrutura eletrônica, cujos quais foram utilizados métodos ab initio, como o método HartreeFock e métodos pós Hartree-Fock, e métodos baseados na teoria do funcional da densidade.

No capítulo 3 será discutido com detalhe o método Multicanal de Schwinger, procedimento utilizado para resolver o problema do espalhamento eletrônico, e no capítulo 4 estão dispostos os resultados para a 5-OCNU e 5-SCNU. Apresento o procedimento utilizado para obtenções das geometrias e das curvas de seção de choque elástico para o espalhamento eletrônico. A partir das seções de choque, apresento os estados aniônicos de valência presentes na região de baixas energias. Além disso, estão dispostos os estados ligados de valência e de dipolo que os sistemas apresentam.

No capítulo 5 dedico-me a apresentar os métodos teóricos utilizados para o estudo dos efeitos do solvente. Mostro como foi abordado o problema da solvatação, apresentando os modelos contínuos e explícitos de solvente utilizados, e assim no capítulo 6 apresento os resultados sobre os efeitos do solvente no espectro de ânions transientes em baixas energias das moléculas de uracila, timina, e das quatro halouracilas.

No capíulo 7 apresento os métodos teóricos de dinâmica não-adiabática utilizados no estudo da 5-BrU e, no capítulo seguinte, os resultados obtidos. 


\section{Alguns considerações inciais}

Todos os métodos teóricos apresentados estão descritos em detalhes em inúmeros livros texto, artigos, revisões e outras referências. Suas apresentações no texto e apêndices têm como objetivo servir de material para futuras consultas e referências. Algumas notações para a derivação de equações são baseadas em desenvolvimentos usuais. Menciono também que para expressar quantidades numéricas utilizo o padrão com ponto (0.000) ao invés do padrão com vírgula $(0,000)$. 


\section{Capítulo 2}

\section{Métodos teóricos I: Estados ligados de moléculas isoladas}

A descrição de moléculas, contemplando a estrutura eletrônica, movimentos nucleares e diversas outras propriedades são dadas através de soluções da equação de Schrödinger. Porém, a equação de Schrödinger dificilmente possui uma solução analítica, principalmente ao se tratar de sistemas envolvendo muitos corpos, em que recorre-se a métodos de aproximação. Assim, utilizou-se métodos de mecânica quântica para se resolver a equação de Schrödinger aproximadamente. Nesse capítulo faço uma breve apresentação dos métodos teóricos utilizados no trabalho para abordar o problema dos estados ligados de moléculas isoladas numa abordagem independente do tempo. Os métodos aqui mencionados podem ser apreciados com mais detalhes em diversas referências como [24-31], entre outras que serão citadas ao longo da discussão. Além disso, foram utilizados alguns softwares comerciais para a solução da equação. Suas referências estão dispostas conformem forem citados no texto.

A descrição de moléculas isoladas sob o ponto de vista da mecânica quântica usualmente se inicia com a aproximação e separação de Born-Oppenheimer (BO), que nos permite buscar soluções da equação de Schrödinger decompostas em parte nuclear e eletrônica. O argumento é baseado essencialmente nas diferenças entre as massas dos núcleos e elétrons, e consequentemente nas escalas de tempo típicas em que seus movimentos se desenrolam. Em todas as etapas do projeto e do texto o uso da aproximação BO está subentendido. Contudo, vale lembrar que a terceira parte (capítulos 
7 e 8) dos objetivos se baseia em uma abordagem dinâmica dos núcleos a qual envolve acoplamentos não-adiabáticos entre os estados eletrônicos envolvidos. Por esse motivo, uma descrição detalhada da separação e aproximação BO está disponível no apêndice $\mathrm{A}$.

Assim, invocamos a aproximação BO para resolvermos a parte eletrônica da equação de Schrödinger para uma dada configuração fixa dos núcleos. A equação eletrônica a ser resolvida, por sua vez, estabelece o objeto central para a descrição de uma grande parte das propriedades químicas de compostos isolados. Estados ligados, no sentido da estrutura eletrônica, constituem um espectro discreto de soluções, e diferem dos estados de espalhamento, que contemplam um espectro contínuo de estados associados a energias acima do limiar de ionização. A discussão sobre os estados de espalhamento se encontra no capítulo 7. As técnicas de estrutura eletrônica são amplamente conhecidas da comunidade científica e largamente exploradas na literatura e, na prática, foram empregadas para otimizações de geometrias, cálculos single point (SP) para estimativas de energias eletrônicas dos sistemas neutros e ânions, cálculos de estados excitados, caráter de orbitais, além do cálculo de algumas propriedades, como momento de dipolo elétrico e cargas efetivas sobre os átomos.

\subsection{Estrutura eletrônica de estados ligados}

Grosso modo, podemos separar metodologias de estrutura eletrônica usuais em duas classes, dentre as quais a primeira delas a de métodos baseados em funções de onda eletrônica. Nessa classe, usualmente toma-se o método Hartree-Fock (HF) como referência[24, 27]. O método $\operatorname{HF}[24,27]$ é o primeiro a ser citado pela por respeito à ordem cronológica a qual os métodos foram desenvolvidos, por ser a referência de muitos métodos mais sofisticados, além de certamente ser um dos mais populares em cálculos de estrutura eletrônica até os dias de hoje. Ele se baseia em um procedimento variacional do funcional de energia eletrônica sobre uma proposta de solução monodeterminantal - produto antissimetrizado de funções de uma partícula - como se as partículas não interagisse, cuja condição de minimização fornece as equações 
de HF. Por esse motivo o método representa uma descrição limitada do problema, por não levar em conta termos de energia atribuídos à correlação eletrônica estática e correlação dinâmica. Uma apresentação suscinta do formalismo HF pode ser encontrada no apêndice $\mathrm{C}$, em que esclaresço as diferenças para o tratamento adequado de sistemas de camada fechada e de camada aberta - no nosso caso; neutros e ânions. Durante o trabalho utilizou-se o método HF principalmente no que diz respeito à descrição do alvo nos processo colisionais, como ficará mais claro no capítuo 3.

Métodos pós-HF foram desenvolvidos de forma a buscarem uma melhor descrição da energia de correlação eletrônica, melhorando a energia obtida com o método HF original. Nesse contexto um dos métodos mais populares é o método MP2 (MøllerPlesset second order perturbation theory)[27, 31], onde a correlação eletrônica é incluída de forma perturbativa, onde é empregada a teoria de perturbação de segunda ordem usual da mecânica quântica. A teoria MP2 foi utilizada principalemente em otimizações de geometria.

Uma outra classe de métodos pós HF são os baseados na interação de configurações (configuration interaction - CI)[27], nos quais parte-se da solução HF para construir a solução do problema como uma expansão de determinantes que contemplam excitações eletrônicas de orbitais ocupados HF para orbitais virtuais HF,

$$
|\psi\rangle=\left|\psi_{0}\right\rangle+\sum_{a, r} C_{a}^{r}\left|\psi_{a}^{r}\right\rangle+\sum_{a, b, r, s} C_{a b}^{r s}\left|\psi_{a b}^{r s}\right\rangle+\sum_{a, b, c, r, s, t} C_{a b c}^{r s t}\left|\psi_{a b c}^{r s t}\right\rangle+\ldots
$$

obtendo-se os coeficientes variacionalmente. Na equação 2.1, $\left|\psi_{0}\right\rangle$ é a solução HF, a primeira soma é realizada sobre os estados determinantais $\left|\psi_{a}^{r}\right\rangle$ onde um spin-orbital ocupado $\left|\chi_{a}\right\rangle$ é substituído por um spin-orbital virtual $\left|\chi_{r}\right\rangle$ e são chamados monoexcitados, o segundo termo está associado ao estados determinantais $\left|\psi_{a b}^{r s}\right\rangle$ onde dois spin-orbitais ocupados $\left|\chi_{a}\right\rangle$ e $\left|\chi_{b}\right\rangle$ são substituídos por dois spin-orbitais virtuais $\left|\chi_{r}\right\rangle$ e $\left|\chi_{s}\right\rangle$ e são chamados duplamente excitados, e assim por diante ${ }^{1}$. O truncamento da soma 2.1 é característica particular do método CI que está sendo empregado. No caso de considerarmos apenas excitações simples, chamamos o método de CIS.

\footnotetext{
${ }^{1}$ Para esclarescimento sobre as notações, ver apêndices B e C.
} 
Caso consideremos excitações simples e duplas, chamamos o método de CISD, e assim sucessivamente. Outras variações são as baseadas em construção de espaços ativos, como o método CASCI (do inglês complete active space - CI), onde selecionase um conjunto de orbitais moleculares ocupados e virtuais, no sentido HF, e faz-se uma expansão 2.1 sem truncamentos (full-CI) dentro do espaço ativo. Em outras palavras, uma abordagem CASCI(N,M) considera todos os possíveis determinantes de $\mathrm{M}$ orbitais ativos populados por $\mathrm{M}$ elétrons. Apesar desse tipo de estratégia ser bastante dependente do espaço ativo escolhido, em muitos casos ela se mostra interessante por recuperar boa parte da correlação eletrônica com um modesto custo computacional.

Os métodos CI também são úteis na estimativa de estados eletrônicos excitados, tanto para espécies neutras como aniônicas. No caso, associamos o número de estados eletrônicos descritos ao número desejado de raízes para a condição de mínimo do funcional da energia construído a partir da proposta 2.1. Durante os cálculos de dinâmica apresentados no capítulo 8 o método de estrutura eletrônica adotado para os cálculos de energias e gradientes foi o FOMO-CASCI[32] (do inglês floating occupation molecular orbitals - CASCI), frequentemente empregado em problemas de fotodinâmica por ser uma alternativa eficaz a métodos multi-configuracionais como SA-CASSCF (do inglês state average - complete active space self-consistence field). Os métodos multiconfiguracionais não serão discutidos aqui, mas vale dizer que eles são eficazes em recuperar parte das energias de correlação estática e correlação dinâmica, em geral. A ideia do FOMO-CASCI, por outro lado, se baseia em uma distribuição de ocupações fracionárias dos elétrons no espaço ativo (mono-configuracional) de acordo com uma distribuição térmica, como a distribuição de Fermi-Dirac, levando em conta as energias dos orbitais. A temperatura utilizada para tal é adotada como um parâmetro, e é tipicamente estabelecida como $T_{\mathrm{FOMO}} \sim 0.2$ [unidades atômicas]. Dessa maneira o FOMO-CASCI é capaz de incluir efeitos de correlação estática, sendo uma opção para simulações de dinâmica não-adiabática em que efeitos de correlação são essenciais, como em casos de quebra de ligação. 
Mencionamos também o método coupled-cluster (CC), um dos métodos ab initio mais sofisticados atualmente. Esse método se baseia em descrever excitações através da ação de um operador de excitação sobre a solução HF, e muitas vezes foi utilizado no trabalho como referência para benchmarks de propriedades de estados ligados. O método também foi empregado para estimativa de energias verticais de ânions (VAE) ligados. Ele não será aqui discutido em detalhes e pode ser encontrado nas referências[27].

A segunda classe de métodos de estrutura eletrônica é a baseada na teoria do funcional da densidade (do inglês, density functional theory - DFT) [27, 28]. Métodos dessa natureza foram diversas vezes utilizados ao longo do trabalho, no que diz respeito principalmente a otimizações de geometrias de moléculas neutras e estimativas de energias de ânions ligados de valência. Assim como o método HF, uma breve descrição matemática do método está disponível no apêndice D.

O DFT utiliza como variável do problema eletrônico a densidade eletrônica $\rho(\mathbf{r})$, e essa abordagem tem a vantagem de lidar com 3 variáveis espaciais ao invés de $3 N$ variáveis espaciais mais o estado de spin, no caso de $N$ elétrons. A ideia de se utilizar a densidade eletrônica como variável básica para o problema de muitos elétrons se iniciou com Drude no começo do século XX, entretanto o desenvolvimento da teoria apenas se deu por Hohenberg e Kohn em 1964, de sorte que o DFT é estruturado em seus dois teoremas variacionais, que por serem amplamente conhecidos não serão discutidos aqui[27]. A teoria ainda sofreu um grande avanço e desenvolvimento em sua aplicabilidade no ano de 1965 devido aos trabalhos de Kohn e Sham, e atualmente é largamente utilizada no estudo de sistemas atômicos, moléculas e sólidos. Em particular, a DFT é muito utilizada para o estudo de propriedades eletrônicas de biomoléculas e macromoléculas em geral (tipicamente com número de átomos acima de 10)[33-36], devido a seu baixo custo computacional quando comparado a métodos ab initio, como MP2 ou métodos CC.

A descrição DFT é baseada na solução monodeterminantal das equações de KohnSham (KS), onde o hamiltoniano de KS contempla um termo que busca modelar a 
correlação e troca. Essa modelagem da correlação e troca não é única. De fato, há um número grande de maneiras de fazê-lo, dando origem a um grande grupo de funcionais disponíveis. Nesse contexto uma subclasse popular é a dos funcionais híbridos, que são assim chamados por modelarem o termo de correlação e troca como combinações lineares de termos ab initio e quantidades aproximadas de outros sistemas, como gases de elétrons. No apêndice E mostro como alguns funcionais híbridos são construídos.

É bem sabido que diferentes funcionais podem ser úteis na descrição de diferentes propriedades, e raramente um certo funcional é eficaz em descrever simultaneamente diversas propriedades eletrônicas de maneira acurada. Porém, aqui vale a pena mencionar a particular popularidade do funcional híbrido B3LYP[37] (Beck, 3-parameter, Lee-Yang-Parr), que é certamente um dos mais versáteis no sentido de aplicações (ver eq. E.11). Muitos outros funcionais híbridos foram propostos e são largamente utilizados, como o funcionais com correções de longo alcance, como CAM-B3LYP[38], LC-PBE[39], alguns outros funcionais híbridos, como o funcional PBE0[40], além dos funcionais híbridos da classe meta-GGA como M05-2X, M06-2X, entre outros[41, 42]. No presente trabalho o uso de DFT limitou-se a otimizações de geometrias de espécies neutras, aniônicas e na investigação de energias verticais de ânions (VAE) de valência.

Os cálculos de estrutura eletrônica foram realizados com o uso dos softwares GAMESS[43], gaussian09[44] e TeraChem (GPU-based)[45-47].

\subsection{Funções Base}

Nessa seção apresentaremos de forma breve os conjuntos de funções base utilizados em métodos de mecânica quântica, e citaremos os conjuntos utilizados ao longo do trabalho, especificamente. Métodos de estrutura eletrônica são formulados para um conjunto infinito de funções atômicas de base para expansões do tipo C.17, embora considerar um conjunto finito de funções seja uma aproximação irremediável.

Há um enorme número de conjuntos de funções base na literatura, como os STOs (Slater Type Orbitals) ou as GTOs (Gaussian Type Orbitals), como os conjuntos 3-21G, 6-31G, 6-311G, entre outros muitos. Devido ao menor custo computacional 
para se calcular integrais de 2 elétrons, as bases GTOs são as mais utilizadas e estão implementadas em grande parte dos programas computacionais de química quântica. A expressão dos orbitais gaussianos possui a seguinte forma

$$
\varphi_{\zeta, l, m}^{G T O}(\mathbf{r})=N Y_{l, m}(\theta, \varphi) r^{2 n-2-l} e^{-\zeta r^{2}}
$$

em que $Y_{l, m}(\theta, \varphi)$ são os harmônicos esféricos escritos em coordenadas esféricas usuais e $N$ é uma constante de normalização. O parâmetro $\zeta$ é o expoente da função. Se ele for pequeno, a função representa um orbital difuso, enquanto que se for grande, a função representa um orbital localizado. Cada orbital atômico 2.2 está centrado em um determinado sítio atômico, escrito em termos de coordenadas esféricas cuja origem coincide com a posição desse sítio em particular.

Para uma descrição mais refinada da estrutura eletrônica, algumas bases consideram, para cada orbital atômico $n, l, m$ de um determinado sítio, uma combinação de funções gaussianas ao invés de uma única função. Esse procedimento é conhecido como CGTOs (Contracted Gaussian Types Orbitals)

$$
\varphi_{\zeta, n, l, m}^{C G T O}(\mathbf{r})=N \sum_{k=1}^{n} c_{k} Y_{l, m}(\theta, \varphi) r^{2 n-2-l} e^{-\zeta_{k} r^{2}}
$$

As constantes c's são chamadas de coeficientes de contração da base. O número $n$ de gaussianas para descrever um determinado orbital atômico pode variar de átomo para átomo, assim como de orbital para orbital. Algumas bases conhecidas utilizam, por exemplo, de $n=1$ para todos os orbitais atômicos. Outras se utilizam de $n=2$ para todos os orbitais, e são conhecidas como bases double-zeta (DZ), ou $n=3$ (TZ), e assim por diante. Algumas também usam diferentes contrações para orbitais de caroço e orbitais de valência.

Podemos também incluir funções de polarização na descrição dos orbitais. Isso significa adicionar ao conjunto base funções relacionadas a momentos angulares maiores que os orbitais da camada de valência. Isso permite que os orbitais possuam mais flexibilidade e possam assim descrever de maneira mais acurada algumas espécies, como 
ânions ou radicais livres. Além disso, há a possibilidade de incluir funções gaussianas no conjunto de base pré-estabelecido. Isso é, adicionar a cada tipo atômico um conjunto extra de funções. Isso é de grande utilidade quando queremos descrever, por exemplo, algum orbital de valência com melhor detalhamento, ou um orbital difuso em uma determinada localização, entre outros fenômenos de interesse.

Do ponto de vista computacional, grande parte dos softwares de mecânica quântica implementam as gaussianas da expansão 2.3 escritas em coordenadas cartesianas, e são assim chamadas de gaussianas cartesianas (GC), escritas na forma

$$
\varphi_{\zeta, \alpha, \beta, \gamma}^{G C}(\mathbf{r})=N x^{\alpha} y^{\beta} z^{\gamma} e^{-\zeta r^{2}}
$$

onde $\alpha+\beta+\gamma=l$ e define o tipo de função.

Para otimização de geometrias, os níveis de teoria mais utilizados foram MP2, que frequentemente foi empregado em conjunto com funções de base 6-31G* , cc-pVDZ, aug-cc-pVDZ e aug-cc-pVTZ, e DFT/B3LYP, que por sua vez foi frequentemente empregado com funções de base aug-cc-pVDZ e aug-cc-pVTZ. 


\section{Capítulo 3}

\section{Métodos teóricos II: $\mathrm{O}$ espalhamento de elétrons e estados ressonantes}

Nesta seção dedico-me a discutir a abordagem utilizada para resolver o problema colisional elétron-molécula a baixas energias. O espalhamento eletrônico por sistemas moleculares é tema central do projeto, e assim a metodologia será discutida com razoável nível de detalhamento. Um comentário preliminar que deve ser feito é de que a abordagem utilizada é não-relativística, independente do tempo e o problema é resolvido na aproximação de núcleos fixos, como ficará mais explícito na seção a seguir.

\subsection{Aspectos gerais do problema de espalhamento}

Consideremos um feixe e elétrons de energia cinética bem definida (o elétron incidente é o projétil do problema colisional) incidindo sobre uma molécula de $N$ elétrons (alvo). O problema geral a ser resolvido refere-se basicamente à equação de Schrödinger A.1, mas diferente do que é feito para estados ligados, a condição de contorno para o espalhamento é uma onda plana mais uma onda esférica no limite assintótico. Essa condição de contorno está associada a soluções da equação de Schrödinger que não são de quadrado integrável, o que requer uma abordagem diferente da discutida na seção anterior. 
A descrição física do problema é dada da seguinte forma. O elétron incidente é espalhado por molécula que inicialmente encontra-se em um estado de energia bem definida, por hipótese. Dessa forma, inicialmente, a função de onda pode ser escrita como a composição de uma onda plana incidente de momento bem definido e uma função de onda associada a um estado ligado estacionário do alvo e, após o espalhamento, o comportamento assintótico do sistema elétron+alvo também pode ser descrito pela composição de uma onda, agora espalhada, de momento bem definido e uma função de onda associada ao estado final do alvo.

Dessa forma, a conservação de energia durante o processo nos leva à relação

$$
\frac{k_{l}^{2}}{2}+E_{l}=\frac{k_{l^{\prime}}^{2}}{2}+E_{l^{\prime}}=E_{T}
$$

em que $l$ e $l^{\prime}$ denotam os estados iniciais e finais do sistema, respectivamente, $k_{l}\left(k_{l^{\prime}}\right)$ é o módulo do momento linear do elétron incidente(espalhado) e $E_{T}$ é a energia total do sistema projétil+alvo. A expressão 3.1 está expressa em unidades atômicas. As possíveis configurações assintóticas finais associadas ao índice $l^{\prime}$ são denominadas canais da colisão. Caso um possível canal respeite a conservação de energia 3.1 para uma dada energia cinética inicial do projétil $k_{l}^{2} / 2$ (ou energia da colisão) com $k_{l^{\prime}}^{2}>0$, o canal é aberto e, caso contrário, o canal é fechado. Essa nomenclatura deixa claro a ideia de quando um possível desfecho do processo é energeticamente acessível para uma dada energia da colisão.

Em baixas energias, consideramos que não há ionização do alvo. Isto é, o espalhamento não induz a perda de elétrons da molécula. É importante também colocar que como estamos interessados em processos de baixas energias, efeitos relativísiticos não serão levados em consideração. Isso faz com que a hamiltoniana eletrônica de espalhamento seja dada por

$$
\mathscr{H}_{N+1}=\mathscr{H}_{0}+\mathscr{V}
$$

em que o subscrito $N+1$ indica $N$ elétrons do alvo mais o elétron incidente, $\mathscr{H}_{0}$ é a hamiltoniana eletrônica da molécula alvo na aproximação BO mais o operador de 
energia cinética do projétil e $\mathscr{V}$ é o operador de energia potencial da interação entre o projétil e o alvo.

A equação utilizada para encontrar as soluções estácionárias $\Psi$ é a equação de Schrödinger independente do tempo, que nesse contexto é convenientemente visualizada como

$$
\mathscr{H}_{N+1}|\Psi\rangle=E|\Psi\rangle=\left(\frac{k_{l}^{2}}{2}+E_{l}\right)|\Psi\rangle
$$

onde, ao lembrar que estamos resolvendo o problema na aproximação de núcleos fixos, $\Psi=\Psi\left(\mathbf{r}_{1}, \ldots, \mathbf{r}_{N+1}\right)$ é uma função de $N+1$ elétrons e, por conveção, $\mathbf{r}_{N+1}$ denota o vetor posição do elétron incidente. A dependência da solução $\Psi$ com as coordenadas nucleares é paramétrica e estará subentendida. A condição de contorno para o problema de espalhamento é dada por

$$
\Psi_{\mathbf{k}_{l}}\left(\mathbf{r}_{1}, \ldots, \mathbf{r}_{N+1}\right) \rightarrow S_{\mathbf{k}_{l}}\left(\mathbf{r}_{1}, \ldots, \mathbf{r}_{N+1}\right)+\sum_{l^{\prime}} f\left(\mathbf{k}_{l^{\prime}}, \mathbf{k}_{l}\right) \phi_{l^{\prime}}\left(\mathbf{r}_{1}, \ldots, \mathbf{r}_{N}\right) \frac{e^{i k_{l^{\prime}} r}}{r}
$$

no limite assintótico $r_{N+1} \rightarrow+\infty$. O primeiro termo da equação 3.4 é a solução do problema sem a interação entre o projétil e alvo. Ela satisfaz a equação $\mathscr{H}_{0}\left|S_{\mathbf{k}_{l}}\right\rangle=$ $E\left|S_{\mathbf{k}_{l}}\right\rangle$ e, podemos assim notar que esse estado pode ser escrito como um produto direto entre um estado do alvo e uma onda plana, associada ao elétron incidente $\left|S_{\mathbf{k}_{l}}\right\rangle=\left|\phi_{l}\right\rangle \otimes\left|\mathbf{k}_{l}\right\rangle$. O segundo termo da equação 3.4, entretanto, está associado à condição de espalhamento. Cada termo da soma refere-se à amplitude de espalhamento de uma onda plana associada ao estado $l$ a uma onda esférica associada ao estado $l^{\prime}$. A função $f\left(\mathbf{k}_{l^{\prime}}, \mathbf{k}_{l}\right)$ contém essencialmente todas as informações relevantes para o problema de espalhamento, sendo assim o objeto central dos métodos teóricos.

Podemos reescrever a equação de Schrödinger de uma forma integral, de maneira a incorporar automaticamente a condição de contorno 3.4. Essa versão integral da equação é conhecida como equação de Lippmann-Schwinger, dada por

$$
\left|\Psi_{\mathbf{k}_{i}}^{( \pm)}\right\rangle=\left|S_{\mathbf{k}_{i}}\right\rangle+\mathscr{G}_{0}^{( \pm)} \mathscr{V}\left|\Psi_{\mathbf{k}_{i}}^{( \pm)}\right\rangle
$$


onde o operador de Green $\mathscr{G}_{0}^{( \pm)}$é dado por

$$
\mathscr{G}_{0}^{( \pm)}=\lim _{\epsilon \rightarrow 0} \frac{1}{E-\mathscr{H}_{0} \pm i \epsilon} .
$$

Na equação acima, a solução $(+)$ contempla uma onda plana incidente mais uma onda esférica divergente (outgoing), sendo essa a solução fisicamente esperada. A solução (-), em contrapartida, contempla uma onda esférica incidente (ingoing) mais uma onda plana. Apesar dessa solução não representar uma solução fisicamente razoável, ela é matemáticamente possível e importante para a derivações de outras expressões úteis.

Para finalizar as considerações gerais, temos da teoria elementar do espalhamento que a amplitude de espalhamento pode ser obtida da equação 3.5 e escrita de diferentes maneiras, dentre as quais duas delas são

$$
f=-\frac{1}{2 \pi}\left\langle S_{\mathbf{k}_{f}}|\mathscr{V}| \Psi_{\mathbf{k}_{i}}^{(+)}\right\rangle=-\frac{1}{2 \pi}\left\langle\Psi_{\mathbf{k}_{f}}^{(-)}|\mathscr{V}| S_{\mathbf{k}_{i}}\right\rangle
$$

Cada uma dessas amplitudes contempla uma condição de contorno diferente e ambas serão úteis na descrição do método multicanal de Schwinger, que será descrito a seguir. Porém, antes de ilustrá-lo, faremos uma brevíssima manipulação. Multiplicando a equação 3.5 por $\mathscr{V}$, obtemos a relação

$$
A^{( \pm)}\left|\Psi_{\mathbf{k}_{i}}^{( \pm)}\right\rangle=\mathscr{V}\left|S_{\mathbf{k}_{i}}\right\rangle
$$

onde o operador $A^{( \pm)}$é definido como $\mathscr{V}-\mathscr{V}_{0}^{( \pm)} \mathscr{V}$. Ao substituir a equação 3.8 no último membro da equação 3.7 conseguimos obter uma terceira expressão para a amplitude de espalhamento;

$$
f=-\frac{1}{2 \pi}\left\langle\Psi_{\mathbf{k}_{f}}^{(-)}\left|A^{(+)}\right| \Psi_{\mathbf{k}_{i}}^{(+)}\right\rangle
$$

Finalmente, somando-se as duas expressões apresentadas na equação 3.7, e posteriormente subtraindo a equação 3.9, obtemos finalmente uma outra expressão alternativa 
para a amplitude $f$, dada por

$$
f=-\frac{1}{2 \pi}\left[\left\langle S_{\mathbf{k}_{f}}|V| \Psi_{\mathbf{k}_{i}}^{(+)}\right\rangle+\left\langle\Psi_{\mathbf{k}_{f}}^{(-)}|V| S_{\mathbf{k}_{i}}\right\rangle-\left\langle\Psi_{\mathbf{k}_{f}}^{(-)}\left|A^{(+)}\right| \Psi_{\mathbf{k}_{i}}^{(+)}\right\rangle\right]
$$

e que será utilizada na formulação do SMC.

\subsection{O método SMC}

Os cálculos das amplitudes de espalhamento são realizados por meio do método multicanal de Schwinger (Schwinger multichannel method-SMC)[48-50]. Esse método é baseado no princípio variacional de Schwinger, que diz que a amplitude de espalhamento deve ser estável $(\delta f=0)$ frente a variações da solução do problema 3.5. Impondo a condição $\delta f=0$ na expressão 3.10, obtemos que a estabilidade variacional corresponde à condição

$$
A^{(-) \dagger}=A^{(+)}
$$

A essa altura podemos expandir as soluções $\Psi$ em uma base de $N+1$ partículas conhecidas, de forma a sermos capazes de traduzir a condição de estabilidade variacional em uma condição para a expansão, e consequentemente uma expressão variacional para a amplitude $f$. Escrevendo, portanto,

$$
\left|\Psi_{\mathbf{k}_{i}}^{(+)}\right\rangle=\sum_{\mu} c_{\mu}^{(+)}\left(\mathbf{k}_{i}\right)\left|\chi_{\mu}\right\rangle
$$

e

$$
\left\langle\Psi_{\mathbf{k}_{i}}^{(-)}\right|=\sum_{\nu} c_{\nu}^{(-) *}\left(\mathbf{k}_{i}\right)\left\langle\chi_{\nu}\right|
$$

podemos usar as condições

$$
\frac{\delta f}{\delta c_{\mu}^{(+)}}=\frac{\delta f}{\delta c_{\nu}^{(-) *}}=0
$$

válida para quaisquer $\mu$ e $\nu$, para obter a expressão

$$
f\left(\mathbf{k}_{i}, \mathbf{k}_{f}\right)=-\frac{1}{2 \pi} \sum_{\mu, \nu}\left\langle S_{\mathbf{k}_{f}}|\mathscr{V}| \chi_{\mu}\right\rangle\left(d^{-1}\right)_{\mu \nu}\left\langle\chi_{\nu}|\mathscr{V}| S_{\mathbf{k}_{i}}\right\rangle
$$


com $d^{-1}$ sendo a inversa da matriz cujos elementos são

$$
d_{\mu \nu}=\left\langle\chi_{\mu}\left|A^{(+)}\right| \chi_{\nu}\right\rangle
$$

A essa altura, dois comentários devem ser feitos. O primeiro é que, uma vez que o alvo é um sistema neutro, o potencial de interação $\mathscr{V}$ entre o elétron incidente e o alvo é de curto alcance, no sentido de sua representação no espaço de posições esteja associada a um potencial proporcional à $\mathscr{O}\left(r^{-2}\right)$, fazendo com que o comportamento das funções $\left\{\chi_{\mu}\right\}$ a grandes distâncias não contribua para as integrais da expressão 3.15. Isso nos permite usar funções de quadrado integrável $\left(\mathscr{L}^{2}\right)$ para contruir o conjunto $\left\{\chi_{\mu}\right\}$, como funções gaussianas-cartesianas, o que representa uma grande vantagem do método SMC sob o ponto de vista computacional. O outro comentário é que, como citado anteriormente, os canais de ionização do alvo podem ser desprezados no limite de baixas energias, o que nos permite reduzir a representação do operador de Green apenas sobre os estados discretos do alvo. Essa redução é usualmente feita através de um operador de projeção $P$, dado por

$$
P=\sum_{l}^{\text {abertos }}\left|\phi_{l}\right\rangle\left\langle\phi_{l}\right|,
$$

onde aqui a soma é feita apenas sobre os canais abertos do alvo. Na prática, a soma na definição 3.17 requer um truncamento que se torna cada vez mais inevitável para energias de colisão cada vez mais próximas do potencial de ionização do alvo, por ser uma região de energia onde tipicamente se encontra uma alta densidade de estados. Como usual, é útil resolver o operador de Green na base dos auto-estados de $\mathscr{H}_{0}$, obtendo a resolução

$$
\mathscr{G}_{0}^{( \pm)}=\lim _{\epsilon \rightarrow 0} \oiint_{l} \int d^{3} \mathbf{k} \frac{\left|\phi_{l} \mathbf{k}\right\rangle\left\langle\phi_{l} \mathbf{k}\right|}{\left(k_{l}^{2}-k^{2}\right) / 2 \pm i \epsilon}
$$

em que o símbolo de soma e integral sobrepostos representa uma soma sobre todos os estados discretos do alvo acrescida de uma integral sobre todos os estados do 
contínuo. Com o uso do operador de projeção podemos adaptar convenientemente o operador de Green sob a forma

$$
\mathscr{G}_{P}^{(+)}=\lim _{\epsilon \rightarrow 0} \sum_{l}^{\text {abertos }} \int d^{3} \mathbf{k} \frac{\left|\phi_{l} \mathbf{k}\right\rangle\left\langle\phi_{l} \mathbf{k}\right|}{\left(k_{l}^{2}-k^{2}\right) / 2 \pm i \epsilon},
$$

e assim refazermos a condição variacional, uma vez que nessa projeção o operador $A^{(+)}$ assume a expressão $\mathscr{V} P-\mathscr{V} \mathscr{G}_{P} \mathscr{V}$. Porém, ao projetar o operador de Green em apenas uma parte dos estados do alvo, perde-se a garantia de que a condição de estabilidade variacional 3.11 seja satisfeita. Isso se deve porque, em geral, o operador de projeção não comuta com o potencial de interação e isso requer uma nova manipulação afim de recurperarmos a informação contida no espaço complementar ao que o operador de Green foi projetado. Fazemos isso reescrevendo a solução da equação de Schrödinger como[51]

$$
\left|\Psi_{\mathbf{k}_{i}}^{(+)}\right\rangle=a P\left|\Psi_{\mathbf{k}_{i}}^{(+)}\right\rangle+(1-a P)\left|\Psi_{\mathbf{k}_{i}}^{(+)}\right\rangle
$$

onde $a$ é um parâmetro a ser obtido. Substituimos então a equação de LippmannSchwinger na equação de Schrödinger com a solução projetada da maneira acima, e ao fim dos cálculos obtemos uma nova expressão para o operador $A^{(+)}$:

$$
A^{(+)}=\frac{1}{2}(P \mathscr{V}+\mathscr{V} P)-\mathscr{V} G_{P}^{(+)} \mathscr{V}+\frac{1}{a}\left[\hat{H}-\frac{a}{2}(\hat{H} P+P \hat{H})\right]
$$

em que $\hat{H} \equiv E-\mathscr{H}_{N+1}$. Impondo a condição $A^{(-) \dagger}=A^{(+)}$para todos os elementos de matriz, incluindo os que envolvem funções do contínuo, obtemos então o valor $a=N+1$.

Em resumo, o princípio variacional de Schwinger nos proporciona uma expressão funcional para a amplitude de espalhamento, dada por

$$
f\left(\mathbf{k}_{i}, \mathbf{k}_{f}\right)=-\frac{1}{2 \pi} \sum_{\mu, \nu}\left\langle S_{\mathbf{k}_{f}}|\mathscr{V}| \chi_{\mu}\right\rangle\left(d^{-1}\right)_{\mu \nu}\left\langle\chi_{\nu}|\mathscr{V}| S_{\mathbf{k}_{i}}\right\rangle
$$


em que $d^{-1}$ é a inversa da matriz cujos elementos são

$$
d_{\mu \nu}=\left\langle\chi_{\mu}\left|A^{(+)}\right| \chi_{\nu}\right\rangle
$$

e o operador $A^{(+)}$é dado por:

$$
A^{(+)}=\frac{\hat{H}}{N+1}-\frac{(\hat{H} P+P \hat{H})}{2}+\frac{(\mathscr{V} P+P \mathscr{V})}{2}-\mathscr{V} G_{P}^{(+)} \mathscr{V}
$$

No mais, vale mencionar que em baixíssimas energias (energias de colisão $\gtrsim 0$ ) as contribuições de canais inelásticos não existem, de forma que apenas o canal elástico deve ser considerado. Naturalmente, no caso particular de espalhamento elástico, o alvo está inicialmente em seu estado fundamental e, após o espalhamento, ele também permanece em seu estado fundamental. Assim, o operador de projeção nesse caso é dado reduzido a $P=\left|\phi_{0}\right\rangle\left\langle\phi_{0}\right|$.

\subsection{Implementação}

Estaremos interessados no cálculo do espalhamento eletrônico elástico por moléculas neutras, de camada fechada, que se encontram inicialmente em seu estado eletrônico fundamental $\left|\phi_{0}\right\rangle$. A primeira etapa consiste na resolução do problema eletrônico do estado fundamental do alvo neutro, e fazemos isso no nível HF implementado com pseudopotenciais (PP) propostos por Bachelet, Hamann e Schlüter (BHS) [52, 53] para a descrição dos núcleos e dos elétrons de caroço dos átomos pesados (todos com exceção dos hidrogênios). O uso de PP se mostra uma prática viável para os cálculos de espalhamento com o SMC, pois o custo computacional para o cálculo das integrais de dois elétrons cresce com a quarta potência do número de elétrons, e considera-se que os elétrons de valência possuem a contribuição mais significativa para a interação com o elétron incidente. A forma dos PP BHS para cada átomo é

$$
\hat{\mathscr{V}}_{P P}=\hat{\mathscr{V}}_{\text {core }}+\hat{\mathscr{V}}_{\text {ion }}
$$


em que os dois termos da soma $\hat{\mathscr{V}}_{\text {core }}$ e $\hat{\mathscr{V}}_{\text {ion }}$ são dados pelas expressões analíticas

$$
\hat{\mathscr{V}}_{\text {core }}=-\frac{Z_{v}}{r} \sum_{i=1}^{2} c_{i} \operatorname{erf}\left(\rho_{i}^{1 / 2} r\right)
$$

e

$$
\hat{\mathscr{V}}_{\text {ion }}=\sum_{n=0}^{1} \sum_{j=1}^{3} \sum_{l=0}^{2} A_{n j l} r^{2 n} e^{-\sigma_{j l} r^{2}} \sum_{m=-l}^{l}|l m\rangle\langle l m|,
$$

onde $Z_{v}$ é a carga de valência e os parâmetros $A_{n j l}, \sigma_{j l}, \rho_{i}$ e $c_{i}$ são características de cada átomo em particular. Na expressão 3.26 erf denota a função erro. Dessa forma, em todas as integrais que envolvem a interação eletrostática entre os núcleos e os elétrons de valência esses termos foram substituídos pelos seus respectivos $\hat{\mathscr{V}}_{P P}$, permitindo que as mesmas sejam resolvidas analiticamente. A implementação dos PP no SMC, assim como a maneira de se determinar os parâmetros de cada átomo, podem ser apreciadas com detalhes nas referências [52, 53].

As funções de base utilizadas para os elétrons de valência dos átomos pesados foram ajustadas para que, juntamente com o PP, descrevam de maneira razoável os elétrons de valência da molécula, e por isso é referida como base BHS. Para os hidrogênios, foi utilizada uma base compacta proposta por Dunning et al[54]. Nos capítulos de resultados exponho os expoentes das bases utilizadas para os átomos envolvidos em cada estudo.

Discuto agora a maneira como são realizados algumas das integrais responsáveis pelo elemento de matriz 3.23. Particularmente, as integrais referentes ao termo $\mathscr{V} G_{P}^{(+)} \mathscr{V}$ na base proposta $\left\{\chi_{\mu}\right\}$ representa de longe a maior dificuldade computacional do método SMC. Partindo-se da resolução do operador de Green nos autoestados de $\mathscr{H}_{0}$ (expressão 3.19), podemos fazer sua decomposição em parte real e imaginária[55],

$$
\mathscr{G}_{P}=\mathscr{G}_{P}^{P r}+\mathscr{G}_{P}^{R},
$$

que correspondem respectivamente ao valor principal de Cauchy $(\operatorname{Pr})$ e ao resíduo 
$(R)$ da integral 3.19, de forma que

$$
\mathscr{G}_{P}^{P r}=\sum_{l}^{\text {abertos }} \mathscr{P} \int_{0}^{\infty} d k \frac{k^{2}}{\left(k_{l}^{2}-k^{2}\right) / 2} \int d \hat{\mathbf{k}}\left|\phi_{l} \mathbf{k}\right\rangle\left\langle\phi_{l} \mathbf{k}\right|
$$

e

$$
\mathscr{G}_{P}^{R}=i \pi \sum_{l}^{\text {abertos }} k_{l} \int d \hat{\mathbf{k}}\left|\phi_{l} \mathbf{k}\right\rangle\left\langle\phi_{l} \mathbf{k}\right|
$$

em que $\mathscr{P}$ indica o valor principal de Cauchy na integral 3.29. Os elementos de matriz envolvidos também podem ser decompostos de maneira que

$$
\left\langle\chi_{\mu}\left|\mathscr{V} \mathscr{G}_{P} \mathscr{V}\right| \chi_{\nu}\right\rangle=\left\langle\chi_{\mu}\left|\mathscr{V} \mathscr{G}_{P}^{P r} \mathscr{V}\right| \chi_{\nu}\right\rangle+\left\langle\chi_{\mu}\left|\mathscr{V}_{P}^{R} \mathscr{V}\right| \chi_{\nu}\right\rangle
$$

donde obtemos expressões para os termos denominados off-shell;

$$
\left\langle\chi_{\mu}\left|\mathscr{V} \mathscr{G}_{P}^{P r} \mathscr{V}\right| \chi_{\nu}\right\rangle=\sum_{l}^{\text {abertos }} \mathscr{P} \int_{0}^{\infty} d k \frac{k^{2}}{\left(k_{l}^{2}-k^{2}\right) / 2} g_{\mu \nu}^{l}(k)
$$

e os termos on-shell;

$$
\left\langle\chi_{\mu}\left|\mathscr{V} \mathscr{G}_{P}^{R} \mathscr{V}\right| \chi_{\nu}\right\rangle=i \pi \sum_{l}^{\text {abertos }} k_{l} g_{\mu \nu}^{l}\left(k_{l}\right)
$$

ambos escritos em termos da função $g_{\mu \nu}^{l}$, definida como

$$
g_{\mu \nu}^{l}(k)=\int d \hat{\mathbf{k}}\left\langle\chi_{\mu}|\mathscr{V}| \phi_{l} \mathbf{k}\right\rangle\left\langle\phi_{l} \mathbf{k}|\mathscr{V}| \chi_{\nu}\right\rangle
$$

Como o método SMC permite o uso de funções de quadrado integrável para a descrição da função de onda de espalhamento e trabalhamos com funções atômicas do tipo GC, lidamos com algumas integrais que podem ser resolvidas analiticamente, como as de um elétron envolvendo duas funções GC e as integrais de dois elétrons envolvendo quatro funções GC. Entretanto, algumas integrais que não podem ser resolvidas analiticamente são as integrais em $\mathbf{k}$ que envolvem ondas planas, como as integrais de um elétron envolvendo uma função GC e uma onda plana e as integrais 
de dois elétrons envolvendo três funções GC e uma onda plana. Todas as integrais em k são resolvidas numericamente com o uso da quadratura de Gauss-Legendre.

\subsection{As aproximações estático-troca e estático-troca mais polarização}

Os elementos $\left|\chi_{\mu}\right\rangle$ são estados de $N+1$ partículas e constituem o espaço de configurações (EC) utilizado na implementação e, para realizar os cálculos da equação 3.22, duas possíveis aproximações para a construção do EC são feitas; a aproximação estático-troca (ET) e a aproximação estático-troca mais polarização (ETP). Na aproximação ET, o EC é basicamente construído mantendo-se o alvo fixo no estado fundamental e os orbitais moleculares virtuais (virtual orbital - VO) sendo os orbitais de espalhamento. Essa aproximação não permite que a estrutura eletrônica do alvo reaja à presença do elétron incidente. Nesse caso, as funções $\left|\chi_{\mu}\right\rangle$ são dadas por $\left|\chi_{\mu}\right\rangle=\mathscr{A}\left[\left|\phi_{0}\right\rangle \otimes\left|\varphi_{\mu}\right\rangle\right]$, onde $\left|\phi_{0}\right\rangle$ é o estado fundamental do alvo, $\left|\varphi_{\mu}\right\rangle$ é um orbital de espalhamento, dado por um orbital molecular virtual do alvo, e $\mathscr{A}$ é um operador de antissimetrização. Já a aproximação ETP contempla excitações simples do alvo, de forma que as funções $\left|\chi_{\mu}\right\rangle$ são dadas agora por $\left|\chi_{\mu}\right\rangle \rightarrow\left|\chi_{\nu \mu}\right\rangle=\mathscr{A}\left[\left|\phi_{\nu}\right\rangle \otimes\left|\varphi_{\mu}\right\rangle\right]$. Nessa aproximação, levamos em consideração os efeitos de relaxação da estrutura eletrônica do alvo frente à presença do elétron incidente. As funções do EC nessa aproximação envolvem assim uma escolha de três orbitais, sendo dois deles associados à excitação do alvo (buraco e partícula) e o terceiro sendo o orbital de espalhamento.

Para a escolha das funções, essencialmente duas estratégias foram utilizadas. A primeira corresponde a um protocolo proposto por Winstead e Mckoy[5], em que todos os orbitais ocupados gerados pelo SCF do sistema neutro são incluídos como orbitais buraco, todos os orbitais virtuais são incluídos como orbitais de partícula e apenas os orbitais associados, numa primeira aproximação, a captura eletrônica são incluídos como orbitais de espalhamento. Essa estratégia foi empregada, principalmente, nos cálculos de espalhamento pela uracila micro-solvatada (ver capítulo 6). A segunda estratégia considerada foi o critério energético proposto por Kossoski e Bettega[56]. 
Nesse critério, inclui-se todos os orbitais de partícula única cujos auto-valores de energia satisfazem $\epsilon_{\text {scat }}+\epsilon_{\text {part }}-\epsilon_{\text {hole }}<\Delta$, em que $\epsilon_{\text {scat }}, \epsilon_{\text {part }}$ e $\epsilon_{\text {hole }}$ são respectivamente os auto-valores do operador de Fock referentes aos orbitais de espalhamento, partícula e buraco, respectivamente, e $\Delta$ é uma energia de corte. As escolhas dos valores de $\Delta$ e assim do número de funções do espaço de configurações (frequentemente referida como quantidade de polarização) constituem uma liberdade do cálculo. Essa estratégia foi particularmente empregada nos estudos da 5-SCNU e 5-OCNU (ver capítulo 4).

Além disso, outro procedimento foi empregado na construção do EC. Com o intuito de descrever bem estados de valência, os orbitais moleculares virtuais modificados (modified virtual orbitals - MVO) foram gerados[57]. Os MVO's são construídos resolvendo a estrutura eletrônica do alvo assumindo que o mesmo é um íon com uma determinada carga positiva. A carga positiva artificialmente assumida faz com que os orbitais desocupados sejam mais compactos do que seriam se realizássemos o cálculo com a molécula neutra. De uma forma geral, diferentes conjuntos de MVO's (isto é, MVO's gerados com diferentes valores de cargas) geram diferentes curvas de seção de choque integral por estarem relacionados a diferentes EC. Isso é uma liberdade natural do SMC, exigindo testes com diferentes MVO's.

\subsection{Seções de choque integral e caracterização de ressonâncias}

A amplitude de espalhamento, uma vez obtida, pode ser usada para a determinação da seção de choque diferencial, sendo proporcional a seu módulo ao quadrado, e consequentemente para a determinação da seção de choque total por meio de uma integração angular. Porém, a amplitude de espalhamento SMC 3.22 é obtida para o referencial de repouso da molécula (body frame - BF), assim como a seção de choque diferencial associada, em contraposição ao que se tem acesso experimentalmente. Em medidas experimentais são medidas de seção de choque no referencial do laboratório (laboratory frame - LF), onde frequentemente se adota o eixo $z$ coincidindo com o feixe incidente. É possível realizar uma transformação (rotação) BF $\rightarrow$ LF da amplitude 
de espalhamento com o uso de harmônicos esféricos e de propriedades das matrizes de Wigner. Contudo, se estivermos interessados apenas na seção de choque integral ao invés da seção de choque diferencial, essa transformação não se faz necessária, pois a integração angular da amplitude de espalhamento é um invariante rotacional. Em outras palavras, a seção de choque integral é a mesma nos dois referenciais BF e LF, apesar de a seção de choque diferencial não o ser.

Calculamos então a seção de choque total a partir da expressão

$$
\sigma(E)=\frac{k_{f}}{k_{i}} \frac{1}{4 \pi} \int d \hat{\mathbf{k}}_{f} \int d \hat{\mathbf{k}}_{i}\left|f\left(\mathbf{k}_{i}, \mathbf{k}_{f}\right)\right|^{2}
$$

em que o fator $4 \pi$ normaliza a integração em $d \hat{\mathbf{k}}_{i}, E$ é a energia de colisão (energia cinética do elétron incidente) e $f$ é a amplitude de espalhamento SMC. Naturalmente, como nos concentramos na descrição do espalhamento elástico, $k_{i}=k_{f}$.

As ressonâncias se manifestam como assinaturas de Breit-Wigner na seção de choque integral sobressalentes ao comportamento de fundo (background). Nas vizinhas da energia de uma ressonância $\left(E_{r}\right)$, a seção de choque integral para o espalhamento elástico se aproxima de um comportamento da forma

$$
\sigma(E) \approx \frac{B}{4} \frac{\Gamma^{2}}{\left(E-E_{r}\right)^{2}+(\Gamma / 2)^{2}}+\sigma_{b g}(E)
$$

em que $B$ é uma constante real e positiva, $\Gamma$ é a largura de autoionização da ressonância e o índice $b g$ denota o background.

\subsection{Considerações finais}

O presente projeto apresenta uma particular dificuldade no que diz respeito a limitações do método SMC. Atualmente, poucos trabalhos implementaram o SMC para abordar problemas colisionais cujos alvos possuem um número de átomos dessa magnitude. No estudo das moléculas 5-OCNU e 5-SCNU em fase gasosa, o número de átomos é 14 e temos 339 gaussianas-cartesianas no conjunto de funções base. Essa 
quantidade é, apesar de maior, razoavelmente comparável com o observado nos trabalhos $[4,9]$ para as 5-halouracilas. Entretanto, ao estudarmos os efeitos do solvente, as moléculas foram micro-solvatadas e assim o alvo contempla, além do sistema de interesse, um certo número de moléculas de água a serem tratadas explicitamente. A escolha desse número, assim como o procedimento para a escolha, serão discutidos nos capítulos 5 e 6, mas um comentário acerca da dificuldade computacional que a proposta apresenta pode ser feito. Com a inclusão das moléculas de solvente, o número de átomos chega a cerca de 30, gerando conjuntos de base da ordem de $460 \sim 500$ para alguns sistemas. Nesse caso, enfrenta-se dificuldades e custos computacionais não apresentados anteriormente na literatura.

O último comentário a ser feito é a respeito do trabalho proposto por Staley et al.[58], em 1994. Esse trabalho relacionou energias de ressonâncias $\pi^{*}$ de uma série de moléculas de interesse biológico com energias dos respectivos orbitais virtuais dessas moléculas. Pela dispersão entre as energias obtidas experimentalmente e as energias HF dos orbitais moleculares virtuais, observou-se uma relação aproximadamente linear. Esse comportamento permitiu com que se propusesse uma relação de escala para estimar ressonâncias de caráter $\pi^{*}$ de uma molécula através de uma metodologia descrita como segue. As geometrias são otimizadas no nível MP2/6-31+G(d). Em seguida, realiza-se um cálculo SP no nível HF/6-31G* e indentifica-se os orbitais moleculares virtuais de valência de natureza $\pi^{*}$, e daí obtemos as energias associadas a esses orbitais (virtual orbital energy - VOE). Faz-se assim o uso da relação linear

$$
\operatorname{VAE}(\mathrm{eV})=0.64795 \times \operatorname{VOE}(\mathrm{eV})-1.4298
$$

onde VAE é a energia da ressonância que queremos estimar. Esse procedimento foi empregado como um guia para as posições das ressonâncias, assim como para a investigação dos orbitais envolvidos nos estados ressonantes. 


\section{Capítulo 4}

\section{Espectro de ânions transientes da 5-SCNU e 5-OCNU}

Este capítulo é dedicado a discutir o estudo dos TNI's da 5-OCNU e 5-SCNU que foram obtidos com o uso do método SMC implementado com pseudopotenciais[53], na aproximação de núcleos fixos. As geometrias da 5-OCNU e 5-SCNU foram obtidas no nível DFT utilizando o funcional híbrido B3LYP e a base aug-cc-pVTZ. Ambas as geometrias não possuem elemento de simetria (pertencendo ao grupo pontual de simetria $C_{1}$ ). Sendo assim, estudamos paralelamente os sistemas em suas geometrias planares $\left(C_{s}\right)$ de mais baixa energia, obtidas com o mesmo nível de cálculo (Fig. 4.1). Para o problema de espalhamento eletrônico, as estruturas eletrônicas dos quatro sistemas foram descritas pelo método Hartree-Fock (HF) restrito, utilizando funções de base gaussianas cartesianas descritas como segue. Os núcleos e elétrons de caroço dos átomos pesados (todos exceto hidrogênio) foram substituídos pelos pseudopotenciais de Bachelet, Hamann e Schluter (BHS)[53], enquanto que os átomos de valência foram descritos por um conjunto $5 s 5 p 2 d$, cujos expoentes encontram-se na Tab. 4.1. Além disso, um conjunto de orbitais virtuais modificados (MVO's)[57] a partir do operador de Fock catiônico associado à carga +6 foi gerado com o intuito de trabalharmos com orbitais mais compactos e com caráteres de valência mais apreciativos. As geometrias foram otimizadas com o uso do software gaussian09[44] e as estruturas eletrônicas HF com os pseudopotenciais foram obtidas com o software GAMESS[43].

Os elementos $\left|\chi_{\mu}\right\rangle$ são estados de $N+1$ partículas e constituem o espaço de 

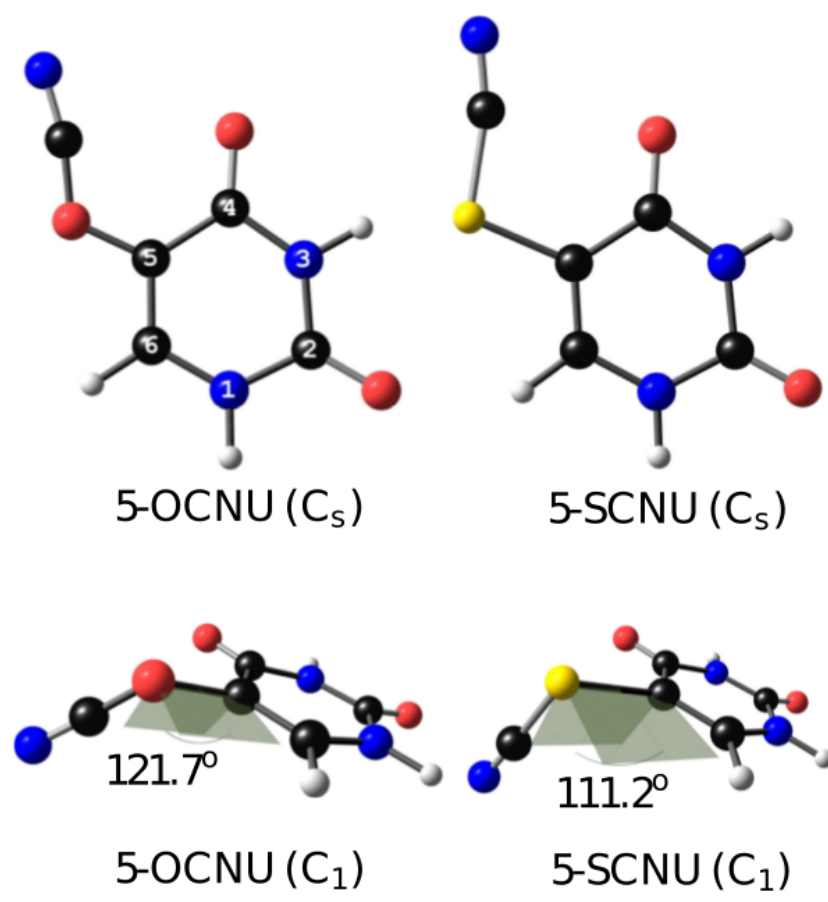

Figura 4.1: Estruturas da 5-OCNU (à esquerda) e 5-SCNU (à direita). O painel superior mostra os sistemas em suas geometrias planares (grupo $C_{s}$ de mais baixa energia, enquanto que as geometrias otimizadas (grupo $C_{1}$ ) estão mostradas nos painéis inferiores. Os átomos de enxofre estão representados em amarelo, os oxigênios em vermelho, nitrogênios em azul, carbonos em cinza e hidrogênios em branco. Os ângulos diedrais entre os planos $\mathrm{C} 6-\mathrm{C} 5-\mathrm{X}$ e $\mathrm{C} 5-\mathrm{X}-\mathrm{C}$, onde $\mathrm{X}=\mathrm{O}, \mathrm{S}$, estão indicados nas estruturas $C_{1}$, e a nomenclatura dos sítios atômicos do anel estão indicados no painel superior esquerdo.

configurações (EC) utilizado na resolução da amplitude de espalhamento do método SMCPP. Na aproximação ET, o EC é basicamente construído mantendo-se o alvo fixo no estado fundamental e os orbitais moleculares virtuais (VOs) sendo os orbitais de espalhamento. Já na aproximação ETP cálculos preliminares foram realizados antes da construção do EC. Estimativas de vertical attachment energy (VAE) para o estado ligado de valência fundamental do ânion foram feitas com DFT, e encontrou-se que os quatro sistemas possuem um estado aniônico ligado em uma energia próxima de $\sim-0.45 \mathrm{eV}$ (Tabelas 4.2 e 4.3). Assim, o número de funções do EC foi calibrado para que a eq.(1) contemplasse um estado ligado nessa energia. Para a escolha das configurações, foi utilizado o critério energético proposto por Kossoski e Bettega[56]. Nesse critério, inclui-se todos os orbitais de partícula única cujos auto-valores de energia satisfazem $\epsilon_{\text {scat }}+\epsilon_{\text {part }}-\epsilon_{\text {hole }}<\Delta$, em que $\epsilon_{\text {scat }}$, $\epsilon_{\text {part }}$ e $\epsilon_{\text {hole }}$ são respectivamente as energias dos orbitais de espalhamento, partícula e buraco, e $\Delta$ é uma 
Tabela 4.1: Expoentes das gaussianas cartesianas pertencentes ao conjunto de base utilizado para os átomos de carbono, nitrogênio, oxigênio e enxofre.

\begin{tabular}{c|cccc}
\hline \hline Tipo & Carbono & Nitrogênio & Oxigênio & Enxofre \\
\hline$s$ & 12.496280 & 17.567340 & 16.058780 & 7.649093 \\
$s$ & 2.470286 & 3.423615 & 5.920242 & 1.743283 \\
$s$ & 0.614028 & 0.884301 & 1.034907 & 0.789128 \\
$s$ & 0.184028 & 0.259045 & 0.316843 & 0.302805 \\
$s$ & 0.039982 & 0.055708 & 0.065203 & 0.063479 \\
& & & & \\
$p$ & 5.228869 & 7.050692 & 10.141200 & 7.203417 \\
$p$ & 1.592058 & 1.910543 & 2.783023 & 3.134723 \\
$p$ & 0.568612 & 0.579261 & 0.841010 & 0.529380 \\
$p$ & 0.210326 & 0.165395 & 0.232940 & 0.154155 \\
$p$ & 0.072250 & 0.037192 & 0.052211 & 0.035523 \\
& & & & \\
$d$ & 0.603592 & 0.403039 & 0.756793 & 1.163168 \\
$d$ & 0.156753 & 0.091192 & 0.180759 & 0.240526 \\
\hline
\end{tabular}

Tabela 4.2: Estimativas da VAE e momentos de dipolo da 5-OCNU em sua geometria plana (grupo de simetria $C_{s}$ ) e em sua geometria otimizada $\left(C_{1}\right)$.

\begin{tabular}{lcccc}
\hline \hline Método & $\operatorname{VAE}\left(C_{s}\right)$ & $\operatorname{VAE}\left(C_{1}\right)$ & $\mu\left(C_{s}\right)$ & $\mu\left(C_{1}\right)$ \\
\hline B3LYP & -0.46 & -0.51 & 6.43 & 5.99 \\
BLYP & -0.28 & -0.43 & 6.31 & 5.90 \\
BP86 & -0.48 & -0.60 & 6.30 & 5.88 \\
BPBE & -0.34 & -0.49 & 6.29 & 5.88 \\
PBEPBE & -0.40 & -0.54 & 6.25 & 5.88 \\
PBEh1PBE & -0.43 & -0.46 & 6.43 & 5.99 \\
LC-wPBE & -0.52 & -0.54 & 6.46 & 6.03 \\
B97D & -0.30 & -0.43 & 6.32 & 5.90 \\
M05 & -0.35 & -0.39 & 6.41 & 5.98 \\
M05-2X & -0.49 & -0.51 & 6.56 & 6.11 \\
M06 & -0.39 & -0.43 & 6.36 & 5.94 \\
M06-2X & -0.43 & -0.45 & 6.38 & 5.95 \\
\hline
\end{tabular}


Tabela 4.3: Estimativas da VAE, em eV, e momentos de dipolo, em D, da 5-SCNU em sua geometria plana $\left(C_{s}\right)$ e em sua geometria otimizada $\left(C_{1}\right)$.

\begin{tabular}{lcccc}
\hline \hline Método & $\operatorname{VAE}\left(C_{s}\right)$ & $\operatorname{VAE}\left(C_{1}\right)$ & $\mu\left(C_{s}\right)$ & $\mu\left(C_{1}\right)$ \\
\hline B3LYP & -0.50 & -0.62 & 6.59 & 5.77 \\
BLYP & -0.33 & -0.52 & 6.45 & 5.66 \\
BP86 & -0.53 & -0.71 & 6.42 & 5.64 \\
BPBE & -0.40 & -0.59 & 6.41 & 5.63 \\
PBEPBE & -0.45 & -0.64 & 6.41 & 5.63 \\
PBEh1PBE & -0.48 & -0.60 & 6.57 & 5.76 \\
LC-wPBE & -0.56 & -0.66 & 6.61 & 5.78 \\
B97D & -0.36 & -0.06 & 6.43 & 5.66 \\
M05 & -0.40 & -0.54 & 6.55 & 5.77 \\
M05-2X & -0.53 & -0.63 & 6.77 & 5.90 \\
M06 & -0.43 & -0.56 & 6.52 & 5.73 \\
M06-2X & -0.47 & -0.58 & 6.59 & 5.76 \\
\hline
\end{tabular}

energia de corte. Para a 5-OCNU $\left(C_{1}\right)$ usamos $\Delta=-1.15$ Hartree, gerando 12307 configurações. Para a 5-OCNU $\left(C_{s}\right)$, usamos $\Delta=-1.10$ Hartree, gerando 7179 coinfigurações de simetria $A^{\prime}$ e 7111 configurações de simetria $A^{\prime \prime}$. Para a 5-SCNU $\left(C_{s}\right)$, usamos $\Delta=-2.00$ Hartree, gerando 11126 configurações. Por último, para a 5$\operatorname{SCNU}\left(C_{s}\right)$, usamos $\Delta=-1.85$ Hartree, gerando 8259 configurações de simetria $A^{\prime}$ e 8030 configurações de simetria $A^{\prime \prime}$.

\subsection{Resultados e discussão}

Na Figura 4.2 apresentamos as seções de choque obtidas para a 5-OCNU nas geometrias $C_{1}$ e $C_{s}$, nas aproximações ET e ETP. Observamos um comportamento típico de establização das ressonâncias ao compararmos as curvas nas diferentes aproximações. Na curva obtida na aproximação ETP, para a estrutura $C_{s}$, observamos três ressonâncias na simetria $A^{\prime \prime}$ em 1.9 eV, 4.4 eV e 5.0 eV. A diagonalização da hamiltoniana de espalhamento representada no EC aponta um estado ligado de valência $\left(A^{\prime \prime}\right)$ em torno de -0.46 eV (esse fato é corroborado pelos cálculos DFT realizados durante a construção do EC). A componente $A^{\prime}$ da seção de choque na aproximação ETP apresenta uma ressonância em $3.5 \mathrm{eV}$ e uma pseudo-ressonância acima de $5 \mathrm{eV}$, 

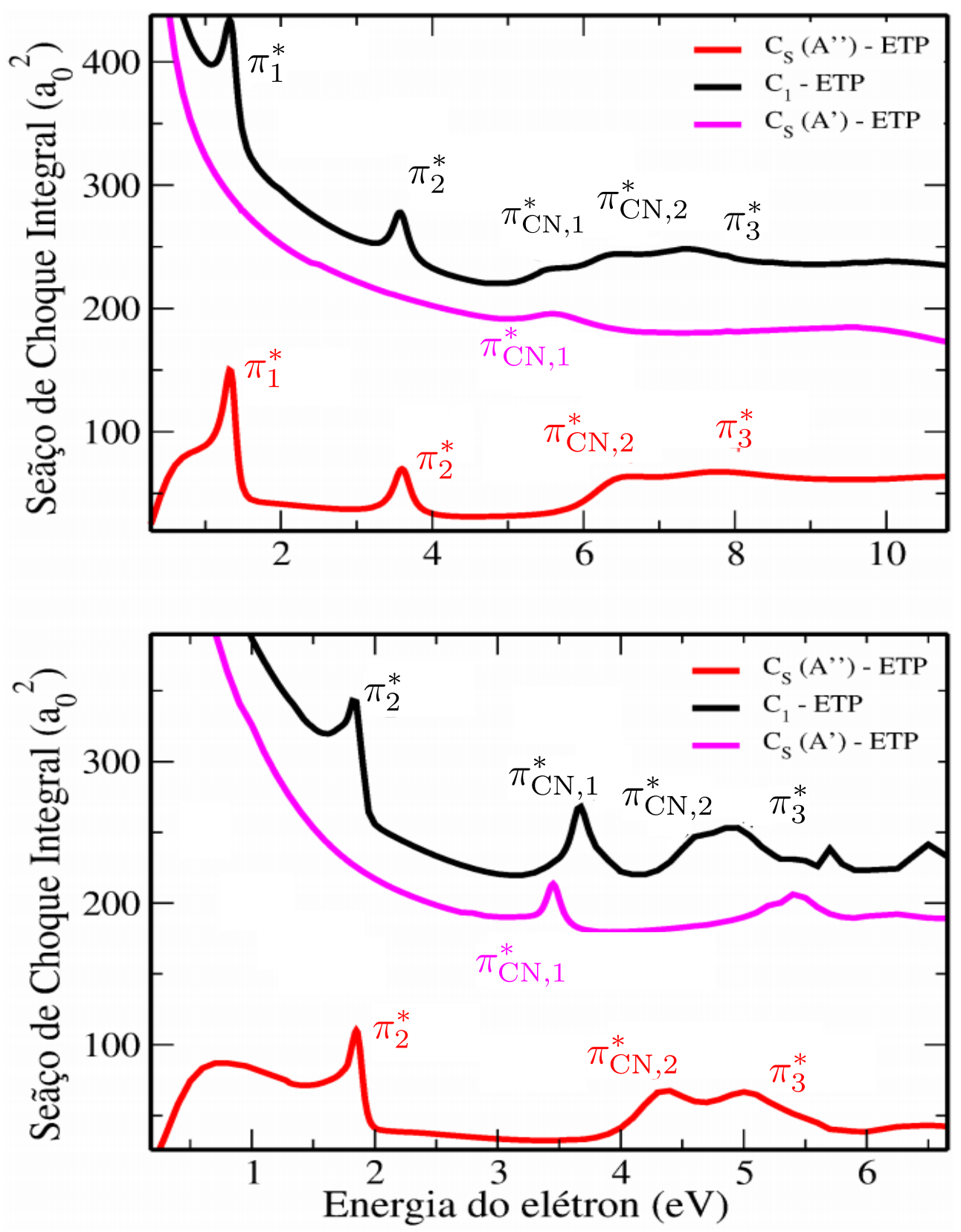

Figura 4.2: Seções de choque integral para o espalhamento eletrônico pela 5-OCNU calculadas nas aproximações ET e ETP. As componentes de simetria $A^{\prime}$ e $A^{\prime \prime}$ obtidas a partir do cálculo da estrutura $C_{s}$ estão mostradas juntamente com as curvas obtidas para a estrutura $C_{1}$ As assinaturas das ressonâncias também estão indicadas. 
que por sua vez se origina do fato de lidarmos com apenas um única canal aberto para o problema de espalhamento.

Paralelamente, usualmente geramos VO's, no contexto HF, com o uso da base compacta 6-31G* , de acordo com Staley e Strnad[58], para auxiliar na interpretação to espectro de estados aniônicos. Para a geometria $C_{s}$ da 5 -OCNU, os VO's de mais baixas energias (LUMO's) das diferentes simetrias $A^{\prime}$ e $A^{\prime \prime}$ estão dispostos na Fig. 4.3. Seguindo a nomenclatura adotada em trabalhos anteriores $[4,9,59]$ sobre a uracila e as halouracilas, os orbitais com amplitudes sobre o anel estão denotados por $\pi_{1}^{*}$, $\pi_{2}^{*}$ e $\pi_{3}^{*}$, por serem primeiras aproximações para capturas eletrônicas de caráter $\pi^{*}$. Há dois estados $\pi^{*}$ adicionais sobre o grupo CN com densidades distribuídas paralela e perpendicularmente ao plano da molécula, e foram nomeados $\pi_{\mathrm{CN}, 1}^{*}$ e $\pi_{\mathrm{CN}, 2}^{*}$, respectivamente (sendo que o primeiro deles apresenta uma natureza híbrida com certo característica $\sigma^{*}$, porém sem caráter antiligante). O orbital rotulado $\sigma_{\mathrm{NH}}^{*}$ na Fig. 4.3

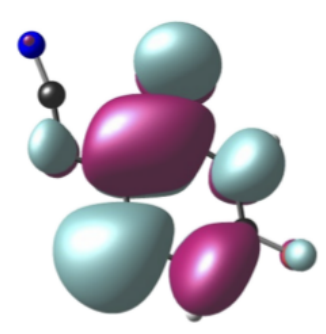

$\pi_{1}^{*}$

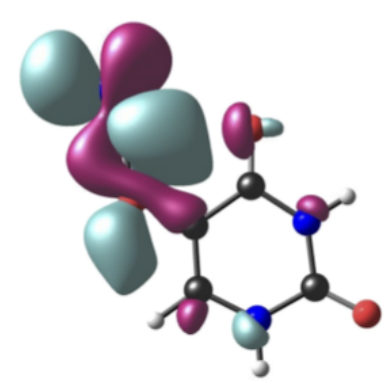

$\pi_{\mathrm{CN}, 1}^{*}$

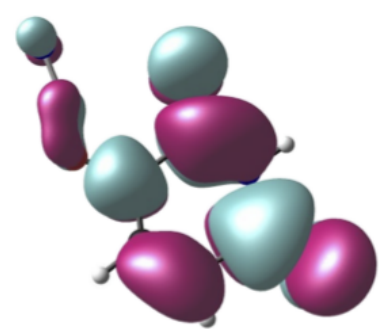

$\pi_{2}^{*}$

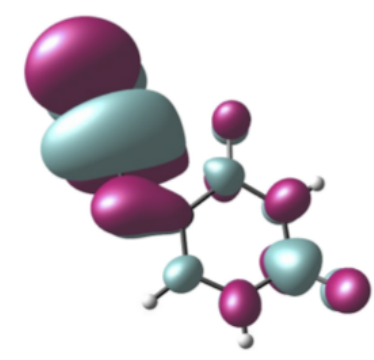

$\pi_{\mathrm{CN}, 2}^{*}$

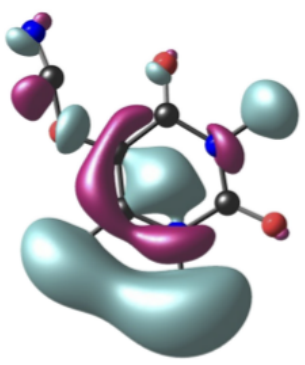

$\sigma_{\mathrm{NH}}^{*}$

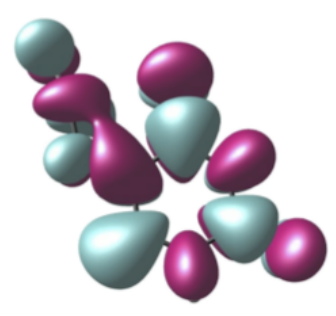

$\pi_{3}^{*}$

Figura 4.3: Orbitais virtuais $\mathrm{HF}$ obtidos com a base $6-31 \mathrm{G}^{*}$ na geometria $C_{s}$ da 5-OCNU. Os painéis foram nomeados de acordo com a natureza das ressonâncias.

é essencialmente uma mistura de uma amplitude antiligante de caráter $\sigma^{*}$ ao longo da ligação NH e de uma amplitude associada a um estado ligado por dipolo (do inglês, dipole bound state- DBS). Tais VO's são típicos da uracila e seus 5-derivados, e indi- 
cam uma ressonância que possui um papel importante dentre os possíveis mecanismos de DEA, esta por sua vez associada à eliminação do hidrogênio. Em vista das grandes larguras (cerca de alguns eV) e da interação de dipolo significativa entre elétron e alvo, essas ressonâncias $\sigma_{\mathrm{NH}}^{*}$ não possuem uma assinatura clara nas seções de choque integrais calculadas ou no espectro de transmissão eletrônica. A ressonância em 3.5 eV apresentada na curva $A^{\prime}$ da seção de choque está relacionada ao VO $\pi_{\mathrm{CN}, 1}^{*}$ na Fig. 4.4, como também pode ser inferido através do pseudo-autoestado da hamiltoniana de espalhamento nessa energia. As ressonâncias $A^{\prime \prime}$ restantes estão indicadas por $\pi_{1}^{*}$, $\pi_{2}^{*}$ e $\pi_{3}^{*}$, como também indicadas na Fig. 4.2 (notando que o estado $\pi^{*}$ é ligado e, assim sendo, não apresenta assinatura na seção de choque na aproximação ETP).

A seção de choque integral obtida na aproximação ETP para a estrutura $C_{1}$, também mostrada na Fig. 4.2, apresenta assinatura de estados aniônicos em 1.8 eV e $3.7 \mathrm{eV}$, assim como duas estruturas sobrepostas em $4 \mathrm{eV}$ e $5 \mathrm{eV}$. Um estado ligado de valência em -0.45 eV também foi obtido da diagonalização da hamiltoniana de espalhamento na representação do EC. Embora o estudo das naturezas das ressonâncias seria em princípio mais difícil na geometria $C_{1}$, inspeções dos pseudo-autoestados da hamiltoniana de espalhamento indica pouca mistura entre os estados aniônicos de interesse. Os VO's compactos na geometria otimizada estão dispostos na Fig. 4.4, e em geral, há uma clara correspondência entre os orbitais obtidos nas estruturas $C_{s}$ e $C_{1}$. Também baseados na investigação do pseudo-espectro, nós estabelecemos as energias das ressonâncias, em ordem crescente, como $\pi_{1}^{*}(-0.45 \mathrm{eV}), \pi_{2}^{*}(1.8 \mathrm{eV}), \pi_{\mathrm{CN}, 1}^{*}$ $(3.7 \mathrm{eV}), \pi_{\mathrm{CN}, 2}^{*}(4.6 \mathrm{eV})$ e $\pi_{3}^{*}(4.9 \mathrm{eV})$. Os resutados estão resumidos na Tab. 4.3.

Tabela 4.4: Energia dos estados aniônicos, em eV, obtidas através da seção de choque calculada na aproximação ETP para a 5-OCNU e 5-SCNU nas geometrias $C_{s}$ e $C 1$.

\begin{tabular}{lcccccc}
\hline \hline Sistema & $\pi_{1}^{*}$ & $\pi_{2}^{*}$ & $\pi_{3}^{*}$ & $\pi_{\mathrm{CN}, 1}^{*}$ & $\pi_{\mathrm{CN}, 2}^{*}$ & $\sigma_{\mathrm{SCN}}^{*}$ \\
\hline 5-OCNU $\left(C_{s}\right)$ & -0.46 & 1.9 & 5.0 & 3.5 & 4.4 & \\
5-OCNU $\left(C_{1}\right)$ & -0.45 & 1.8 & $\approx 4.9$ & 3.7 & $\approx 4.6$ & \\
\hline 5-SCNU $\left(C_{s}\right)$ & -0.46 & 1.8 & 4.8 & 0.4 & 2.8 & 1.9 \\
5-SCNU $\left(C_{1}\right)$ & -0.46 & 1.6 & & 1.0 & $\approx 3.4$ & $\approx 3.9$ \\
\hline \hline
\end{tabular}

O mesmo estudo foi realizado para a 5-SCNU, e a seções de choque obtidas nas 


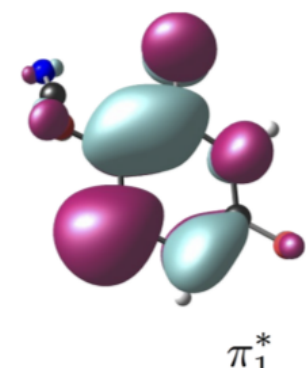

$\pi_{1}^{*}$

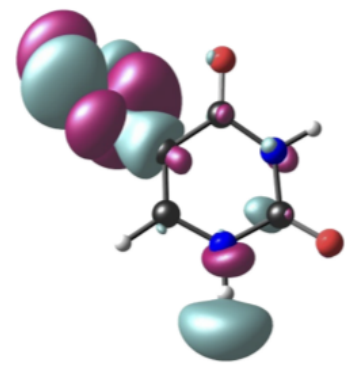

$\pi_{\mathrm{CN}, 1}^{*}$
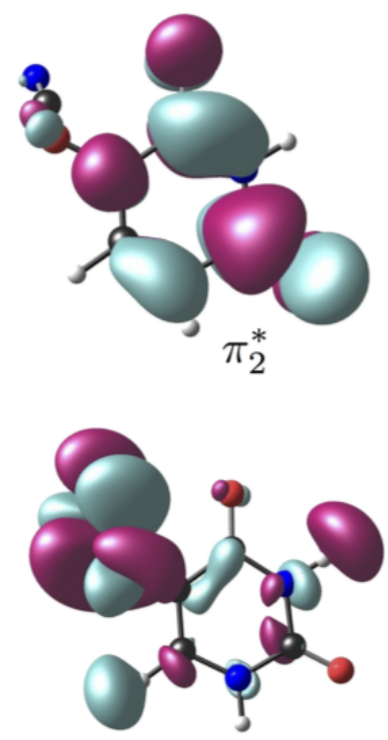

$\pi_{\mathrm{CN}, 2}^{*}$
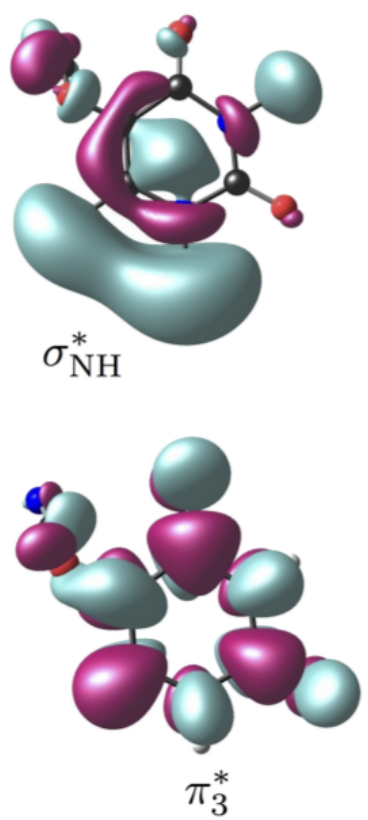

Figura 4.4: Orbitais virtuais $\mathrm{HF}$ obtidos com a base $6-31 \mathrm{G}^{*}$ na geometria $C_{1}$ da 5-OCNU. Os painéis foram nomeados de acordo com a natureza das ressonâncias.

aproximações ET e ETP, em ambas as geomestrias, são mostradas na Fig. 4.5. A componente $A^{\prime \prime}$ da seção de choque $C_{s}$ na aproximação ETP mostra um estado ligado de valência em -0.46 eV e três ressonâncias de forma em $1.8 \mathrm{eV}, 2.8 \mathrm{eV}$ e $4.8 \mathrm{eV}$. A componente $A^{\prime}$ apresenta duas ressonâncias em 0.4 eV e 1.9 eV, além de uma larga estrutura em cerca de $3.5 \mathrm{eV}$.

Assim como o caso anterior, o espectro de estados aniônicos da 5-SCNU também pode ser interpretado com o auxílio dos VO's obtidos do sistema em sua geometria plana, mostrados na Fig. 4.6, além do pseudo-espectro da hamiltoniana de espalhamento. Os orbitais $\pi_{1}^{*}, \pi_{2}^{*}$ e $\pi_{3}^{*}$ são similares aos da 5-OCNU e também da uracila. As energias das ressonâncias correspondentes também são comparáveis, com exceção do estado $\pi_{1}^{*}$, que não é um estado ligado no caso da uracila. A parte disso, as ressonâncias $\pi_{\mathrm{CN}}^{*}$ são distintas das obtidas no caso da 5-OCNU. Ambas as ressonâncias aparecem em energias menores do que no caso anterior, devido à presença do enxofre. A ressonância energeticamente mais estável da 5-SCNU tem uma contribuição significativa de um orbital atômico do tipo $d$ do enxofre e um caráter antiligante ao longo da ligação C5-S. Além disso, a ressonância adicional no espectro $A^{\prime}$ da 5-SCNU plana é interpretado como um estado $\sigma_{\mathrm{SCN}}^{*}$, com caráter predominantemente antiligante 

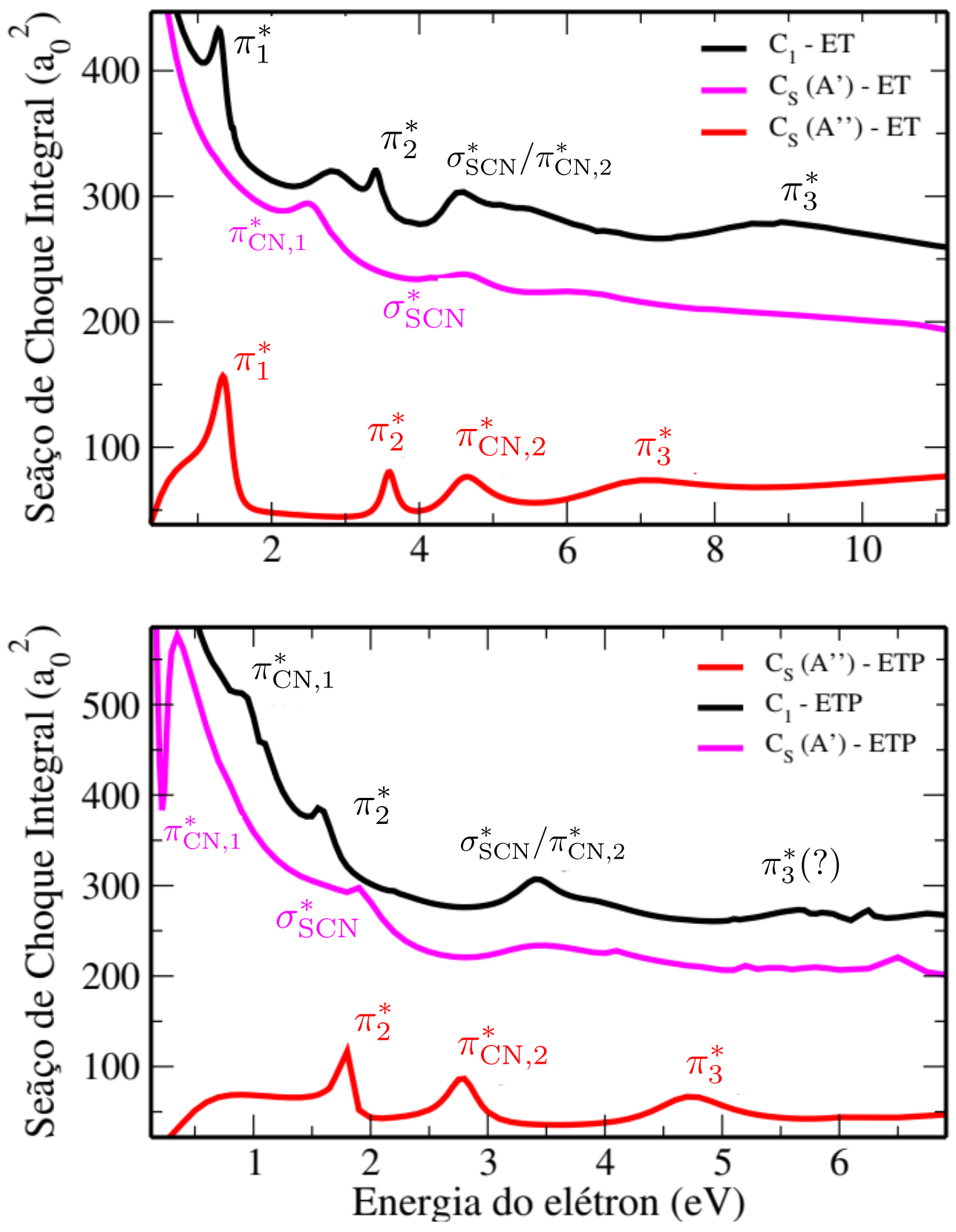

Figura 4.5: Seções de choque integral para o espalhamento eletrônico pela 5-SCNU calculadas nas aproximações ET e ETP. As componentes de simetria $A^{\prime}$ e $A^{\prime \prime}$ obtidas a partir do cálculo da estrutura $C_{s}$ estão mostradas juntamente com as curvas obtidas para a estrutura $C_{1}$ As assinaturas das ressonâncias também estão indicadas. 
sobre o grupo C5SCN (desprezando-se a clara e significativa mistura com o estado $\sigma_{\mathrm{NH}}^{*}$ ). Por fim, uma ressonância larga $\sigma_{\mathrm{NH}}^{*}$ é prevista por um VO de mesma natureza (não mostrado na Fig. 4.6).

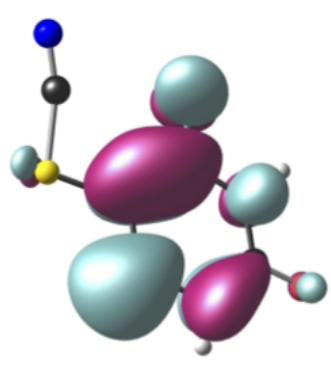

$\pi_{1}^{*}$

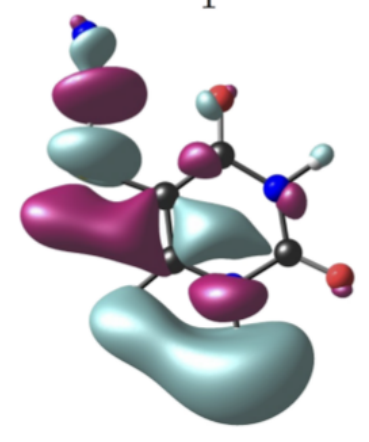

$\sigma_{\mathrm{SCN}}^{*}$

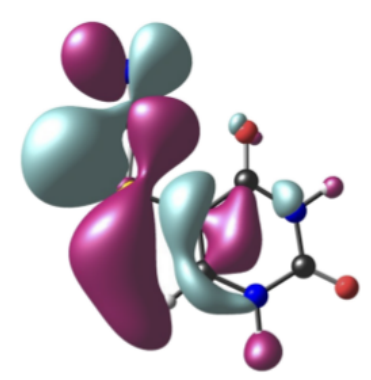

$\pi_{\mathrm{CN}, 1}^{*} / \sigma^{*}$

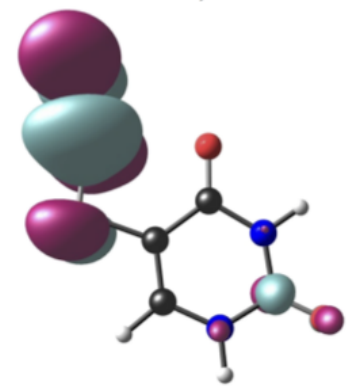

$\pi_{\mathrm{CN}, 2}^{*}$

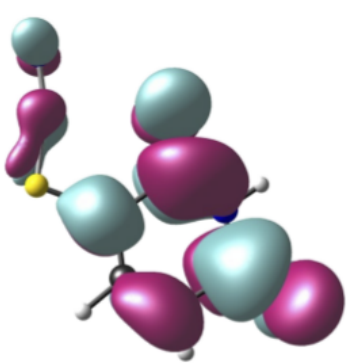

$\pi_{2}^{*}$

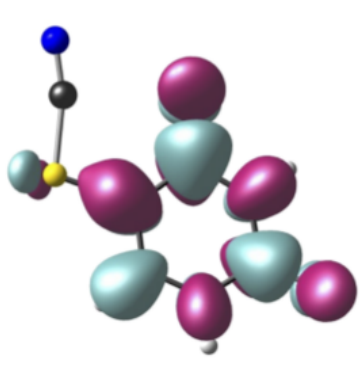

$\pi_{3}^{*}$

Figura 4.6: Orbitais virtuais $\mathrm{HF}$ obtidos com a base $6-31 \mathrm{G}^{*}$ na geometria $C_{s}$ da 5-SCNU. Os painéis foram nomeados de acordo com a natureza das ressonâncias.

A correspondência entre os espectros aniônicos obtidos para a geometria planar e otimizada é menos clara no caso da 5-SCNU do que na 5-OCNU. Na seção de choque obtida para a estrutura $C_{1}$ da 5 -SCNU (Fig. 4.5), as ressonâncias $\pi_{\mathrm{CN}, 2}^{*}$ e $\sigma_{\mathrm{SCN}}^{*}$ se sobrepõem, originando uma larga estrutura com máximo entre $3.4 \mathrm{eV}$ e $3.9 \mathrm{eV}$. A análise do pseu-espectro corrobora que o estado $\sigma_{\mathrm{SCN}}^{*}$ na geometria otimizada se encontra e uma energia maior $(\approx 3.9 \mathrm{eV})$ quando comparado ao mesmo na geometria plana $(1.9 \mathrm{eV})$. A seção de choque mostra uma larga estrutura acima de $5 \mathrm{eV}$ que em princípio poderia estar relacionada à ressonância $\pi_{3}^{*}$, porém sua assinatura não é claramente indicada pelo pseudo-espectro ou pelo conjunto de VO's compactos. Os cálculos para a geometria $C_{1}$ da 5 -SCNU entretanto apontam assiaturas claras das ressonâncias $\pi_{\mathrm{CN}, 1}^{*} / \sigma^{*}(1.0 \mathrm{eV})$ e $\pi_{2}^{*}(1.6 \mathrm{eV})$, além da estrutura larga proveniente da sobreposição dos estados $\pi_{\mathrm{CN}, 2}^{*}(\approx 3.4 \mathrm{eV})$ e $\sigma_{\mathrm{SCN}}^{*}(\approx 3.9 \mathrm{eV})$. O estado ligado de valência $\pi_{1}^{*}$ foi obtido, como nos casos anteriores, a partir da diagonalização da 
hamiltoniana de espalhamento, e os resultados estão resumidos na Tab. 4.3.

Os VO's compactos obtidos para a geometria otimizada da 5-SCNU estão dispostos na Fig. 4.7. Enquanto esses orbitais se mostraram menos úteis, uma vez que suas amplitudes não estão sempre de acordo com a análise do pseudo-espectro, eles sistematicamente sugerem uma forte mistura entre caráteres $\pi^{*}$ e $\sigma^{*}$ além de delocalizar sobre o grupo (no caso, SCN) de forma mais significativa do que ocorre na 5-OCNU. A falta de um orbital virtual claramente associado ao estado $\pi_{3}^{*}$ é também consistente com a evidente falta de assinatura na curva da seção de choque. O orbital o qual nos referimos como $\pi_{3}^{*}$ na Fig. 4.7 é o VO que mais claramente apresenta a estrutura nodal característica sobre o anel, com algumas contribuições de orbitais atômicos do tipo $3 d$ do enxofre.

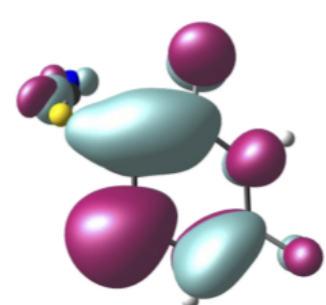

$\pi_{1}^{*}$

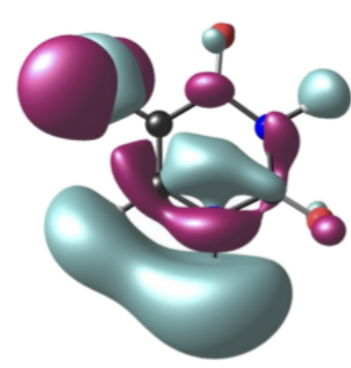

$\sigma_{\mathrm{SCN}}^{*}$

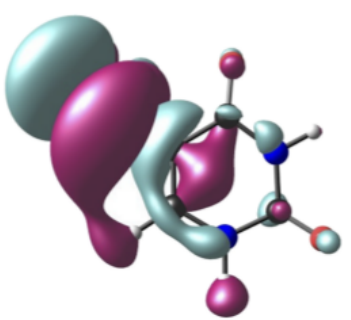

$$
\pi_{\mathrm{CN}, 1}^{*} / \sigma^{*}
$$

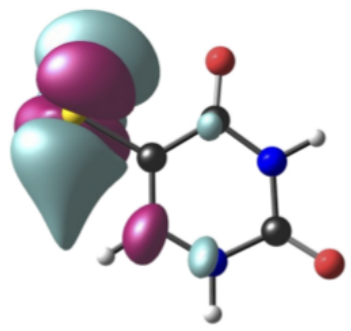

$\pi_{\mathrm{CN}, 2}^{*}$

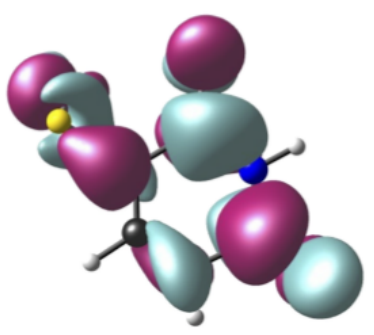

$\pi_{2}^{*}$

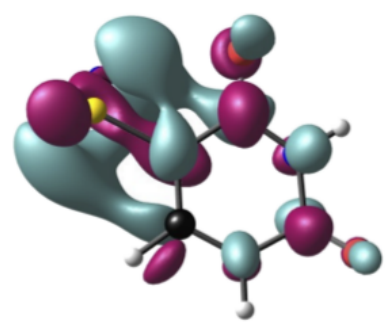

$\pi_{3}^{*}(?)$

Figura 4.7: Orbitais virtuais $\mathrm{HF}$ obtidos com a base $6-31 \mathrm{G}^{*}$ na geometria $C_{1}$ da 5-SCNU. Os painéis foram nomeados de acordo com a natureza das ressonâncias.

Apresentamos o estudo dos espectros de estados aniônicos da 5-OCNU e 5-SCNU a baixas energias, e algumas discussões e conclusões podem ser feitas da maneira como segue. A partir das ressonâncias obtidas, podemos predizer possíveis rotas de fragmentação da 5-OCNU e 5-SCNU. Até onde sabemos, há disponível apenas dados de espectro de massa para o ânion de 5-SCNU obtidos através de espectroscopia fotoeletrônica[1], e até a presente data não há dados de DEA para ambos os sistemas. 
Evitando especulações sobre reações complexas que possivelmente envolvem isomerizações ou quebra de muitas ligações, nos limitamos apenas a discutir quebras de ligações simples que podem ser inferidas através de ressonâncias de caráteres $\sigma^{*}$ antiligantes, acoplamentos com estados $\pi^{*}$ e limiares energéticos de dissociação. Análises qualitativas similares já foram utilizadas para entender dados de DEA em derivados de uracila, cloroadenina, isômeros de clorofenol e até para obter uma melhor compreensão das medidas de fragmentação dos nitroimidazóis.

Abaixo de $1.5 \mathrm{eV}$ o espectro de DEA da uracila é essencialmente associado à eliminação de hidrogênio induzida por uma ressonância vibracional de Feshbach (do inglês, vibrational Feshbach resonance - VFR). VFR's foram também observadas na eliminação de $\mathrm{H}$ e HF na 5-FU, assim como na eliminação de $\mathrm{H}$ e $\mathrm{HCl}$ na 5-ClU, apesar da eliminação de $\mathrm{H}$ ou HBr não terem sido observadas no estudo da 5-BrU. O orbital LUMO de simetria $A^{\prime}$ da 5-OCNU possui um caráter $\sigma_{\mathrm{NH}}^{*}$, similar ao orbital virtual análogo na uracila e na 5-FU. No caso da 5-SCNU, o orbital $\sigma_{\mathrm{NH}}^{*}$ observado possui uma densidade sobre o grupo SCN, sendo sob esse aspecto similar ao estado equivalente observado na 5-ClU e na 5-BrU. Baseado nessa análise, podemos esperar a eliminação de hidrogênio na 5-OCNU mas não necessariamente na 5-SCNU. As energias verticais (VAE's) do DBS, calculadas no nível MP2, são de -143 meV e -144 meV para a 5-OCNU e 5-SCNU, respectivamente, enquanto que as mesmas energias estimadas no nível CCSD(T) são de -177 meV e -189 meV, respectivamente. Esses valores são significamente maiores que os obtidos para a uracila e para as 5halouracilas, cerca de $-40 \sim-50 \mathrm{meV}$ e $-70 \sim-80 \mathrm{meV}$ segundo cada um dos níveis MP2 e CCSD(T), respectivamente.

O mecanismo de eliminação de hidrogênio associado a uma VFR envolve um acoplamento entre um DBS e uma ressonância $\sigma_{\mathrm{NH}}^{*}$. De fato, o estado aniônico adiabático de menor energia deve ter caráter DBS em torno da geometria de equilíbrio da molécula neutra, adquirindo um caráter $\sigma_{\mathrm{NH}}^{*}$ ao longo da ligação N1-H subsequentemente. Após a formação de uma VFR através de uma captura eletrônica, a eliminação de hidrogênio pode ocorrer devido ao acoplamento DBS $/ \sigma_{\mathrm{NH}}^{*}$. As energias 
das VFR's podem ser estimadas por um procedimento proposto por Scheer et al., no qual assume-se que o estiramento N1-H deve ter frequências similares no DBS e no estado fundamental do neutro $(0.45 \mathrm{eV}$ segundo a estimativa feita com o método G4(MP2)). Pela aproximação harmônica e pela energia de ligação calculada com o método CCSD(T), esperaríamos que 5-OCNU apresente VFR's em 0.27 eV, 0.73 eV e $1.2 \mathrm{eV}$, correspondendo aos níveis vibracionais $\nu_{\mathrm{NH}}=1,2,3$. Por outro lado, a estimativa G4(MP2) para o limiar de energia para a eliminação de hidrogênio é 0.21 $\mathrm{eV}$ (Tab. 4.5), valor próximo da ressonância $\nu_{\mathrm{NH}}=1$. No caso da 5-SCNU, por mais que a análise dos VO's descrita acima sugira que não haja, necessariamente, eliminação de hidrogênio, o procedimento para estimar as energias das VFR's prevê ressonâncias nas energias $0.26 \mathrm{eV}, 0.71 \mathrm{eV}$ e $1.2 \mathrm{eV}$. Para esse sistema, o limiar de energia para a dissociação é de 0.14 eV com o mesmo nível de cálculo.

Tabela 4.5: Limiares de energia, entalpia e energia livre de dissociação, em eV, para $T=298.15 \mathrm{~K}$. Os valores foram obtidos com o método G4(MP2), implementado no software gaussian09.

\begin{tabular}{lccc}
\hline \hline Reação & $\Delta E$ & $\Delta H$ & $\Delta G$ \\
\hline $5-\mathrm{OCNU}+e^{-} \rightarrow \mathrm{OCN}^{-}+\mathrm{U}^{\bullet}$ & -0.53 & -0.50 & -0.90 \\
$5-\mathrm{OCNU}+e^{-} \rightarrow \mathrm{OCN}^{\bullet}+\mathrm{U}^{-}$ & 0.79 & 0.82 & 0.32 \\
$5-\mathrm{OCNU}+e^{-} \rightarrow \mathrm{CN}^{-}+\mathrm{OU}^{\bullet}$ & -0.74 & -0.71 & -1.19 \\
$5-\mathrm{OCNU}+e^{-} \rightarrow \mathrm{CN}^{\bullet}+\mathrm{OU}^{-}$ & 0.87 & 0.90 & 0.41 \\
$5-\mathrm{OCNU}+e^{-} \rightarrow[5-\mathrm{OCNU}-\mathrm{H}]^{-}+\mathrm{H}$ & 0.18 & 0.21 & -0.14 \\
\hline 5-SCNU $+e^{-} \rightarrow \mathrm{SCN}^{-}+\mathrm{U}^{\bullet}$ & 0.04 & 0.07 & -0.31 \\
$5-\mathrm{SCNU}+e^{-} \rightarrow \mathrm{SCN}^{\bullet}+\mathrm{U}^{-}$ & 1.30 & 1.33 & 0.90 \\
$5-\mathrm{SCNU}+e^{-} \rightarrow \mathrm{CN}^{-}+\mathrm{SU}^{\bullet}$ & -0.15 & -0.12 & -0.58 \\
$5-\mathrm{SCNU}+e^{-} \rightarrow \mathrm{CN}^{\bullet}+\mathrm{SU}^{-}$ & 1.33 & 1.36 & 0.89 \\
5-SCNU $+e^{-} \rightarrow\left[5-\mathrm{SCNU}^{-\mathrm{H}}\right]^{-}+\mathrm{H}$ & 0.11 & 0.14 & -0.20 \\
\hline
\end{tabular}

A análise das energias e das densidades eletrônicas dos orbitais sugerem que os estados aniônicos $\pi_{1}^{*}, \pi_{2}^{*}$ e $\pi_{3}^{*}$ da 5-OCNU e 5-SCNU são similares aos seus análogos na uracila e nas 5-halouracilas[9, 59]. Enquanto os halogênios dão origem a estados aniônicos $\sigma_{\mathrm{CX}}^{*}$ nas 5-halouracilas (X=F,Cl,Br,I), os casos da 5-OCNU e 5-SCNU introduzem novos caráteres $\left(\pi_{\mathrm{CN}, 1}^{*} / \sigma^{*}, \pi_{\mathrm{CN}}^{*}\right.$ e $\left.\sigma_{\mathrm{SCN}}^{*}\right)$. Na uracila e nas 5-halouracilas, a ressonância $\pi_{2}^{*}$ pode iniciar diferentes processos de dissociação em torno de $1.5 \mathrm{eV}$, 
incluindo eliminação de hidrogênio, halogênios radicais e ânions. De forma similar, espera-se que as ressonâncias $\pi^{*}$ nos casos da 5-OCNU e 5-SCNU também dêem origem a diferentes processos dissociativos através do acoplamento vibracional com estados $\sigma^{*}$. As amplitudes dos orbitais virtuais, em particular a sobreposição entre os orbitais $\pi^{*}$ e $\sigma^{*}$ sobre os grupos C5-XCN $(\mathrm{X}=\mathrm{O}, \mathrm{S})$, sugerem acoplamentos $\pi^{*} / \sigma^{*}$ favoráveis, especialmente para a 5-SCNU. Os limiares de dissociação indicam que as eliminações de $\mathrm{XCN}^{-}$e $\mathrm{CN}^{-}$são reações exotérmicas. Por suas vezes, as dissociações dos radicais $\mathrm{XCN}^{\bullet}$ e $\mathrm{CN}^{\bullet}$ possuem limiares maiores, mas ainda abaixo das energias estimadas das ressonâncias $\pi_{2}^{*}$. A dissociação induzida pela captura eletrônica da 5-SCNU deve ser favorecida pelos formação das ressonâncias $\sigma_{\mathrm{SCN}}^{*}$ e $\pi_{\mathrm{CN}, 1}^{*} / \sigma^{*}$, uma vez que a primeira porrui um caráter antiligante ao longo das ligações C5-S e S-C, enquanto que a última possui um caráter antiligante sobre a ligação C5-S. Logo, a formação das ressonâncias $\pi^{*}$ também podem dar início a fragmentações $\mathrm{U}^{\bullet}+\mathrm{SCN}^{-}$ e $\mathrm{SU}^{\bullet}+\mathrm{CN}^{-}$, assim como $\mathrm{U}^{-}+\mathrm{SCN}^{\bullet}$ e $\mathrm{SU}^{-}+\mathrm{CN}^{\bullet}$. Uma vez que as ressonâncias da 5-OCNU não possuem um caráter dissociativo claro (pelo menos nas geometrias estudadas), podemos em princípio esperar que as reações de DEA sejam menos eficientes na 5-OCNU que na 5-SCNU. Por fim, o mecanismo de acoplamento $\pi_{2}^{*} / \sigma_{\mathrm{NH}}^{*}$, que dá origem à eliminação de hidrogênio discutida anteriormente, se mostra presente, pelo menos na 5-OCNU.

Em resumo, através da análise do espectro de estados aniônicos e das naturezas dos VO's, nós podemos inferir reações de dissociações prováveis de serem medidas em experimentos de DEA. A eliminação de H, observada na uracila, 5-FU e 5-ClU pode também ser esperada na 5 -OCNU por ter um orbital virtual $\sigma_{\mathrm{NH}}^{*}$ similar aos análogos na uracila e 5-FU. No caso da 5-SCNU, o VO correspondente possui um caráter híbrido $\sigma_{\mathrm{SCN}}^{*} / \sigma_{\mathrm{NH}}^{*}$, não garantindo que o sistema admite uma perda de $\mathrm{H}$ nesse cenário. Sob o ponto de vista das reações de DEA envolvendo os grupos substituintes OCN e SCN podemos esperar o comportamento oposto. O caráter antiligante dos estados $\pi_{\mathrm{CN}, 1}^{*} / \sigma^{*}$ e $\sigma_{\mathrm{SCN}}^{*}$ deve ocasionar a ruptura das ligações C5-S e S-C de forma eficiente na 5-SCNU. No caso da 5-OCNU, a não observância de um estado $\sigma^{*}$ 
essencialmente sobre o grupo OCN e o baixo caráter $\sigma^{*}$ nos estados $\pi_{\mathrm{CN}}^{*}$ sugere que a ruptura da ligação C5-S seja menos eficiente do que no caso da 5-SCNU.

Ao compararmos os resultados da 5-OCNU e 5-SCNU, vemos que a única rota de fragmentação que é mais favorável na 5-OCNU é a eliminação de hidrogênio proveniente do acoplamento DBS $/ \sigma_{\mathrm{NH}}^{*}$. Uma vez que esse tipo de acoplamento perde relevância em ambientes solvatados (solução aquosa - meio biológico), inferimos que a 5-SCNU se apresenta como um potencial radiossensibilizador mais eficaz do que a 5-OCNU. Esse resultado também pode ser corroborado pelos limiares energéticos apresentados na Tab. 4.5 . 


\section{Capítulo 5}

\section{Métodos teóricos III: Modelos de solvatação}

Sistemas moleculares de interesse biológico no geral se manifestam em solução aquosa, e por isso apresentam uma grande dificuldade teórica acerca de sua descrição. Por isso, há um grande interesse acerca da inclusão e da investigação dos efeitos do solvente em propriedades físicas de moléculas. Um dos objetivos do projeto é estudar o efeito do ambiente (solução aquosa) na descrição do espectro de estados aniônicos das uracilas substituídas e propriedades relacionadas a processos de DEA. Nesse capítulo eu recoloco a metodologia utilizada para descrever o solvente, assim como a escolha dos primeiros sistemas a serem estudados e alguns resultados preliminares.

Do ponto de vista de modelo e implementação, há atualmente algumas maneiras de construir um solvente, que se baseiam essencialmente em dois tipos de abordagem; a solvatação implícita e explícita. No primeiro caso, usualmente consideramos o solvente como um dielétrico que responde eletrostaticamente à presença do soluto, este tratado quanticamente. O modelo mais comum de solvatação implícita é o PCM[28], além do modelo SMD proposto por Truhlar et al[60, 61]. No segundo caso, moléculas do solvente são tratadas explícitamente, seja de forma clássica ou quântica. O projeto se propõe a investigar o efeito do solvente na descrição dos estados aniônicos de complexos de uracila e timina, e para isso utilizou-se principalmente um modelo explícito de solvatação, na qual configurações soluto-solvente foram geradas por uma simulação computacional clássica e no qual os cálculos quânticos incluem algumas moléculas de 
solvente a serem tratadas quanticamente. Neste capítulo serão descritos os métodos de solvatação utilizados no trabalho. O software DICE[62], desenvolvido pela profa. Kaline Coutinho do Instituto de Física da Universidade de São Paulo e colaboradores, foi utilizado para as simulações computacionais.

\subsection{Solvatação implícita - Modelos contínuos}

Os modelos de solvatação implícita, ou modelos contínuos, levam em consideração contribuições eletrostáticas através de um meio contínuo - sem a necessidade de tratar o solvente como um sistema constituído de moléculas explícitas. Tipicamente esse meio é descrito por um material dielétrico cuja constante dielétrica $\epsilon$ é previamente estabelecida para cada solvente, e isto significa que o solvente pode ser caracterizado, a priori, por um único parâmetro. Esses modelos foram inicialmente propostos na década de 1930[63, 64] e ainda hoje estão sendo largamente utilizados e desenvolvidos. A principal característica das solvatações implícitas é o tratamento de interações eletrostáticas e contribuições de longo alcance, além de incluírem efeitos de polarização do soluto devido à presença do solvente. Na aproximação Born-Oppenheimer, o hamiltoniano eletrônico do sistema é dado por

$$
\hat{\mathscr{H}}_{\text {ele }}=\hat{\mathscr{H}}_{S}^{(0)}+\hat{V}_{i}
$$

em que $\hat{\mathscr{H}}_{S}^{(0)}$ é o operador hamiltoniano eletrônico do soluto e $\hat{V}_{i}$ é o operador que descreve a interação soluto-solvente. Essa energia potencial de interação é modelada

como $\hat{V}_{i}=\hat{V}_{i}\left(\mathbf{r}, \mathbf{R}, \rho_{S} ; \epsilon\right)$, onde $\rho_{S}$ é a densidade de cargas induzidas na superfície da cavidade e $\mathbf{r}=\left\{\mathbf{r}_{1}, \ldots, \mathbf{r}_{N}\right\}$ e $\mathbf{R}=\left\{\mathbf{R}_{1}, \ldots, \mathbf{R}_{N}\right\}$ representam as posições dos elétrons e núcleos do soluto, respectivamente. A energia do sistema pode ser expressa como

$$
E=\left\langle\psi\left|\hat{\mathscr{H}}_{\text {ele }}\right| \psi\right\rangle=\left\langle\psi\left|\hat{\mathscr{H}}_{S}^{(0)}\right| \psi\right\rangle+\left\langle\psi\left|\hat{V}_{i}\right| \psi\right\rangle=E^{(0)}+W
$$


na qual $W$ é o valor da energia de interação soluto-solvente. É importante mencionar que $\hat{V}_{i}$ é um operador de um elétron, e portanto, o cálculo de $W$ não necessita de um acréscimo de custo computacional significativo.

A proposta dos modelos contínuos é partir da interação $\hat{V}_{i}$, escrita em termos de um potencial eletrostático gerado pela distribuição de cargas do soluto. Esse potencial polariza o solvente, que por sua vez gera um potencial eletrostático sobre o soluto, também induzindo sua polarização. O resultado é que, ao longo das iterações, o potencial eletrostático converge para $\Phi$. Uma vez que o potencial $\Phi$ e a interação $\hat{V}_{i}$ dependem da densidade $\rho_{S}$, temos um problema não linear e, assim, sua solução requer um ciclo adicional de auto-consistência. A saber, há um ciclo de auto-consistência para se determinar a distribuição $\rho_{S}$ através de cálculos quânticos, enquanto simultaneamente há um ciclo de auto-consistência para a determinação do potencial $\Phi$ através do problema eletrostático (equação de Poisson). Esse método é conhecido como Campo de Reação Auto-Consistente, ou SCRF (Self Consistent Reaction Field) $[65,66]$.

Muitos modelos contínuos foram propostos diferindo essencialmente na descrição do potencial eletrostático e na construção da cavidade que acomoda o soluto. Dentre todos os modelos hoje aceitos, o mais utilizado é o modelo contínuo polarizável, PCM (Polarizable Continuum Model).

\section{PCM - Modelo contínuo polarizável}

No atual modelo contínuo polarizável, a cavidade do solvente é construída sobrepondose cavidades esféricas centradas nos sítios atômicos do soluto, isto é, para cada átomo do soluto forma-se uma cavidade esférica cujo centro coincide com o centro do sítio atômico. A primeira proposta foi utilizar os raios de van der Waals para as cavidades $\left(R_{\alpha}=R_{\alpha}^{v d W}\right)$. Entretanto, alguns resultados experimentais sugeriram que para alguns sistemas a cavidade deveria ser ajustada de forma que os raios $R_{\alpha}$ fossem cerca de $20 \%$ maiores do que os respectivos raios de van der Waals para que o modelo conseguisse descrever bem algumas propriedades. Assim, implementações usuais em 
sofwtares de química quântica utilizam $R_{\alpha}=f R_{\alpha}^{v d W}$, em que $f$ é um fator de ajuste e seu valor depende do modelo da construção da cavidade.

O problema a ser resolvido é do tipo SCRF e, em um determinado passo $j$ do ciclo de auto-consistência, o potencial eletrostático $\Phi^{(j)}=\Phi^{(j)}(\mathbf{x})$ é dado pela equação de Poisson

$$
\nabla^{2} \Phi^{(j)}(\mathbf{x})=\left\{\begin{array}{cc}
-4 \pi \rho_{S}^{(j)}, & \text { se } \mathbf{x} \in \Omega \\
0, & \text { se } \mathbf{x} \notin \Omega
\end{array},\right.
$$

em que $\Omega$ é o volume coompreendido pela cavidade e a equação está expressa em unidades gaussianas. A determinação do potencial nos permite escrever o potencial $V_{i}^{(j)}$, que por sua vez é utilizado para resolver a equação de Schrödinger independente do tempo;

$$
\left[\hat{\mathscr{H}}_{S}^{(0)}+\hat{V}_{i}^{(j)}\left(\mathbf{r}, \mathbf{R}, \rho_{S}^{(j)} ; \epsilon\right)\right]\left|\psi^{(j)}\right\rangle=E^{(j)}\left|\psi^{(j)}\right\rangle
$$

em que $\left|\psi^{(j)}\right\rangle$ é o estado do sistema no $j$-ésimo passo do ciclo de auto-consistência, e $E^{(j)}$ é a energia associada a esse estado. Resolvida essa equação para o estado $\left|\psi^{(j)}\right\rangle$, obtém-se a densidade de cargas do soluto $\rho_{S}^{(j+1)}$ do passo seguinte, iniciando-se assim uma nova iteração. Ao longo do ciclo SCRF, o potencial converge para $\Phi^{(j)}(\mathbf{x}) \rightarrow$ $\Phi(\mathbf{x})$, ao passo que a energia, a densidade de cargas e a função de onda também convergem para a solução de interesse. Essa discussão se encontra em detalhes nas seções que seguem, e mais detalhes sobre a formulação do meio contínuo polarizável encontra-se nas referências[28, 67-69].

Embora os modelos contínuos sejam muito utilizados devido a seus baixos custos computacionais, eles se mostram ineficientes na investigação de certos fenômenos que necessitam de modelos solvatação explícita, por exemplo, a descrição da primeira camada de solvatação associada à solução. Outro fenômeno que podemos citar são as ligações de hidrogênio entre o soluto e as moléculas do solvente. Essas ligações podem explicar diversos comportamentos em solução e não são levados em conta nos modelos contínuos. 


\subsection{Simulação Computacional}

A simulação computacional de líquidos moleculares e soluções é uma ferramenta que descreve de maneira sofisticada fenômenos de solvatação, podendo investigar comportamentos que foram desprezados em modelos contínuos, como o PCM. A simulação trata as moléculas do soluto e do solvente explicitamente e suas técnicas se baseiam tradicionalmente em duas metodologias: o método de Monte Carlo e a Dinâmica Molecular. As simulações em ambas metodologias são computacionalmente muito mais custosas que os modelos contínuos, e geralmente requerem uma série de parâmetros numéricos associados ao particular sistema de interesse. No presente trabalho, utilizou-se exclusivamente o método de Monte Carlo nas simulações[70, 71], cujas características serão apresentadas a seguir.

\section{O método de Monte Carlo}

O método de Monte Carlo é uma técnica relativamente eficaz para se tratar problemas de alta complexidade. De modo geral, o método de Monte Carlo é todo e qualquer método que se utiliza de números aleatórios para cálculos, estimativas ou geração de configurações. No nosso caso, o método abordará a solvatação através de um sistema de amostragem baseado no algoritmo de Metropolis.

Na nossa implementação do método para tratar sistemas moleculares, particularmente para líquidos, tratamos as moléculas como consituintes rígidos (movimentos internos de vibração desconsiderados) formando um sistema cuja energia total está associada a um hamiltoniano clássico da forma

$$
H(\mathbf{x}, \mathbf{p})=\sum_{i=1}^{3 N} \frac{\mathbf{p}_{i}^{2}}{2 m_{i}}+U(\mathbf{x}),
$$

em que $N$ é o número total de moléculas do sistema, e a soma é feita sobre os $3 N$ graus de liberdade translacionais e $3 N$ graus de liberdade configuracionais dos constituintes e $U$ é o potencial de interação intermolecular. Além disso, o método consiste no uso de números aleatórios para a produção de configurações termodinamicamente estáveis, 
onde busca-se obter uma amostragem que satisfaça a distribuição de probabilidades de Boltzmann,

$$
\rho_{\mathrm{NVT}}(\Gamma)=\frac{e^{-\frac{U(\Gamma)}{k_{B} T}}}{Z_{\mathrm{NVT}}}
$$

$\mathrm{Ou}$

$$
\rho_{\mathrm{NPT}}(\Gamma)=\frac{e^{-\frac{U(\Gamma)+P V}{k_{B} T}}}{Z_{\mathrm{NPT}}},
$$

nas quais $\Gamma$ é um vetor multidimensional que representa a configuração do sistema no espaço de posições, isto é, para $N$ átomos, temos que $\Gamma=\left(\mathbf{x}_{1}, \mathbf{x}_{2}, \ldots, \mathbf{x}_{N}\right), U(\Gamma)$ é a energia potencial associada a essa configuração, $T$ é a temperatura absoluta, $k_{B}$ é a constante de Boltzmann e $Z$ é a função de partição configuracional, isto é,

$$
Z_{\mathrm{NVT}}=\int e^{-\frac{U\left(\mathbf{x}_{1}, \mathbf{x}_{2}, \ldots, \mathbf{x}_{N}\right)}{k_{B} T}} d^{N} \mathbf{x}=\int e^{-\frac{U(\Gamma)}{k_{B} T}} d \Gamma
$$

e

$$
Z_{\mathrm{NPT}}=\iint e^{-\frac{U\left(\mathbf{x}_{1}, \mathbf{x}_{2}, \ldots, \mathbf{x}_{N}\right)+P V}{k_{B} T}} d^{N} \mathbf{x} d V=\iint e^{-\frac{U(\Gamma)+P V}{k_{B} T}} d \Gamma d V
$$

Nas equações acima, as indicações NVT e NPT nas distribuições de probabilidade e funções de partição indicam dois diferentes ensembles, sendo o primeiro vinculado à pressão e temperatura constantes e o segundo ao volume e temperatura constantes, respectivamente. Como dito anteriormente, o processo para a geração de tais configurações é baseado no algoritmo de Metropolis, que funciona de maneira um pouco diferente para cada um dos ensembles. No presente trabalho, apenas o ensemble NPT foi utilizado, por razões que remetem às motivações biológicas dos problemas estudados. Entretanto, a título de comparação, uma breve discussão dos dois ensembles e seus respectivos critérios de aceitação de configurações são apresentadas como segue.

Ensemble NVT Nesse ensemble o número de consituintes, o volume do sistema e sua temperatura são mantidos constantes. Inicialmente, cria-se uma caixa de simulação, e gera-se uma configuração aleatória com a molécula do soluto e $N$ moléculas do solvente $\Gamma_{i}$, cuja energia associada é $U\left(\Gamma_{i}\right) \equiv U_{i}$. Em seguida sorteia-se uma das $N+1$ moléculas do sistema. A molécula sorteada terá seu 
centro de massa deslocado de uma quantidade, também sorteada, $\delta \mathbf{x}$, além de ser reorientada angularmente por uma quantidade (angular) também aleatória. O sistema então atinge uma nova configuração $\Gamma_{j}$, cuja nova energia é $U\left(\Gamma_{j}\right) \equiv$ $U_{j}$. Então, calcula-se a quantidade

$$
\pi_{i j} \equiv e^{-\frac{U\left(\Gamma_{j}\right)-U\left(\Gamma_{i}\right)}{k_{B} T}}=e^{-\frac{\Delta U_{i j}}{k_{B} T}}
$$

e:

- Se $U_{j} \leq U_{i}$, a nova configuração é aceita.

- Se $U_{j}>U_{i}$, sorteia-se um número aleatório $p \in[0,1]$ e o comparamos com $\pi_{i j}$. Caso $p<\pi_{i j}$, a nova configuração é aceita. Caso contrário, a nova configuração é rejeitada.

Essa repetição é realizada $N+1$ vezes a cada ciclo. Assim, depois de um número suficiente $n$ de ciclos Monte Carlo (um total de $n_{T}=n \times(N+1)$ passos), o sistema atinge o equilíbrio termodinâmico e passa a construir configurações que satisfazem a distribuição de Boltzmann nesse ensemble.

Ensemble NPT Nesse ensemble o número de constituintes, a pressão do sistema e sua temperatura são mantidos constantes. Assim como no ensemble NVT, inicialmente cria-se uma caixa de simulação e gera-se uma configuração inicial aleatória com a molécula de soluto e $N$ moléculas do solvente. Em seguida sorteia-se uma das moléculas que terá seu centro de massa deslocado de uma quantidade, também sorteada, $\delta \mathbf{x}$, além de ser reorientada angularmente por uma quantidade (angular) também aleatória. Após isso calcula-se a quantidade 5.9 e mesmo critério de aceitação é empregado. Esse procedimento é repetido $n$ vezes. Em seguida sorteia-se uma quantidade $\delta L$ para que cada lado da caixa seja modificado, mudando assim o volume do sistema. Após isso, calcula-se

$$
\Pi_{i j} \equiv e^{-\frac{U\left(\Gamma_{j}\right)-U\left(\Gamma_{i}\right)+P\left(V_{j}-V_{i}\right)-N k_{B} T \ln V_{j}+N k_{B} T \ln V_{i}}{k_{B} T}}=e^{-\frac{\Delta U_{i j}+P \Delta V_{i j}}{k_{B} T}-N \ln V_{j} / V_{i}}
$$


e:

- Se $U_{j}+P V_{j}-N k_{B} T \ln V_{j} \leq U_{i}+P V_{i}-N k_{B} T \ln V_{i}$, a nova configuração é aceita.

- Se $U_{j}+P V_{j}-N k_{B} T \ln V_{j}>U_{i}+P V_{i}-N k_{B} T \ln V_{i}$, sorteia-se um número aleatório $p$, tal que $0<p<1$, e o comparamos com $\Pi_{i j}$. Caso $p<\Pi_{i j}$, a nova configuração é aceita. Caso contrário, a nova configuração é rejeitada. Vale mencionar que a quantidade $U_{i}+P V_{i}-N k_{B} T \ln V_{i}$ nada mais é do que a entalpia conformacional acrescida de um termo de reescalonamento, proporcional à $\ln V_{i}$. Esse termo é responsável por reescalonar as posições moleculares de forma a evitar que moléculas saiam da caixa, ou que surjam buracos dentro dela, no processo de alteração do volume.

Essa repetição é realizada $n_{V}$ vezes, sendo que a cada repetição se realiza $n$ ciclos descritos anteriormente, totalizando $n \times n_{V}$ ciclos. Isto é, $n_{T}=n \times n_{V} \times(N+1)$ passos ao longo da simulação. Assim como no ensemble anterior, após um número suficiente de ciclos o sistema atinge o equilíbrio termodinâmico, gerando configurações que satisfazem a distribuição de Boltzmann nesse ensemble.

Para se obter médias de grandezas termodinâmicas, a princípio definiríamos a grandeza de interesse $A$ em cada configuração $A=A(\Gamma)$, e faríamos

$$
\langle A\rangle=\frac{1}{Z} \int_{\{\Gamma\}} A(\Gamma) \rho(\Gamma) \mathrm{d} \Gamma,
$$

onde a integral é realizada sobre todas as possíveis configurações termodinamicamente acessíveis do sistema. A função de partição $Z$ e a distribuição $\rho$ são características do ensemble em que se está trabalhando. Independente do ensemble em questão, a simulação gerará um conjunto de $n_{T}$ configurações $\{\Gamma\}=\left\{\Gamma_{1}, \Gamma_{2}, \ldots, \Gamma_{n_{T}}\right\}$. Então a média de uma grandeza $A$ é pode ser obtida sob a forma

$$
\langle A\rangle=\frac{1}{n_{T}} \sum_{i=1}^{n_{T}} A\left(\Gamma_{i}\right),
$$


em que $A\left(\Gamma_{i}\right)$ é a própria grandeza avaliada em cada configuração $\Gamma_{i}$.

\section{O Potencial de Interação}

Uma vez que não há um potencial intermolecular clássico único, as simulações dependem diretamente de um potencial efetivo conveniente para aquele tipo de sistema. O potencial de interação intermolecular clássico utilizado foi o potencial de Lennard-Jones (LJ) acrescido do termo de Coulomb:

$$
U(\Gamma)=\sum_{(i, j)}\left\{4 \epsilon_{i j}\left[\left(\frac{\sigma_{i j}}{r_{i j}}\right)^{12}-\left(\frac{\sigma_{i j}}{r_{i j}}\right)^{6}\right]+\frac{1}{4 \pi \epsilon_{0}} \frac{q_{i} q_{j}}{r_{i j}}\right\}
$$

Em que $r_{i j}=\left|\mathbf{x}_{j}-\mathbf{x}_{i}\right|$ é a distância entre o sítio atômico $i$ e o sítio atômico $j$, $\epsilon_{i j}=\sqrt{\epsilon_{i} \epsilon_{j}}$ e $\sigma_{i j}=\sqrt{\sigma_{i} \sigma_{j}}$ onde $\epsilon_{i}$ e $\sigma_{i}$ são os parâmetros de LJ associados ao sítio atômico $i, q_{i}$ é a carga desse sítio, $\epsilon_{j}$ e $\sigma_{j}$ são os parâmetros de LJ associados ao sítio atômico $j$ e $q_{j}$ é a carga desse sítio. Vemos assim que, se tratando da simulação computacional, a molécula (tanto do soluto quanto do solvente) pode ser caracterizada apenas por uma geometria e pelo conjunto de parâmetros $\{q, \epsilon, \sigma\}$.

O conjunto de parâmetros utilizados, combinados ao potencial de interação, definem o campo de força utilizado na simulação computacional. Para os parâmetros $\epsilon$ 's e $\sigma$ 's dos sítios atômicos, há hoje em dia uma série de campos de força parametrizados na literatura, como o OPLS (Optimized Parameters for Liquid Simulations)[72], o AMBER (Assisted Model Building with Energy Refinement)[73], entre outros. Com relação às cargas, alguns campos de força possuem valores parametrizados de q's, como os citados anteriormente. Entretanto, uma maneira conveniente de se determinar as cargas efetivas de cada sítio atômico é através de um cálculo quântico sob a metodologia CHELPg[74]. Essa metodologia obtém o potencial eletrostático no espaço devido ao estado do sistema calculado quanticamente. Em seguida o método ajusta uma carga efetiva em cada sítio atômico para melhor descrever o potencial gerado.

No presente trabalho, foram utilizados em todas as simulações os campos de força OPLS para os parâmetros $\epsilon$ e $\sigma$ dos átomos dos solutos. O conjunto de cargas foi 
gerado pela metodologia CHELPg, baseados em cálculos quânticos no nível MP2/631G*/PCM. Quanto ao solvente, foi utilizado o campo de força SPC/E[75] para as moléculas de água. Esse campo de força é largamente utilizado atualmente em várias trabalhos envolvendo água líquida e vapor de água, em diversas condições[76]. A geometria SPC/E da água corresponde a distâncias interatômicas O-H de $1 \AA$ e ângulo planar $\mathrm{H}-\mathrm{O}-\mathrm{H}$ de $\sim 109.47^{\circ}$ (Fig. 5.1). Os valores dos parâmetros $\epsilon$ e $\sigma$ pros

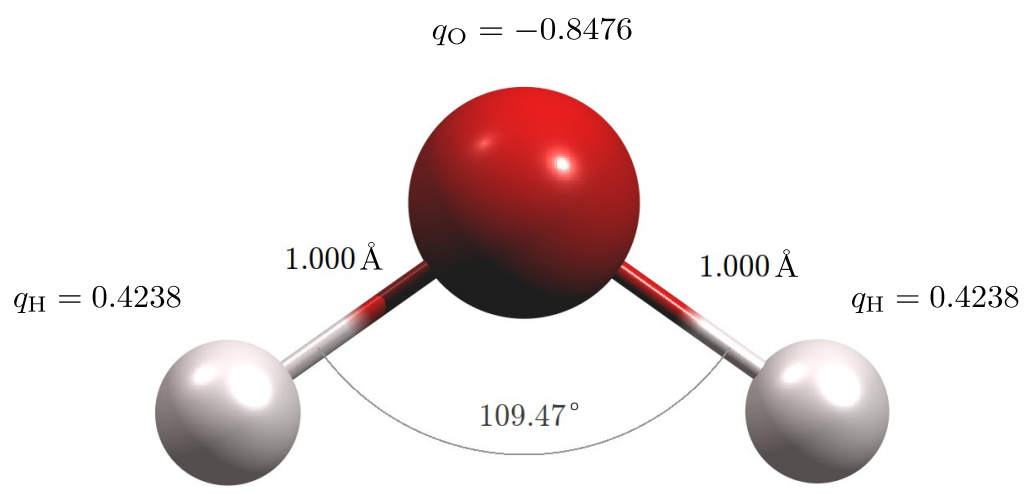

Figura 5.1: Geometria e cargas da molécula de água no modelo SPC/E. O oxigênio está disposto em vermelho e os hidrogênios em branco. As cargas $q_{\mathrm{O}}$ e $q_{\mathrm{H}}$ indicam os valores dos parâmetros de carga utilizados no campo de força.

hidrogênios são nulos, fazendo com que os mesmos correspondam exclusivamente a cargas pontuais no sentido da equação 6.19. Pro oxigênio, os parâmetros $\epsilon$ e $\sigma$ são respectivamente $0.155 \mathrm{kcal} / \mathrm{mol}$ e $3.165 \AA$. As cargas, em termos da carga elementar, são $q_{\mathrm{O}}=-0.8476$ e $q_{\mathrm{H}}=0.4238$, e estão também indicadas no painel da Fig. 5.1.

As simulações levam em conta o método das imagens para evitar os efeitos das bordas na caixa. Isso significa que a caixa e todas moléculas nela são replicadas em todas as direções. Dessa forma, em teoria, a energia potencial sobre um átomo se dá pela presença de infinitas moléculas distribuídas em infinitas caixas replicadas. Porém, a fim de evitar cálculos dispendiosos e estudos de convergência, na implementação atual do software DICE[62] o potencial de interação sobre um sítio atômico é calculado até um raio de corte, definido como $48 \%$ da aresta da caixa de simulação. 


\subsubsection{Análise da simulação - Erros e distribuição radial de pares}

\section{Erros estatísticos}

Uma vez que uma determinada grandeza física pode ser calculada como uma média sobre configurações dada por 5.12. O erro associado a essa grandeza é dado por

$$
\operatorname{err}(\langle A\rangle)=\sqrt{\frac{\left\langle\delta A^{2}\right\rangle}{n}}
$$

em que

$$
\left\langle\delta A^{2}\right\rangle=\left\langle A^{2}\right\rangle-\langle A\rangle^{2}
$$

e $n$ é o número de configurações utilizadas para o cálculo da média. Em geral, a expressão 5.14 é válida quando as configurações são independentes, isto é, estatisticamente descorrelacionadas (ver sç. 5.2.2).

\section{Distribuição radial de pares}

Uma das ferramentas mais utilizadas para analisar simulações clássicas de líquidos é a distribuição radial de pares (RDF - do inglês radial distribution function), que por sua vez está associada à distância entre pares de átomos ou moléculas $i j$, fornecendo a probabilidade de encontrar esse par a uma distância entre $r$ e $r+d r$. A função, portanto, carrega informações sobre a estrutura e disposição das moléculas dentro do sistema, e experimentalmente tais informações podem ser obtidas através de técnicas usuais de cristalografia. Para um par de elementos em específico, podemos expressá-la como

$$
G_{i j}(r)=\frac{n_{i j}(r, r+d r)}{n_{0}(r, r+d r)}
$$

em que o numerador $n_{i j}(r, r+\mathrm{d} r)$ é o número de pares $i j$ separados por uma distância entre $r$ e $r+\mathrm{d} r$, e o denominador $n_{0}(r, r+d r)$ está associado a esse mesmo número caso o sistema fosse idealmente homogêneo de densidade $\rho$. Além disso, $G(r)$ deve ser uma distribuição devidamente normalizada, tal que o número total de moléculas 
deve corresponder a

$$
N=\frac{4 \pi}{V} \int G(r) r^{2} d r
$$

Podemos, evidentemente, calcular a função $G(r)$ de diversas maneiras, visto que há diversos modos de definir distâncias entre pares de moléculas. Uma das maneiras mais convencionais de gerar a RDF é definindo $r$ como a distância entre os centros de massa (CM) das moléculas, conveniente quando a molécula do soluto é pequena ou cuja estrutura é aproximadamente esférica. Nesse caso, a RDF de centros de massa fornece satisfatoriamente informações sobre camadas de solvatação, concentrações de moléculas de solvente, entre outras. Caso o soluto possua dimensões muito diferentes, como uma molécula alongada em uma certa direção, a RDF de centros de massa deixa de ser conveniente. A partir disso, desenvolveu-se outra função $G(r)$ dada pela minima distância entre duas moléculas $(\mathrm{MDDF})[77,78]$, que permite melhor descrição da estrutura do solvente em torno do soluto.

\subsubsection{O método QM/MM e s-QM/MM}

O método QM/MM (Quantum Mechanics/Molecular Mechanics) é um procedimento eficiente para tratar sistemas de alto número de graus de liberdade quando estamos interessados em uma determinada propriedade quântica local (do soluto ou na interação entre o soluto e o solvente), como a estrutura eletrônica de uma molécula em meio a um sistema líquido. A questão central do método consiste em dividir o sistema em uma parte quântica e uma clássica, tratando o hamiltoniano como a soma de um termo quântico, um termo puramente clássico e um termo de interação entre as duas partes

$$
\mathscr{H}=\mathscr{H}_{Q M}+\mathscr{H}_{M M}+\mathscr{H}_{Q M / M M},
$$

em que o primeiro termo refere à parte quântica, o segundo à parte clássica e o terceiro à interação entre ambas. A vantagem do procedimento é o custo computacional relativamente reduzido, em vista da possibilidade de tratar um número muito grande de moléculas explicitamente. No caso de soluções, a abordagem típica consiste em 
tratar o soluto, ou o hamiltoniano eletrônico do soluto, quanticamente e o solvente como classicamente.

A parte clássica pode ser tratada através de uma simulação computacional, gerando as configurações de equilíbrio termodinâmico. A cada passo da simulação clássica, realiza-se um cálculo quântico da propriedade desejada. O que difere os diferentes métodos QM/MM é o modo de acoplar a parte quântica e a parte clássica, isto é, como construir o termo $\mathscr{H}_{Q M / M M}$ de maneira apropriada.

A maneira de realizar cálculos de propriedades quânticas em sistemas solvatados adotada no trabalho foi o s-QM/MM (sequential-Quantum Mechanics/Molecular Mechanics), proposto por Canuto e Coutinho[77, 78], que funciona como uma alternativa ao QM/MM convencional. Nessa abordagem utiliza-se um subconjunto particular de configurações dentre as geradas na simulação computacional e realizam-se cálculos quânticos das propriedades desejadas em cada uma delas, tomando-se uma média ao fim do processo. Em outras palavras, o método requer a seleção, dentre as configurações geradas, de um subgrupo sobre o qual serão efetivamente realizados cálculos quânticos das propriedades físicas de interesse. Esse aspecto da metodologia faz com que consigamos obter propriedades quânticas devidamente convergidas com um número relativamente reduzido de cálculos. Um dos aspectos mais importantes do s-QM/MM é a possibilidade de obter distribuições térmicas das propriedades.

Para selecionar as configurações estatisticamente descorrelacionadas da simulação clássica, basta estudar o intervalo de descorrelação da simulação, que é o número de ciclos entre duas configurações necessário para torná-las descorrelacionadas. Trabalhamos com a função de autocorrelação de energia, $C(t)$, dada por

$$
C(t)=\frac{\left\langle\delta E_{i} \delta E_{i+t}\right\rangle}{\left\langle\delta E^{2}\right\rangle}=\frac{\sum_{i}\left(E_{i}-\langle E\rangle\right)\left(E_{i+t}-\langle E\rangle\right)}{\sum_{i}\left(E_{i}-\langle E\rangle\right)^{2}},
$$

em que $E_{i}$ é a energia total da configuração no $i$-ésimo ciclo de Monte Carlo, e $\langle E\rangle$ é o valor médio da mesma sobre todas as configurações geradas. Em seguida, realiza-se 
um ajuste da expressão 5.19 da forma

$$
C(t)=\sum_{j} c_{j} e^{-t / \tau_{j}} \simeq c_{1} e^{-t / \tau_{1}}+c_{2} e^{-t / \tau_{2}}
$$

onde $c_{j}$ e $\tau_{j}$ são constantes do ajuste. O último membro da expressão 5.20 sugere que na prática seja suficiente considerar apenas dois termos da expressão acima, de forma que o decaimento da função de correlação seja biexponencial. As configurações descorrelacionadas são aquelas cuja separação (em passos de MC) nos fornece uma correlação menor que cerca de $\sim 13 \%$. Após definida a separação necessária para a descorrelação, seleciona-se um conjunto relativamente pequeno de configurações descorrelacionadas para se realizar cálculos quânticos e tomar médias das propriedades de interesse. Esse número de configurações necessárias para obter médias de propriedades quânticas devidamente convergidas é tipicamente da ordem de 100.

Outra possível maneira de tratar o solvente como um campo de cargas pontuais é o ASEC (Average Solvent Eletrostatic Configuration)[79] em que sobrepõe-se todas as $n_{T}$ configurações geradas em uma única configuração. Todas as moléculas agora são substituídas por cargas pontuais cujo valor é dado pelas cargas admitidas na simualçao computacional divididas por $n_{T}$. Assim, realiza-se um único cálculo quântico da propriedade desejada, e seu valor pode ser interpretado como o resultado médio do efeito do ambiente, sob o ponto de vista da interação eletrostática. O ASEC não foi explorado no presente trabalho, mas é uma ferramenta que pode ser muito utilizada nesse contexto em futuras realizações.

\subsubsection{Micro-solvatação}

Alguns aspectos estruturais das moléculas de água que envolvem um determinado soluto são úteis em estudos de solvatação. Devido às interações soluto-solvente e solvente-solvente, as moléculas de água se organizam ao redor do soluto em camadas de solvatação, que podem ser determinadas através de uma análise da distribuição radial de pares. As camadas de solvatação correspondem a mínimos locais na função 

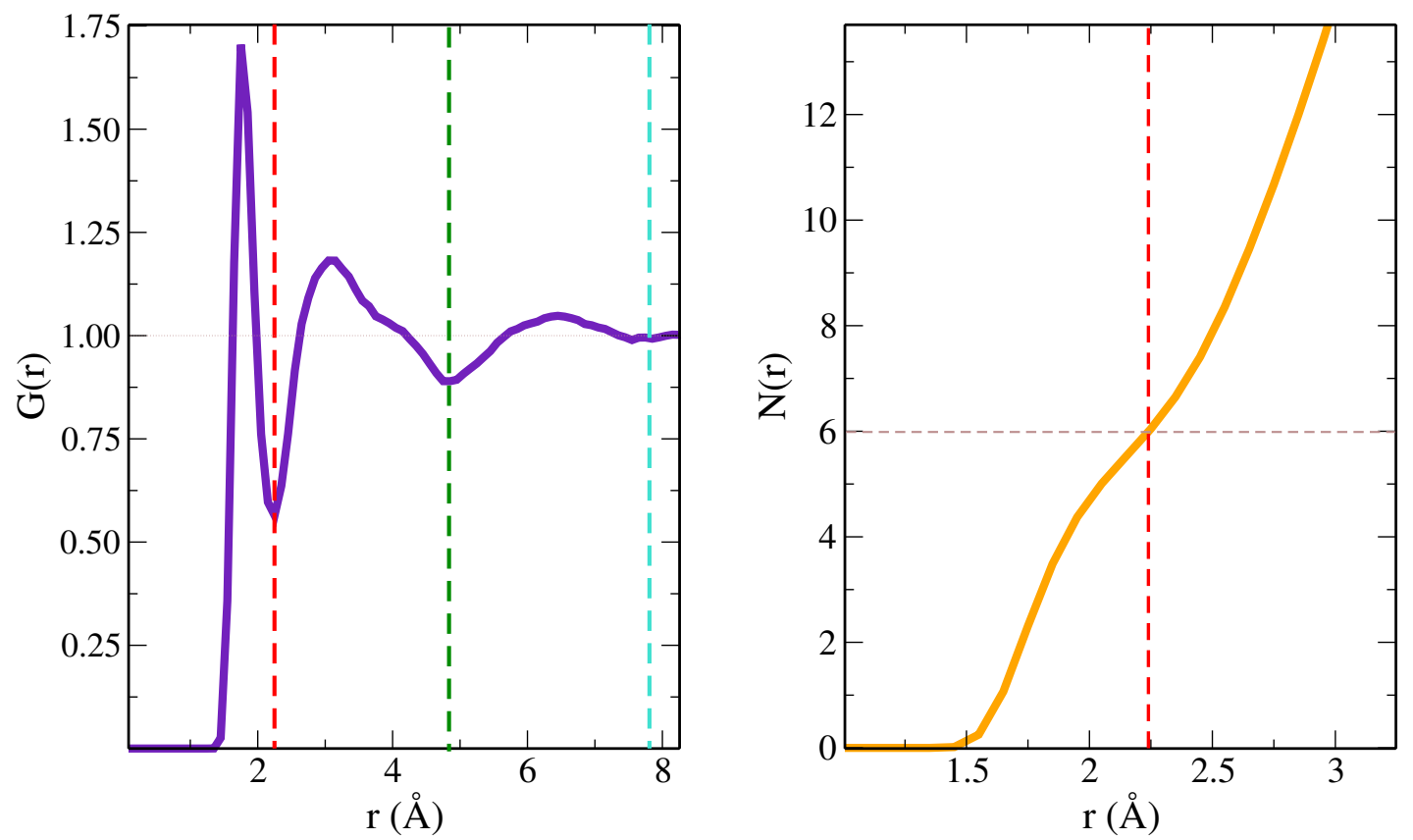

Figura 5.2: Exemplo de distribuição radial de pares $G(r)$, à esquerda (linha contínua roxa), e sua integral $N(r)$, à direita (linha contínua laranja). No painel à esquerda, a linha tracejada vermelha indica o mínimo local correspondente à camada de microsolvatação, e no painel à direita o número de moléculas de água presente nessa camada. As linhas tracejadas em verde e azul indicam a primeira e a segunda camada de solvatação, respectivamente.

$G(r)$, e o número de moléculas nas camadas são obtidas através da integral da função $G(r)$ entre $r=0$ até o valor correspondente ao mínimo local em questão. Na Fig. 5.2 mostro um exemplo de determinação das camadas de solvatação através da função distribuição radial de pares. Os resultados são da molécula de uracila, cujos resultados estão discutidos em detalhes no capítulo 6. Apresento-os aqui apenas a título de ilustração. A linha tracejada em verde no painel esquerdo localiza-se em $r=4.86$ A indica a primeira camada de solvatação, enquanto que a linha tracejada azul em $r=7.83 \AA$ indica a segunda camada. Além dessas duas estruturas, vemos também um mínimo local em curta distância, $r=2.27 \AA$, indicado na figura por uma linha tracejada em vermelho. Essa estrutura corresponde a uma camada mais interna, que se manifesta exclusivamente devido às ligações de hidrogênio entre o soluto e as moléculas de água. Essa camada é chamada de camada de ligações de hidrogênio ou camada de micro-solvatação. Na Fig. 5.3 apresento exemplos de configurações da uracila com camada de micro-solvatação e com a primeira camada de solvatação 


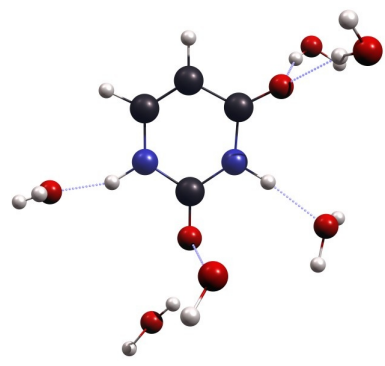

(a) camada de micro-solvatação

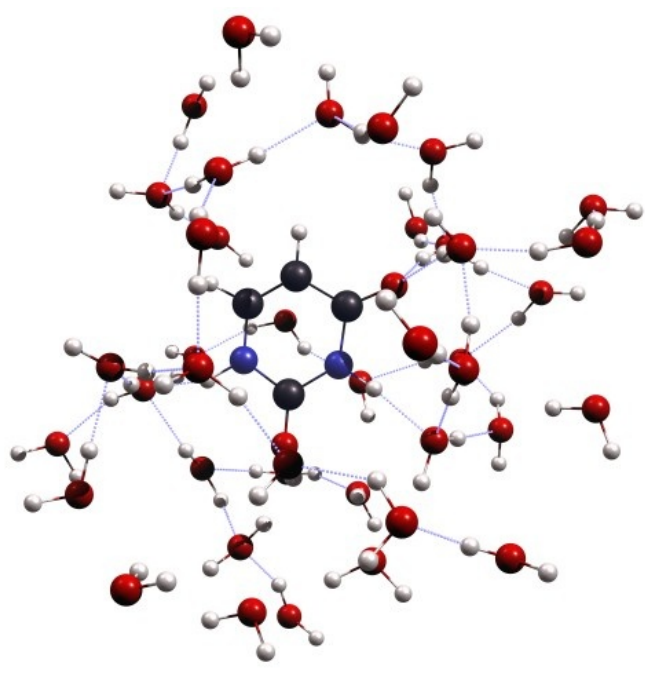

(b) primeira camada de solvatação

Figura 5.3: Exemplos de agregados da uracila micro-solvatada, com o número de moléculas de água compatíveis (a) com a camada de micro-solvatação e (b) com a primeira camada de solvatação.

inteira.

Para o cálculo de seções de choque integral para o espalhamento eletrônico, considerou-se alvos constituídos pelo soluto e pelas moléculas de água na camada mais interna. Isso significa que os sistemas estudados foram do tipo molécula- $\left[\mathrm{H}_{2} \mathrm{O}\right]_{n}$ (muitas vezes referidos como clusters ou agregados). A adoção de um $n$ razoável e a seleção dos clusters foram obtidas combinando simulações MC com a ideia da metodologia s-QM/MM. No trabalho, o modelo de micro-solvatação usado para o estudo dos efeitos do solvente se limitou às camadas de micro-solvatação, principalmente pelo custo computacional dos cálculos de espalhamento, e o número de moléculas de água na camada é esclarescido no capítulo a seguir. Os clusters micro-solvatados foram extraídos das configurações estatisticamente descorrelacionadas, no sentido das equações 5.19 e 5.20, e um esquema está ilustrado na Fig. 5.4. 
$\mathrm{s}-\mathrm{QM} / \mathrm{MM}$

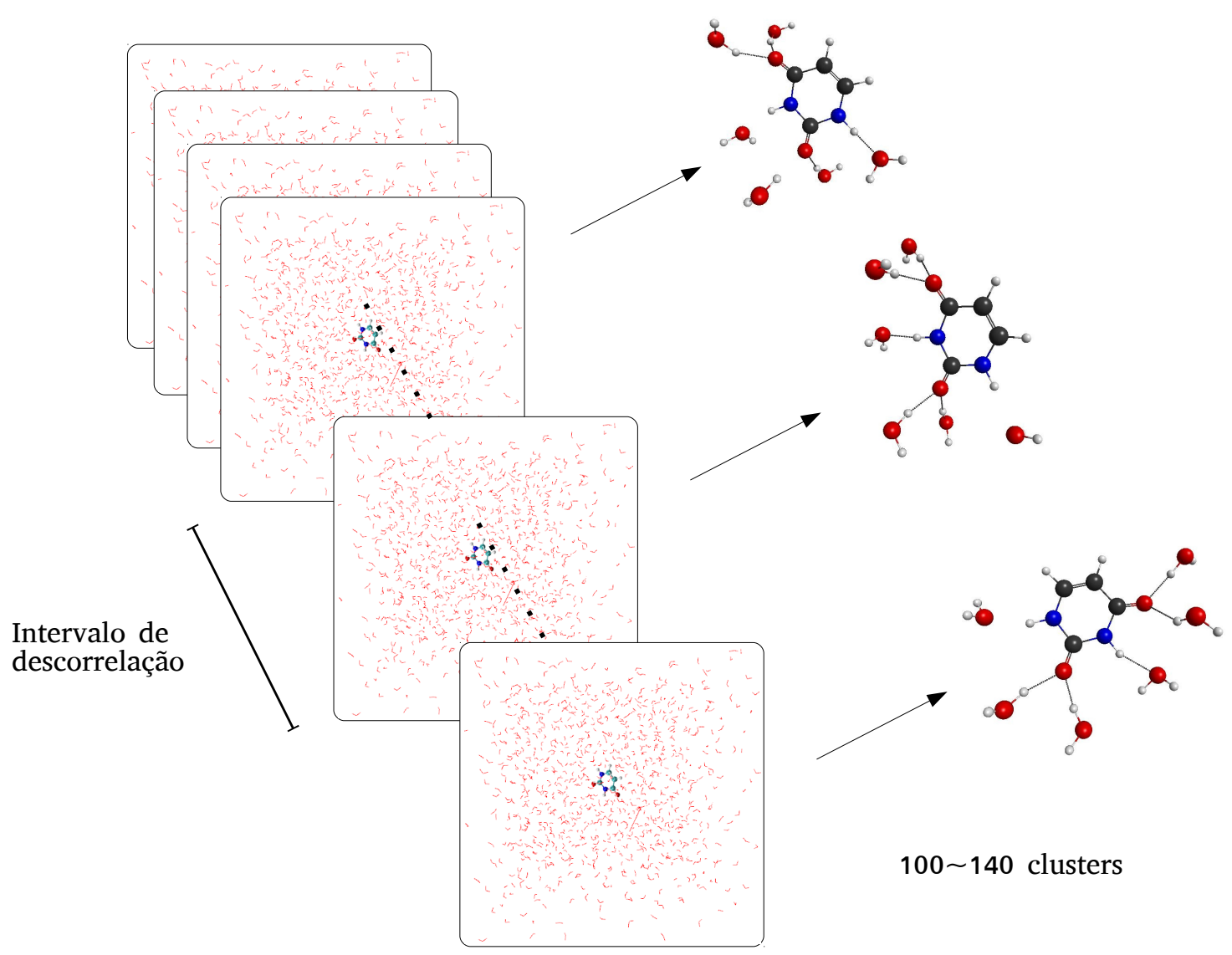

Figura 5.4: Esquema da combinação s-QM/MM com a seleção de clusters empregado para estudar os sistemas micro-solvatados. 


\section{Capítulo 6}

\section{Efeitos do solvente no espectro de estados aniônicos transientes de algumas biomoléculas}

A relevância do estudo de espectro de ressonâncias de biomoléculas em fase condensada é imediata. Como discutido nos capítulos 1 e 5, estudos de DEA em subunidades de DNA, RNA ou bases modificadas são importantes para descrever manifestações que ocorrem em solução aquosa. Devido ao grande esforço computacional, a grande maioria dos trabalhos teóricos a respeito da caracterização de posições, larguras e da natureza de estados ressonantes limitam-se ao estudo de moléculas isoladas, usualmente baseados em técnicas de espalhamento [50, 80-83] ou métodos de química quântica adaptados a esse tipo de problema[84]. No entanto, estudos sobre a barreira metodológica existente entre a fase gasosa e a fase condensada nesse contexto foram publicados no últimos anos e foram recentemente revisados[85]. Entre as metodologias, as simulações do processo colisional entre LEEs e agregados do tipo biomolécula$\left[\mathrm{H}_{2} \mathrm{O}\right]_{n}[86-92]$ são de particular interesse para o trabalho. Mesmo que empregando uma quantidade de $n=1$ à 5 moléculas de água, além de diferentes modelagens para a interação intermolecular e efeitos de polarização, as caracterizações de ressonâncias de moléculas micro-solvatadas frequentemente negligenciam efeitos termodinâmicos. A grande dificuldade enfrentada pelos modelos computacionais, que explica assumir que os agregados-alvo estão à temperatura zero, se dá acerca de incorporar o acoplamento dos estados aniônicos com o contínuo (largura de autoionização) nos 
métodos usuais de solvatação explícita. Termoestatística de soluções aquosas utilizando técnicas como dinâmica molecular ou MC no contexto de solvatação de ânions são usualmente limitadas a técnicas de estado ligado[93-96].

Quanto à captura eletrônica por agregados de biomoléculas micro-solvatadas, em água, trabalhos teóricos relevantes foram realizados nas duas últimas décadas, mas vale mencionar os importantes resultados publicados por Freitas et al.[86, 88] sobre sistemas contendo ligações de hidrogênio. Particularmente, as publicações apresentam cálculos de seções de choque integral para o espalhamento eletrônico por aglomerados de formaldeído micro-solvatado $\left(\mathrm{CH}_{2} \mathrm{O}-\mathrm{H}_{2} \mathrm{O}\right)$ com uma molécula de água $(n=1)$ e pelo ácido fórmico micro-solvatado $\left(\mathrm{CHOOH}^{-}-\left[\mathrm{H}_{2} \mathrm{O}\right]_{n}, \operatorname{com} n=1,2\right)$, e a principal conclusão dos trabalhos diz respeito à estabilização ou desestabilização dos estados ressonantes dos solutos, ou seja, a alteração na posição em energia, quando a interação soluto-solvente admite ligações de hidrogênio. A saber, os resultados apontam uma sistemática estabilização das ressonâncias quando o soluto cumpre o papel de aceitador da ligação de hidrogênio e uma sistemática desestabilização das ressonâncias quando o soluto cumpre o papel de doador. Como, no presente trabalho, buscou-se estudar distribuições térmicas da influência do solvente na captura eletrônica, esse aspecto da influência das ligações de hidrogênio foi levado com consideração.

O objetivo principal dessa parte do projeto é utilizas as modelos micro-solvatados para estimar os efeitos da fase líquida, à temperatura ambiente e pressão constante, no espectro de ressonâncias e outras propriedades do espalhamento eletrônico. Os estudos foram realizados levando em conta uma quantidade da ordem de $\sim 100$ clusters soluto-solvente em cada um dos casos estudados, que tipicamente é um número reduzido de configurações no contexto de simulações de líquidos. Mesmo assim, seria computacionalente impraticável realizar cálculos de espalhamento de elétrons por cerca de 100 agregados de biomoléculas- $\left[\mathrm{H}_{2} \mathrm{O}\right]_{n}$, e por isso foi feito o uso de relações de escala (regressões lineares) e ajustes gaussianos para extrapolar resultados de espalhamento realizado em um número ainda mais reduzido de clusters. Em outras palavras, 
propomos uma metodologia admite o cálculo de seção de choque para poucos agregados e a partir deles inferir distribuições térmicas das propriedades. O tratamento baseado na micro-solvatação ainda é motivado por estudos experimentais recentes de DEA em algumas biomoléculas micro-solvatadas[97-99], apesar de não considerarmos aqui dinâmicas vibracionais induzidas pela captura eletrônica.

As biomoléculas estudas no trabalho foram a uracila (U), timina (T), e as quatro 5-halouracilas 5-XU ( $\mathrm{X}=\mathrm{F}, \mathrm{Cl}, \mathrm{Br}, \mathrm{I})$, e os resultados encontram-se nas seções a seguir. Metodologicamente, o primeiro passo dos estudos consistiu na simulação MC das biomoléculas como soluto e 1000 moléculas de água como solvente na caixa de simulação. As geometrias das moléculas, tanto soluto quanto solvente, foram mantidas rígidas durante a simulação. Os detalhes das simulações em cada caso estudado estão dispostos em cada uma das seções (ver capítulo 5). O segundo passo foi a análise e seleção de aglomerados menores, cujo número e critério de seleção também está apresentado a seguir caso a caso. O último passo é a realização dos cálculos quânticos, utilizando tanto as técnicas de espalhamento (método SMC - descrito no capítulo 3) quanto técnicas de estado ligado (descritas no capítulo 2). A uracila foi o primeiro sistema a ser investigado, e as conclusões obtidas foram relevantes no estudo dos sistemas seguintes.

\section{$6.1 \quad$ Uracila}

Nesta seção apresentamos a caracterização das ressonâncias $\pi^{*}$ da U, que podem ser entendidas como estados eletrônicos formados a partir da acomodação do elétron adicional em um orbital descoupado de caráter $\pi^{*}$ do alvo neutro. Em geral, ressonâncias $\pi^{*}$ apresentam assinaturas bem definidas em cálculos de espalhamento a baixas energias e acredita-se que cumprem papéis importantes em mecanismos de dissociação de biomoléculas relevantes[14, 19, 100-104].

A geometria otimizada do estado fundamental da uracila em fase gasosa foi obtida no nível DFT com o uso do funcional híbrido B3LYP e a base aug-cc-pVDZ, implementados no pacote Gaussian09[44]. A geometria da molécula isolada foi usada 
para descrever o soluto nas simulações da fase líquida, e foi mantida fixa apesar das alterações estruturais induzidas pelo meio solvente[105-107]. Esse procedimento é conveniente para conseguirmos comparar a caracterização das ressonâncias (posições e larguras) entre a fase gasosa e a fase condensada, de modo que conseguimos analisar com clareza as mudanças induzidas exclusivamente por efeitos eletrônicos, como polarização e ligações de hidrogênio. Apesar disso, vale mencionar que estado fundamental da uracila neutra deve possuir uma geometria plana tanto em fase gasosa quanto em solução, apenas com algumas mudanças em comprimentos de ligação e ângulos planares[107].

A simulação $\mathrm{MC}$ foi realizada no ensemble NPT à temperatura $T=298.15 \mathrm{~K} \mathrm{e}$ $p=1.0$ atm. O potencial de LJ acrescido da interação de Coulomb (equação 5.13) foi utilizado para descrever a interação intermolecular, e os campos de força adotados para o solvente e o soluto foram, respectivamente, SPC/E e OPLS/CHELPg. As cargas CHELPg do soluto foram obtidas através de um cálculo single point no nível MP2/6-31G*, com a presença ainda de um modelo contínuo de solvente (PCM) mimetizando o ambiente aquoso. Depois de uma termalização de $2 \times 10^{5}$ ciclos MC, $4 \times 10^{5}$ ciclos de $\mathrm{MC}$ foram simulados para a amostragem. Dentre as configurações geradas foram impressas 133 configurações estatisticamente descorrelacionadas. A função de descorrelação ajustada foi uma expressão biexponencial do tipo 5.20 e o critério para o intervalo de descorrelação foi estabelecido como sendo o que torna $C(t)<13 \%$. As médias obtidas de densidade de massa $\langle\rho\rangle=1.025 \pm 0.007 \mathrm{~g} / \mathrm{cm}^{3}$, energia por molécula $\langle U / N\rangle=-35.4 \pm 0.06 \mathrm{kcal} / \mathrm{mol}$ e entalpia conformacional por molécula $\left\langle H_{c} / N\right\rangle=-11.52 \pm 0.05 \mathrm{kcal} / \mathrm{mol}$ são compatíveis com o campo de força $\mathrm{SPC} / \mathrm{E}[75]$.

Em seguida determinou-se o tamanho dos agregados micro-solvatados (número de moléculas de água) para serem usados nos cálculos de espalhamento, e para tal realizou-se o estudo das distribuição radial de pares $G(r)$. A função $G(r)$ apresentada na Fig. 6.1 (painel esquerdo) foi calculada sobre a distribuição de menores distâncias entre sítios atômicos entre o soluto e o solvente. O primeiro mínimo local em cerca 

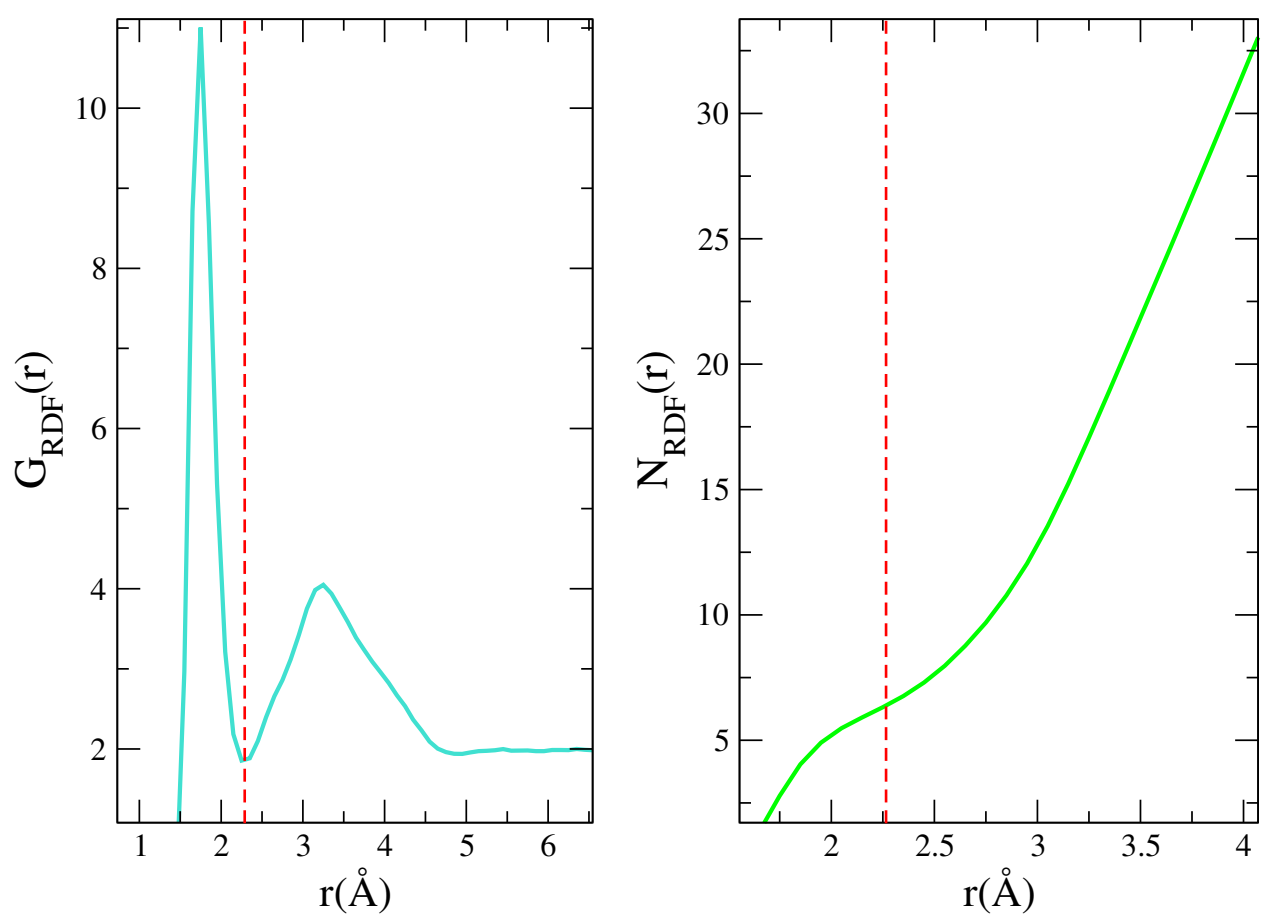

Figura 6.1: MDDF, à esquerda, e o número médio de moléculas obtido pela integral da distribuição $G(r)$, à direita, da simulação da uracila. A camada de micro-solvatação pode ser obtida através do primeiro mínimo local na distribuição $G(r)$, indicada pela linha tracejada em vermelho. O número de moléculas a primeira camada de solvatação, por sua vez, é obtido pela curva $N(r)$ uma vez que a distância $r$ foi estabelecida.

de $\sim 2.3 \AA$ mostra a existência de uma camada de micro-solvatação (ou camada de ligações de hidrogênio), que acabou se mostrando apropriada para definirmos o tamanho dos sistemas. A integral da $G(r)$ entre $r=0$ e $r \sim 2.3 \AA$ aponta que o número de moléculas na camada (painel direito da Fig. 6.1) é $n=6$. Analisando a distribuição de ligações de hidrogênio soluto-solvente no subconjunto das 133 configurações descorrelacionadas estimou-se que a média do número dessas ligações é 6, em que cada um dos oxigênios da uracila assume o papel de aceitador de duas ligações e cada um dos dois hidrogênios ligados aos nitrogênios (H-N) assume o papel de doador de uma ligação de hidrogênio, em média. Esses valores médios das distribuições de ligações de hidrogênio são uma boa representação dos resultados da simulação. De fato, ao analisar as funções $G(r)$, dessa vez definida entre os pares de átomos responsáveis pelas ligações de hidrogênio soluto-solvente, percebemos que há uma estrutura fina na distribuição associada a essas ligações (Fig. 6.2). O pico fino da curva azul no gráfico 

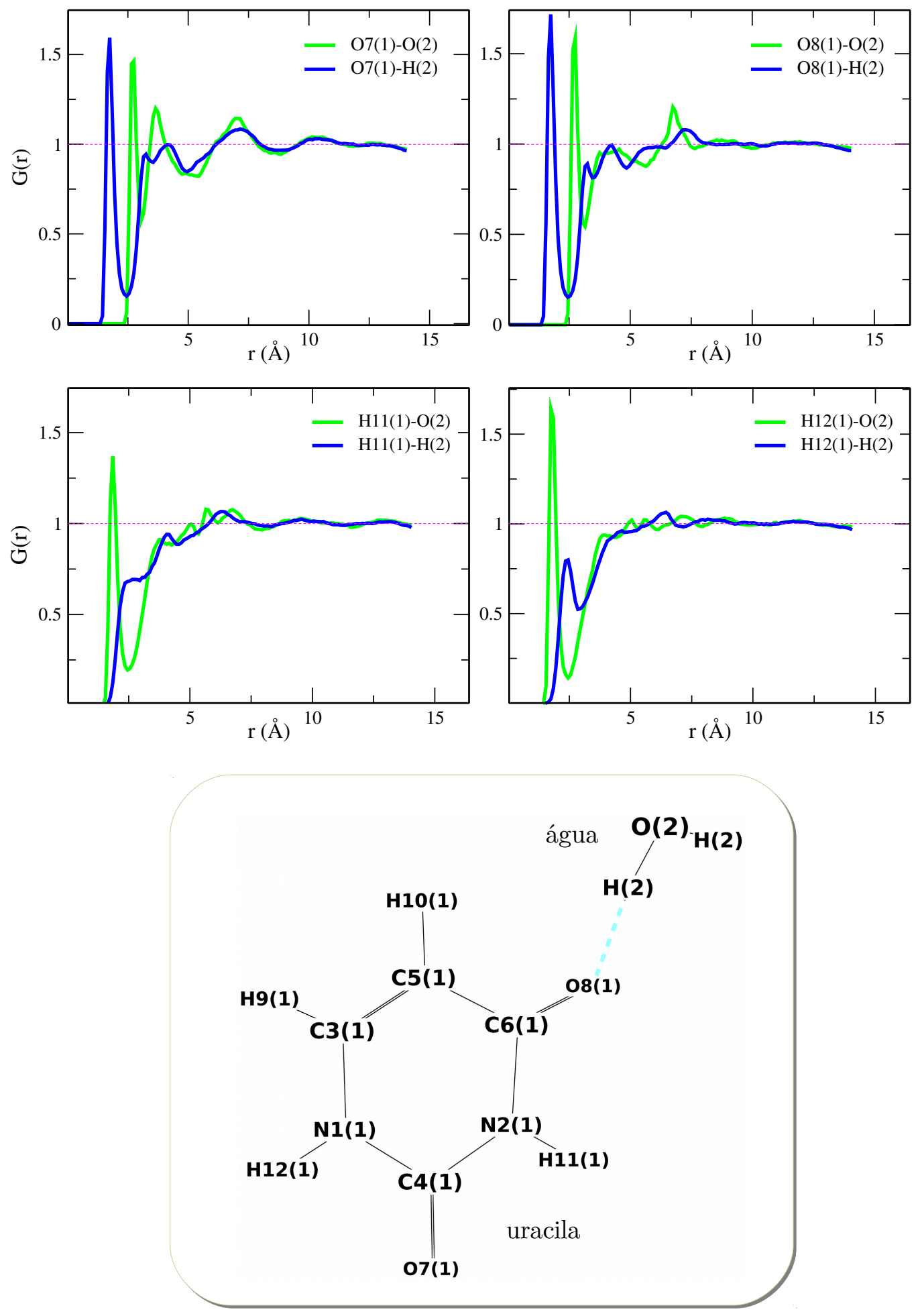

Figura 6.2: Os gráficos apresentam a distribuição radial de pares $G(r)$ referentes às distâncias entre átomos que realizam ligações de hidrogênio soluto-solvente. Abaixo um painel mostrando, como legenda, a numeração adotada para o estudo das distribuições. Os números entre parêntesis indicam se o átomo pertence ao soluto (1) ou ao solvente (2).

superior esquerdo aponta ligações de hidrogênio soluto(aceitador)-solvente(doador) 
cujas distâncias se dão em torno de $\sim 1.8$ A. A integral da $G(r)$ nesse gráfico até o primeiro mínimo em torno de $\sim 2.4 \AA$ vale $0.66(=2 / 3)$, que pode ser interpretado como 2/3 em unidades de moléculas de água, correspondendo a dois átomos de hidrogênio responsáveis pelas duas ligações de hidrogênio no oxigênio O7(1), em média. O primeiro pico da curva verde, por sua vez, se apresenta em torno de $\sim 2.8 \AA$, e a diferença das posições dos picos das duas curvas $(1 \AA$ ) é comparável ao comprimento da ligação O-H da molécula de água no modelo SPC/E (ver Fig. 5.1), indicando que essa ligação O-H se dá aproximada e essencialmente ao longo da mesma direção da ligação de hidrogênio associada. Essa mesma análise pode ser estendida para o oxigênio O8(1), cujas distribuições de pares nesse contexto é semelhante. O pico em $\sim 1.8 \AA$ da curva azul no painel superior direito é similar ao do oxigênio O7(1), e a integral da $G(r)$ até o primeiro mínimo em $\sim 2.4$ Å vale também 0.66 , levando à mesma interpretação. O caso dos paineis inferiores, referentes aos hidrogênios do soluto, é diferente. Os primeiros picos das curvas verdes nos painéis à esquerda e à direita se encontram em $\sim 1.86$, mostrando que as ligações de hidrogênio que o soluto doa para o solvente são ligeiramente maiores, em comprimento, do que as de aceitação. As integrais das curvas verdes até o primeiro mínimo estão entre 0.40 e 0.48 , corroborando a estimativa de 1 ligação de hidrogênio em cada um desses hidrogênios, em média. Além disso, não há uma estrutura clara nas curvas azuis análogas aos primeiros picos estreitos das curvas verdes nos gráficos superiores, o que pode ser interpretado como havendo uma distribuição mais larga de orientações geométricas das ligações de hidrogênio nesse caso.

A análise da camada de micro-solvatação nos permitiu estabelecer clusters de $\mathrm{U}-\left[\mathrm{H}_{2} \mathrm{O}\right]_{n}$ com $n=6$ para os cálculos de espalhamento, e portanto em um primeiro momento obtemos 133 agregados de $\mathrm{U}-\left[\mathrm{H}_{2} \mathrm{O}\right]_{6}$ a partir das 133 configurações descorrelacionadas obtidas na simulação MC. Nota-se que 101 dos 133 agregados representam a média de ligações de hidrogênio, por átomo, em cada sítio atômico. Isto é, em 101 clusters observa-se duas ligações de hidrogênio em cada um dos oxigênios da uracila e uma ligação de hidrogênio em cada hidrogênio H-N. Isso é um claro acordo com a 

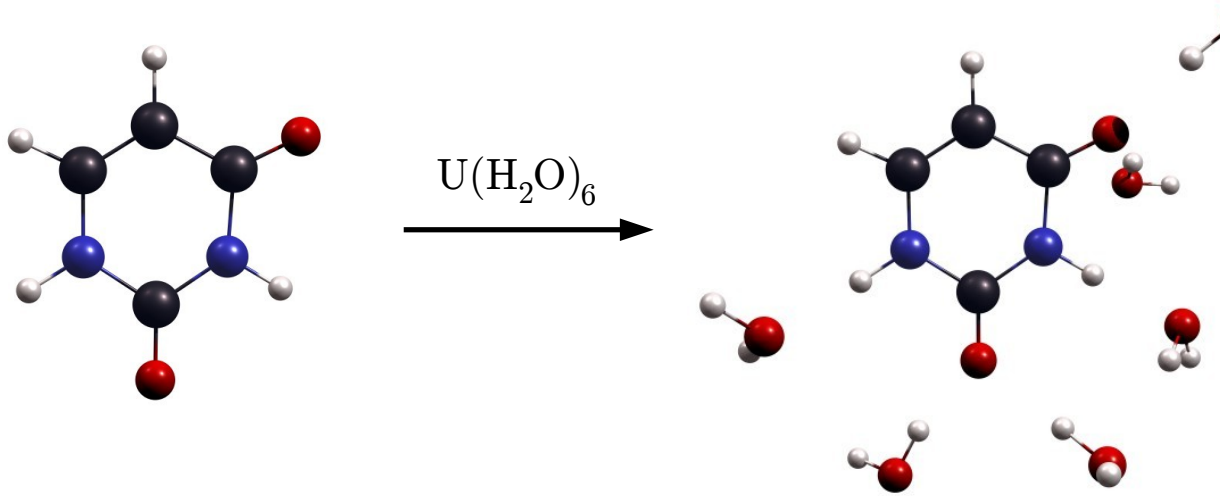

Figura 6.3: Estrutura da uracila (à esquerda) e de um cluster $\mathrm{U}-\left[\mathrm{H}_{2} \mathrm{O}\right]_{6}$ (à direita).

observação da distribuição fina das funções $G(r)$ mostradas no painel 6.2 , como foi discutido no último parágrafo.

Selecionaram-se, primeiramente, 5 clusters de maneira aleatória dentro do subgrupo de 101 configurações que representavam as médias de ligação de hidrogênio, os quais nomeamos de $\mathrm{C} 1, \mathrm{C} 2, \mathrm{C} 3, \mathrm{C} 4$ e C5. O primeiro passo do estudo consistiu do cálculo da seção de choque elástica, na aproximação ET, desses cinco clusters. Para os cálculos de espalhamento, foi empregado o método SMC, implementado com PP, assim como descrito em detalhes no capítulo 3. A uracila micro-solvatada possui 30 átomos no total e a estrutura eletrônica do sistema neutra, com o uso dos pseudopotenciais, é resolvida a partir de 438 funções de base. Para a uracila, empregou-se a base BHS constituída de um conjunto $5 s 5 p 2 d$ para todos os átomos com exceção do hidrogênio e uma base $3 s$ para os hidrogênios, a mesma utilizada nos estudos da 5-OCNU/5-SCNU. Para cada uma das moléculas de água, a alteração está no conjunto de bases para o oxigênio, onde foi empregado um conjunto $5 s 5 p 1 d$, em que o expoente das funções do tipo $s$ e $p$ foram os mesmos dos empregados na uracila e o expoente da função do tipo $d$ foi 0.291060 . Temos nesse caso 90 elétrons de valência e, na aproximação ET, o número de funções no EC é 393. A quadratura utilizada no cálculo das integrais de um e dois elétrons foi a mesma utilizada no caso da 5-OCNU/5-SCNU em fase gasosa, e foi descrita no capítulo 4 e no apêndice F.

Na Fig. 6.4 apresentamos a seção de choque integral dos cinco clusters C1-C5, 
na aproximação ET. Os cinco agregados apresentam duas estruturas na seção de

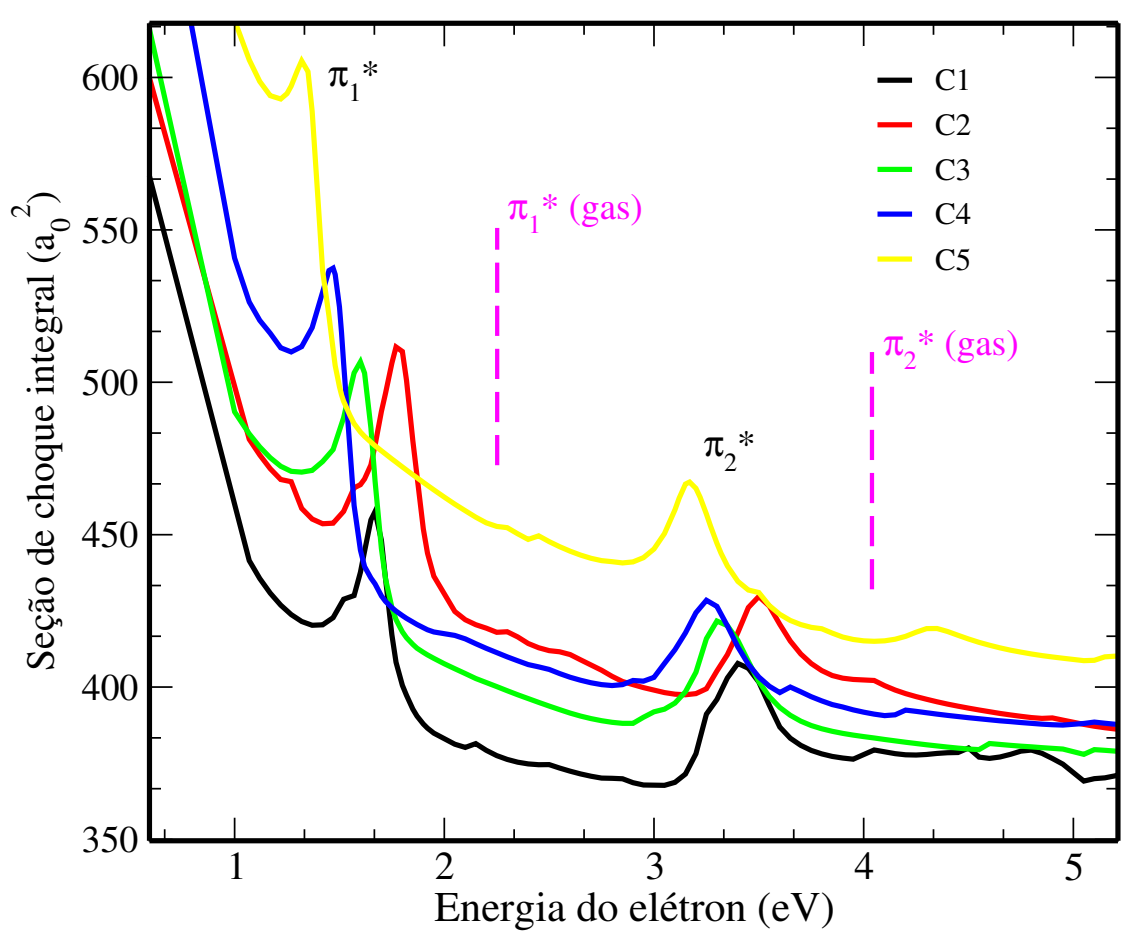

Figura 6.4: Seção de choque integral dos cinco clusters C1-C5 da uracila- $\left[\mathrm{H}_{2} \mathrm{O}\right]_{6}$, na aproximação ET. As posições das duas ressonâncias $\pi_{1}^{*}$ e $\pi_{2}^{*}$ estão indicadas. Além disso, as linhas tracejadas em rosa indicam a posição das ressonâncias $\pi_{1}^{*}$ e $\pi_{2}^{*}$ da uracila isolada (gas), para comparação.

choque, relacionadas às ressonâncias $\pi_{1}^{*}$ e $\pi_{2}^{*}$. As posições dos estados $\pi_{1}^{*}$ se encontram entre $1.34 \mathrm{eV}$ e $1.77 \mathrm{eV}$, enquanto que as posições dos estados $\pi_{2}^{*}$ estão entre 3.17 eV e $3.54 \mathrm{eV}$. As posições das duas primeiras ressonâncias $\pi^{*}$ da uracila em fase gasosa, obtidas também com o método SMC na mesma aproximação ET, também está indicada na Fig. 6.4 para comparação. A estabilização dos estados aniônicos induzida pela presença do solvente é significativa, em torno de $0.5 \sim 0.9 \mathrm{eV}$ no caso da $\pi_{1}^{*}$ e $0.7 \sim 0.9 \mathrm{eV}$ no caso da $\pi_{2}^{*}$. Vale reiterar que, como a geometria da uracila é a mesma em todos os clusters, e corresponde a geometria otimizada no vácuo, as estabilizações observadas são de natureza puramente eletrônica, e os efeitos aparecem mesmo sem levar em conta efeitos de polarização. Os resultados de posições e larguras estão resumidos na Tab. 6.1 .

A análise do pseudo-espectro do hamiltoniano de espalhamento também foi importante na investigação dos estados. Como discutido no capítulo 3, a resolução 
do hamiltoniano na base do EC dá origem, quando diagonalizado, a um espcetro discreto de auto-estados e auto-valores que podem ser usados na interpretação das ressonâncias. Essa mesma análise foi feita nos estudos da timina e das halouracilas (ver as seções seguintes). No caso dos clusters C1 - C5, os cinco pseudo-espectros apresentam autovalores muito próximos em energia dos picos referentes às ressonâncias $\pi_{1}^{*}$ e auto-valores muito próximos dos picos referentes às $\pi_{2}^{*}$. Como os auto-estados do pseudo-espectro na aproximação ET podem ser entendidos como o estado eletrônico fundamental do neutro, no caso contemplando 90 elétrons, mais uma combinação linear de orbitais virtuais de uma partícula representando o elétron incidente, os coeficientes dessa combinação fornecem informações sobre o caráter de cada pseudoestado. Os pseudo-estados correspondentes às ressonâncias estão associados à captura do elétron incidente em orbitais muito similares aos obtidos em cálculos de estado ligado no nível HF com o uso da base compacta 6-31G*.

Tabela 6.1: Posições (e larguras) das ressonâncias, em eV, dos cinco clusters C1 - C5 e do cluster $\overline{\mathrm{C}}$, assim como os resultados para a uracila em fase gasosa. Os resultados obtidos nas aproximações ET e ETP estão dispostos separadamente. A largura da ressonância $\pi_{1}^{*}$ do cluster $\overline{\mathrm{C}}$ não pôde ser obtida a partir da seção de choque.

\begin{tabular}{l|cccc}
\hline \hline Cluster & $\pi_{1}^{*}($ gas $)$ & $\pi_{1}^{*}$ & $\pi_{2}^{*}$ (gas) & $\pi_{2}^{*}$ \\
\hline uracila - ET & 2.27 & - & 4.04 & - \\
C1 - ET & - & $1.67(0.13)$ & - & $3.37(0.36)$ \\
C2 - ET & - & $1.77(0.16)$ & - & $3.54(0.33)$ \\
C3 - ET & - & $1.61(0.16)$ & - & $3.29(0.34)$ \\
C4 - ET & - & $1.47(0.12)$ & - & $3.25(0.38)$ \\
C5 - ET & - & $1.34(0.10)$ & - & $3.17(0.30)$ \\
$\bar{C}-$ SE & - & $1.74(0.16)$ & - & $3.53(0.32)$ \\
\hline uracila - ETP & $0.37(0.019)$ & - & $2.02(0.15)$ & - \\
$\bar{C}-$ ETP & - & $0.18(?)$ & - & $1.83(0.16)$ \\
\hline \hline
\end{tabular}

Os cálculos de espalhamento são computacionalmente custosos e é naturalmente impraticável realizá-los para todo o conjunto de 101 ou 133 clusters. Tendo isso em vista, foi providencial que buscássemos maneiras de correlacionar as posições e larguras das ressonâncias com propriedades eletrônica menos custosas. Na seção 3.6 menciono a existência de relações de escala comumente utilizadas como guia na identificação das ressonâncias. Em particular frequentemente usamos a relação 
proposta por Staley e Strnad 3.37 em que obtemos uma boa estimativa das energias verticais do ânion a partir de cálculos $\mathrm{HF} / 6-31 \mathrm{G}^{*}$. Porém, além dessa relação ter sido obtida a partir de estudos sobre moléculas isoladas, o que não é o caso, esse procedimento acaba sendo impraticável nesse caso também porque requer otimizações de geometria.
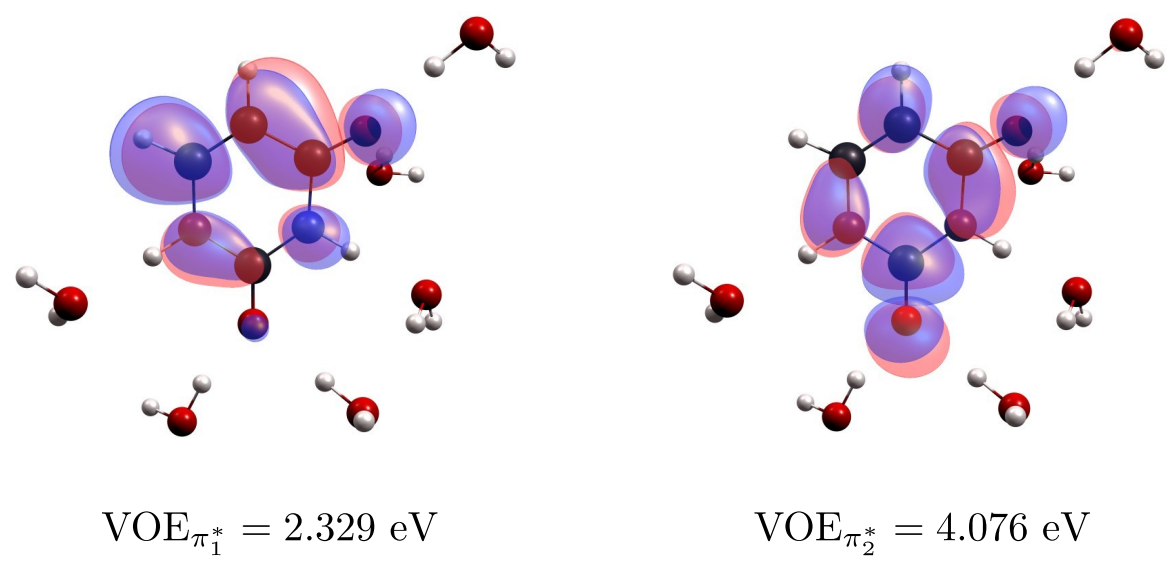

Figura 6.5: Estrutura do cluster $\overline{\mathrm{C}}$. Os VO's correspondentes aos estados $\pi_{1}^{*}$ e $\pi_{2}^{*}$, assim como suas energias HF/6-31G*, estão mostrados na esquerda e direita, respectivamente.

Nossa proposta foi estabelecer uma relação de escala apropriada para clusters de uracila micro-solvatada, promovendo regressões lineares que correlacionassem as energias ET das ressonâncias com energias dos orbitais virtuais no nível HF/6-31G* calculadas para o mesmo conjunto de clusters. A correlação não era clara à priori, mas acabou por se mostrar devidamente apropriada para o estudo, como ficará claro a seguir. No lado esquerdo do painel 6.6 se encontram regressões lineares relacionando as posições ET das ressonâncias $\pi_{1}^{*}$ e $\pi_{2}^{*}$ com as energias dos respectivos orbitais virtuais (VOE) associados à captura eletrônica desses dois estados, calculadas no nível HF/6-31G*. Os ajustes lineares deram origem às expressões

$$
E_{\mathrm{ET}}^{\pi_{1}^{*}}[\mathrm{eV}]=(-0.674 \pm 0.049)+(1.031 \pm 0.022) \times \mathrm{VOE}_{\pi_{1}^{*}}[\mathrm{eV}]
$$

e

$$
E_{\mathrm{ET}}^{\pi_{2}^{*}}[\mathrm{eV}]=(-0.36 \pm 0.15)+(0.959 \pm 0.038) \times \mathrm{VOE}_{\pi_{2}^{*}}[\mathrm{eV}]
$$




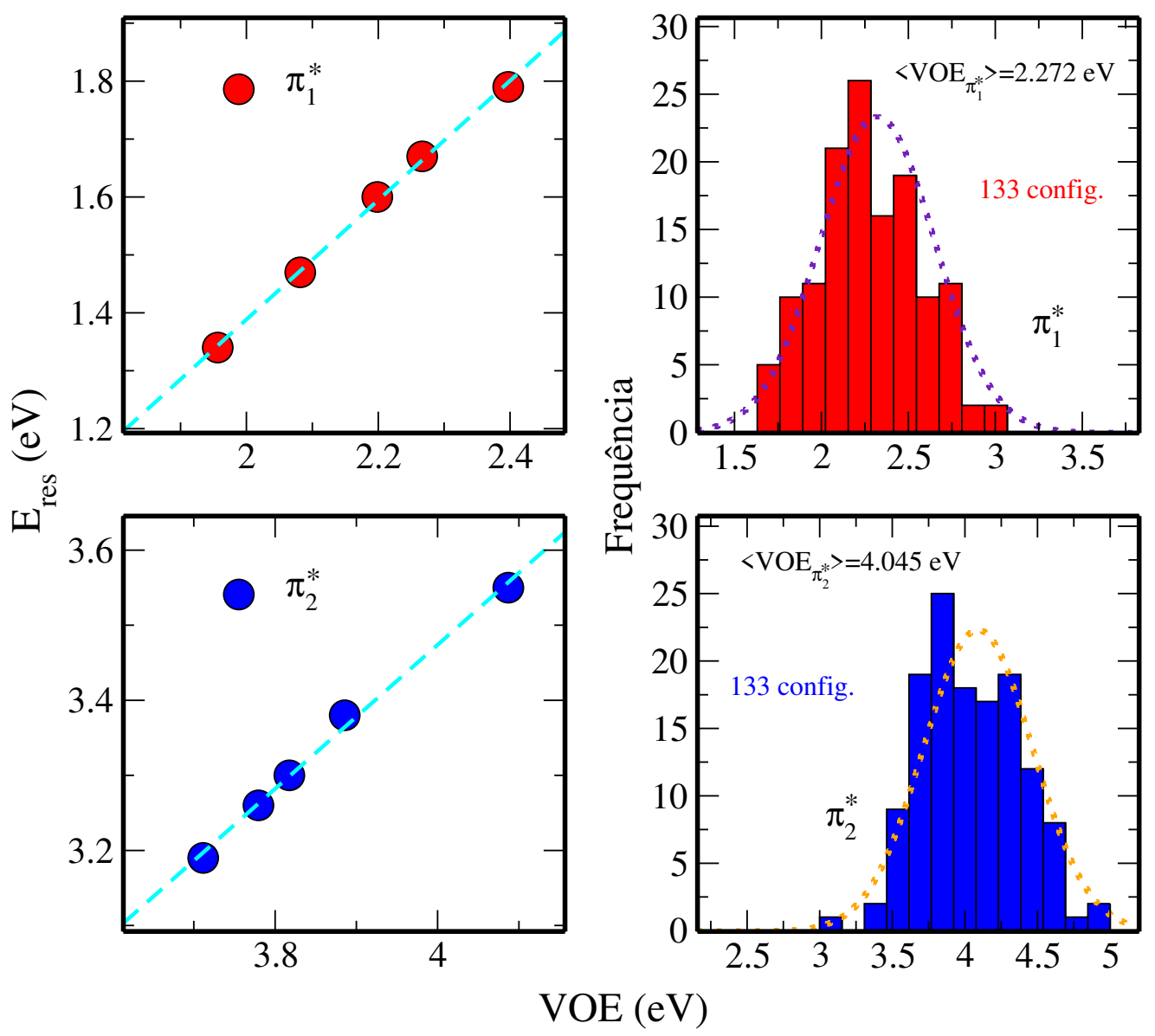

Figura 6.6: Esquerda: Gráficos mostrando as posições das ressonâncias $\pi_{1}^{*}$ e $\pi_{2}^{*}\left(E_{\mathrm{res}}\right)$, obtidas na aproximação ET para os cinco clusters C1-C5, em função das energias dos orbitais virtuais correspondentes, calculadas no nível HF/6-31G*. As linhas retas mostram as regressões lineares em cada caso. Direita: Distribuição térmica das energias dos VO's sobre o conjunto das 133 configurações estatisticamente descorrelacionadas geradas pela amostragem MC.

As qualidades dos ajustes altas, no sentido das incertezas dos parâmetros ajustados serem relativamente baixas. Vale observar também que os coeficientes lineares dos ajustes são ambos da ordem de $\sim 1$, mostrando que as regressões das duas ressonâncias diferem essencialmente pela diferença dos coeficientes lineares.

Dado que a correlação entre $E_{\mathrm{ET}}$ e VOE é alta, o passo seguinte do estudo foi calcular energia dos orbitais virtuais para todas as 133 configurações, obtendo uma distribuição. Os histogramas referentes a essa distribuição tanto para $\pi_{1}^{*}$ quanto $\pi_{2}^{*}$ se encontram nos painéis direito da Fig. 6.6 e podem ser encarados como a distribuição térmica dos VOE's à temperatura $T=298.15 \mathrm{~K}$. A partir de ajustes gaussianos, indicados por linhas sólidas sobre os histogramas, pudemos obter médias e larguras 
(correspondentes a desvios padrões - $1 \sigma)\left\langle\mathrm{VOE}_{\pi_{1}^{*}}\right\rangle=(2.27 \pm 0.32) \mathrm{eV}$ e $\left\langle\mathrm{VOE}_{\pi_{2}^{*}}\right\rangle=$ $(4.04 \pm 0.38) \mathrm{eV}$ e, com uso dos ajustes 6.1 e 6.2 , obtemos $\left\langle E_{\mathrm{ET}}^{\pi_{1}^{*}}\right\rangle=(1.73 \pm 0.75) \mathrm{eV}$ $\mathrm{e}\left\langle E_{\mathrm{ET}}^{\pi_{2}^{*}}\right\rangle=(3.56 \pm 0.90) \mathrm{eV}$. Nessa etapa buscou-se investigar a existência de um

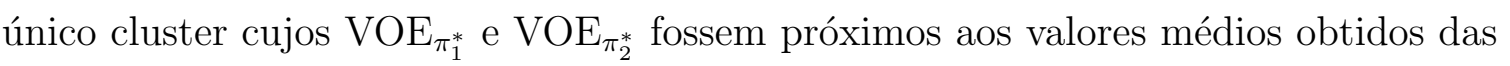
distribuições. De fato, o cluster nomeado $\overline{\mathrm{C}}$ apresenta $\mathrm{VOE}_{\pi_{1}^{*}}=2.33 \mathrm{eV}$ e $\mathrm{VOE}_{\pi_{2}^{*}}=$ $4.08 \mathrm{eV}$, correspondendo a $E_{\mathrm{ET}}^{\pi_{1}^{*}}=1.79 \mathrm{eV}$ e $E_{\mathrm{ET}}^{\pi_{2}^{*}}=3.55 \mathrm{eV}$ (Fig. 6.5). A ordem em energia dos orbitais virtuais de interesse não se mantém de um agregado para outro. A saber, os VO's $\pi_{1}^{*}$ e $\pi_{2}^{*}$ correspondem ao LUMO e LUMO+2 no cluster $\overline{\mathrm{C}}$. Sob o ponto de vista estatístico e metodológico, a existência de um cluster como $\overline{\mathrm{C}}$ por si só já sugere uma maneira de encará-lo como um representante do efeito médio do solvente, tanto no que diz respeito às ligações de hidrogênio quanto à estrutura eletrônica do soluto.

A aproximação ET é qualitativamente correta, apesar de superestimar posições e larguras de uma maneira sistemática. O nosso próximo passo foi incluir efeitos de polarização, realizando assim uma conta na aproximação ETP. Para nosso conhecimento, trabalhos reportando seções de choque de espalhamento eletrônico calculadas para clusters micro-solvatados cujo número de átomos é da ordem de $\sim 30$ são realizados apenas na aproximação ET. A proposta foi encarar o desafio apenas para o cluster $\overline{\mathrm{C}}$. O EC usado na conta foi construído segundo a estratégia proposta por Winstead e Mckoy (ver capítulo 3), no qual incluimos todos os orbitais virtuais no conjunto de orbitais de buraco e apenas os orbitais $\pi^{*}$ de interesse no conjunto de orbitais de espalhamento. Essa estratégia deu origem a 32163 configurações, que está seguramente no limite computacional para uma aplicação do método SMC hoje em dia. Foi empregado a técnica $\mathrm{MVO}+2$ para gerar os orbitais virtuais. Na Fig. 6.7 encontra-se o resultado ET e ETP para a seção de choque integral. Há duas estruturas associadas às ressonâncias $\pi_{1}^{*}$ e $\pi_{2}^{*}$ em $1.74 \mathrm{eV}$ e $3.53 \mathrm{eV}$, respectivamente, na aproximação ET. Já na curva ETP observamos apenas uma única estrutura em 1.83 eV, correspondendo à $\pi_{2}^{*}$. Situações como essa são comum quando lidamos com estados ligados, que na aproximação ETP não aparecem na seção de choque. Porém, a 
análise do pseudo-espectro do hamiltoniano de espalhamento, que de fato corrobora o estado $\pi_{2}^{*}$ em uma energia próxima a $1.8 \mathrm{eV}$, também prediz uma ressonância $\pi_{1}^{*}$ em 0.18 eV ao invés de um estado ligado. A curva sólida preta na Fig. 6.7 tem um comportamento divergente para baixas energias que ofusca a assinatura do estado ressonante $\pi_{1}^{*}$. Comportamentos desse tipo já foram observados em outras aplicações do SMC, como é o caso do estado $\sigma_{\mathrm{CBr}}^{*}$ no estudo sobre a 5-bromouracila[9]. O as-

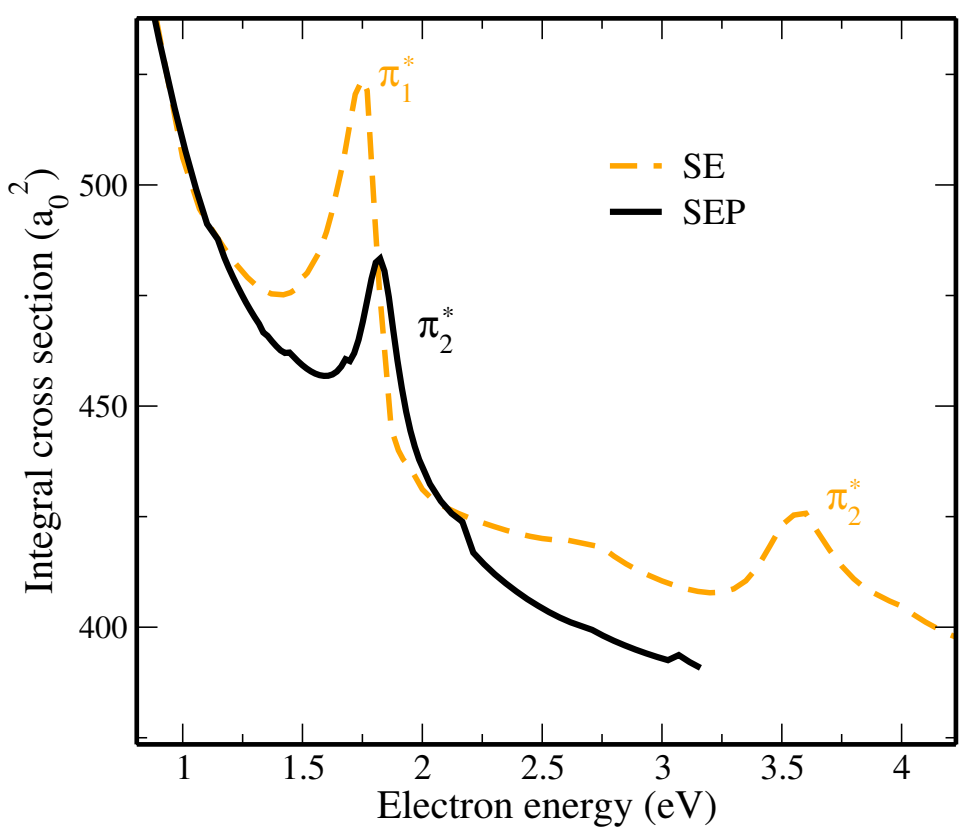

Figura 6.7: Seção de choque integral para o espalhamento eletrônico pelo cluster $\overline{\mathrm{C}}$ obtida tanto na aproximação ET (linha laranja tracejada) quanto na aproximação ETP (linha preta sólida).

pecto obscurecido da ressonância $\pi_{1}^{*}$ faz com que não obtenhamos informações sobre seu tempo de vida de auto-ionização (largura). Esses resultados para o cluster $\overline{\mathrm{C}}$ estão resumidos na Tab. 6.1.

O cálculo ETP para o cluster $\overline{\mathrm{C}}$ representa um dos maiores esforços computacionais já realizados, no contexto das aplicações do método SMC. Apesar de ser um importante resultado do trabalho, não seria razoável realizá-lo para cada um dos 133 (ou mesmo 101, contando apenas o subgrupo que representam a média de ligações de hidrogênio) clusters. A estratégia então foi explorar ainda mais regressões lineares, dessa vez a respeito do efeito da polarização na descrição das ressonâncias. É claro 
que esse efeito depende da maneira como foi construído o espaço de configurações, e portanto esse estudo corresponde ao efeito ET $\rightarrow$ ETP na seção de choque apenas sob a luz da estratégia que foi utilizada para polarizar o cálculo.

De antemão, buscou-se descrever as duas ressonâncias $\pi^{*}$ da uracila em fase gasosa, na aproximação ETP utilizando o critério de polarização em questão. As ressonâncias $\pi^{*}$ da uracila em fase gasosa foram estudadas teórica e experimentalmente, e no caso dos trabalhos publicados com estimativas teóricas dessas ressonâncias, há uma diversidade de metodologias, como diferentes critérios de polarização ou a exploração da simetria planar da uracila, por exemplo. Isso justifica a necessidade de termos uma descrição que consideramos comparável, no sentido metodológico, com os resultados obtidos para o cluster $\overline{\mathrm{C}}$. As estruturas na seção de choque obtidas se encontram em $0.37 \mathrm{eV}$ e $2.02 \mathrm{eV}$, correspondendo respectivamente às ressonâncias $\pi_{2}^{*}$ e $\pi_{1}^{*}$ (Fig. 6.8), e suas larguras são 0.019 eV e 0.15 eV. Os resultados estão também dispostos

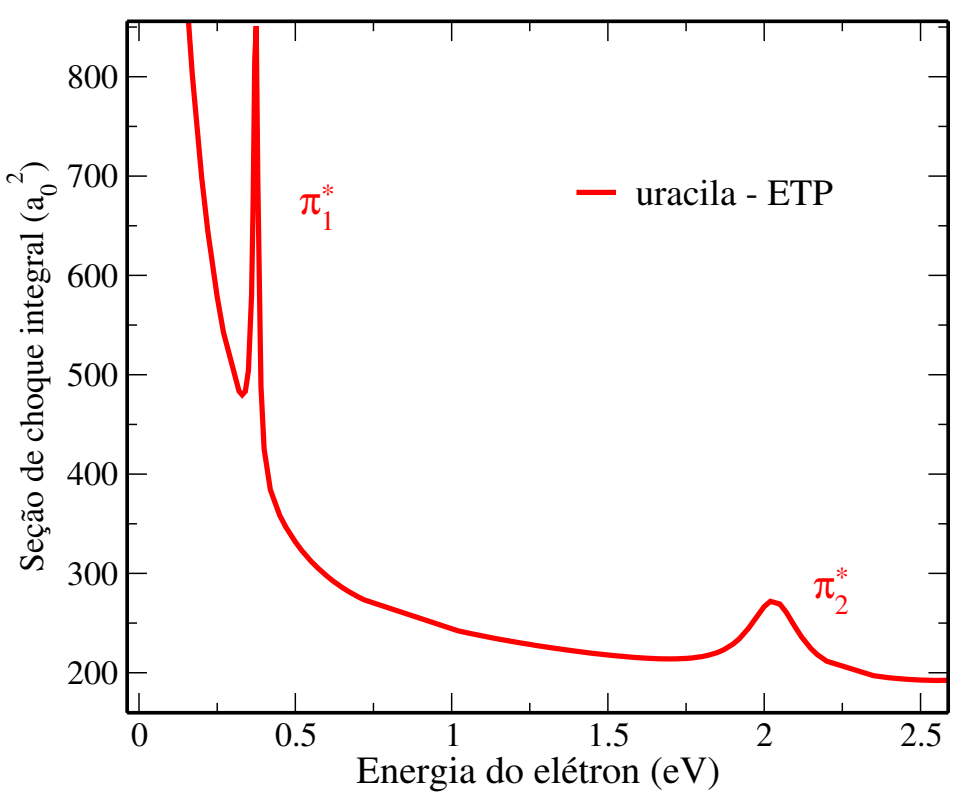

Figura 6.8: Seção de choque integral para o espalhamento eletrônico pela molécula de uracila isolada, na aproximação ETP, onde foi utilizado a mesma estratégia para a construção do espaço de configurações. As ressonâncias $\pi_{1}^{*}$ e $\pi_{2}^{*}$ estão indicadas.

na Tab. 6.1.

As ressonâncias obtidas na aproximação ETP são interpretadas como estimativas das energias de captura eletrônica verticais (VAEs) e, com o uso das regressões li- 
neares, pudemos obter uma estimativa da distribuição térmica dessas energias. Um ajuste linear relacionando posições das ressonâncias na aproximação ET com as mesmas ressonâncias na aproximação ETP foi feito, baseado nos resultados obtidos para a uracila isolada e nos resultados do cluster $\overline{\mathrm{C}}$, resultando na expressão

$$
E_{\mathrm{ETP}}[\mathrm{eV}]=(-1.46 \pm 0.32)+(0.88 \pm 0.11) \times E_{\mathrm{ET}}[\mathrm{eV}]
$$

Na Fig. 6.9 é possível observar a reta ajustada, assim como os pontos usados. A maior diferença metodológica dessa etapa, quando comparada às equações 6.1 e 6.2, é que estamos estabelecendo uma única estimativa para as duas ressonâncias simultaneamente. Uma segunda maneira de se ajustar a mesma regressão é considerar dados de ressonâncias $\pi^{*}$ de sistemas similares que foram estudados também com o método SMC cujo espaço de configurações foi construído utilizando-se o mesmo critério. Consideramos assim o caso da glicina[2] (Gly), do fenol[3] (Phe) e do guaiacol[3] (Gua), uma subunidade da lignina. Esse segundo ajuste linear está também disposto na Fig. 6.9 e a expressão obtida foi

$$
E_{\mathrm{ETP}}[\mathrm{eV}]=(-1.43 \pm 0.27)+(0.829 \pm 0.080) \times E_{\mathrm{ET}}[\mathrm{eV}]
$$

As expressões 6.3 e 6.4 são próximas uma da outra, analisando sob o ponto de vista das incertezas dos parâmetros ajustados. Daqui pra frente, essas duas relações darão origem a duas estimativas, referidas como Modelo I e Modelo II. Há ciência de que os modelos podem ser melhorados no futuro, com a inclusão de mais pontos para o ajuste, além de um estudo mais detalhado dos efeitos da polarização eletrônica no cálculo ETP. Porém, para o nosso propósito de estimar VAEs, e posteriormente larguras de auto-ionização, as equações 6.3 e 6.4 se mostram suficientemente apropriadas. Além disso, vale mencionar que a proximidade dos dois modelos nos leva a conclusões similares, como ficará claro em seguida. Juntando as equações $6.1,6.2$, e 6.3, obtemos as expressões para o Modelo I, 


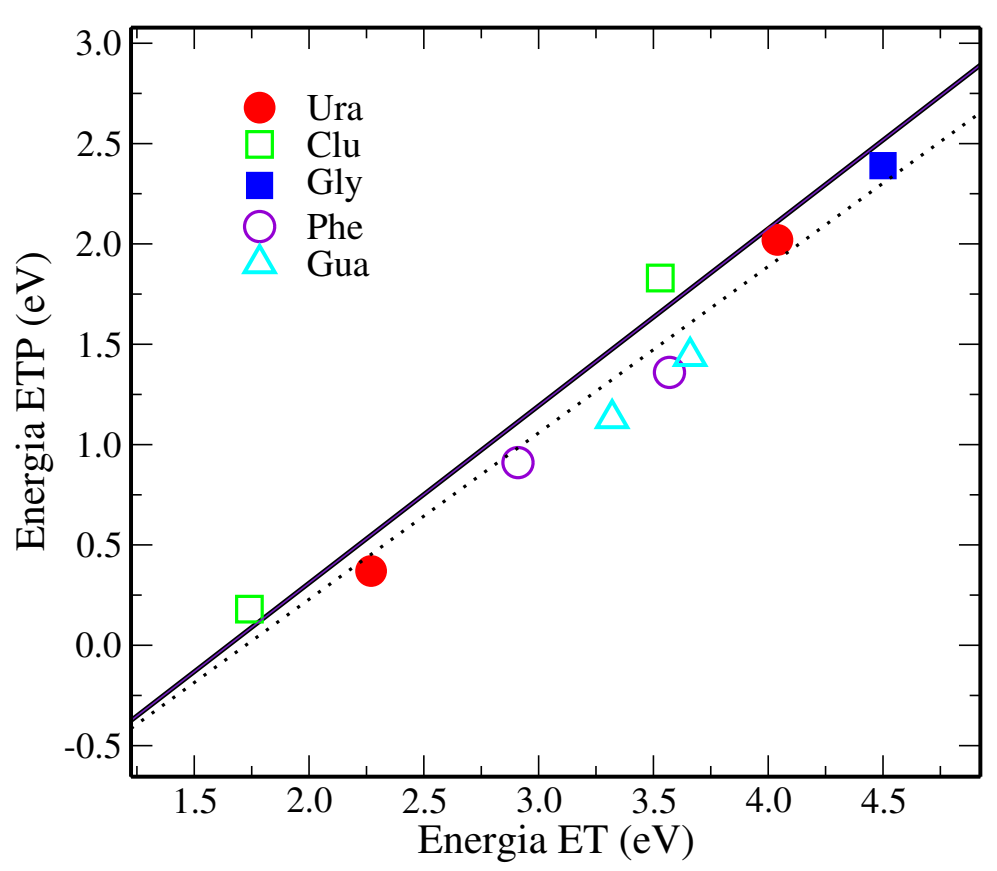

Figura 6.9: Estimativas das posições das ressonâncias $\pi^{*}$ na aproximação ETP em função das estimativas ET para uracila (Ura), para o cluster $\overline{\mathrm{C}}\left(\mathrm{U}\left[\mathrm{H}_{2} \mathrm{O}\right]_{6}\right)(\mathrm{Clu})$, glicina (Gly) [2], fenol (Phe) [3] e guaiacol (Gua) [3]. A linha sólida preta indica a regressão linear baseada apenas nos nossos resultados para a uracila e para o cluster $\overline{\mathrm{C}}$, enquanto que a linha tracejada leva em consideração todos os pontos.

$$
E_{\mathrm{res}}^{\pi_{1}^{*}}=(-2.02 \pm 0.34)+(0.86 \pm 0.14) \times \mathrm{VOE}_{\pi_{1}^{*}},
$$

e

$$
E_{\text {res }}^{\pi_{2}^{*}}=(-1.78 \pm 0.35)+(0.85 \pm 0.11) \times \mathrm{VOE}_{\pi_{2}^{*}},
$$

enquanto que ao juntar as equações 6.1, 6.2, e 6.4, estabelece-se o Modelo II,

$$
E_{\mathrm{res}}^{\pi_{1}^{*}}=(-1.99 \pm 0.28)+(0.855 \pm 0.084) \times \mathrm{VOE}_{\pi_{1}^{*}}
$$

$\mathrm{e}$

$$
E_{\mathrm{res}}^{\pi_{2}^{*}}=(-1.73 \pm 0.30)+(0.795 \pm 0.083) \times \mathrm{VOE}_{\pi_{2}^{*}}
$$

A distribuição térmica dos VAEs, obtidas diretamente da distribuição dos VOEs via equações 6.5 e 6.6 (Modelo I) e equações 6.7 e 6.8(Modelo II), sobre o conjunto total de 133 configurações descorrelacionadas, estão mostradas na Fig. 6.10. Observou-se sobre ambos os modelos que o estados $\pi_{1}^{*}$ são estados ligados em mais 
Modelo I

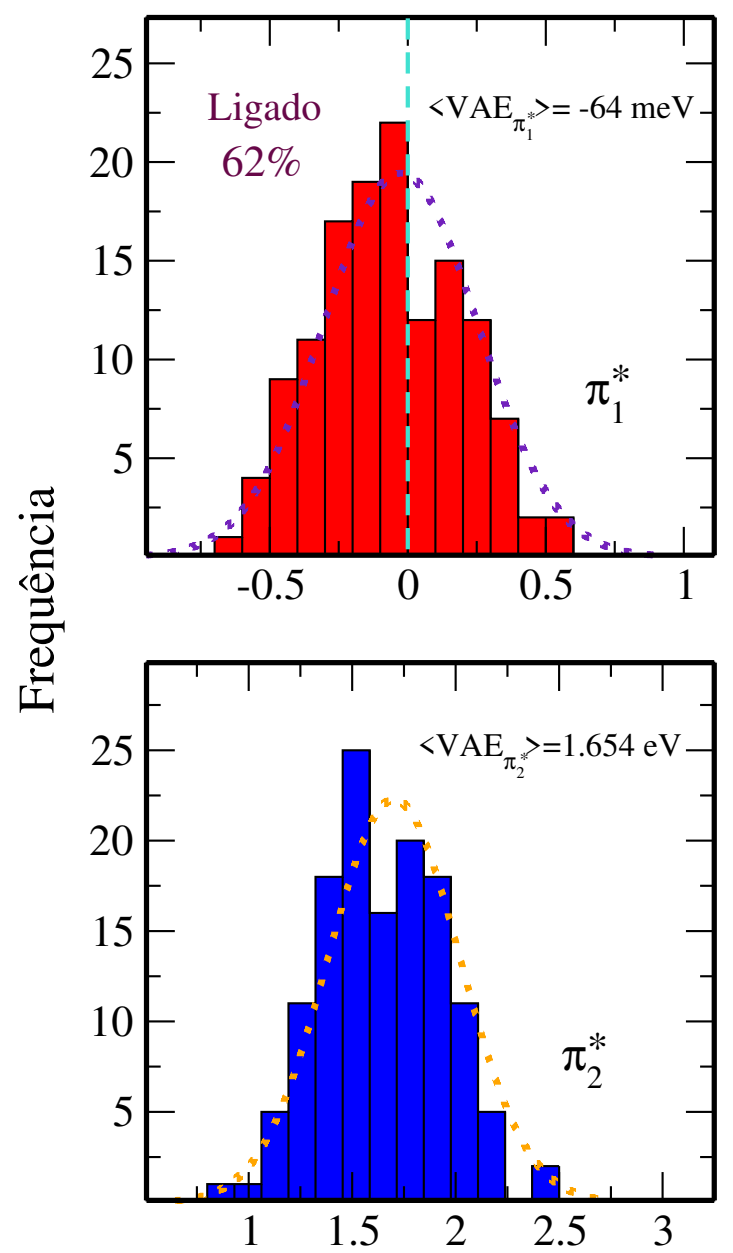

Modelo II
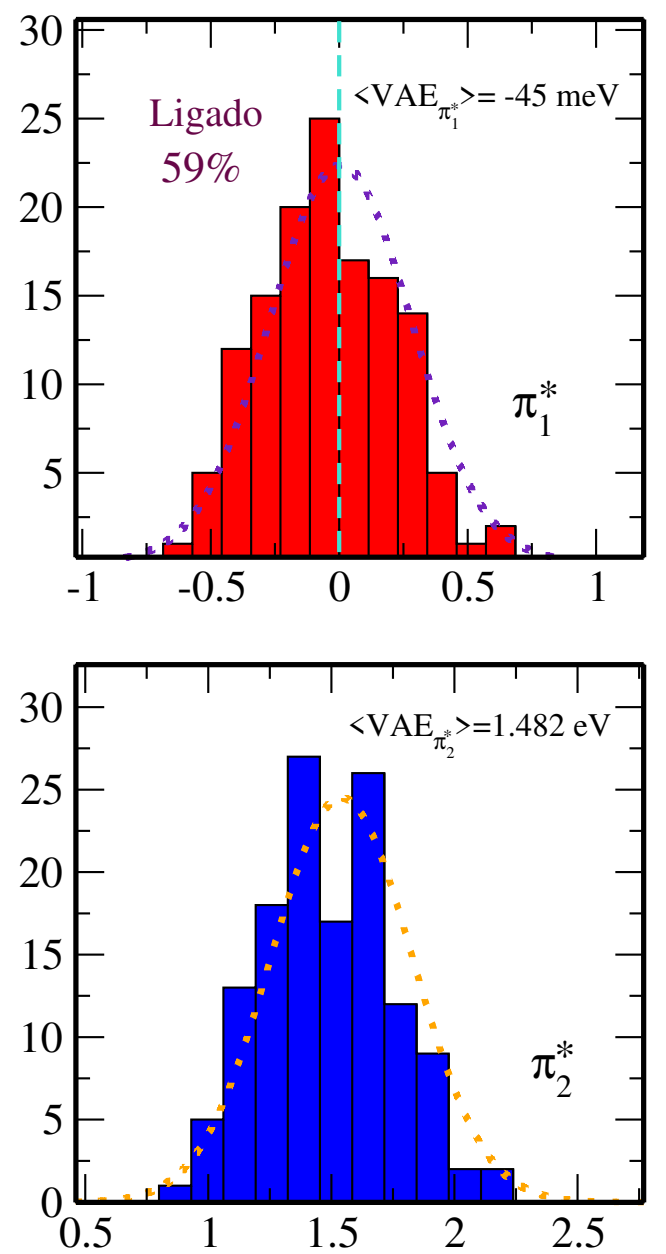

\section{VAE (eV)}

Figura 6.10: Distribuições térmicas de VAEs $\pi_{1}^{*}$ e $\pi_{2}^{*}$ obtidas sobre o conjunto de 133 configurações $\mathrm{U}\left[\mathrm{H}_{2} \mathrm{O}\right]_{6}$ estatisticamente descorrelacionadas à temperatura $T=298 \mathrm{~K}$. O Modelo I (à esquerda) foi obtido das equações 6.5 e 6.6, enquanto que o Modelo II (à direita) das equações 6.7 e 6.8 .

de $50 \%$ dos agregados - isto é, VAE negativo, indicando que o estado $\pi_{1}^{*}$ se encontra a uma energia menor do que a energia do estado fundamental do agregado neutro. Os valores médios das distribuições referentes aos estados $\pi_{1}^{*}$ são portanto negativas, naturalmente, e valem respectivamente $-64 \mathrm{meV}$ e $-45 \mathrm{meV}$ para o Modelo I e para o Modelo II. Essa diferença é desprezível quando comparada às larguras das distribuições (desvios padrão), cujos valores obtidos foram $\sigma=0.28 \mathrm{eV}$ (Modelo I) e $\sigma=0.27 \mathrm{eV}$ (Modelo II). Quanto aos estados $\pi_{2}^{*}$, obteve-se valores positivos de VAEs para toda a distribuição de agregados - descrevendo ressonâncias, efetivamente 
- e seus valores médios foram estimados em $(1.65 \pm 0.32)$ eV e $(1.49 \pm 0.29)$ eV para os Modelos I e II. As incertezas dos valores correspondem aos respectivos desvios padrão. Aqui, vale também observar que as equações 6.5 - 6.8, juntamente com as energias dos orbitais virtuais mostrados na Fig. 6.5, predizem valores de VAE para o cluster $\overline{\mathrm{C}}$ bem próximos das médias obtidas, como era de se esperar. De fato, as energias dos estados $\pi_{1}^{*}$ e $\pi_{2}^{*}$ obtidos na aproximação ETP (Tab. 6.1), são maiores do que as médias obtidas, porém a observação anterior sobre a proximidade tem em vista o valor das larguras das distribuições, que faz com que eles sejam compatíveis. No mais, vale o comentário de que os resultados ETP, no geral, estão em boas concordâncias com valores medidos em experimentos de transferência eletrônica. Para diversas moléculas isoladas, essa concordância é da ordem de $0.1 \mathrm{eV}$ a $0.4 \mathrm{eV}$. Nesse sentido, a diferença nas estimativas advindas dos Modelos I e II podem ser vistas como irrelevantes.

Por último, estudou-se como se dá a distribuição térmica das larguras das ressonâncias, e para tal nos baseamos em uma dependência direta entre a posição e largura, assumindo que ele é dada por uma expressão funcional do tipo $\Gamma=\Gamma\left(E_{\text {res }}\right)=$ $A E_{\mathrm{res}}^{b}$, em que $E_{\text {res }}$ é a posição em energia da ressonância. Relações entre energias e larguras de ressonâncias são frequentemente úteis no contexto da dinâmica de ânions transientes para modelar superfícies de energia potencial complexas de uma maneira relativamente simples. A forma funcional proposta foi baseada em outros estudos já publicados $[108,109]$. A largura $\Gamma$ é uma propriedade das ressonâncias que é crescente com sua energia, o que nos faz esperar $A, b>0$ no ajuste proposto. Além disso, a relação posição e largura foi admitida a mesma para ambas as ressonâncias $\pi_{1}^{*}$ e $\pi_{2}^{*}$, e para obtermos um ajuste razoável consideramos estudos teóricos anteriores sobre as ressonâncias $\pi^{*}$ da uracila. Inlcuímos resultados publicados por Kossoski et al.[4], Winstead et al.[5], Dora et al.[7], Tonzani et al. [6] e Gianturco et al.[8] (Fig. 6.11). A relação obtida foi

$$
\Gamma[\mathrm{eV}]=(0.0703 \pm 0.0036) E_{\mathrm{res}}^{(1.301 \pm 0.038)}[\mathrm{eV}]
$$


em que a qualidade do ajuste é considerada boa, no sentido das incertezas dos parâmetros ajustados, apesar de a concordância de alguns dos dados previamente reportados por trabalhos citados com dados experimentais não serem razoáveis. É

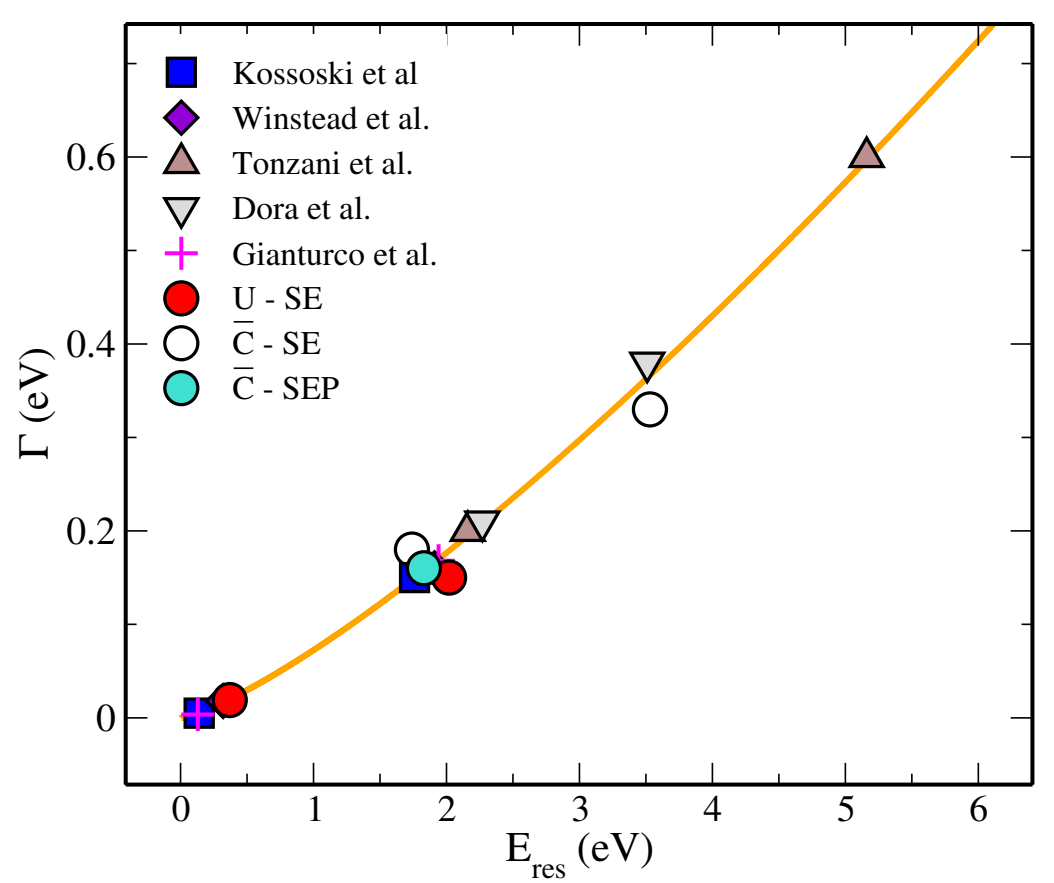

Figura 6.11: Largura de auto-ionização $(\Gamma)$ como uma função da posição em energia das ressonâncias $\pi^{*}\left(E_{\text {res }}\right)$ da uracila, assim como também da ressonância $\pi_{2}^{*}$ do cluster $\overline{\mathrm{C}}$ obtida no presente trabalho. Também foram incluídos dados apresentados por Kossoski et al.[4], Winstead et al.[5], Tonzani et al. [6], Dora et al.[7] e Gianturco et al. [8].

claro que a expressão 6.9 deve valer apenas para $E_{\text {res }}>0$.

A partir da expressão que relaciona $E_{\text {res }} \operatorname{com} \Gamma$ e dos Modelos I e II para as energias, pudemos obter a distribuição térmica de larguras auto-ionização, apresentadas na Fig. 6.12. Como discutido anteriormente, de $59 \%$ à $62 \%$ das distribuições de VAEs referentes aos estados $\pi_{1}^{*}$ são estados ligados, dependendo do modelo. Essas frações das distribuições estão associadas a larguras $\Gamma_{\pi_{1}^{*}}=0$, como indicado pela linha tracejada em azul nos histogramas superiores. O valor médio $\left\langle\Gamma^{\pi_{1}^{*}}\right\rangle$ estimados pelos Modelos I e II foram calculados portanto sobre a região positiva da distribuição, para os desvios padrão, utilizou-se a expressão $\sqrt{\left\langle\Gamma_{\pi_{1}^{*}}^{2}\right\rangle-\left\langle\Gamma_{\pi_{1}^{*}}\right\rangle^{2}}$. Os valores obtidos foram $\left\langle\Gamma_{\pi_{1}^{*}}\right\rangle=(0.010 \pm 0.008) \mathrm{eV}$ (Modelo I) e $\left\langle\Gamma_{\pi_{1}^{*}}\right\rangle=(0.010 \pm 0.009) \mathrm{eV}$ (Modelo II). Quanto ao estado $\pi_{2}^{*}$, calculou-se assim os valores médios e desvios de forma usual, e 


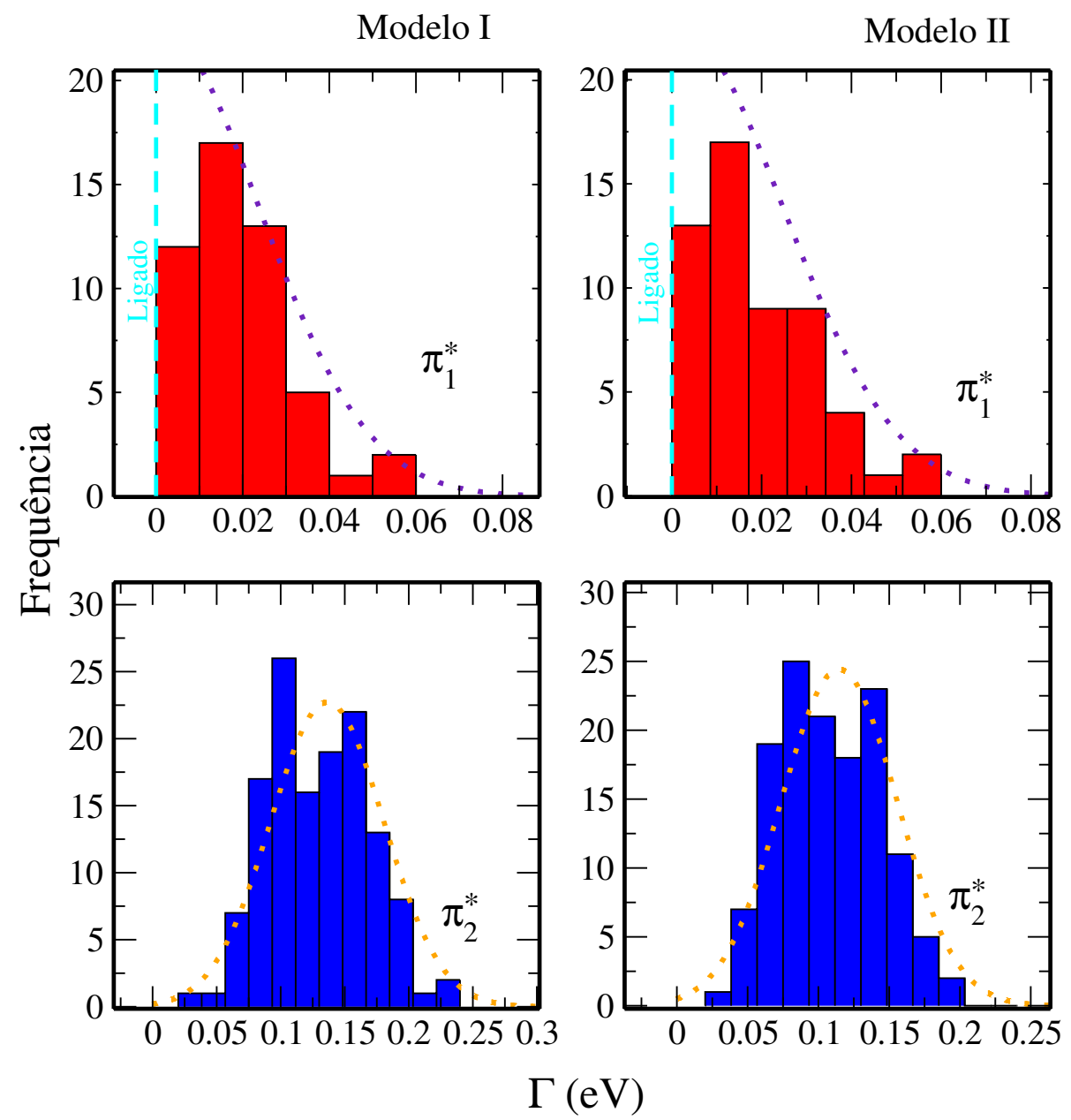

Figura 6.12: Distribuição térmica das larguras de auto-ionização $(\Gamma)$ dos estados aniônicos $\pi_{1}^{*}$ e $\pi_{2}^{*}$ calculados sobre o conjunto de 133 configurações estatisticamente descorrelacionadas, à temperatura $T=298 \mathrm{~K}$. Os dois painéis à esquerda e os dois painéis à direita foram obtidos com os Modelos I e II, respectivamente.

os valores obtidos são $\left\langle\Gamma_{\pi_{2}^{*}}\right\rangle=(0.136 \pm 0.031) \mathrm{eV}$ e $\left\langle\Gamma_{\pi_{2}^{*}}\right\rangle=(0.118 \pm 0.028) \mathrm{eV}$ para os Modelos I e II, respectivamente.

Concluimos assim o estudo dos efeitos do solvente na descrição das ressonâncias $\pi^{*}$ da uracila, e passo agora a algumas discussões e análises finais. O efeito da água na captura eletrônica de baixas energias por nucleobases tem sido bem estudado, como mencionado no início do capítulo. Os trabalhos teóricos citados, que foram realizados cálculos de espalhamento em agregados micro-solvatados com $n=1$ a $n=5$ moléculas de água, mostram a importância das ligações de hidrogênio no efeito de estabilização ou desestabilização das ressonâncias de forma. Os resultados obtidos para a uracila no presente trabalho corroboram a tendência que já vem sendo 
apontada. De fato, obteve-se das simulações que a uracila aceita, em média, 4 ligações de hidrogênio e doa, em média, 2 ligações de hidrogênio, e as estabilizações médias das duas ressonâncias $\pi^{*}$ podem ser interpretadas como resultados de um balanço entre aceitações e doações de ligações de hidrogênio. De fato, em 101 das 133 dos agregados considerados, o padrão de ligações de hidrogênio é similar ao mostrado para o cluster $\overline{\mathrm{C}}$. Entretanto, os trabalhos anteriores de espalhamento admitem clusters otimizados que negligenciam os efeitos de temperatura aqui considerados. Como mostrado na

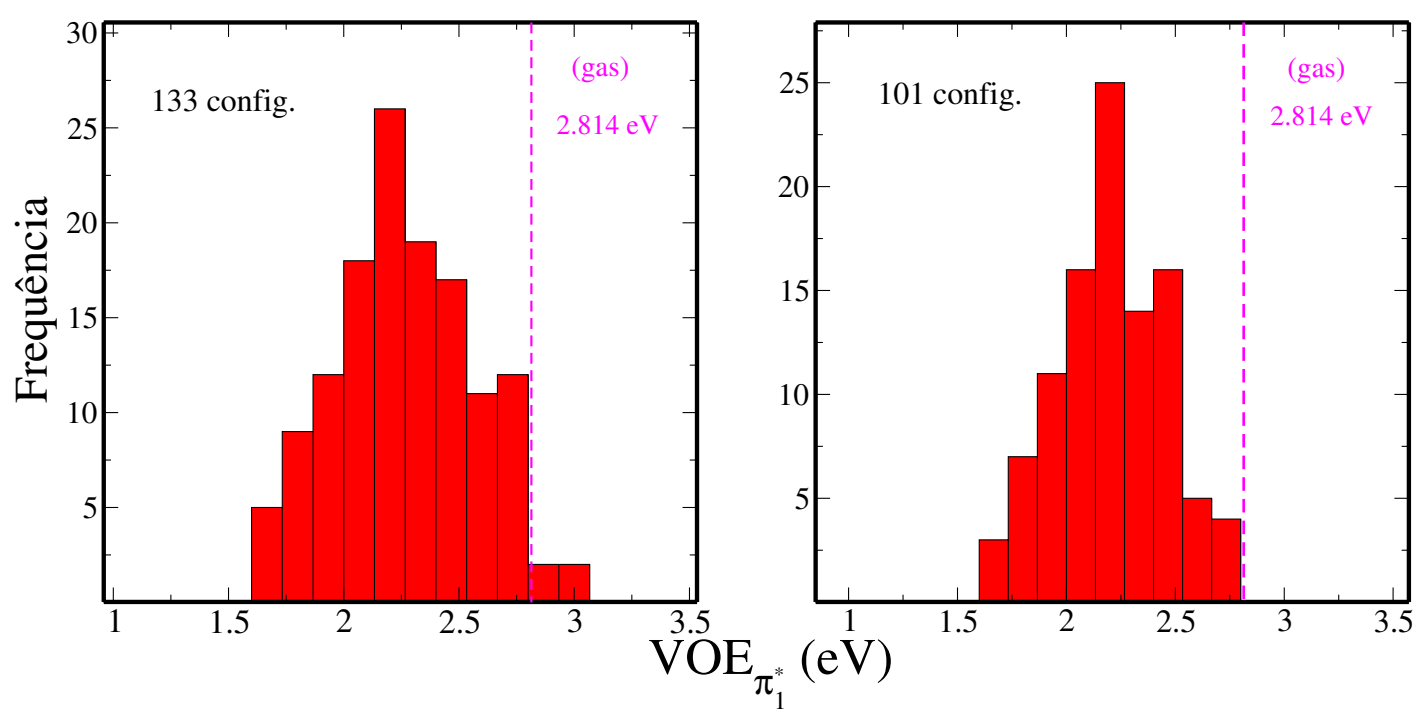

Figura 6.13: Distribuição de VOEs dos estados $\pi_{1}^{*}$ para o conjunto completo de 133 configurações, à esquerda, e para o subconjunto representativo de 101 configurações que apresentam o padrão médio de ligações de hidrogênio, à direita. $\mathrm{O}$ valor do VOE $\pi_{1}^{*} \mathrm{HF} / 6-31 \mathrm{G}^{*}$ para a uracila em fase gasosa também está indicado (rosa) para comparação.

Fig. 6.14, as distribuições de VOEs $\pi_{1}^{*}$ sobre o subconjunto das 101 configurações difere relativamente pouco da distribuição sobre o conjunto total. Podemos notar que os agregados responsáveis pela desestabilização dos VOEs não representam o padrão médio de ligações de hidrogênio.

Os modelos propostos de regressões lineares se mostraram apropriados para estimar distribuições térmicas dos valores de VAEs e de larguras de auto-ionização para os estados aniônicos $\pi_{1}^{*}$ e $\pi_{2}^{*}$, estudos que até onde conhecemos não haviam sido reportados. Importantes conclusões se dão acerca das distribuições em si, dos valores médios e das larguras das distribuições, que são grandes quando comparadas às concordâncias usuais entre cálculos SMC e resultados experimentais. Além disso, 


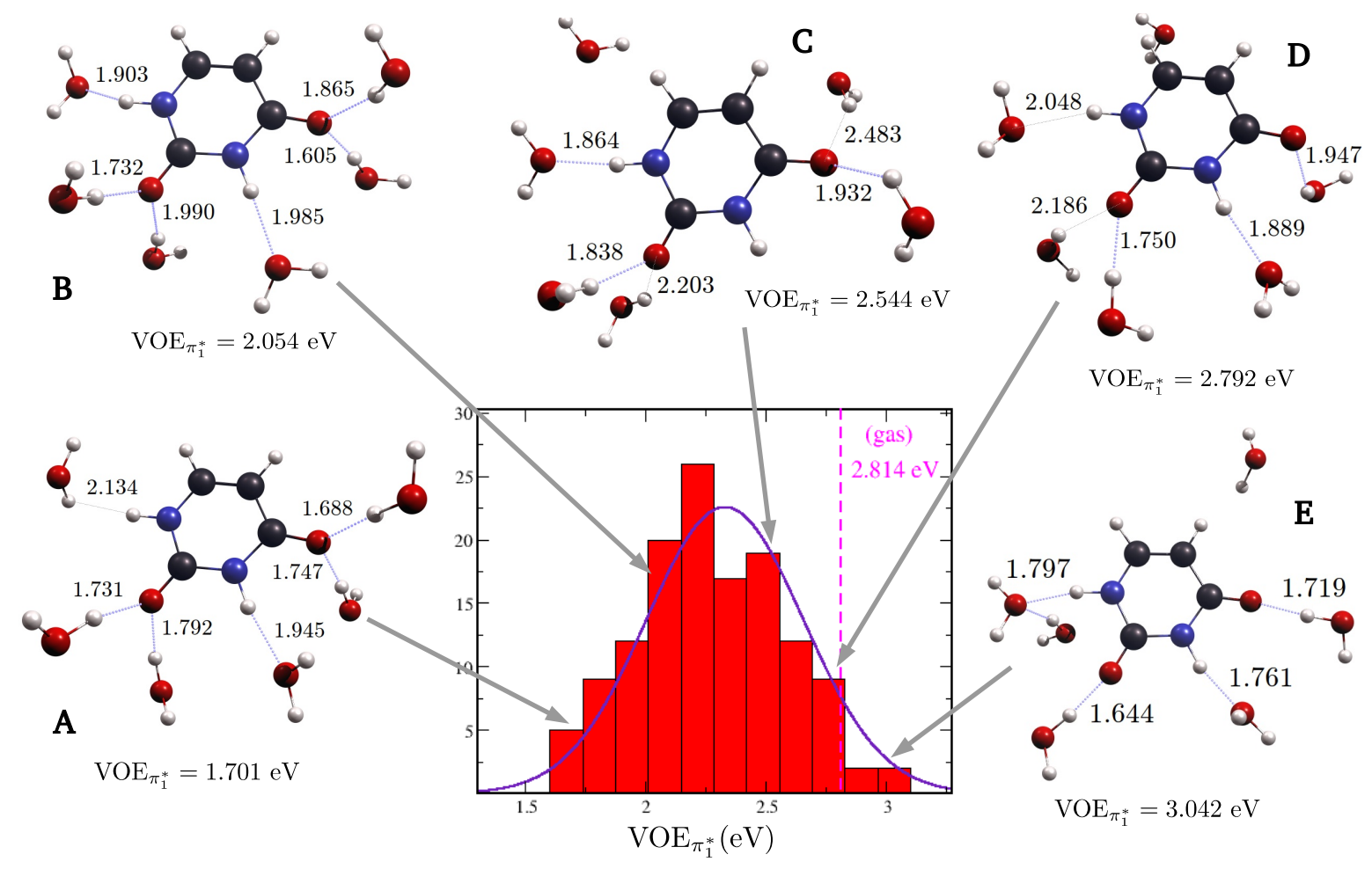

Figura 6.14: Distribuição de VOEs dos estados $\pi_{1}^{*}$ para o conjunto completo de 133 configurações, à esquerda, e para o subconjunto representativo de 101 configurações que apresentam o padrão médio de ligações de hidrogênio, à direita. $\mathrm{O}$ valor do VOE $\pi_{1}^{*} \mathrm{HF} / 6-31+\mathrm{G}(\mathrm{d})$ para a uracila em fase gasosa também está indicado (rosa) para comparação.

também estimamos um pequeno overlap entre as distribuições dos VAEs referentes aos dois estados $\pi^{*}$, e isso é observado em ambos os modelos. Esse overlap indica que a captura eletrônica pode acontecer em um contínuo de energias, entre $\sim 0 \mathrm{eV}$ e cerca de $1.8 \sim 1.9 \mathrm{eV}$.

O efeito das estabilizações das ressonâncias $\pi^{*}$ da uracila favorece a captura eletrônica e, como consequência, os processos de DEA em solução. O fato de mais da metade da distribuição térmica dos estados $\pi_{1}^{*}$ serem ligados também favorece processos de DEA, uma vez que a captura eletrônica pode formar ânions estáveis com energias vibracionais suficientes para promover dissociações. Um resultado experimental relevante para a discussão foi publicado recentemente por Poštulka et al. [99], no qual clusters de $\mathrm{U}\left[\mathrm{H}_{2} \mathrm{O}\right]_{n}$, com $n \leq 7$, foram atingidos por elétrons de energias calibradas em $1.2 \mathrm{eV}$, e as medidas de transferência de energia vibracional indica a formação de ressonâncias nessa faixa, o que pode ser explicado pelos resultados aqui 
apresentados, apesar das diferenças em temperatura, tamanhos dos clusters e possivelmente geometrias dificultarem uma comparação ainda mais realista. De qualquer forma, como espera-se que as ressonâncias sejam deslocadas, com relação as mesmas em fase gasosa, em clsuters de diferentes números de moléculas de água[91, 92], a distribuição térmica pode favorecer a captura eletrônica nessa energia.

Quanto às larguras, as distribuições térmicas representadas pelos histogramas na Fig. 6.12 correspondem a distribuições de tempos de vida dos estados aniônicos transientes associados. Se considerarmos, por exemplo, variações dentro do intervalo de $\pm 1 \sigma$ nas distribuições das larguras, os tempos de vida correspondentes das ressonâncias $\pi_{1}^{*}$ variam de 20 fs à 165 fs, enquanto que para os estados $\pi_{2}^{*}$ os tempos de vida variam de 4 fs à 10 fs - em que aqui consideramos os tempos de vida verticais, isto é, sem considerar relaxação vibracional. Essas distribuições térmicas de tempos de vida acabam sendo portanto significativas, uma vez que cálculos recentes[104, 110] a respeito de dinâmicas pré-dissociativas de estados $\pi^{*}$, com VAEs da cerca de $\approx 1.5 \mathrm{eV}$, indicam escalas de tempo tipicamente da ordem de $20 \mathrm{fs}$.

No mais, temos que os Modelos I e II se mostraram muito próximos entre si, no sentido em que ambos fornecem estimativas equivalentes de distribuições térmicas de posição e largura, mais particularmente no que diz respeito a médias e desvios padrão. A princípio, deve ser possível encontrar outras propriedades moleculares que correlacionam fortemente com parâmetros usados para descrever ressonâncias, como foi observado para os VOEs nos ajustes dispostos da Fig. 6.6. A saber, Sieradzka e Gorfinkiel observaram em um recente estudo[91] uma correlação entre o efeito de estabilização de ressonâncias $\pi^{*}$ da molécula de piridina micro-solvatada com o momento de dipolo dos clusters neutros de piridina- $\left[\mathrm{H}_{2} \mathrm{O}\right]_{n}$, embora os mesmos não tenham observado a mesma tendência para clusters de timina- $\left[\mathrm{H}_{2} \mathrm{O}\right]_{n}[92]$. Para o caso da uracila, não observamos nenhuma correlação entre as energas dos orbitais virtuais HF /6-31G*, que por sua vez correlacionam fortemente com o efeito das estabilizações promovidas pelas moléculas de água, com momentos de dipolo dos agregados neutros. A Fig. 6.15 contempla gráficos dos VOEs em função dos momentos de dipolo dos 
133 clusters $\mathrm{U}\left[\mathrm{H}_{2} \mathrm{O}\right]_{6}$ neutros, em D, calculados no nível DFT/B3LYP/aug-cc-pVDZ, e podemos ver claramente que não há uma correlação entre essas propriedades. A
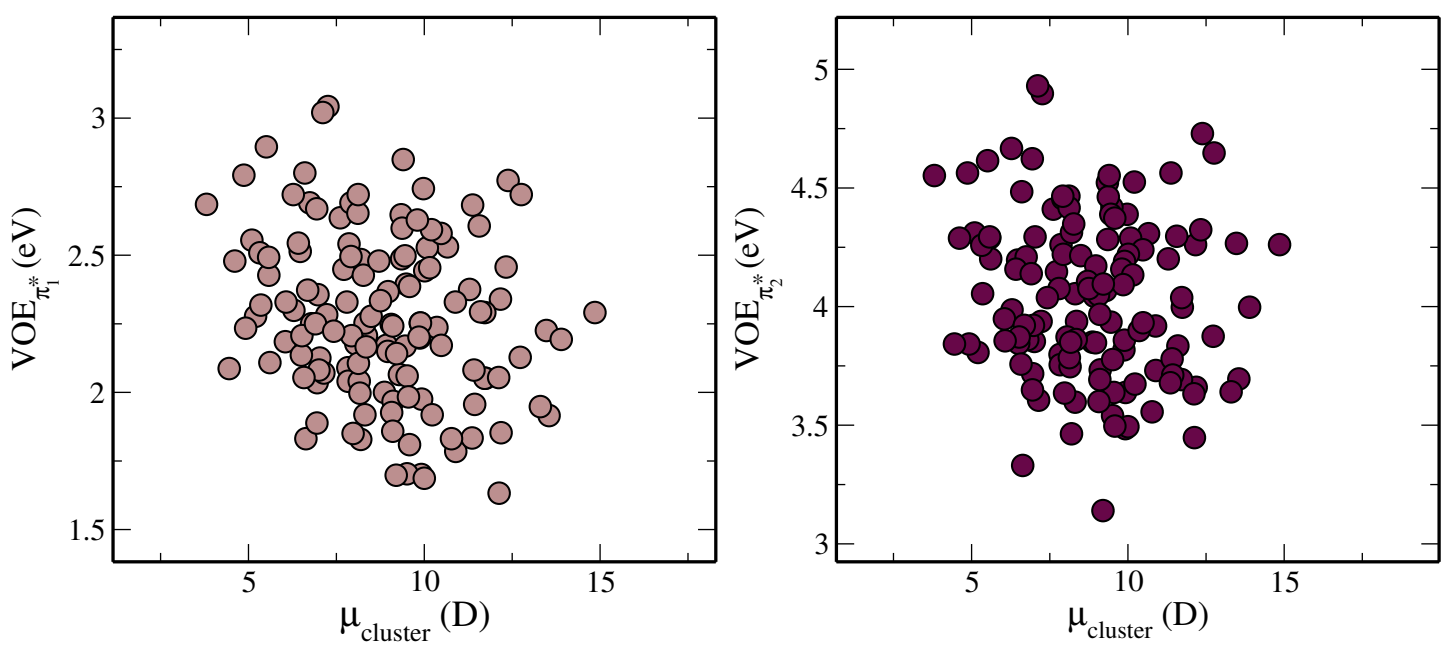

Figura 6.15: Gráficos de dispersão entre as energias dos orbitais virtuais $\pi_{1}^{*}$ (à esquerda) e $\pi_{2}^{*}$ (à direita) em função dos momentos de dipolo dos clusters $\mathrm{U}\left[\mathrm{H}_{2} \mathrm{O}\right]_{6}$ neutros, $\mu_{\text {cluster }}$, calculados no nível DFT/B3LYP/aug-cc-pVDZ, em D.

título de esclarescimento, os momentos de dipolo dos clusters em questão constituem uma distribuição térmica de valores em torno de $9.21 \mathrm{D}$ com desvio padrão de 2.38 D. Isso mostra que os clusters considerados são fortemente polares.

Um último comentário que pode ser feito diz respeito à relação entre os efeitos do solvente nos VAEs dos estados $\pi_{1}^{*}$ e $\pi_{2}^{*}$. Podemos nos perguntar se a estabilização ou desestabilização em um estado implica em uma sistemática correspondência no outro. A pergunta pode ser respondida olhando a relação entre os VOEs. A Fig. 6.16 mostra as energias dos VOs $\pi_{1}^{*}$ contra as energias dos VOs $\pi_{2}^{*}$ para a uracila em fase gasosa e para os 133 clusters $\mathrm{U}\left[\mathrm{H}_{2} \mathrm{O}\right]_{6}$ considerados no estudo. Observamos um indicativo de que o efeito é de fato sistemático. Vemos que em 129 agregados o solvente estabiliza ambos VOEs, e em 2 deles o efeito é de desestabilização. A distribuição em torno da linha tracejada cinza indica que a magnitude do efeito é respeitada para as duas energias. Em apenas 2 casos $(\sim 1.5 \%)$ o solvente desestabiliza o VOE $\pi_{1}^{*}$ ao mesmo tempo que estabiliza o VOE $\pi_{2}^{*}$. Contudo, nesses casos as comparações com os valores correspondentes à fase gasosa são diferenças comparáveis aos desvios das respectivas distribuições da Fig. 6.10. 


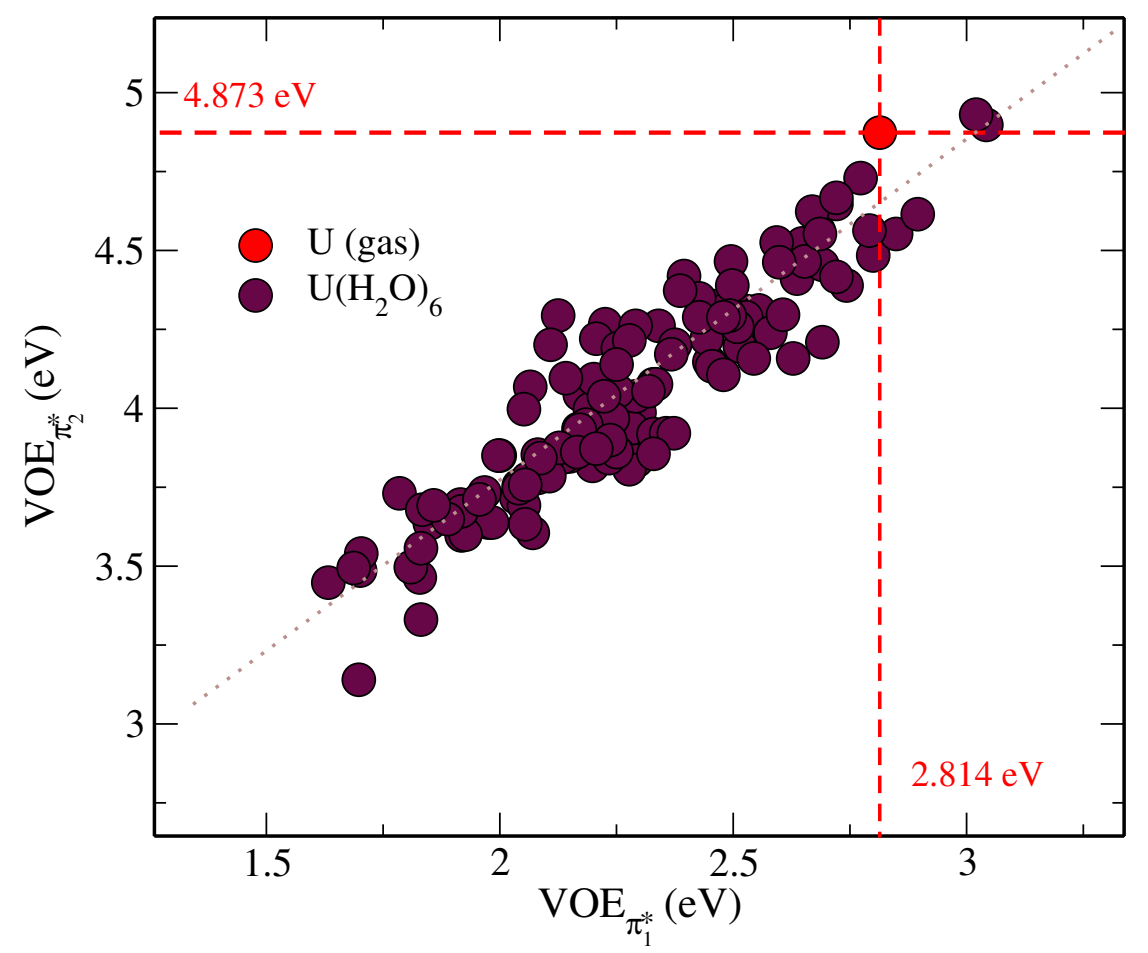

Figura 6.16: Energias dos orbitais virtuais $\mathrm{HF} / 6-31 \mathrm{G}^{*} \pi_{1}^{*}$ como função das energias dos VOs $\pi_{2}^{*}$ para a uracila em fase gasosa (vermelho) e para os 133 clusters estatisticamente descorrelacionados $\mathrm{U}\left[\mathrm{H}_{2} \mathrm{O}\right]_{6}$ (roxo).

Nas duas seções a seguir discorro sobre os resultados obtidos para a timina microsolvatada e para as quatro 5-halouracilas micro-solvatadas. Os estudos desses sistemas foram baseados no que foi realizado e apresentado para a uracila.

\subsection{Timina}

Nesta seção dedico-me a apresentar o estudo feito sobre o efeito do solvente nas ressonâncias de forma $\pi^{*}$ da timina $(\mathrm{T})$. Experimentos de transferência eletrônica observam a formação de ressonâncias da timina em $0.29 \mathrm{eV}\left(\pi_{1}^{*}\right)$ e $1.71 \mathrm{eV}\left(\pi_{2}^{*}\right)[111]$. A ressonância $\pi_{1}^{*}$ da $\mathrm{T}$ isolada se apresenta em energias compatíveis à das ressonâncias $\pi_{1}^{*}$ da $\mathrm{U}(0.22 \mathrm{eV})$, enquanto que pra $\pi_{2}^{*}$ se encontra em uma energia $\sim 0.13 \mathrm{eV}$ mais alta do que a da $\mathrm{U}(1.58 \mathrm{eV})$. Trabalhos teóricos baseados no método SMC para a descrição das ressonâncias de forma da $\mathrm{U}$ e $\mathrm{T}$ isoladas podem ser comparados. Cálculos na aproximação ETP apontam as duas primeiras ressonâncias $\pi^{*}$ da U em $0.14 \mathrm{eV}$ e $1.76 \mathrm{eV}[4]$, enquanto que as duas primeiras ressonâncias da T encontram-se 
em 0.3 eV e 1.9 eV[5]. Já na aproximação ET as mesmas ressonâncias aparecem em 2.27 eV e 4.04 eV para U e 2.23 eV e 4.27 eV para a T. Além de trabalhos envolvendo o método SMC, podemos citar o estudo de Tonzani et al[6], que também aponta que as ressonâncias $\pi^{*}$ da timina estão sistematicamente deslocadas para energias maiores, quando comparadas com a uracila. Seus resultados estimam diferenças entre $2.4 \mathrm{eV}$ (T) contra $2.2 \mathrm{eV}(\mathrm{U})$ para a $\pi_{1}^{*}$ e $5.5 \mathrm{eV}(\mathrm{T})$ contra $4.9 \mathrm{eV}(\mathrm{U})$ para a $\pi_{2}^{*}$, em que todos os valores foram obtidos com cálculos que podem ser comparáveis com nossos cálculos ET.

O trabalho de Sieradzka e Gorfinkiel[92], publicado em 2017, estima que as duas primeiras ressonâncias $\pi^{*}$ são estabilizadas devido a presença de moléculas de água. O estudo foi realizado também com técnicas de micro-solvatação com $n=1,2,3,5$. Empregando técnicas de espalhamento baseadas na matriz-R, os autores apontam que a estabilização devida à água é diferente para a $\pi_{1}^{*}$ e para a $\pi_{2}^{*}$, e vale mencionar que muitos dos cálculos foram realizados apenas na aproximação ET, devido ao alto custo computacional que os cálculos requerem. Apesar disso, não houve discussão sobre a distribuição térmica dos clusters, que aqui avaliamos como um passo importante para podermos conectar estudos de sistemas micro-solvatados com fase condensada à temperatura finita.

O objetivo dessa etapa do trabalho foi expandir a aplicação dos modelos lineares obtidos para a uracila, na seção anterior, agora para a timina, com o intuito de investigar efeitos do solvente sob o ponto de vista termoestatístico. No caso, combinamos novamente simulações clássicas com modelos de micro-solvatação para selecionar clusters de $\mathrm{T}\left[\mathrm{H}_{2} \mathrm{O}\right]_{n}$, e pouco mais que 100 agregados foram utilizados no estudo. Não sabemos de antemão se a distribuição de ligações de hidrogênio solutosolvente é similar àquela obtida para a uracila, ou se as distribuições de VOEs são comparáveis. Os resultados mostrados a seguir dizem respeito à simulação MC, à seleção dos agregados, e posteriormente às estimativas das distribuições térmicas das ressonâncias.

A geometria da timina isolada foi primeiramente otimizada no nível B3LYP/aug- 
cc-pVDZ. A simulação MC foram realizadas sob as mesmas condições que no caso da uracila. Foi utilizado o ensemble NPT à temperatura $T=298.15 \mathrm{~K}$ e $p=1.0$ atm, assim como o potencial de LJ acrescido da interação de Coulomb (equação 5.13) para descrever a interação intermolecular, e os campos de força adotados para o solvente e o soluto foram, respectivamente, SPC/E e OPLS/CHELPg. As cargas CHELPg do soluto também foram obtidas através de um cálculo single point no nível $\mathrm{PCM}\left(\right.$ água)/MP2/6-31G* . Depois de uma termalização de $2 \times 10^{5}$ ciclos $\mathrm{MC}, 4 \times 10^{5}$ ciclos de MC foram simulados para a amostragem. Dentre as configurações geradas foram impressas 133 configurações estatisticamente descorrelacionadas. A função de descorrelação ajustada foi uma expressão biexponencial do tipo 5.20 e o critério para o intervalo de descorrelação foi estabelecido como sendo o que faz $C(t)<13 \%$. As médias obtidas de densidade de massa $\langle\rho\rangle=1.023 \pm 0.007 \mathrm{~g} / \mathrm{cm}^{3}$, energia por molécula $\langle U / N\rangle=-35.4 \pm 0.06 \mathrm{kcal} / \mathrm{mol}$ e entalpia conformacional por molécula $\left\langle H_{c} / N\right\rangle=-11.53 \pm 0.05 \mathrm{kcal} / \mathrm{mol}$ são compatíveis com o campo de força SPC/E[75].

Realizou-se em seguida o estudo das distribuição radial de pares $G(r)$, com o intuito de identificarmos a camada de micro-solvatação. A $G(r)$ de mínima distância
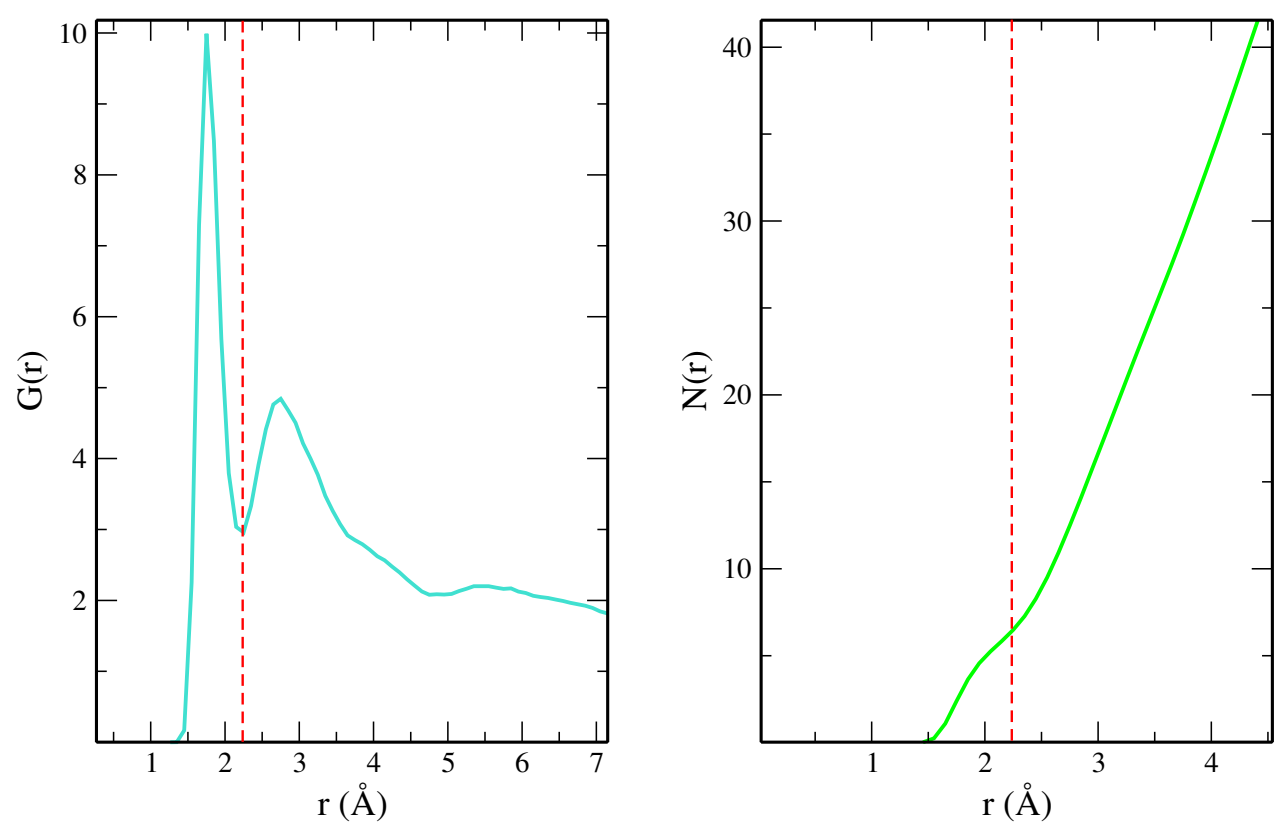

Figura 6.17: MDDF, à esquerda, e o número médio de moléculas obtido pela integral da distribuição $G(r)$, à direita, da simulação da timina. 
apresentada na Fig. 6.17 (painel esquerdo) mostra essencialmente o que foi observado para a U. O primeiro mínimo local em cerca de $\sim 2.3 \AA$ mostra a existência de uma camada de micro-solvatação de mesmas características da anterior, e sua integral entre $r=0$ e $r \sim 2.3 \AA$ aponta que o número de moléculas na camada (painel direito da Fig. 6.17) é $n=6$. Analisando a distribuição de ligações de hidrogênio soluto-solvente no subconjunto das 133 configurações descorrelacionadas estimou-se que a média do número dessas ligações é 6 , em que cada um dos oxigênios da uracila assume o papel de aceitador de duas ligações e cada um dos dois hidrogênios ligados aos nitrogênios (H-N) assume o papel de doador de uma ligação de hidrogênio, em média. Esses valores médios das distribuições de ligações de hidrogênio são uma boa representação dos resultados da simulação. A representatividade de configurações correspondentes aos números médios de ligações de hidrogênio parece ser razoável quando, novamente, olhamos para as distribuições de pares entre átomos participantes das ligações. Obteve-se comportamentos muito similares ao mostrado para o estudo da U na Fig. 6.2. Na nossa descrição, o grupo $\mathrm{CH}_{3}$ da timina parece não alterar números médios de ligações de hidrogênio, tampouco as distâncias típicas dessas ligações.

O primeiro passo dessa vez foi olhar para as distribuições térmicas das energias dos VOs no nível HF/6-31G*. Esse primeiro passo foi estimulado pela forte correlação entre efeitos de estabilização e energia dos VOs mostrada na Fig. 6.6, e assim buscouse uma única configuração representativa, sob esse aspecto, para realizar o cálculo de espalhamento. A Fig. 6.18 mostra a distribuição obtida para os VOEs associados aos estados aniônicos $\pi_{1}^{*}$ e $\pi_{2}^{*}$ dos agregados. Os ajustes gaussianos das distribuições deram origem aos valores médios $\left\langle\operatorname{VOE}_{\pi_{1}^{*}}\right\rangle=2.459 \pm 0.246 \mathrm{eV}$ e $\left\langle\mathrm{VOE}_{\pi_{2}^{*}}\right\rangle=4.126 \pm$ $0.287 \mathrm{eV}$. Nota-se que esses valores são maiores (uma diferença entre $\sim 0.1 \mathrm{eV}$ e $\sim 0.2 \mathrm{eV}$ ) do que os valores médios das distribuições de VOEs dos estados $\pi^{*}$ da U. As larguras associadas aos desvios padrão, entretanto, são comparáveis. Temos também que o mesmo overlap entre as distribuições que observamos no caso da uracila está presente aqui, o que sugere que ao associar VOEs e energias das ressonâncias 


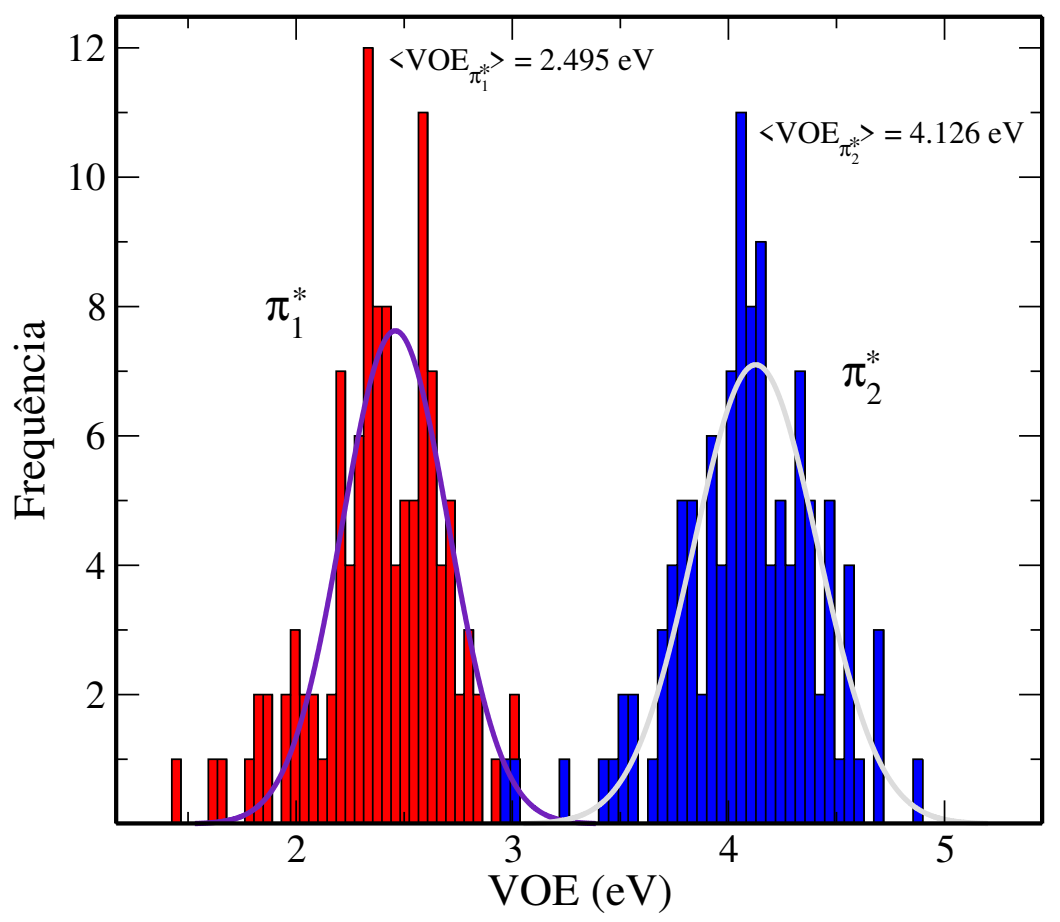

Figura 6.18: Distribuição térmica de VOEs referentes aos estados $\pi_{1}^{*}$ e $\pi_{2}^{*}$ sobre o conjunto de 133 agregados de $\mathrm{T}\left[\mathrm{H}_{2} \mathrm{O}\right]_{6}$ à temperatura $T=298.15 \mathrm{~K}$. Os orbitais virtuais e suas energias foram obtidas no nível $\mathrm{HF} / 6-31 \mathrm{G}^{*}$.

esperamos que o sistema admita a captura eletrônica em um contínuo de energias.

O cluster nomeado $\overline{\mathrm{C}}$ foi selecionado dentre os 133 agregados descorrelacionados e seus valores de VOE fossem próximos às médias obtidas das distribuições para os dois estados, simultaneamente. No caso, essas energias são $2.443 \mathrm{eV}$ e $4.146 \mathrm{eV}$ para $\pi_{1}^{*}$ e $\pi_{2}^{*}$, respectivamente (Fig. 6.19). A existência de um cluster representativo tanto no sentido das energias dos $\mathrm{VOs} \mathrm{HF} / 6-31 \mathrm{G}^{*}$ quando das médias de ligação de hidrogênio soluto-solvente, em cada átomo, sugere um protocolo para calcularmos um efeito médio do solvente abordando apenas uma única configuração.

A Fig. 6.20 mostra a seção de choque para o espalhamento eletrônico elástico, na aproximação ET, pelo cluster $\overline{\mathrm{C}}$. Na figura também estão indicados os resultados das posições das ressonâncias $\pi_{1}^{*}$ e $\pi_{2}^{*}$ da $\mathrm{T}$ isolada, reportados pelos trabalhos de Winstead et al[5] e Tonzani et al[6]. As estruturas na seção de choque correspondentes aos estados aniônicos do cluster se encontram em $1.84 \mathrm{eV}\left(\pi_{1}^{*}\right)$ e $3.65 \mathrm{eV}\left(\pi_{2}^{*}\right)$, onde vemos a estabilização sistemática das ressonâncias induzidas pela presença da microsolvatação. As larguras das ressonâncias são 0.20 eV e 0.22 eV, onde observamos 

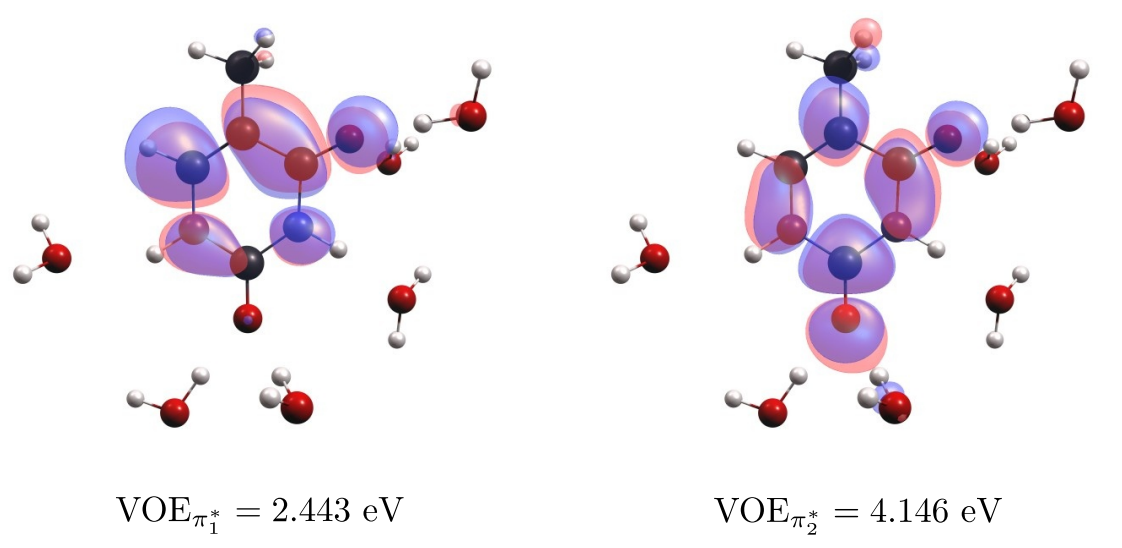

Figura 6.19: Estrutura do cluster $\overline{\mathrm{C}}$ do sistema $\mathrm{T}\left[\mathrm{H}_{2} \mathrm{O}\right]_{6}$. Os VOs correspondentes aos estados $\pi_{1}^{*}$ e $\pi_{2}^{*}$, assim como suas energias $\mathrm{HF} / 6-31 \mathrm{G}^{*}$, estão mostrados na esquerda e direita, respectivamente.

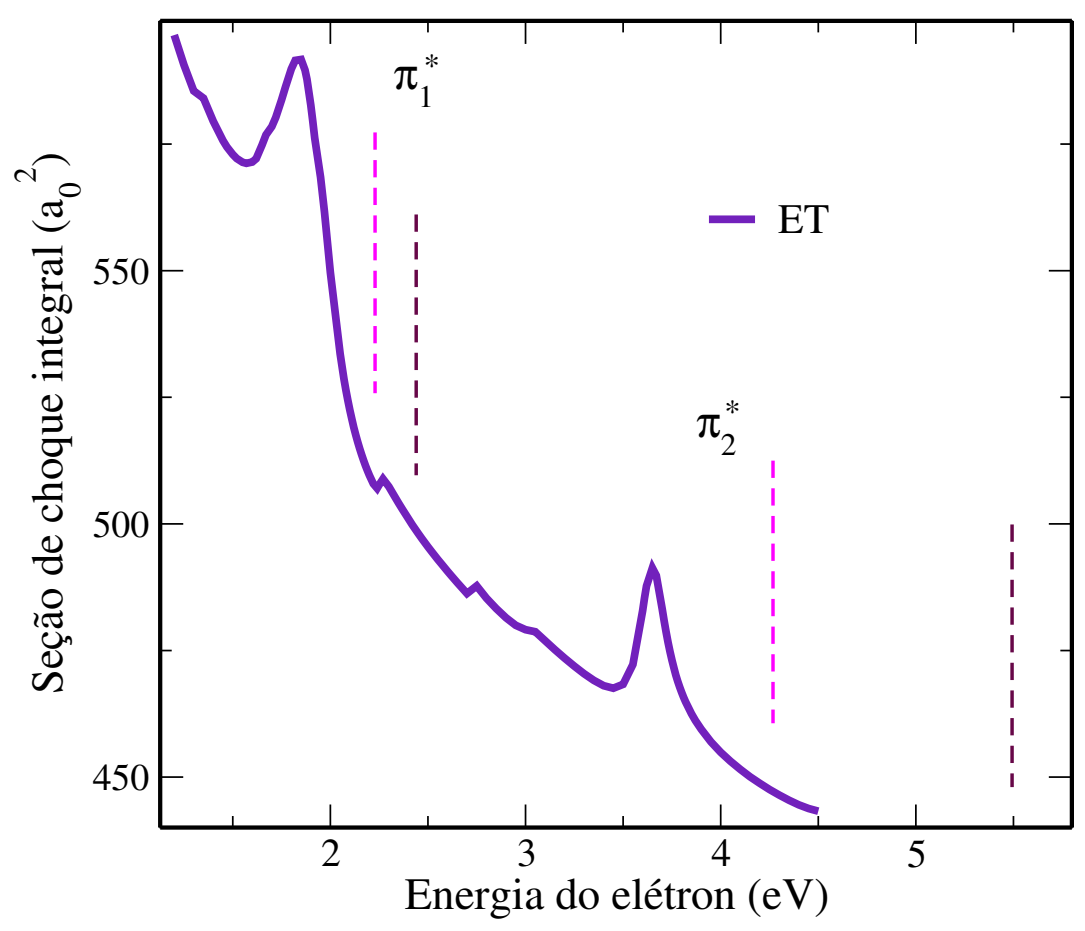

Figura 6.20: Seção de choque integral para o espalhamento eletrônico elástico pelo cluster $\overline{\mathrm{C}}$ da $\mathrm{T}\left[\mathrm{H}_{2} \mathrm{O}\right]_{6}$, na aproximação ET. As duas estruturas na curva sólida representam as ressonâncias $\pi_{1}^{*}$ e $\pi_{2}^{*}$, como indicado. As linhas tracejadas correspondem a resultados ET para a timina em fase gasosa reportados por Winstead et al[5] (linha tracejada rosa) e Tonzani et al[6] (linha tracejada marrom).

uma incompatibilidade com os valores obtidos para os clusters C1-C5 e $\overline{\mathrm{C}}$ estudados no caso da U. Apontamos essa incompatibilidade como uma deficiência do cálculo de espalhamento na aproximação ET, que apesar de qualitativamente correto, não 
se apresentou capaz de descrever as larguras de maneira razoável, e assim não foi possível compará-las com os dados da T isolada. Melhorias nos cálculos ET podem ser realizadas no futuro, como aumento de quadratura para a resolução dos elementos de matriz presentes na expressão funcional da amplitude de espalhamento. No presente, isso não foi feito por questões de comparação entre os resultados de diferentes sistemas além de termos evitado mais esforços computacionais.

Se utilizássemos as equações 6.1 e 6.2 para estimarmos as posições das ressonâncias diretamente dos VOEs, obteríamos $E_{\mathrm{ET}}^{\pi_{1}^{*}}=1.84 \mathrm{eV}$ e $E_{\mathrm{ET}}^{\pi_{2}^{*}}=3.62 \mathrm{eV}$, que são valores perfeitamente compatíveis com os obtidos nos cálculos de espalhamento. Assumimos portanto que essas regressões lineares, obtidas para a U, podem funcionar bem para os estados $\pi^{*}$ da T. Resta saber se podemos relacionar as energias ET, estimadas pelas regressões lineares, com valores estimados ETP pela relação 6.3 (Modelo I) ou 6.4 (Modelo II). Segundo essas relações, as energias das ressonâncias $\pi_{1}^{*}$ e $\pi_{2}^{*}$ estão estimadas respectivamente em $0.08 \mathrm{eV}$ e $1.73 \mathrm{eV}$ (Modelo I) ou em $0.10 \mathrm{eV}$ e 1.57 eV (Modelo II). Uma forma de testar a relação seria checar se a mesma funciona suficientemente bem para os dados da $\mathrm{T}$ isolada. Winstead et al[5] usaram a mesma estratégia de polarização para realizar os cálculos de espalhamento para a T, e as energias ETP (ET) das ressonâncias $\pi_{1}^{*}$ e $\pi_{2}^{*}$ reportadas foram $0.3 \mathrm{eV}(2.2 \mathrm{eV})$ e 1.9 eV $(4.3 \mathrm{eV})$. Dessa forma, aplicando a relação ET $\rightarrow$ ETP sobre os valores ET obtemos estimativas de $0.47 \mathrm{eV}$ e $2.3 \mathrm{eV}$ segundo o Modelo I, e $0.39 \mathrm{eV}$ e $2.1 \mathrm{eV}$. Apesar de estarem $0.09 \sim 0.2 \mathrm{eV}$ acima, consideramos que a compatibilidade é suficientemente razoável para que possamos aplicar os ajustes. Assim, também no caso dos clusters $\mathrm{T}\left[\mathrm{H}_{2} \mathrm{O}\right]_{6}$, o mapeamento das posições das ressonâncias, diretamente do VOEs, serão dados pelas equações 6.5 e 6.6 (Modelo I), e 6.7 e 6.8 (Modelo II). A distribuição térmica dos VAEs, obtidas diretamente da distribuição dos VOEs via equações 6.5 e 6.6 (Modelo I) e equações 6.7 e 6.8 (Modelo II), sobre o conjunto total de 133 configurações descorrelacionadas, estão mostradas na Fig. 6.21. Em contraposição ao que foi observado para U, observou-se aqui que em ambos os modelos os estados $\pi_{1}^{*}$ são estados ressonantes em mais de $60 \%$ dos agregados - $66 \%$ no Modelo I e 


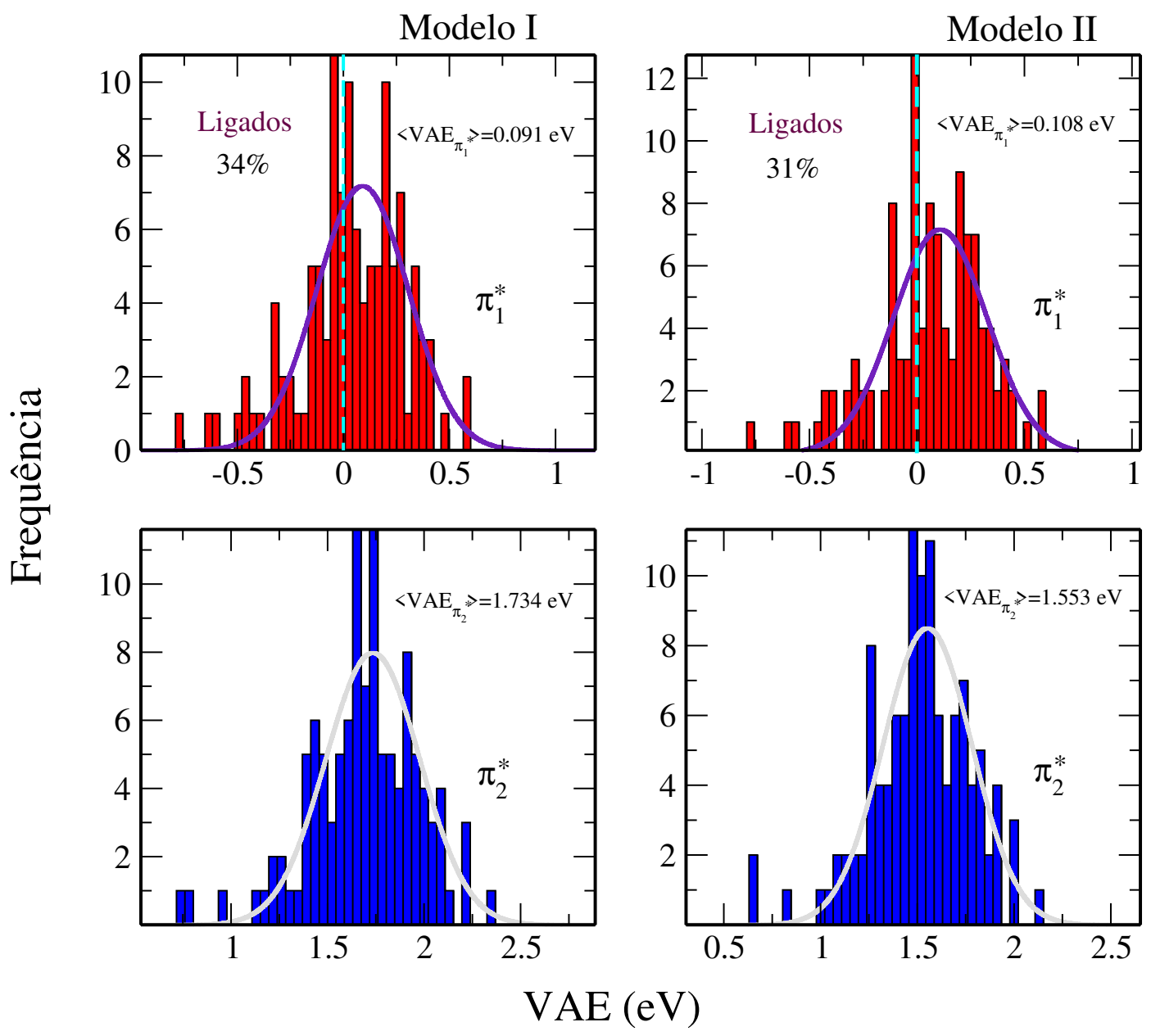

Figura 6.21: Distribuições térmicas de VAEs $\pi_{1}^{*}$ e $\pi_{2}^{*}$ obtidas sobre o conjunto de 133 configurações $\mathrm{T}\left[\mathrm{H}_{2} \mathrm{O}\right]_{6}$ estatisticamente descorrelacionadas à temperatura $T=298 \mathrm{~K}$. O Modelo I (à esquerda) foi obtido das equações 6.5 e 6.6, enquanto que o Modelo II (à direita) das equações 6.7 e 6.8 .

69\% no Modelo II. Os valores médios das distribuições referentes aos estados $\pi_{1}^{*}$ são assim positivas, e valem respectivamente $91 \mathrm{meV}$ e $108 \mathrm{meV}$ para o Modelo I e para o Modelo II. Essa diferença entre os resultados é pequena quando comparada às larguras das distribuições (desvios padrão), cujo valor obtido foi $\sigma=0.22 \mathrm{eV}$ para ambos os Modelos. Quanto aos estados $\pi_{2}^{*}$, obteve-se valores positivos de VAEs para toda a distribuição de agregados - descrevendo ressonâncias, efetivamente - e seus valores médios foram estimados em $(1.73 \pm 0.25) \mathrm{eV}$ e $(1.55 \pm 0.23) \mathrm{eV}$ para os Modelos I e II. As incertezas dos valores correspondem aos respectivos desvios padrão. Vale por fim notar que as equações 6.5 - 6.8, juntamente com as energias dos orbitais virtuais mostrados na Fig. 6.5, predizem valores de VAE para o cluster $\overline{\mathrm{C}}$ muito próximos das médias obtidas. 
Por fim, estudou-se a distribuição térmica das larguras dos estados aniônicos ressonantes. Na Fig. 6.22 encontram-se quatro panéis, correspondendo às distribuições das larguras dos estados $\pi_{1}^{*}$ e $\pi_{2}^{*}$, segundo os Modelos I e II. Novamente,

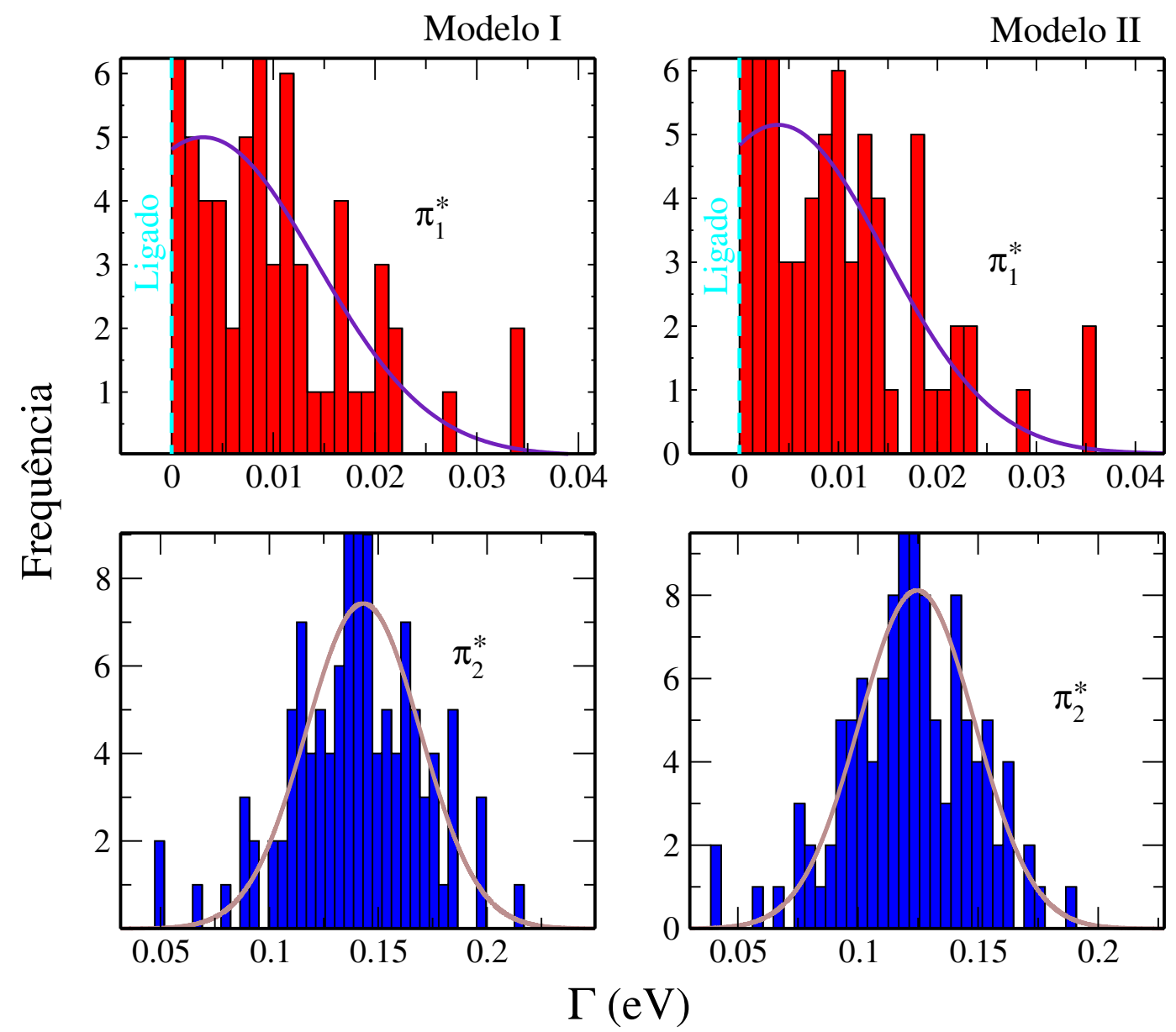

Figura 6.22: Distribuição térmica das larguras de auto-ionização $(\Gamma)$ dos estados aniônicos $\pi_{1}^{*}$ e $\pi_{2}^{*}$ calculados sobre o conjunto de 133 configurações estatisticamente descorrelacionadas, à temperatura $T=298 \mathrm{~K}$. Os dois painéis à esquerda e os dois painéis à direita foram obtidos com os Modelos I e II, respectivamente.

no caso dos estados $\pi_{1}^{*}$, as médias foram obtidas apenas sobre os estados ressonantes da distribuição. Os valores obtidos foram $\left\langle\Gamma_{\pi_{1}^{*}}\right\rangle=(0.010 \pm 0.008) \mathrm{eV}$ (Modelo I) e $\left\langle\Gamma_{\pi_{1}^{*}}\right\rangle=(0.010 \pm 0.008) \mathrm{eV}$ (Modelo II). Quanto ao estado $\pi_{2}^{*}$, as distribuições térmicas de larguras são distribuições estritamente positivos. Calculou-se assim os valores médios e desvios de forma usual, sobre todos os valores das distribuições, e oobtivemos $\left\langle\Gamma_{\pi_{2}^{*}}\right\rangle=(0.143 \pm 0.026) \mathrm{eV}$ e $\left\langle\Gamma_{\pi_{2}^{*}}\right\rangle=(0.126 \pm 0.024) \mathrm{eV}$ para os Modelos I e II, respectivamente.

Finalizamos aqui a apresentação dos resultados para a timina. O efeito das es- 
tabilizações das ressonâncias $\pi^{*}$ da timina devido à presença do solvente favorece a captura eletrônica e, como consequência, os processos de DEA em solução. A timina difere da uracila no que diz respeito aos valores e distribuições das energias, em que agora cerca de um terço dos clusters admitem o estado $\pi_{1}^{*}$ como ligado. Como dito anteriormente, os estados ligados também podem favorecer o processo dissociativo, uma vez que a captura eletrônica pode formar ânions estáveis com energias vibracionais suficientes para promover dissociações.

As distribuições térmicas de tempos de vida das ressonâncias podem ser obtidas diretamente das distribuições térmicas de larguras representadas pelos histogramas na Fig. 6.22. Se considerarmos, por exemplo, variações dentro do intervalo de $\pm 1 \sigma$ nas distribuições das larguras, os tempos de vida correspondentes das ressonâncias $\pi_{1}^{*}$ variam de $36 \mathrm{fs}$ à $330 \mathrm{fs}$, enquanto que para os estados $\pi_{2}^{*}$ os tempos de vida variam de 4 fs à 6 fs - em que aqui consideramos os tempos de vida sem considerar relaxação vibracional.

\subsection{Halouracilas}

Seguimos agora para o estudo das 5-halouracilas. Como apresentado no capítulo 1, as halouracilas consideradas possuem um halogênio (F,Cl,Br ou I) ligado ao carbono C5 ao invés do hidrogênio (no caso da uracila) ou do grupo $\mathrm{CH}_{3}$ (no caso da timina). Os quatro casos foram considerados.

Observou-se que a presença do halogênio na molécula a torna capaz de admitir um estado aniônico de caráter $\sigma_{\mathrm{CX}}^{*}$, em que $\mathrm{X}=\mathrm{F}, \mathrm{Cl}, \mathrm{Br}, \mathrm{I}$, na região de Franck-Condon do sistema neutro. Esses estados possuem papéis importantes nas propriedades radiossensibilizadoras das halouracilas, pois participam do acoplamento $\pi^{*} / \sigma^{*}$ na dinâmica de pré-dissociação - no caso, relativa à eliminação do halogênio. Os estados ressonantes das halouracilas em baixas energias foram medidos experimentalmente por experimentos de transferência eletrônica, e medidas de seção de choque de DEA foram reportadas para a 5-FU, 5-ClU e 5-BrU[112], todas em fase gasosa. Cálculos de espalhamento foram realizados para as moléculas isoladas, de forma que os estados 
ligados e as ressonâncias de forma $\pi^{*}$ e $\sigma^{*}$ possuem energias e larguras reportadas na literatura[4, 9], e no que segue será apresentado um breve resumo dos resultados obtidos

No caso da 5-FU, os cálculos de espalhamento realizados com o método SMC apontam um estado $\pi_{1}^{*}$ fracamente ligado, em $-0.09 \mathrm{eV}$ e um estado $\pi_{2}^{*}$ em $1.7 \mathrm{eV}$. Na aproximação ET esses mesmos estados aparecem em 1.82 eV e 4.02 eV, respectivamente. Nenhuma assinatura referente ao estado $\sigma_{\mathrm{CF}}^{*}$ foi observado na seção de choque.

No caso da 5-ClU observa-se o estado $\pi_{1}^{*}$ ligado em -0.23 eV e o estado $\pi_{2}^{*}$ em 1.63 eV. Esses mesmos estados aparecem na seção de choque ET como estruturas em 1.69 $\mathrm{eV}$ e $3.97 \mathrm{eV}$, respectivamente. Um estado de natureza $\sigma_{\mathrm{CCl}}^{*}$ foi observado como uma larga estrutura na seção de choque em torno de $2.54 \mathrm{eV}$, na aproximação ETP, e 4.8 eV, na aproximação ET.

No caso da 5-BrU observa-se o estado $\pi_{1}^{*}$ ligado em -0.30 eV e o estado $\pi_{2}^{*}$ em 1.50 eV. Esses mesmos estados aparecem na seção de choque ET como estruturas em 1.74 $\mathrm{eV}$ e $3.92 \mathrm{eV}$, respectivamente. Um estado de natureza $\sigma_{\mathrm{CBr}}^{*}$ foi observado como uma evidente estrutura na seção de choque em torno de $3.7 \mathrm{eV}$, na aproximação ET, porém nenhuma estrutura correspondente pôde ser observada na seção de choque ETP. Kossoski et al apontaram o estado $\sigma_{\mathrm{CBr}}^{*}$ como efetivamente existente, mas obscurecido pelo seção de choque de fundo. Um fenômeno equivalente ocorreu na descrição ETP do estado $\pi_{1}^{*}$ do cluster $\overline{\mathrm{C}}$ da $\mathrm{U}\left[\mathrm{H}_{2} \mathrm{O}\right]_{6}$. A estimativa da posição e largura do estado $\sigma_{\mathrm{CBr}}^{*}$ foi então realizada a partir de cálculos de espalhamento auxiliares, cada qual com uma particular polarização, além de um ajuste extrapolado. O resultado obtido foi uma posição em torno de $0.73 \mathrm{eV}$.

No caso da 5-IU observa-se dois estados ligados de valência, dentre os quais o próprio estado $\sigma_{\mathrm{CI}}^{*}$. A saber, o estado ligado $\pi_{1}^{*}$ possui uma energia estimada em $-0.35 \mathrm{eV}$ e o estado ligado $\sigma_{\mathrm{CI}}^{*}$ se encontra em $-0.1 \mathrm{eV}$. A ressonância $\pi_{2}^{*}$ foi observada em $1.54 \mathrm{eV}$. Na aproximação ET, os estados $\pi_{1}^{*}, \sigma_{\mathrm{CI}}^{*}$ e $\pi_{2}^{*}$ aparecem em $1.78 \mathrm{eV}, 2.1$ $\mathrm{eV}$ e $3.86 \mathrm{eV}$, respectivamente. 
Uma das observações que pode ser feita é do efeito de estabilização dos estados frente à troca do halogênio. De fato, vemos uma estabilização dos estados aniônicos, em energia, crescente com a massa/número atômico do halogênio. Quando o número atômico do halogênio cresce $(\mathrm{F} \rightarrow \mathrm{I})$ vemos o estado ligado $\pi_{1}^{*}$ assumir valores cada vez menores em energia, assim como a ressonância $\pi_{2}^{*}$. O efeito de estabilização nos estados $\sigma^{*}$ é ainda mais significativo, no sentido que a energia decresce de maneira muito mais apreciada.

O objetivo dessa etapa do trabalho se dá acerca do estudo do efeito do solvente nos estados aniônicos dos quatro sistemas, com o uso das mesmas técnicas de microsolvatação. Ao que se sabe, não há estudos teóricos sobre estimativas de ressonâncias e/ou estados ligados de valência do ânion para as halouracilas em solução. Trabalhouse nas estimativas das distribuições térmicas de VAEs e larguras, no caso de ressonâncias, de maneira análoga ao que foi realizado para a uracila e timina, mostrado nas seções anteriores.

As geometrias das halouracilas isoladas foram otimizadas no nível B3LYP/augcc-pVDZ. Para o iodo, foi utilizada a base implementada com pseudopotenciais LANL2DZP-ECP durante a otimização. As simulações MC foram realizadas nas mesmas condições que nos casos anteriores. Cada uma das moléculas, juntamente com 1000 moléculas de água, foram incluídas na caixa de simulção mantida à temperatura $T=298.15 \mathrm{~K}$ e pressão $p=1.0 \mathrm{~atm}$ (ensemble NPT). Novamente, o potencial de LJ acrescido da interação de Coulomb (equação 5.13) foi empregado para descrever a interação intermolecular, e os campos de força adotados para o solvente e os solutos foram, respectivamente, SPC/E e OPLS/CHELPg. As cargas CHELPg dos solutos foram obtidas através de cálculos single point no nível PCM(água)/MP2/6-31G*. O conjunto de parâmetros $\epsilon$ e $\sigma$ para os átomos do soluto são basicamente os mesmos da uracila e da timina, com exceção do halogênio. O campo de força OPLS para halogênios em solução aquosa foi parametrizado e os valores utilizados podem ser encontrados na referência[113]. Depois de uma termalização de $2 \times 10^{5}$ ciclos $\mathrm{MC}, 4 \times 10^{5}$ ciclos de MC foram simulados para a amostragem em cada uma das quatro simulações. 
Em cada caso, foram impressas 133 configurações estatisticamente descorrelacionadas dentre as configurações geradas. A função de descorrelação ajustada foi uma expressão biexponencial do tipo 5.20 e o critério para o intervalo de descorrelação foi o mesmo utilizado nos estudos anteriores $(C(t)<13 \%)$. As médias obtidas de densidade de massa estão entre $\langle\rho\rangle=1.022 \pm 0.007 \mathrm{~g} / \mathrm{cm}^{3}$ e $\langle\rho\rangle=1.023 \pm 0.007 \mathrm{~g} / \mathrm{cm}^{3}$, as energias internas por molécula estão entre $\langle U / N\rangle=-35.2 \pm 0.08 \mathrm{kcal} / \mathrm{mol}$ e $\langle U / N\rangle=-35.5 \pm 0.06 \mathrm{kcal} / \mathrm{mol}$, e as entalpias conformacionais por molécula obtidas estão entre $\left\langle H_{c} / N\right\rangle=-11.56 \pm 0.07 \mathrm{kcal} / \mathrm{mol}$ e $\left\langle H_{c} / N\right\rangle=-11.54 \pm 0.07 \mathrm{kcal} / \mathrm{mol}$. Todos os valores obtidos são compatíveis com o campo de força SPC/E e com as simulações realizadas para a uracila e timina.

Uma análise da distribuição radial de pares de mínima distância nos permitiu checar a existência da camada de micro-solvatação, presente nos quatro casos, além de fornecer o número de moléculas de água na camada. As distribuições obtidas foram análogas às apresentadas para a uracila (Fig. 6.1) e timina (Fig. 6.17), e obtivemos $n=6$ para todos os casos. Analisando as ligações de hidrogênio soluto-solvente notamos que os quatro sistemas apresentam distribuições similares. Em média, duas ligações de aceitação, por parte dos solutos, foram observadas em cada oxigênio das halouracilas, enquanto que uma ligação de doação foi observada em cada hidrogênio (H-N), totalizando 6 ligações em média. Portanto, lidamos novamente com o caso em que as 6 moléculas de água na camada de micro-solvatação representam associamse a média de ligações de hidrogênio soluto-solvente. Os comprimentos das ligações de hidrogênio de aceitação e doação são tipicamente em torno de $\sim 1.85 \AA$, e a distribuição de valores é relativamente fina em torno desse valor.

Não se observa ligações de hidrogênio nos halogênios, e uma breve discussão sobre esse resultado pode ser feita como segue. As cargas efetivas dos halogênios aumentam conforme aumentamos o número atômico. Os valores obtidos pelo procedimento CHELPg, consequentemente utilizados nas simulações, para os átomos $\mathrm{F}, \mathrm{Cl}, \mathrm{Br}$ e I são respectivamente $-0.1644,-0.0848,-0.0485$ e +0.1593 , e podemos checar que a sequência respeita a diferença de eletronegatividade dos átomos. Esses valores são 
relativamente baixos, em valores absolutos, o que por si só já justifica a ausência de ligações de hidrogênio entre os halogênios e o solvente. A Fig. 6.23 mostra um estudo das distribuições radiais de pares referentes às distânias entre os halogênios, em cada caso, e os átomos do solvente (hidrogênio e oxigênio). De fato, em nenhum dos casos observamos estruturas finas em torno de $1.8 \sim 2 \AA$, como nas distribuições típicas de distâncias O7(1)-H(2) ou H11(1)-O(2), por exemplo. Ao invés disso, observou-se
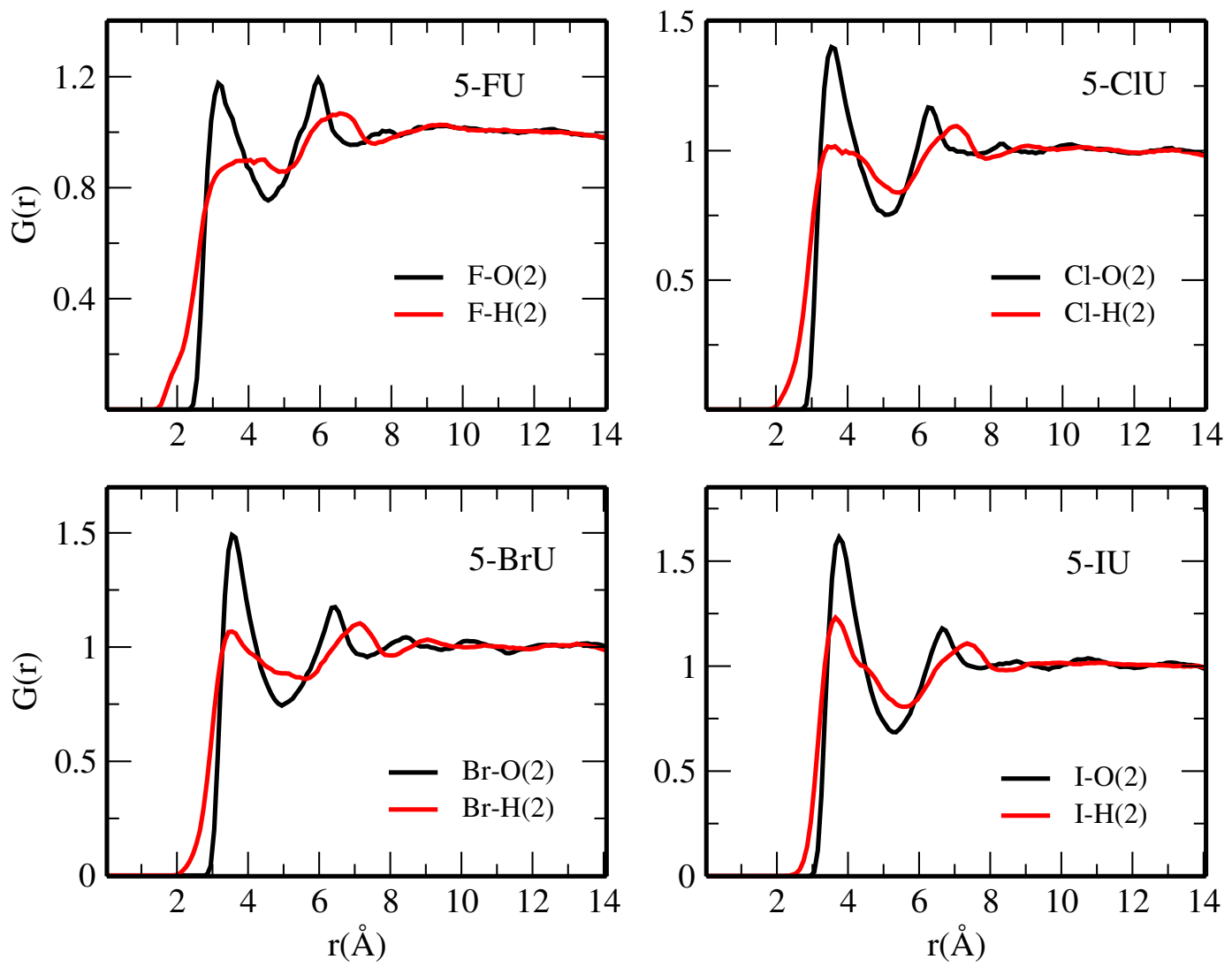

Figura 6.23: Os gráficos apresentam a distribuição radial de pares $G(r)$ referentes às distâncias entre os halogênios, em cada um dos casos 5-XU (X=F,Cl,Br,I), e os átomos do solvente. Os números (2) entre parêntesis indicam que o átomo pertence ao solvente.

um primeiro mínimo local nas curvas sólidas pretas em torno de $4.6 \sim 5.2 \AA$, representando a primeira camada de solvatação, externa à camada de micro-solvatação. Esse valores também se distribuem em ordem crescente com o número atômico do halogênio, apontando camadas de solvatação maiores, em volume, para halogênios maiores, em número atômico.

Motivados pela forte correlação entre energias doe VOs correspondentes aos esta- 
dos $\pi^{*}$ e as posições em energia das ressonâncias ET dos agregados, passou-se para um estudo das distribuições térmicas dos VOEs. No caso das halouracilas, esperaríamos encontrar um orbital virtual $\mathrm{HF} / 6-31 \mathrm{G}^{*}$ associado aos estados $\sigma_{\mathrm{CX}}^{*}$, além dos orbitais $\pi_{1}^{*}$ e $\pi_{2}^{*}$. Cálculos single point nesse nível de teoria foram realizados para os 133 agregados obtidos para cada halouracila. Para o iodo, utilizou-se o conjunto de base LANL2DZP-ECP implementado com pseudopotenciais para a descrição dos elétrons de caroço. O orbital $\sigma^{*}$ pode ser efetivamente observado nas 133 configurações nos casos de 5-BrU e 5-IU. No caso da 5-ClU o orbital só foi observado em 33 configurações $(\sim 25 \%)$, indicando que a combinação de orbitais atômicos que descrevem o $\mathrm{VO} \sigma_{\mathrm{CCl}}^{*}$ é mais sensível à presença e geometria das moléculas de água do que nos casos dos halogênios mais pesados. No caso da 5 -FU o orbital $\sigma_{\mathrm{CF}}^{*}$ sequer foi observado. Na Fig. 6.24 exibo as distribuições térmicas dos VOEs, em quatro painéis de histogramas. Os valores médios e desvios padrão de cada uma das distribuições encontram-se na Tab. 6.2. Para evitarmos confusão com os estados $\sigma^{*}$, a notação para os desvios

Tabela 6.2: Médias e desvios padrão das distribuições térmicas dos VOEs HF/6$31 \mathrm{G}^{*}$ (HF/LANL2DZP-ECP para o iodo), em eV. Os valores dos respectivos VOEs das moléculas em fase gasosa também estão disposto (segundo bloco).

\begin{tabular}{ccccccc}
\hline \hline & $\pi_{1}^{*}$ & VAR $\pi_{1}^{*}$ & $\sigma_{\mathrm{CX}}^{*}$ & $\mathrm{VAR} \sigma_{\mathrm{CX}}^{*}$ & $\pi_{2}^{*}$ & $\mathrm{VAR} \pi_{2}^{*}$ \\
\hline $5-\mathrm{FU}$ & 2.08 & 0.31 & - & - & 4.10 & 0.35 \\
$5-\mathrm{ClU}$ & 2.12 & 0.32 & 5.17 & 0.27 & 4.05 & 0.36 \\
$5-\mathrm{BrU}$ & 2.13 & 0.23 & 3.74 & 0.21 & 4.01 & 0.26 \\
$5-\mathrm{IU}$ & 2.10 & 0.28 & 2.47 & 0.22 & 3.94 & 0.36 \\
\hline 5-FU (gas) & 2.45 & - & 4.98 & - & 4.59 & - \\
$5-\mathrm{ClU}$ (gas) & 2.38 & - & 4.51 & - & 4.54 & - \\
$5-\mathrm{BrU}$ (gas) & 2.38 & - & 3.92 & - & 4.53 & - \\
$5-\mathrm{IU}$ (gas) & 2.41 & - & 2.60 & - & 4.55 & - \\
\hline \hline
\end{tabular}

padrão obtidos nessa seção estão indicados por VAR, ao invés da letra grega $\sigma$. O que podemos observar imediatamente é que o efeito da mudança do halogênio de uma molécula para outra é muito mais apreciativo nos VOEs $\sigma^{*}$ do que nos VOEs $\pi^{*}$, que parecem ser poucos sensíveis frente a essa alteração.

Assumindo que de fato os VOEs correlacionam bem com os VAEs, tanto pros 


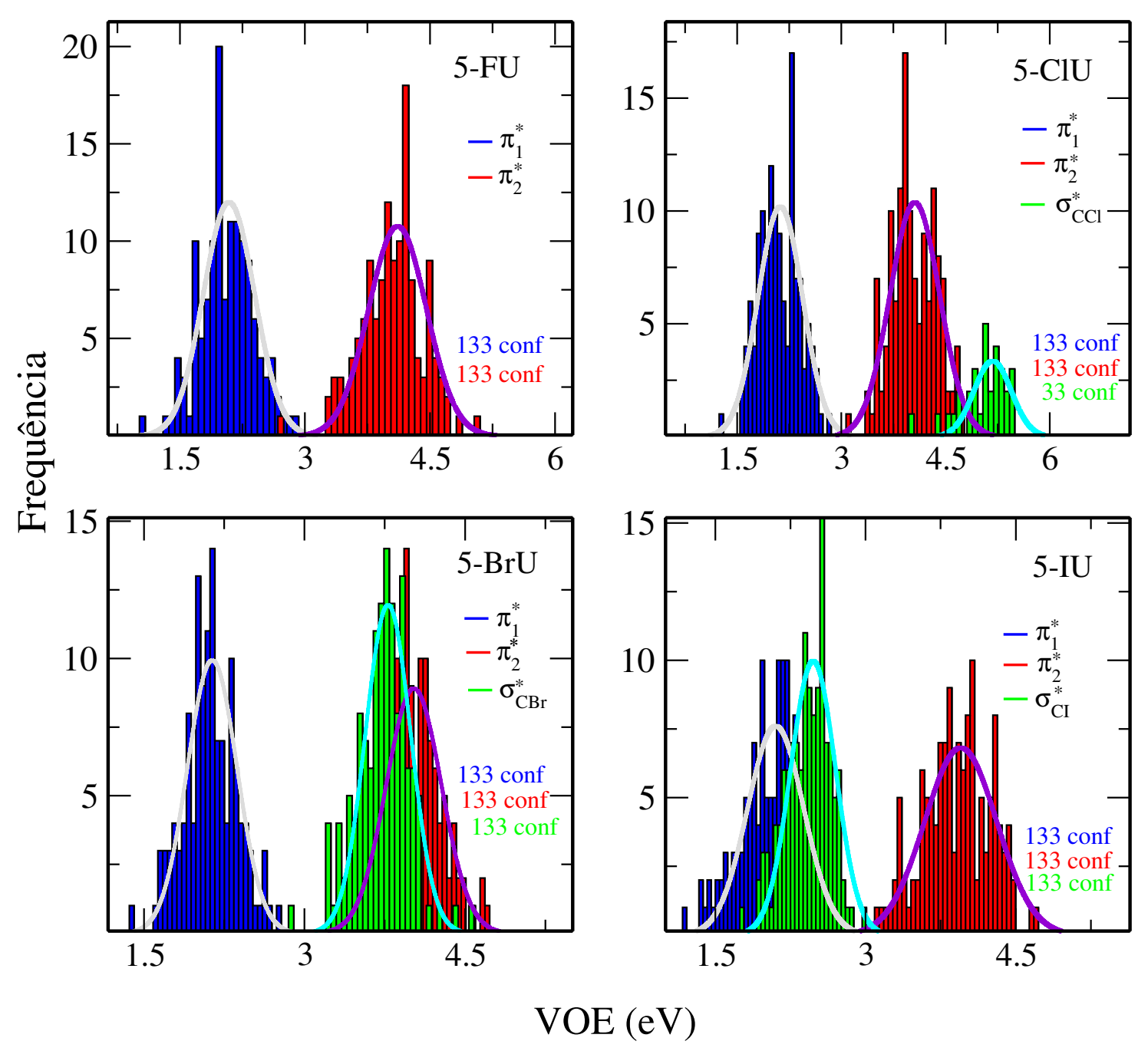

Figura 6.24: Distribuições térmicas das energias HF/6-31G* (HF/LANL2DZP-ECP para o iodo) dos orbitais virtuais $\pi_{1}^{*}, \pi_{2}^{*}$ e $\sigma_{\mathrm{CX}}^{*}$, em eV, para cada um dos conjuntos de agregados de $5-\mathrm{XU}\left[\mathrm{H}_{2} \mathrm{O}\right]_{6}$, para $\mathrm{X}=\mathrm{F}, \mathrm{Cl}, \mathrm{Br}$,I. O sistema correspondente a dada histograma está indicado em cada um dos quartro painéis. Os histogramas referentes às distribuições dos VOEs $\sigma_{\mathrm{CX}}^{*}$ só estão presentes no caso da 5-ClU, 5-BrU e 5-IU, enquanto que no primeiro dos três casos o orbital só foi apreciado em 33 configurações.

estados de natureza $\pi^{*}$ quanto $\sigma^{*}$, algumas conclusões importantes podem ser tiradas apenas olhando para os resultados da Fig. 6.24 e da Tab. 6.2. Ao comparar os VOEs dos sistemas em fase gasosa com as médias das distribuições térmicas dos sistemas micro-solvatados, notamos uma sistemática estabilização dos estados $\pi_{1}^{*}$ e $\pi_{2}^{*}$. Além disso, não se observa uma diferença significativa entre os VOEs $\pi_{1}^{*}$ e $\pi_{2}^{*}$ quando mudamos de um sistema para outro. Isso parece ser razoável na medida em que os orbitais $\pi^{*}$ possuem pouca delocalização sobre os halogênios. No caso dos orbitais $\sigma^{*}$, observamos uma tendência interessante. Enquanto que o VOE é estabilizado devido 
às águas na 5-BrU e 5-IU, há uma desestabilização no caso da 5-ClU micro-solvatada. De fato, se considerarmos um intervalo $\pm 2 \mathrm{VAR}_{\sigma_{\mathrm{CCl}}^{*}}$ em torno da média, concluimos que as energias desse orbitais se encontram entre $4.64 \mathrm{eV}$ e $5.61 \mathrm{eV}$ - isto é, acima da energia do orbital correspondente em fase gasosa - em cerca de $95 \%$ da distribuição térmica. Esse efeito é um pouco mais difícil de ser entendido, mas uma maneira de intepretá-lo é notar que devido à faixa de energia em que se encontra o VO em fase gasosa, além de observar que o orbital possui uma grande densidade eletrônica sobre os hidrogênios H9 e H12 (aqui estou adaptando a numeração utilizada para a uracila - ver Fig. 6.2), é razoável esperar que a diagonalização do hamiltoniano eletrônico contemple um estado $\sigma_{\mathrm{CCl}}^{*}$ que mistura orbitais das moléculas de água mais próximas. As energias mais altas dos VOs das águas portanto fazem com que os VOEs $\sigma_{\mathrm{CCl}}^{*}$ dos clusters aumentem. Isso não acontece no orbitais $\sigma^{*}$ da 5 -BrU e 5-IU, pois eles se encontram em energias mais baixas e são mais localizados ao longo da ligação C-Br e C-I, respectivamente, impedindo que essa mistura aconteça.

A seguir investigou-se a existência de agregados $5-\mathrm{XU}\left[\mathrm{H}_{2} \mathrm{O}\right]_{6}$ representativos, no que diz respeito aos VOEs e distribuição de ligações de hidrogênio soluto-solvente, dentre os 133 estatisticamente descorrelacionados, para cada sistema. A tarefa de identificar tais agregados é mais difícil nesse caso do que foi para a uracila e timina, pois agora o cluster deve estar associado a três VOEs simultaneamente. Portanto, estabelecemos que seria suficiente os VOEs serem compatíveis com as médias térmicas apresentadas na Tab. 6.2 dentro de um intervalo de \pm 1 VAR. Os clusters foram nomeados $\overline{\mathrm{C}}$ em cada um dos quatro casos e cálculos de espalhamento foram realizados para cada um deles. A Fig. 6.25 exibe os VOs HF/6-31G* (LANL2DZP-ECP para o iodo no caso da $\left.5-\mathrm{IU}\left[\mathrm{H}_{2} \mathrm{O}\right]_{6}\right)$ de cada cluster $\overline{\mathrm{C}}$. No caso da 5 -FU, os VOEs $\pi_{1}^{*}$ e $\pi_{2}^{*}$ são respectivamente $2.06 \mathrm{eV}$ e $3.95 \mathrm{eV}$. No caso da 5 -ClU, os VOEs $\pi_{1}^{*}, \sigma_{\mathrm{CCl}}^{*}$ e $\pi_{2}^{*}$ são respectivamente $2.00 \mathrm{eV}, 5.07 \mathrm{eV}$ e $3.78 \mathrm{eV}$. No caso da 5 -BrU, os VOEs $\pi_{1}^{*}, \sigma_{\mathrm{CBr}}^{*}$ e $\pi_{2}^{*}$ são respectivamente $1.95 \mathrm{eV}, 2.57 \mathrm{eV}$ e $3.52 \mathrm{eV}$. No caso da 5 -IU, os VOEs $\pi_{1}^{*}, \sigma_{\mathrm{CI}}^{*}$ e $\pi_{2}^{*}$ são respectivamente $1.83 \mathrm{eV}, 2.33 \mathrm{eV}$ e $3.58 \mathrm{eV}$.

Em seguida foram realizados os cálculos de espalhamento para os quatro clusters 


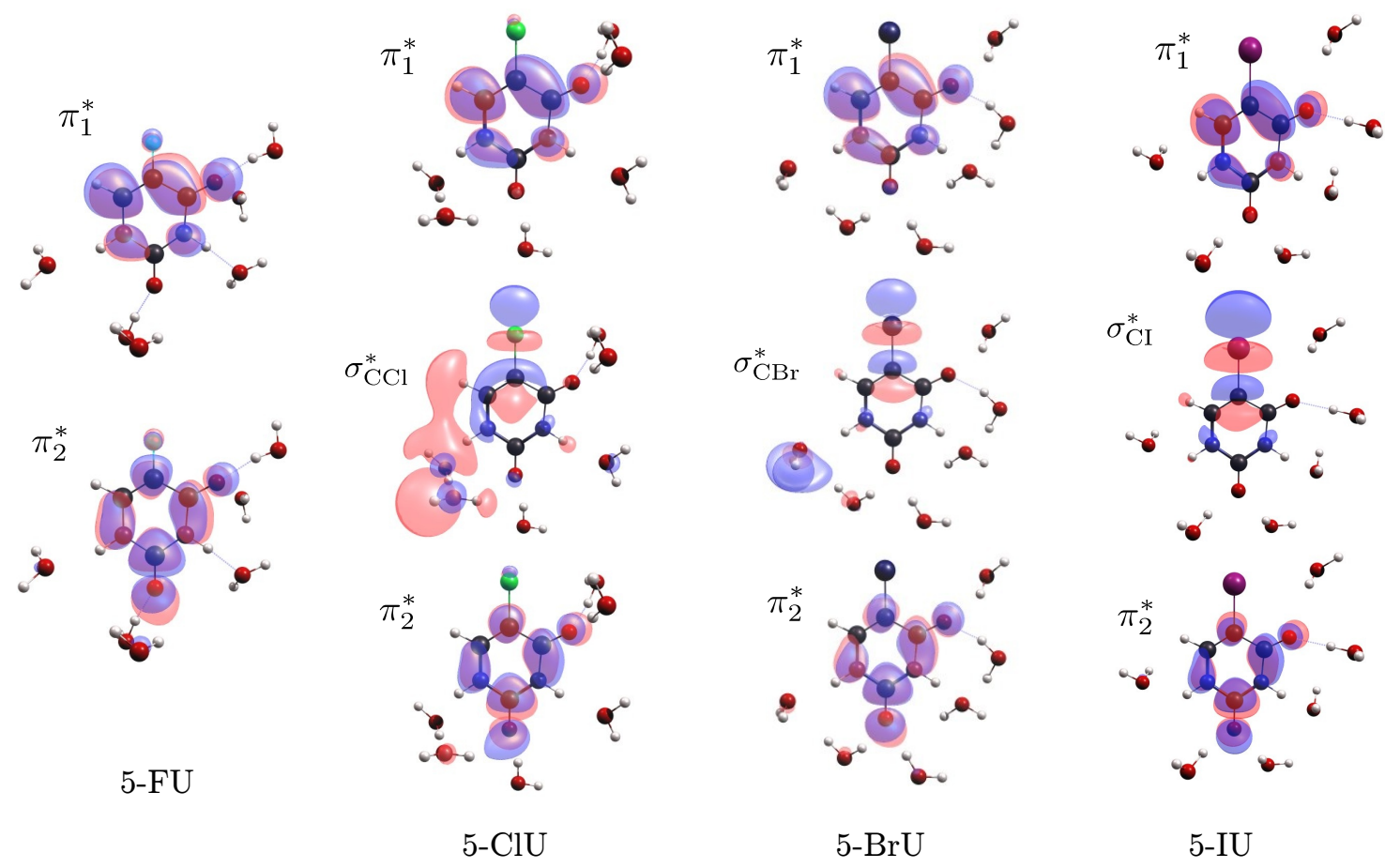

Figura 6.25: Painel de VOs $\pi^{*}$ e $\sigma^{*}$ dos clusters representativos $\overline{\mathrm{C}}$ associados aos quatro sistemas $5-\mathrm{XU}\left[\mathrm{H}_{2} \mathrm{O}\right]_{6}$, para $\mathrm{X}=\mathrm{F}, \mathrm{Cl}, \mathrm{Br}, \mathrm{I}$, esquematizados em colunas.

selecionados. O uso do método SMCPP para a obtenção dessas seções de choque representa um grande esforço do ponto de vista computacional, mesmo que na aproximação ET. Os clusters possuem 30 átomos cada, e correspondem a 418 funções gaussianas primitivas. A Fig. 6.26 exibe as quatro seções de choque integral para o espalhamento elástico, na aproximação ET. Como pode-se observar facilmente, as curvas estão sujeitas a inúmeras estruturas espúrias que dificultam sua interpretação, e consequentemente a descrição das ressonâncias. Mesmo assim, foi possível associar os estados $\pi_{1}^{*}$ e $\pi_{2}^{*}$ a duas estruturas nas assinaturas das curvas. Na curva 5-FU (painel superior esquerdo) os estados $\pi_{1}^{*}$ e $\pi_{2}^{*}$ são descritos pelos picos em $1.47 \mathrm{eV}$ e 3.56 $\mathrm{eV}$, respectivamente. Na curva 5-ClU (painel superior direito) os estado $\pi_{1}^{*}$ e $\pi_{2}^{*}$ são descritos pelos picos em 1.19 eV e 3.08 eV, respectivamente. Além disso, observamos uma larga estrutura em cerca de $\sim 4.6 \mathrm{eV}$, que pode estar associada ao estado $\sigma_{\mathrm{CCl}}^{*}$ pela região em energia onde se encontra. O caso da 5-BrU (painel inferior esquerdo) talvez seja o mais patológico no sentido da contaminação da seção de choque. O pico em 1.35 eV está associado ao estado $\pi_{1}^{*}$, enquanto que o pico em 3.07 eV está 

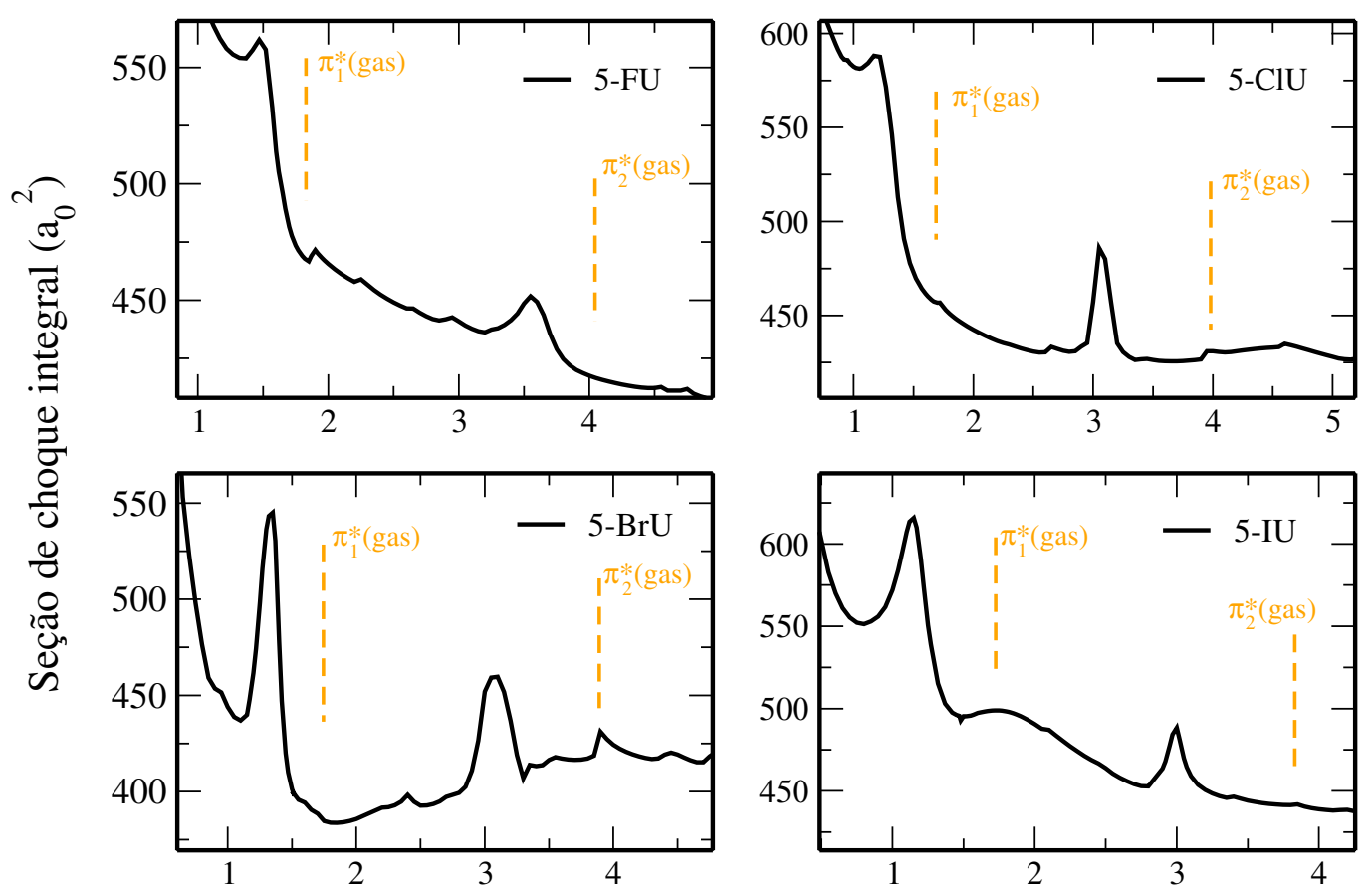

Energia do elétron $(\mathrm{eV})$

Figura 6.26: Seções de choque integral para o espalhamento eletrônico elástico pelos quatro agregados $\overline{\mathrm{C}}$ dos sistemas $5-\mathrm{XU}\left[\mathrm{H}_{2} \mathrm{O}\right]_{6}(\mathrm{X}=\mathrm{F}, \mathrm{Cl}, \mathrm{Br}, \mathrm{I})$, na aproximação ET. As duas estruturas em cada curva sólida preta representam as ressonâncias $\pi_{1}^{*} \mathrm{e}$ $\pi_{2}^{*}$. As linhas tracejadas laranjas correspondem a resultados ET para as respectivas halouracilas em fase gasosa reportados por Kossoski et al[9].

associado ao estado $\pi_{2}^{*}$. Entre $2.5 \mathrm{eV}$ e cerca de $6 \mathrm{eV}$ nota-se um grande número de pequenas estruturas espúrias e descontinuidades. É possível que uma assinatura do estado $\sigma_{\mathrm{CBr}}^{*}$ esteja obscurecida sobre essa região, uma vez que pelas distribuições térmicas dos VOEs esperaríamos esse estado quase degenerado em relação ao $\pi_{2}^{*}$. Por fim, no caso da 5-IU (painel inferior direito) identificam-se claramente duas estruturas em $1.16 \mathrm{eV}$ e $3.00 \mathrm{eV}$, as quais associamos respectivamente aos estados $\pi_{1}^{*}$ e $\pi_{2}^{*}$. Além disso, vemos uma larga estrutura em torno de $1.75 \mathrm{eV}$ que possivelmente representa a assinatura do estado $\sigma_{\mathrm{CI}}^{*}$. Os resultados para as posições das ressonâncias $\pi^{*}$, assim como os respectivos resultados em fase gasosa, estão resumidos na Tab. 6.3. Devido a esse dificuldade para a descrição das ressonâncias, não foi possível assegurar uma boa descrição das larguras, e por isso limitamos essa etapa a análise das posições.

Por fim, as regressões lineares obtidas na seção 6.1 foram utilizadas para mapear a distribuição de VOEs em VAEs e larguras de auto-ionização dos estados $\pi^{*}$ das 
Tabela 6.3: Posição das ressonâncias $\pi^{*}$ dos clusters representativos $\overline{\mathrm{C}}$ associados aos quatro sistemas $5-\mathrm{XU}\left[\mathrm{H}_{2} \mathrm{O}\right]_{6}(\mathrm{X}=\mathrm{F}, \mathrm{Cl}, \mathrm{Br}, \mathrm{I})$, em eV, na aproximação ET. Também estão dispostos os resultados ET para as ressonâncias $\pi^{*}$ das quatro halouracilas isoladas, obtidas com o método SMCPP e reportadas por Kossoski et al[9], para comparação.

\begin{tabular}{ccccc}
\hline \hline & $\pi_{1}^{*}$ (gas) & $\pi_{1}^{*}$ & $\pi_{2}^{*}($ gas $)$ & $\pi_{2}^{*}$ \\
\hline $5-\mathrm{FU}$ & 1.82 & 1.47 & 4.02 & 3.56 \\
$5-\mathrm{ClU}$ & 1.69 & 1.19 & 3.97 & 3.08 \\
$5-\mathrm{BrU}$ & 1.74 & 1.35 & 3.92 & 3.07 \\
$5-\mathrm{IU}$ & 1.72 & 1.16 & 3.86 & 3.00 \\
\hline \hline
\end{tabular}

halouracilas. O cuidado inicial foi checar se os resultados das ressonâncias para os clusters $\overline{\mathrm{C}}$ podem ser bem descritos pelo mapeamento. As equações 6.5 (Modelo I), 6.6 (Modelo I), 6.7 (Modelo II) e 6.8 (Modelo II) podem ser testadas para as halouracilas isoladas. O Modelo I prevê VAEs para os estados $\pi_{1}^{*}$ em $0.09 \mathrm{eV}, 0.02$ eV, $0.02 \mathrm{eV}$ e $0.05 \mathrm{eV}$ respectivamente para a 5-FU, 5-ClU, 5-BrU e 5-IU, enquanto que prevê VAEs dos estados $\pi_{2}^{*}$ em 2.12 eV, 2.08 eV, 2.07 eV e 2.09 eV. Já o Modelo II prevê VAEs para os estados $\pi_{1}^{*}$ em $0.09 \mathrm{eV}, 0.03 \mathrm{eV}, 0.03 \mathrm{eV}$ e $0.06 \mathrm{eV}$ para a 5 FU, 5-ClU, 5-BrU e 5-IU, respectivamente, e para os estados $\pi_{2}^{*}$ prevê VAEs em 1.92 eV, $1.88 \mathrm{eV}, 1.87 \mathrm{eV}$ e $1.89 \mathrm{eV}$. Assim notamos que os Modelos I e II superestimam os VAEs em cerca de $0.1 \sim 0.2 \mathrm{eV}$, em relação aos valores ETP reportados. Essa diferença pode ser entendida como uma limitação dos Modelos, que é baseado em uma regressão linear cujos parâmetros ajustados possuem incertezas consideráveis. Também vale levar em consideração que os valores ETP publicados empregaram uma estratégia diferente para polarizar o cálculo de espalhamento. A saber, foi utilizado o critério energético, similar ao que foi realizado para a 5-OCNU e 5-SCNU (ver capítulo 4), que acaba por descrever VAEs sistematicamente mais baixos do que a estratégia utilizada nos sistemas micro-solvatados, que por sua vez foi usada para ajustar os Modelos lineares. À luz dessas considerações, conclui-se que para uma primeira aproximação os Modelos I e II são razoavelmente satisfatórios para prever VAEs dos estados $\pi^{*}$ das halouracilas micro-solvatadas. Como os Modelos são muito próximos numericamente, escolheu-se utilizar apenas o Modelo II para a previsão. A 
escolha se dá pelo fato de que a equação 6.4 leva em consideração sistemas além da uracila.

Na Fig. 6.27 constam oito histogramas associados a distribuições térmicas de VAEs $\pi^{*}$, sendo dois de cada sistema. Os quatro histogramas relativos aos estados $\pi_{1}^{*}$ são próximos. Todos eles descrevem um estado $\pi_{1}^{*}$ ligado em pouco mais de $80 \%$ da distribuição, chegando a $86 \%$ no caso da 5-IU. Os valores médios obtidos foram $\left\langle\mathrm{VAE}_{\pi_{1}^{*}}\right\rangle=-0.221 \pm 0.247 \mathrm{eV}$ para a $5-\mathrm{FU},\left\langle\mathrm{VAE}_{\pi_{1}^{*}}\right\rangle=-0.195 \pm 0.272 \mathrm{eV}$ para a $5-\mathrm{ClU},\left\langle\mathrm{VAE}_{\pi_{1}^{*}}\right\rangle=-0.180 \pm 0.199 \mathrm{eV}$ para a $5-\mathrm{BrU}$ e $\left\langle\mathrm{VAE}_{\pi_{1}^{*}}\right\rangle=-0.251 \pm 0.284 \mathrm{eV}$ para a 5-IU. Os valores médios dos estados $\pi_{2}^{*}$ também são comparáveis. Obtivemos $\left\langle\mathrm{VAE}_{\pi_{2}^{*}}\right\rangle=1.511 \pm 0.274 \mathrm{eV}$ para a $5-\mathrm{FU},\left\langle\mathrm{VAE}_{\pi_{2}^{*}}\right\rangle=1.484 \pm 0.284 \mathrm{eV}$ para a $5-\mathrm{ClU}$, $\left\langle\mathrm{VAE}_{\pi_{2}^{*}}\right\rangle=1.440 \pm 0.203 \mathrm{eV}$ para a $5-\mathrm{BrU}$ e $\left\langle\mathrm{VAE}_{\pi_{2}^{*}}\right\rangle=1.371 \pm 0.286 \mathrm{eV}$ para a 5 -IU. Dessa forma somos capazes de descrever distribuições cujas médias correspondem a estabilizações sistemáticas dos estados $\pi_{1}^{*}$ e $\pi_{2}^{*}$, quando comparados aos VAEs das moléculas isoladas. Além disso, todas as distribuições admitem um pequno overlap em torno de $0.5 \mathrm{eV}$, sugerindo que a formação do ânion $\pi^{*}$ induzida pela captura eletrônica pode ser realizada num contínuo de energias. Vale retomar aqui a discussão sobre experimental publicado por Poštulka et al. [99], que foi citado durante a análise dos resultados na seção 6.1. O trabalho também reportou sinais de transferência de energia vibracional mediada pela formação de ânions em clusters de $5-\mathrm{FU}\left[\mathrm{H}_{2} \mathrm{O}\right]_{n}$ e 5 - $\mathrm{BrU}\left[\mathrm{H}_{2} \mathrm{O}\right]_{n}$, com $n \leq 7$, no qual os elétrons incidentes possuiam um valor fixo de energia em $1.2 \mathrm{eV}$. A formação do ânion nessa energia pode ser explicada pelos resultados apresentados aqui.

O mapeamento das larguras das ressonâncias $\pi_{1}^{*}$, com o intuito de descrever suas distribuições térmicas, também foi realizado com o uso da relação 6.9. Essa relação foi obtida através de um conjunto de dados reportados para as ressonâncias $\pi^{*}$ da uracila, além dos resultados obtidos no presente trabalho. Assumimos que a relação entre posição e largura das ressonâncias $\pi^{*}$ das halouracilas podem ser também relacionadas pela mesma expressão, como uma primeira aproximação. A Fig. 6.28 contém oito painéis com histrogramas referentes a essas distribuições para os quatro sistemas 
estudados. Os valores médios e desvios padrão foram obtidos da forma usual, tendo o cuidado de considerar apenas as frações ressonantes das distribuições, nos casos dos estados $\pi_{1}^{*}$. Nesses casos, os valores obtidos foram $\left\langle\Gamma_{\pi_{1}^{*}}\right\rangle=7.72 \pm 7.26 \mathrm{meV}$ para a $5-\mathrm{FU},\left\langle\Gamma_{\pi_{1}^{*}}\right\rangle=6.56 \pm 5.77 \mathrm{meV}$ para a $5-\mathrm{ClU},\left\langle\Gamma_{\pi_{1}^{*}}\right\rangle=5.18 \pm 5.09 \mathrm{meV}$ para a 5-BrU e $\left\langle\Gamma_{\pi_{1}^{*}}\right\rangle=4.59 \pm 4.49 \mathrm{meV}$ para a 5 -IU. A análise estatística desses valores acabam tendo suas limitações, devido ao número reduzido de dados para calcular os desvios padrão. No caso mais crítico (5-IU) apenas 19 dos 133 agregados apresentam ressonâncias $\pi_{1}^{*}$. Já para o estudo de larguras das $\pi_{2}^{*}$ obtivemos $\left\langle\Gamma_{\pi_{2}^{*}}\right\rangle=0.121 \pm 0.029$ $\mathrm{eV}$ para a $5-\mathrm{FU},\left\langle\Gamma_{\pi_{2}^{*}}\right\rangle=0.118 \pm 0.029 \mathrm{eV}$ para a $5-\mathrm{ClU},\left\langle\Gamma_{\pi_{2}^{*}}\right\rangle=0.116 \pm 0.024 \mathrm{eV}$ para a $5-\mathrm{BrU}$ e $\left\langle\Gamma_{\pi_{2}^{*}}\right\rangle=0.110 \pm 0.029 \mathrm{eV}$ para a 5 -IU.

As distribuições térmicas das larguras de auto-ionização estão associadas a distribuições térmicas do tempo de vida das ressonâncias. Ao considerarmos tempos de vida verticais - isto é, desconsiderando relaxação vibracional - e análises baseadas em intervalos de mais ou menos 1 desvio padrão, temos que os estados $\pi_{1}^{*}$ da 5 -FU micro-solvatada possuem tempos de vida entre 44 fs e 1400 fs (1.4 ps), enquanto que os estados $\pi_{2}^{*}$ possuem tempos de vida entre 4.4 fs e 7.2 fs. Os estados $\pi_{1}^{*}$ da 5 -ClU micro-solvatada possuem tempos de vida entre $53 \mathrm{fs}$ e $840 \mathrm{fs}$, enquanto que os estados $\pi_{2}^{*}$ possuem tempos de vida entre 4.5 fs e 7.4 fs. No caso da 5 -BrU, os estados $\pi_{1}^{*}$ possuem tempos de vida distribuídos entre 64 fs e 7300 fs ( 7.3 ps), enquanto que os estados $\pi_{2}^{*}$ correspondem a tempos de vida entre 4.7 fs e 7.2 fs. Por fim, os tempos de vida dos estados $\pi_{1}^{*}$ da 5-IU micro-solvatada estão entre 72 fs e 6600 fs (6.6 ps), enquanto que os tempos de vida dos estados $\pi_{2}^{*}$ estão entre 4.8 fs e 8.13 fs. Esses resultados indicam que os estados $\pi_{1}^{*}$ podem possui tempos de vida verticais muito longos, na escala de movimento vibracional, chegando a unidades de ps. É claro que devido ao número reduzido de dados nas distribuições dos estados $\pi_{1}^{*}$, os desvios padrão são naturalmente mais largos do que usualmente se esperaria, o que implica que esses intervalos de tempos de vida pode estar superestimado.

Finalizamos aqui a apresentação e análise dos resultados dos efeitos do solvente na formação de ânions transientes das quatro halouracilas, encerrando assim o capítulo. 
Por ora não temos dados o suficiente para estender a análise para os estados $\sigma^{*}$, devido ao baixo número de dados reportados na literatura, além da dificuldade na interpretação desses estados nas nossas seções de choque. 


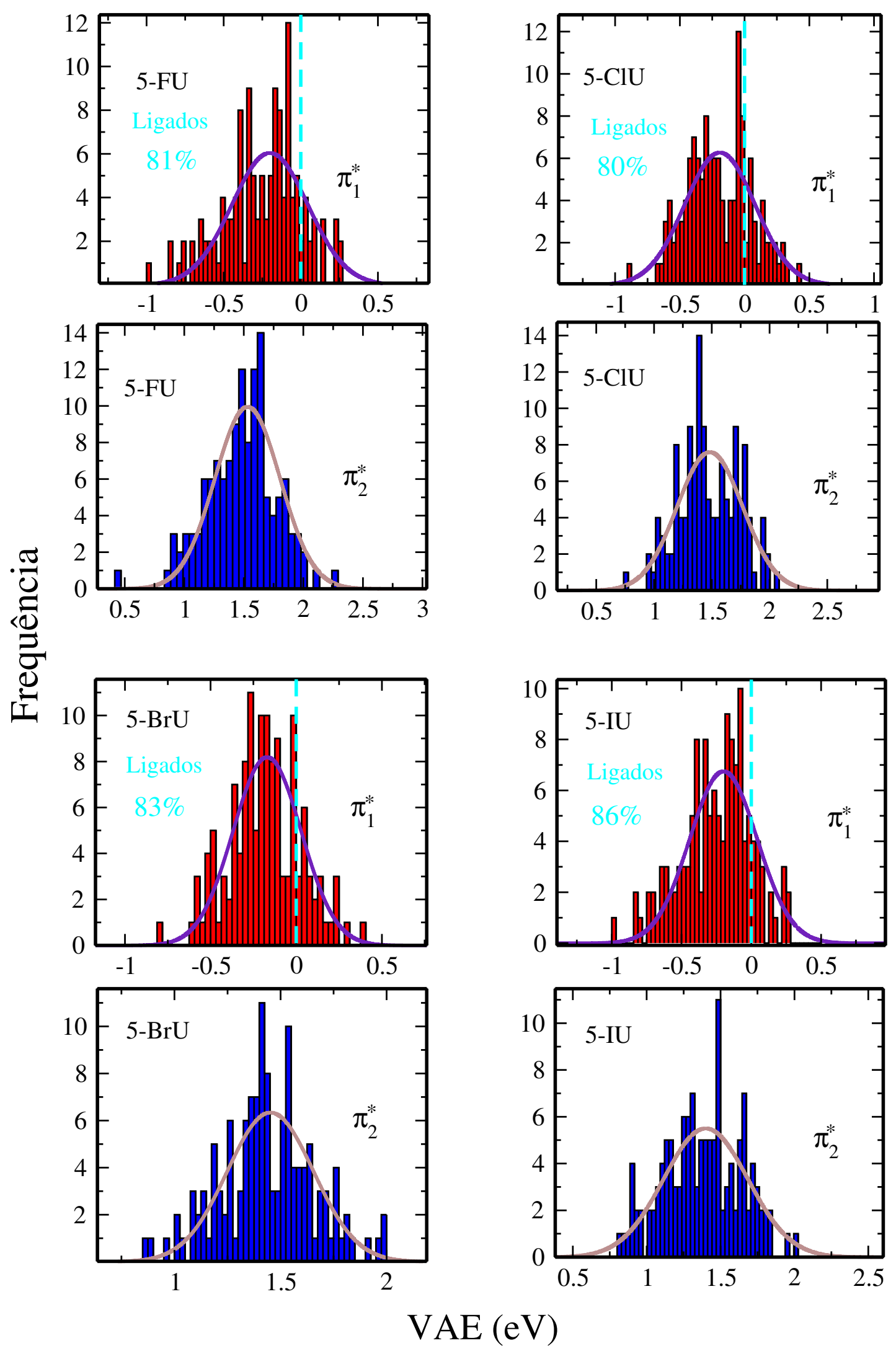

Figura 6.27: Distribuições térmicas dos VAEs $\pi^{*}$ das quatro halouracilas microsolvadas, em eV, segundo o Modelo II, à temperatura $T=298.15 \mathrm{~K}$. As distribuições foram obtidas sobre o conjunto das 133 configurações estatisticamente descorrelacionadas, em cada caso. A fração de estados ligados descritas pelas distribuições dos VAEs $\pi_{1}^{*}$ estão indicados em azul. 

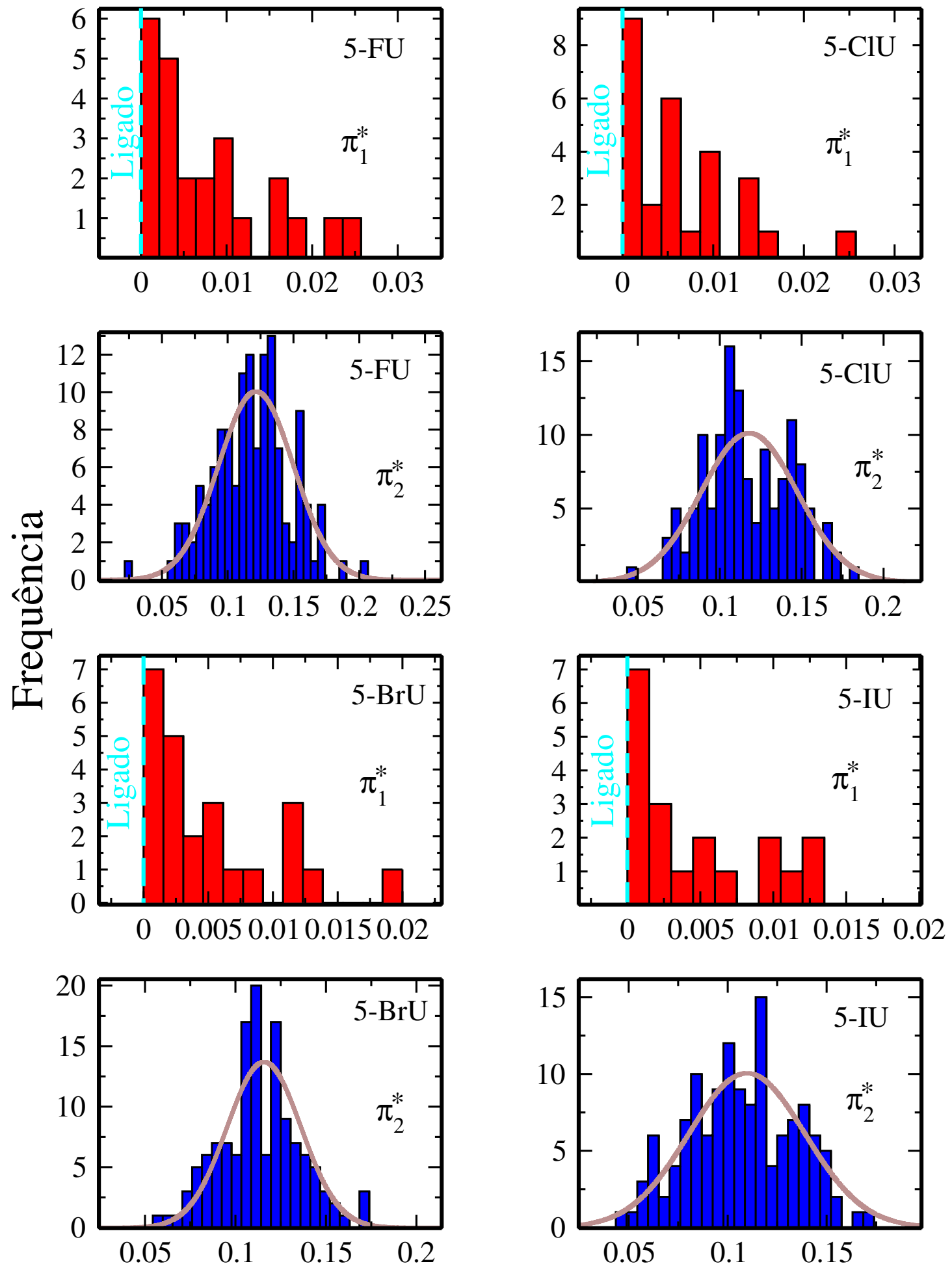

$\Gamma(\mathrm{eV})$

Figura 6.28: Distribuições térmicas das larguras $\Gamma$, das ressonâncias $\pi^{*}$, das quatro halouracilas micro-solvadas, em eV, segundo o Modelo II, à temperatura $T=298.15$ K. As distribuições das larguras das ressonâncias $\pi_{1}^{*}$ foram obtidas apenas sobre as parcelas ressonante das distribuições. Quanto às larguras das ressonâncias $\pi_{2}^{*}$, as distribuições foram obtidas sobre todo o conjunto das 133 configurações estatisticamente descorrelacionadas, em cada caso. 


\section{Capítulo 7}

\section{Métodos teóricos IV: Dinâmica nuclear dos ânions transientes}

Este capítulo inicia a discussão do terceiro e último segmento do trabalho, que diz respeito ao estudo da dinâmica dos ânions temporários. Nessa etapa discorro sobre o problema da dinâmica nuclear não-adiabática, amplamente utilizados na descrição de processos fotoquímicos e fotofísicos, e a adaptação que foi realizada para a descrição dos TNIs. Em problemas de fotoquímica, tipicamente temos um sistema inicialmente em seu estado fundamental que, uma vez interagido com um fóton, transfere-se para um estado eletronicamente excitado, porém ainda ligado. Dessa forma, ao usar métodos usuais de dinâmica de estados excitados para abordar esse tipo de problema não precisamos nos preocupar com as complicações extras dos ânions transientes. Contudo, mesmo apesar de todas essas considerações, nós podemos abordar os estados ressonantes com técnicas de estado ligado, utilizados em química quântica usual, mas de alguma forma adaptadas para tratar o acoplamento com o contínuo.

Antes de apresentar o desenvolvimento a respeito dos ânions temporários, apresento na próxima seção a teoria utilizada para descrever a dinâmica não-adiabática, i. e., a propagação do pacote de ondas nuclear em diferentes estados eletrônicos. Os estudos foram baseados no ab initio multiple spawning (AIMS), uma técnica de natureza MQC (clássica-quântica) desenvolvida principalmente pelo grupo do prof. Dr. Todd Martinez, da Universidade de Stanford. O método simula a dinâmica onthe-fly dos núcleos, tratados como partículas semi-clássicas, sobre estados eletrônicos 
descritos na representação adiabática, de forma que o acoplamento não-adiabático entre os estados eletrônicos é introduzido ad-hoc[10, 114-117].

\subsection{O método ab initio multiple spawning}

O ponto de partida é a equação de Schrödinger não-relativística dependente do tempo,

$$
i \hbar \frac{\partial \Psi(\mathbf{r}, \mathbf{R}, t)}{\partial t}=\hat{\mathscr{H}} \Psi(\mathbf{r}, \mathbf{R}, t)
$$

em que $\Psi(\mathbf{r}, \mathbf{R}, t)$ a função de onda molecular dependente do tempo e $\hat{\mathscr{H}}$ é o hamiltoninano molecular total. A solução da equação 7.1 no método AIMS é expressa de acordo com a expressão de Born-Huang,

$$
\Psi^{\mathrm{AIMS}}(\mathbf{r}, \mathbf{R}, t)=\sum_{J} \psi_{J}(\mathbf{r} \mid \mathbf{R}) \chi_{J}(\mathbf{R}, t)
$$

em que $J$ é índice do do estado eletrônico adiabático $\psi_{J}(\mathbf{r} \mid \mathbf{R}), \mathbf{r}$ representa a coleção de coordenadas eletrônicas e $\mathbf{R}$ a coleção de coordenadas nucleares. A expansão acima é equivalente à expansão de Born-Huang, descrita no apêndice A, mas agora com a dependência temporal da solução embutida nos coeficientes $\chi_{J}(\mathbf{R}, t)$. A função de onda eletrônica é uma auto-função do hamiltoniano eletrônico,

$$
\hat{\mathscr{H}}_{\text {ele }} \psi_{J}(\mathbf{r} \mid \mathbf{R})=\epsilon_{J}(\mathbf{R}) \psi_{J}(\mathbf{r} \mid \mathbf{R})
$$

e é parametricamente dependente das coordenadas nucleares.

Os coeficientes $\chi_{J}(\mathbf{R}, t)$ representam as funções de onda nucleares, e a proposta para essas funções é uma das principais características do método. $\chi_{J}$ é dado pela combinação linear de todos pacotes de onda que se manifestam sobre o estado eletrônico J. Cada um desses pacotes são modelados por um produto de gaussianas congeladas, isto é, de largura fixa, cada qual representando uma das três coordenadas cartesianas (graus de liberdade) de cada um dos núcleos. Em outras palavras, se tivermos $N_{\text {nuc }}$ núcleos cada pacote de ondas é um produto de $3 N_{\text {nuc }}$ gaussianas congeladas, 
caracterizando o pacote (do inglês trajectory basis function - TBF). O AIMS propaga o pacote de ondas nuclear sobre uma determinada superfície de energia potencial eletrônica adiabática até o momento onde o mesmo atinge regiões de alto acoplamento com outros estados eletrônicos. Enquanto passa por essa região, o pacote se divide (spawn) em dois novos pacotes de onda independentes (Fig. 7.1). O número de
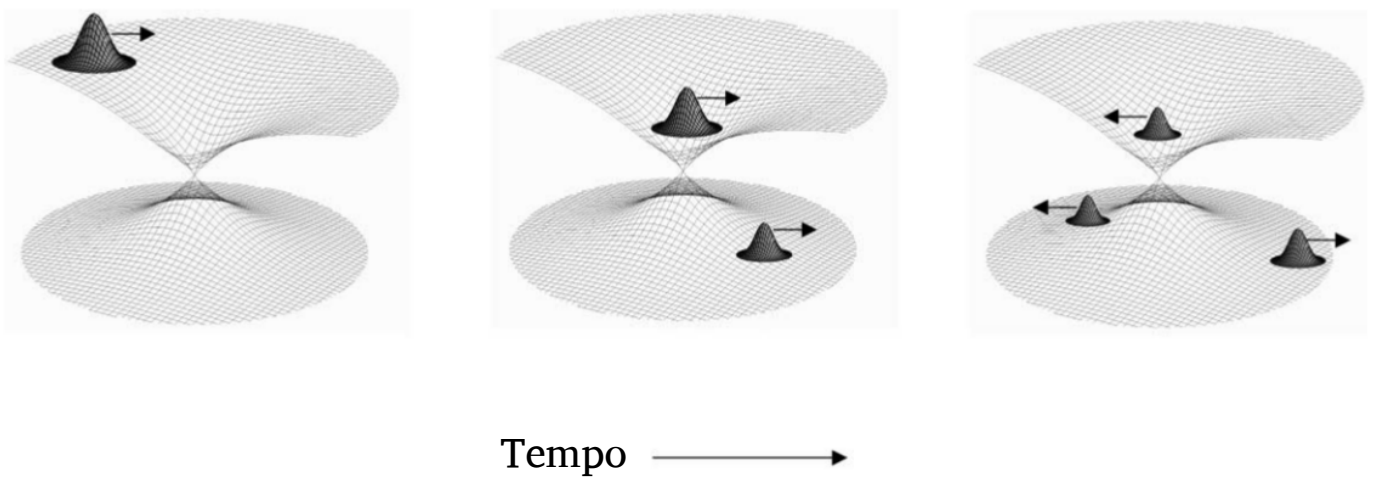

Figura 7.1: (Adaptado da referência [10])Esquema da propagação do pacote de ondas nuclear na metodologia AIMS. Nesse esquema mostro dois estados eletrônicos envolvidos (digamos, $J=0,1$ ). O pacote de onda, no caso, se encontra inicialmente sobre o estado eletrônico $J=1$ e é submetido a uma divisão (spawning) ao atravessar a região de alto acoplamento.

TBFs sobre um dado estado eletrônico $J$ não é um número constante, $N_{J}=N_{J}(t)$, e cada pacote de ondas subsequente é capaz de posteriormente subdividir, e assim por diante. Dessa forma, a função nuclear $\chi_{J}$ é dada por

$$
\chi_{J}(\mathbf{R}, t)=\sum_{j}^{N_{J}(t)} C_{j}^{J}(t) \chi_{j}^{J}\left(\mathbf{R} \mid \overline{\mathbf{R}}(t), \overline{\mathbf{P}}(t), \bar{\gamma}_{j}^{J}, \alpha_{j}^{J}\right)
$$

onde a soma é realizada sobre os $N_{J}$ existentes no instante $t$ e as funções $\chi_{j}^{J}$ descreve a j-ésima TBF sobre o estado eletrônico $J$. Além disso, essa função é parametricamente dependente dos parâmetros $\overline{\mathbf{R}}(t)$ e $\overline{\mathbf{P}}(t)$, que representam respectivamente a coleção de valores médio de posição e momento de cada gaussiana que constitui $\chi_{j}^{J}$, ambos 
avaliados em cada instante de tempo. Finalmente, a expressão para $\chi_{j}^{J}$ é

$$
\begin{aligned}
& \chi_{j}^{J}\left(\mathbf{R} \mid \overline{\mathbf{R}}(t), \overline{\mathbf{P}}(t), \bar{\gamma}_{j}^{J}, \alpha_{j}^{J}\right)=e^{i \bar{\gamma}_{j}^{J}} \times \\
& \times \prod_{\eta}^{3 N_{\text {nuc }}}\left(\frac{2 \alpha_{j \eta}^{J}}{\pi}\right)^{1 / 4} \exp \left[-\alpha_{j \eta}^{J}\left(R_{\eta}-\bar{R}_{j \eta}^{J}(t)\right)^{2}+i \bar{P}_{j \eta}^{J}(t)\left(R_{\eta}-\bar{R}_{j \eta}^{J}(t)\right)\right],
\end{aligned}
$$

em que o índice $\eta$ rotula cada uma das coordenadas cartesianas de cada um $\operatorname{dos} N_{\text {nuc }}$ núcleos atômicos. Além disso, as funções dependem de uma fase $\bar{\gamma}_{j}^{J}=\bar{\gamma}_{j}^{J}(t)$ e de um conjunto de parâmetros $\alpha_{j}^{J}=\left(\alpha_{j 1}^{J}, \ldots, \alpha_{j 3 N_{\text {nuc }}}^{J}\right)$ que descrevem a largura associada a cada núcleos da $j$-ésima TBF em $J$. As larguras $\alpha$ são calibradas de maneira a melhor descreverem o movimento dos núcleos em diferentes tipos de estados eletrônicos. Enfatizo que para $N_{\text {nuc }}$ núcleos temos $3 N_{\text {nuc }}$ larguras, pois cada núcleo pode se mover em três direções, o que significa que esses parâmetros podem ser diferentes para movimentos em direções diferentes de um mesmo núcleo. Essa é uma liberdade útil em casos delicados mas não exploraremos esse tipo de problema. No presente trabalho a trinca de larguras de cada núcleo são valores iguais.

Apresento agora a propagação das TBFs. Partindo de uma condição inicial de posição e momentos dos núcleos, temos apenas uma única TBF em $t=0$, em um dado estado eletrônico definido. Constroi-se a função 7.4 com um único pacote 7.6, cujos parâmetros $\overline{\mathbf{R}}(t=0)$ e $\overline{\mathbf{P}}(t=0)$ devem corresponder à condição inicial. Então resolvemos as equações clássicas de movimento

$$
\begin{gathered}
\frac{\partial \bar{R}_{j \eta}^{J}}{\partial t}=\frac{\bar{P}_{j \eta}^{J}}{m_{\eta}}, \\
\frac{\partial \bar{P}_{j \eta}^{J}}{\partial t}=-\frac{\partial V_{J J}(\mathbf{R})}{\partial R_{\eta}},
\end{gathered}
$$

$\mathrm{e}$

$$
\frac{\partial \bar{\gamma}_{j}^{J}}{\partial t}=-V_{J J}(\mathbf{R})+\sum_{\eta}^{3 N_{\text {atom }}} \frac{\left(\bar{P}_{j \eta}^{J}(t)\right)^{2}}{2 m_{\eta}},
$$

em que $m_{\eta}$ é a massa associada ao $\eta$-ésimo grau de liberdade e $V_{J J}(\mathbf{R})=\epsilon_{J}(\mathbf{R})$ é a 
energia eletrônica do estado adiabátio $J$. O gradiente na equação 7.7 é calculado da maneira

$$
\frac{\partial V_{J J}(\mathbf{R})}{\partial R_{\eta}}=\left\langle\psi_{J}\left|\frac{\partial \hat{\mathscr{H}}_{\text {ele }}}{\partial R_{\eta}}\right| \psi_{J}\right\rangle
$$

uma vez que o SCF para o problema eletrônico $\psi_{J}$ é atingida.

Em cada passo da simulação o acoplamento não-adiabático (do inglês non-adiabatic coupling - NAC) entre os estados eletrônicos para cada uma das TBFs. Há essencialmente duas maneiras de definir o NAC. A primeira é através do elemento de matriz do acoplamento não adiabático (non-adiabatic coupling matrix element - NACME), que é um vetor dado por

$$
\mathbf{c}_{I J}=\left\langle\psi_{I}\left|\vec{\nabla}_{\mathbf{R}}\right| \psi_{J}\right\rangle=\frac{\left\langle\psi_{I}\left|\vec{\nabla}_{\mathbf{R}} \hat{\mathscr{H}}_{\text {ele }}\right| \psi_{J}\right\rangle}{V_{J J}(\mathbf{R})-V_{I I}(\mathbf{R})},
$$

que é talvez a definição mais usual. Ao invés disso, foi utilizada uma outra maneira de definí-lo, através do acoplamento da derivada temporal (time derivative coupling - TDC), dado por

$$
\mathbf{d}_{I J}=\left\langle\psi_{I}\left|\frac{\partial}{\partial t}\right| \psi_{J}\right\rangle=\dot{\mathbf{R}} \cdot \frac{\left\langle\psi_{I}\left|\vec{\nabla}_{\mathbf{R}} \hat{\mathscr{H}}_{e l e}\right| \psi_{J}\right\rangle}{V_{J J}(\mathbf{R})-V_{I I}(\mathbf{R})}
$$

As duas definições diferem pois o TDC avalia quanto do movimento (velocidade) nuclear é dado, naquele instante, na direção do acoplamento, e acaba sendo mais apropriada. Foi utilizado o TDC nas simulações que serão apresentadas no próximo capítulo.

Durante a simulação, a cada instante o acoplamento 7.11 foi avaliado para cada TBF, entre o estado eletrônico em que se encontra e os demais envolvidos na dinâmica. Detalhadamente, define-se dois valores de corte para serem comparados com o TDC. O primeiro, menor, define a região de alto acoplamento. Uma vez inserida nessa região, o passo temporal da simulação diminui, de forma a descrever mais precisamente a propagação e a superfície de energia potencial. O segundo, maior, define quando o decaimento passa a acontecer. Os dois valores de corte são definidos antes da simulação. A amplitude de cada TBF na composição da função de onda nuclear 
é dada pelo coeficiente $C_{j}^{J}(t)$ na expressão 7.4. Naturalmente, em $t=0$ há uma única TBF, e portanto seu coeficiente vale 1 nesse instante. Conforme a dinâmica se desenvolve, ocorre transferência parcial de amplitudes para novas trajetórias que começam a surgir por divisões. Quando uma condição inicial dá origem a muitas divisões, as trajetórias podem acabar tendo coeficientes muito baixos ao final do tempo de integração da simulação. Define-se assim um valor mínimo de corte, cujo qual nos faz desprezar a TBF cujo coeficiente ao quadrado é menor.

Os valores das amplitudes $C$ 's são propagados através da equação de Schrödinger dependente do tempo. Durante as regiões de acoplamento, as equações de movimentos das funções $C_{j}^{J}(t)$ podem ser compactadas numa forma matricial do tipo

$$
\mathbf{S} \dot{\mathbf{C}}=-\frac{i}{\hbar}(\mathbf{H}-\dot{\mathbf{S}}) \mathbf{C}
$$

onde os elementos de matriz são dados por $\mathrm{H}_{i j}^{I J}=\left\langle\chi_{i}^{I}|\hat{\mathscr{H}}| \chi_{j}^{J}\right\rangle, \mathrm{S}_{i j}^{I J}=\left\langle\chi_{i}^{I} \mid \chi_{j}^{J}\right\rangle \delta_{I J} \mathrm{e}$ $\dot{\mathrm{S}}_{i j}^{I J}=\left\langle\chi_{i}^{I}\left|\frac{\partial}{\partial t}\right| \chi_{j}^{J}\right\rangle$. A integração da equação 7.12 fornece as amplitudes devidamente normalizadas de cada trajetória em cada instante de tempo, e com isso podemos avaliar médias de alguns observáveis físicos relevantes. Por exemplo, o valor médio da população de um certo estado eletrônico $I$ no instante $t$ pode ser escrito como

$$
P_{I}(t)=\frac{1}{N_{C I}} \sum_{M=1}^{N_{C I}}\left[\sum_{k, l}^{N_{I}(t)} C_{k, M}^{* I}(t) C_{l, M}^{I}(t) S_{k l, M}^{I I}\right]
$$

em que a soma interna corre sobre o número total de TBF's sobre um dado estado eletrônico $I, N_{I}(t)$, que foram originadas por uma mesma condição inicial, enquanto que a soma externa corre sobre todas as diferentes condições iniciais, e $N_{C I}$ representa o quantidade total de condições iniciais. Na equação 7.13, adiciona-se um índice $M$ tanto nos coeficientes $C_{k, M}^{I}(t)$ quanto nos elementos de overlap nuclear $S_{k l, M}^{I I}$, fazendo com que as somas internas sejam feitas separadamente para cada condição inicial. 


\section{Condições iniciais e detalhes computacionais}

A geração de condições iniciais foi baseada na técnica de amostragem de Wigner, e requer as seguintes etapas. Obtém-se a geometria otimizada associada à condição inicial. Como estamos concentrados na descrição de um ânion formado pela captura eletrônica por um sistema inicialmente neutro, a otimização foi realizada para o sistema neutro. Em seguida realiza-se um cálculo de frequência, no mesmo nível de teoria da otimização. A amostragem de Wigner usa o cálculo da matriz Hessiana para distribuir valores de posição e momento sobre a superfície de energia potencial, assumida harmômica quando em torno da geometria de mínima energia. Esse procedimento torna possível associar valores esperados de momento linear para cada grau de liberdade dos núcleos, sendo possível gerar da ordem de centenas de condições iniciais. Distribuições como essa requerem a definição de uma temperatura como parâmetro. Essa temperatura está associada à quantidade clássica de energia cinética que é atribuída aos núcleos na aproximação harmônica. A temperatura de Wigner utilizada no trabalho foi $300 \mathrm{~K}$.

É usual levantar um espectro de absorção óptica em problemas de fotodinâmica, e assim nos certificar que os estados eletrônicos envolvidos estão sendo bem descritos. Podemos usar para isso as condições iniciais geradas pela amostragem de Wigner. Calcula-se a energia de excitação $\Delta E_{I L}(\mathbf{R})$ entre os estados eletrônicos $I$ (referência) e $L$, assim como a força de oscilador $f_{I L}(\mathbf{R})$ para cada condição inicial, isto é, para um conjunto de diferentes geometrias $\left\{\mathbf{R}_{k}\right\}$. A seção de choque de absorção óptica é calculata com a expressão

$$
\sigma_{a b s}(E)=\frac{\pi e^{2}}{2 m c \epsilon_{0}} \sum_{\mathrm{L} \neq \mathrm{I}}^{N_{s}}\left[\frac{1}{N_{p}^{\mathrm{L}}} \sum_{k}^{N_{p}^{\mathrm{L}}} f_{\mathrm{IL}}\left(\mathbf{R}_{k}\right) g\left(E-\Delta E_{\mathrm{IL}}\left(\mathbf{R}_{k}\right), \delta\right)\right]
$$

em que $N_{p}^{\mathrm{L}}$ indica o número total de condições iniciais, $N_{s}$ é o número de estados eletrônicos excitados que estamos utilizando, $m$ é a massa do elétron e $g$ é uma distribuição Lorentziana em torno de $\Delta E_{I L}$ e de largura $\delta$. Novamente, enfatizo que a seção de choque de captura eletrônica não corresponde a seção de choque de 
absorção óptica. Entretanto, essa expressão será útil para futuros comentários e comparações.

Todos os cálculos de estrutura eletrônica, gradientes e acoplamentos foram calculados com o sofwtare TeraChem (GPU-based)[45-47]. A dinâmica foi simulada com o código AIMS.

\subsection{Adaptação do método AIMS para TNIs e seção de choque de DEA}

A dinâmica dos ânions transientes é um problema de alta complexidade. Como discutido nos capítulos 1 e 3, ressonâncias de forma podem ser entendidas como a captura eletrônica em um orbital virtual de valência da molécula neutra, que no caso dos problemas aqui abordados pode ser assumida como um sistema de camada fechada. Devido ao acoplamento com o contínuo as energias dos estados ressonantes $E_{r}$ não são auto-valores do hamiltoniano eletrônico, mas sim deslocadas, em relação a pseudo-estados correspondentes, de um quantidade conhecida como energy shift. Além disso, o acoplamento com o contínuo também se associa a probabilidade de autoionização, que constitui parte dos maiores desafios na descrição da dinâmica. Há muitas tentativas para adaptar técnicas usuais de química quântica para tratar estados ressonantes, e possivelmente os principais métodos na literatura são o método de estabilização baseado em cálculos equation of motion (EOM-CCSD) e o método complex scaling[84], altamente custosos sob o ponto de vista computacional. No nosso caso, propomos utilizar métodos usuais, computacionalmente mais simples do que EOM-CCSD, contanto que a adaptação para tratar as ressonâncias se apoie em cálculos de espalhamento obtidos previamente com o SMCPP. Essa etapa do projeto corresponde ao desenvolvimento de um protótipo. Reitero que adaptar técnicas de MQC como o AIMS para a dinâmica de ressononâncias requer uma série aproximações.

Recentemente, um trabalho sobre a dinâmica on-the-fly de TNIs foi publicado por Kossoski et al.[118]. O estudo realizado focou, entre outros objetivos, na adaptação do 
método Surface Hopping[119] para simular a dinâmica semi-clássica da ressonância incorporando o tempo de vida. No caso, foi estudado o cloroetano, sistema que admite uma captura eletrônica dissociativa direta via formação do ânion $\sigma_{\mathrm{CCl}}^{*}$. Os desenvolvimentos teóricos apresentados no artigo citado influenciaram diretamente o que foi feito para o AIMS e será apresentado a seguir.

O desenvolvimento teórico a respeito da dinâmica dos TNIs se inicia com um tratamento do acoplamento com o contínuo, representado por $\Gamma$, que no geral é uma função não-local da posição dos núcleos $\mathbf{R}$ e da energia de colisão E. O acoplamento cumpre um papel fundamental na captura eletrônica - amplitude de entrada, durante a propagação do pacote de ondas nuclear e na ejeção do elétron - amplitude de saída. Como uma abordagem adequada depende de técnicas de espalhamento severamente custosas, é usual realizar aproximações locais e/ou semi-locais para a função $\Gamma[120]$. Na abordagem local, aproxima-se $\Gamma(\mathbf{R}, E)$ para $\Gamma_{L}(\mathbf{R})=\Gamma\left(\mathbf{R}, E_{r}(\mathbf{R})\right)$. Grosso modo, na troca $E \rightarrow E_{r}(\mathbf{R})$ admitimos que o valor assumido pela largura $\Gamma$ é a mesma que se a energia equivalesse à própria energia da ressonância. Essa descrição acaba sendo uma boa aproximação para o $\Gamma$ exato (não-local) caso o mesmo não seja suficientemente largo[108]. Já na abordagem semi-local, admitimos que a largura é uma função separável da forma $\Gamma(\mathbf{R}, E)=g^{2}(\mathbf{R}) \gamma(E)$. A condição de que, para uma dada geometria nuclear, a aproximação semi-local da largura deve se reduzir à aproximação local quando $E=E_{r}(\mathbf{R})$ faz com que

$$
\Gamma(\mathbf{R}, E)=\Gamma_{L}(\mathbf{R}) \frac{\gamma(E)}{\gamma\left(E_{r}(\mathbf{R})\right)}
$$

Particularmente, alguns trabalhos utilizam aproximações locais para descrever o efeito da largura na propagação do pacote de ondas e aproximações semi-locais para as amplitudes de entrada (captura) e saída (ejeção) do elétron[108, 121]. A forma funcional de $\gamma(E)$ deve respeitar a lei de Wigner para baixas energias[122], assumindo o comportamento do tipo $\gamma(E) \sim E^{l+1 / 2}$, onde $l$ é o maior número quântico de momento angular que contribui para o espalhamento, no sentido da decomposição em ondas parciais. Assim assumimos a forma $\gamma(E)=A E^{1 / 2}$ para processos de baixas energias 
(onda $s$ ), e a expressão para a aproximação semi-local fica

$$
\Gamma(\mathbf{R}, E)=\Gamma_{L}(\mathbf{R})\left(\frac{E}{E_{r}(\mathbf{R})}\right)^{1 / 2}
$$

agora dependendo apenas de um modelo mais específico para $\Gamma_{L}$. A aproximação local é tipicamente modelada de uma forma simples, como por exemplo sendo linearmente proporcional à energia da ressonância, observando que a mesma deve ir a zero para $E_{r}=0$. No nosso caso, como o modelo foi aplicado ao estudo da 5-BrU, a forma adotada para a aproximação local foi inspirada na relação energia-largura ajustada no capítulo 6 (eq. 6.9 ), em que $\Gamma_{L}(\mathbf{R})=\alpha E_{r}(\mathbf{R})^{b}$, onde o $b$ utilizado é 1.301 e $\alpha$ é ajustado de modo que a expressão deve ser capaz de descrever a mesma relação energia-largura obtida com o SMC. É nesse ponto que os cálculos de espalhamento são relevantes. Vale esclarecer que a relação energia-largura depende da natureza do estado com que lidamos. Duas ressonâncias de caráteres distintos ( $\pi^{*}$ e $\sigma^{*}$ é um exemplo imediato) não possuem larguras iguais em energias iguais. Assim, o parâmetro $\alpha$ deve ser calculado de forma adequada para a ressonância em questão.

Com as aproximações para $\Gamma$, o primeiro passo é tratar da captura eletrônica. Nas simulações processo de captura ocorre pela molécula neutra numa dada geometria $\mathbf{R}_{0}$, que será assim denotada por ser a condição incial da dinâmica no espaço de posições nucleares. A seção de choque do processo deve seguir a mesma ideia da eq. 7.14, referente à absorção óptica. Entretanto, como não há análogo imediato do termo $f_{\mathrm{IL}}$ para o caso da captura eletrônica, trabalharemos com uma distribuição Lorentziana normalizada do tipo ${ }^{1}$

$$
f_{l}\left(\mathbf{R}_{0}, E\right)=\frac{1}{\pi} \frac{\eta\left(\mathbf{R}_{0}, E\right) / 2}{\left(E-E_{r}\left(\mathbf{R}_{0}\right)\right)^{2}+\left(\eta\left(\mathbf{R}_{0}, E\right) / 2\right)^{2}},
$$

em que a função $\eta\left(\mathbf{R}_{0}, E\right)$ carrega implicitamente a física do acoplamento contínuo

\footnotetext{
${ }^{1} \mathrm{O}$ subscrito $l$ é responsável apenas por explicitar a forma Lorentziana da função.
} 
$\rightarrow$ ressonância e é dada por

$$
\eta\left(\mathbf{R}_{0}, E\right)=\eta \frac{\gamma(E)}{\gamma\left(E_{r}\left(\mathbf{R}_{0}\right)\right)}=\eta\left(\frac{E}{E_{r}\left(\mathbf{R}_{0}\right)}\right)^{1 / 2}
$$

com $\eta$ uma constante a ser modelada. Nessa abordagem, a seção de choque de captura eletrônica pode ser interpretada como proporcional ao produto $\Gamma\left(\mathrm{R}_{0}, E\right) f_{l}\left(\mathbf{R}_{0}, E\right)$.

Nota-se que devido à forma funcional de $\gamma(E)$ a função 7.17 já está automaticamente normalizada independente de $\eta$ e $\mathbf{R}_{0}$. Caso tivéssemos adotado um outro modelo para $\gamma$, uma constante de normalização se faria conveniente. Os cálculos realizados para a determinação do parâmetro $\eta$ estão apresentados na seção de resultados.

O segundo passo diz respeito à probabilidade de auto-ionização. Depois de formada, a ressonância pode decair via devolução do elétron para o contínuo. Nesse contexto é conveniente trabalhar com a probabilidade de sobrevida, $P_{\mathrm{sv}}$, ao invés da probabilidade de auto-ionização. A quantidade $P_{\mathrm{sv}}$ mensura a probabilidade da ressonância sobreviver ao processo de auto-ionização e é uma função decrescente do tempo. Podemos construí-la de uma de uma maneira heurística, partindo da ideia de que, a núcleos fixos, a probabilidade de uma ressonância não decair via auto-ionização $\mathrm{e}^{2}$

$$
P_{\mathrm{sv}}(t)=\exp \left[-\frac{\Gamma}{\hbar} t\right] \rightarrow \exp \left[-\frac{\Gamma_{L}(\mathbf{R})}{\hbar} t\right],
$$

onde assumo que $t=0$ é o instante em que a ressonância é formada. Acontece que no caso dinâmico $(\mathbf{R}=\mathbf{R}(t))$ a função $\Gamma_{L}(\mathbf{R}(t))$ é atualizada a cada geometria acessada, de forma que a expressão 7.19 deve ser alterada para

$$
P_{\mathrm{sv}}(t)=\exp \left[-\frac{1}{\hbar} \int_{0}^{t} \Gamma_{L}\left(\mathbf{R}\left(t^{\prime}\right)\right) d t^{\prime}\right]
$$

Em dinâmicas não-adiabáticas o sistema pode sofrer um decaimento interno entre dois estados eletrônicos, mediado pelo acoplamento TDC. Caso esse decaimento ocorra num determinado instante $\bar{t}$, a função $P_{\mathrm{sv}}(t)$ após o decaimento é fatorada, de

\footnotetext{
${ }^{2}$ Já deixo indicado que utilizaremos a aproximação local de $\Gamma$ para o cálculo de $P_{\mathrm{sv}}$.
} 
forma que

$$
P_{\mathrm{sv}}(t)=\exp \left[-\frac{1}{\hbar} \int_{0}^{\bar{t}} \Gamma_{L}\left(\mathbf{R}\left(t^{\prime}\right) ; a\right) d t^{\prime}-\frac{1}{\hbar} \int_{\bar{t}}^{t} \Gamma_{L}\left(\mathbf{R}\left(t^{\prime}\right) ; b\right) d t^{\prime}\right]=P_{\mathrm{sv}}(t ; a) P_{\mathrm{sv}}(t-\bar{t} ; b)
$$

onde os índices $a$ e $b$ indicam o $\Gamma$ local em cada uma das ressonâncias. Na metodologia AIMS, uma condição inicial $j$ (caracterizada pelo par $\left(\mathbf{R}_{0}^{j}, \mathbf{P}_{0}^{j}\right)$ ) pode dar origem a várias TBFs, como discutido na seção anterior. Como as TBFs traçam caminhos distintos, ao final da simulação $\left(t=t_{\text {final }}\right)$ associamos uma probabilidade de sobrevia a cada uma delas, a qual denotaremos por $P_{\mathrm{sv}}^{n_{j}}\left(t_{\text {final }}\right)$. Nessa notação, o índice $n_{j}$ indica a $n$-ésima TBF advinda da condição inicial $j$.

O último passo é a obtenção da seção de choque de DEA propriamente dita. A expressão de trabalho utilizada é, em unidades atômicas $\left(a_{0}^{2}\right)$,

$$
\sigma_{\mathrm{DEA}}(E)=\frac{\pi}{N_{C I} E} \sum_{j=0}^{N_{C I}} \Gamma\left(\mathrm{R}_{0}^{j}, E\right) f_{l}\left(\mathbf{R}_{0}^{j}, E\right) \wp_{j}
$$

em que o termo $\wp_{j}$ é dado por

$$
\wp_{j}=\sum_{n_{j}=1}^{N_{\mathrm{TBF}}^{j}} a_{n_{j}} P_{\mathrm{Sv}}^{n_{j}}\left(t_{\text {final }}\right)
$$

onde $a_{n_{j}}$ é a população (módulo do coeficiente ao quadrado) da trajetória $n_{j}, N_{\mathrm{TBF}}^{j}$ denota o número total de TBFs da $j$-ésima condição inicial e os coeficientes das TBFs de uma particular condição inicial estão devidamente normalizados. Explicitando a aproximação local da largura, a expressão final para a seção de choque é

$$
\sigma_{\mathrm{DEA}}(E)=\frac{\pi}{N_{C I} \sqrt{E}} \sum_{j=0}^{N_{C I}} \frac{\Gamma_{L}\left(\mathbf{R}_{0}^{j}\right) f_{l}\left(\mathbf{R}_{0}^{j}, E\right)}{\sqrt{E_{r}\left(\mathbf{R}_{0}^{j}\right)}}\left[\sum_{n_{j}=1}^{N_{\mathrm{TBF}}^{j}} a_{n_{j}} P_{\mathrm{sv}}^{n_{j}}\left(t_{\text {final }}\right)\right]
$$

O maior cuidado que devemos tomar ao usar a expressão 7.24 é a restrição sobre a soma entre colchetes, caso o sistema admita mais de um canal dissociativo. Se estivermos interessados no estudo de uma particular dissociação $\mathrm{AB}^{-} \rightarrow \mathrm{A}+\mathrm{B}^{-}$, a 
soma deve ser restrita às TBFs que contemplam esse processo.

\section{Algumas considerações}

Nas simulações AIMS, escolhe-se de antemão os estados eletrônicos envolvidos. Em geral para descrever processos complicados em energias mais altas esse número pode ser grande, porém em um grande número de processos esse número varia entre 2 e 3. A escolha do nível de teoria para resolver o problema eletrônico é um fator importante para a simulação, pois ele deve ser suficientemente capaz de descrever as energias e os caráteres dos estados eletrônicos de interesse. O método também deve ser capaz de descrever acoplamentos não-adiabáticos entre estados eletrônicos e intersecções cônicas / cruzamentos evitados (do inglês avoided crosings). Métodos baseados em teoria da resposta linear como os baseados em DFT dependente do tempo (TDDFT), por exemplo, não são apropriados, pois tratam não tratam em pés de igualdade o estado de referência dos demais, de certo que em processos fotoquímicos de moléculas neutras de camada fechada, não são capazes de descrever acoplamentos do tipo $\mathrm{S}_{0} / \mathrm{S}_{1}$. Por outro lado, como a simulação exige o cálculo de energias, gradientes e acoplamentos em cada passo da dinâmica, não seria praticável utilizar métodos mais sofisticados, devido ao custo computacional. Adotamos assim métodos baseados na teoria do espaço ativo completo (do inglês complete active space - CAS). Particularmente, foi utilizado o FOMO-CASCI (fractional occupiancy molecular orbital-complete active space - configuration interaction), método que nos últimos anos vem se mostrando uma boa escolha para tratar esse tipo de problema. 


\section{Capítulo 8}

\section{A dinâmica dos ânions transientes da 5 -BrU}

Tratamos de apresentar e interpretar os resultados experimentais do espectro de DEA das 5 -BrU a baixas energias $(0 \sim 4 \mathrm{eV})$. A 5 -BrU foi escolhida por ter canais dissociativos bastante conhecidos na literatura, além de historicamente ter sido o primeiro radiossensibilizador a ser identificado[23]. Os experimentos [112, 123, 124] reportam dissociações induzidas pela captura eletrônica em diferentes energias do feixe de elétrons incidente, sendo o ânion $\mathrm{Br}^{-}$o fragmento mais abundante. Observase um conjunto de três finas estruturas entre $0 \mathrm{eV}$ e $\sim 0.3 \mathrm{eV}$ nos canais de eliminação de $(\mathrm{U}-\mathrm{H})^{-}$e de $\mathrm{Br}^{-}$, as quais podem ser atribuídas a ressonâncias vibracionais de Feshbach (FVR). Também observamos uma fina estrutura próxima a $\sim 0 \mathrm{eV}$ no canal da formação do ânion 5-BrU ${ }^{-}$. Além dessas estruturas em baixíssimas energias, observa-se uma estrutura em 1.5 eV no canal de eliminação do radical (U-H) ${ }^{-}$, que pode ser atribuída a formação de uma ressonância. No canal de eliminação de $\mathrm{Br}^{-}$ observa-se uma estrutura também em torno de $1.4 \sim 1.5 \mathrm{eV}$, cujo sinal é mais intenso quando comparado à eliminação de $(\mathrm{U}-\mathrm{H})^{-}$.

Os picos em $1.4 \sim 1.5 \mathrm{eV}$ nos sinais experimentais de DEA correspondem a dinâmicas dissociativas mediadas pela formação da ressonância $\pi_{2}^{*}$ do ânion 5-BrU, e o objetivo dessa etapa é aplicar o método apresentado no capítulo anterior para tentar descrever o TNIs $\pi_{2}^{*}$. Sob o ponto de vista teórico, cálculos de espalhamento foram realizados e ressonâncias de forma da 5-BrU foram caracterizadas por Kossoski 
et al.[9]. Os autores apontam a existência de um ânion ligado de valência $\left(\pi_{1}^{*}\right)$ em torno de $-0.3 \mathrm{eV}$, um estado fracamente ligado por dipolo (DBS) entre $-71 \mathrm{meV}$ e $-42 \mathrm{meV}$, e três ressonâncias de forma. A ressonância $\sigma_{\mathrm{CBr}}^{*}$ foi estimada em 0.73 $\mathrm{eV}$, a ressonância $\pi_{2}^{*}$ foi estimada em $1.5 \mathrm{eV}$ e a ressonância $\pi_{3}^{*}$ se encontra em torno de $4.45 \mathrm{eV}$. A comparação entre as estimativas teóricas e as estruturas na seção de choque de DEA propõe que o mecanismo indireto - captura eletrônica na ressonância $\pi_{2}^{*}$ seguida de um acoplamento $\pi_{2}^{*} / \sigma_{\mathrm{CBr}}^{*}$ - é capaz de induzir a eliminação do $\mathrm{Br} / \mathrm{Br}^{-}$ de forma mais eficaz que o mecanismo direto - captura eletrônica na ressonância $\sigma_{\mathrm{CBr}}^{*}$ seguida de uma dissociação. Segundo as larguras de autoionização reportadas, os estados $\sigma_{\mathrm{CBr}}^{*}$ e $\pi_{2}^{*}$ possuem tempos de vida verticais - isto é, sem considerar relaxação vibracional - de 1.1 fs e $6.6 \mathrm{fs}$, respectivamente. O tempo de sobrevida do TNI é naturalmente maior do que esses valores, uma vez que a relaxação vibiracional tende a estabilizar a ressonância, diminuindo a probabilidade de autoionização. Porém, ainda assim o tempo de vida do estado $\sigma^{*}$ é muito curto, podendo por si só explicar a ausência de sua assinatura no mecanismo dissociativo direto.

Um aspecto intrigante a respeito do espectro de $\mathrm{DEA}$ da 5 -BrU é a ausência de sinal referente à eliminação de hidrogênio. Apesar do papel questionável desse processo em fase condensada, a quebra da ligação N1-H em bases pirimidínicas pode ser observada em moléculas isoladas, e em particular se manifestam nos espectros de DEA da 5-ClU e 5-FU[112]. No caso da 5-BrU, esperaria-se que a eliminação de hidrogênio fosse mediada pelo acoplamento da ressonância $\pi_{2}^{*}$ com um estado de caráter antiligante ao longo da ligação N1-H. O limiar energético de dissociação dessa fragmentação, segundo cálculos G4MP2, está em torno de $0.52 \mathrm{eV}$, sendo dessa forma um canal aberto na energia da ressonância $\pi_{2}^{*}$. Entretanto, como mencionado, não se observa um sinal correspondente.

Dito isso, o objetivo principal é a simulação da dinâmica do estado transientes $\pi_{2}^{*}$, ressonâncias de forma, onde buscou-se reproduzir os resultados experimentais. Para descrever os picos próximos a $0 \mathrm{eV}$ seria preciso um modelo para as FVRs. No entanto, como esses estados estados correspondem a uma estrutura vibracional do 
ânion ligado, o tratamento não é possível com a progação clássica ou semi-clássica do pacote de ondas nuclear. Ainda não há, até onde conhecemos, maneira de incorporar diferentes estados do espectro vibracional (quântico) na amostragem de condições iniciais (clássica). Por esse motivo a dinâmica desses estados não foi abordada no trabalho.

\subsection{Alguns cálculos e modelagens preliminares}

Os quatro estados envolvidos são as três ressonâncias do ânion, $\pi_{1}^{*}, \sigma_{\mathrm{CBr}}^{*}$ e $\pi_{2}^{*}$, além do estado fundamental do neutro. Como os estados do ânion são sistemas de camada aberta, me referirei a eles como $\mathrm{D}_{0}, \mathrm{D}_{1}$ e $\mathrm{D}_{2}$ (dubletos), respectivamente. O estado fundamental do neutro é um singleto de camada fechada, e por sua vez será referido como S0. Os cálculos baseados no método SMC descrevem energias compatíveis com excitações de $1.03 \mathrm{eV}\left(\pi_{1}^{*} \rightarrow \sigma_{\mathrm{CBr}}^{*}\right)$ e $1.80 \mathrm{eV}\left(\pi_{1}^{*} \rightarrow \pi_{2}^{*}\right)$.

A geometria da 5-BrU neutra foi incialmente otimizada no nível DFT/B3LYP/augcc-pVDZ, e a resolução da matriz Hessiana, no mesmo nível de cálculo, permitiu que a amostragem de Wigner fosse realizada. O método FOMO-CASCI/6-31G* foi testado antes da simulação, e há praticamente duas justificativas para o uso da base compacta 6-31G*. A primeira é que essa base é capaz de descrever orbitais de valência $\pi^{*}$ e $\sigma^{*}$ associados às ressonâncias. Outro motivo é a facilidade computacional. Como já mencionado, é importante estabelecer um nível de teoria sob o qual a realização de muitos cálculos seja praticável. Em unidades atômicas, a temperatura FOMO utilizada é de 0.2. O método FOMO-CASCI, juntamente com a base compacta, descreve os estados $\sigma_{\mathrm{CBr}}^{*}$ e $\pi_{2}^{*}$ em energias $\sim 1.30 \mathrm{eV}$ e $\sim 2.50 \mathrm{eV}$, respectivamente, em relação à energia do estado fundamental $\pi_{1}^{*}$. Os caráteres dos orbitais SOMO dos estados podem ser conferidos no painel da Fig. 8.1. Os valores das energias de excitação são relativamente comparáveis com os descritos pelas técnicas de espalhamento. A diferença entre as ressonâncias, obtida em $1.2 \mathrm{eV}$, pode ser comparada com a diferença correspondete de $\sim 0.8 \mathrm{eV}$ obtida com o SMC. A compatibilidade é ainda mais justificável se observarmos que o cálculo foi realizado com um espaço ativo bem 


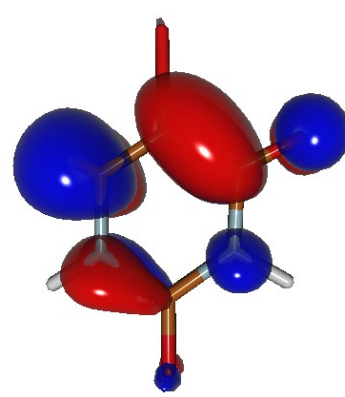

(a)

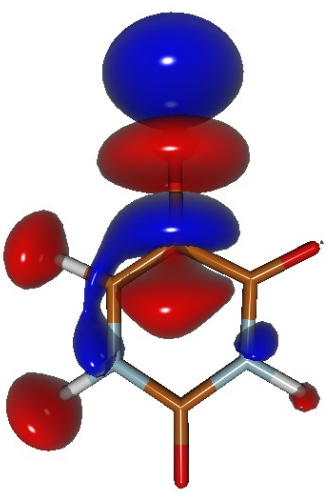

(b)

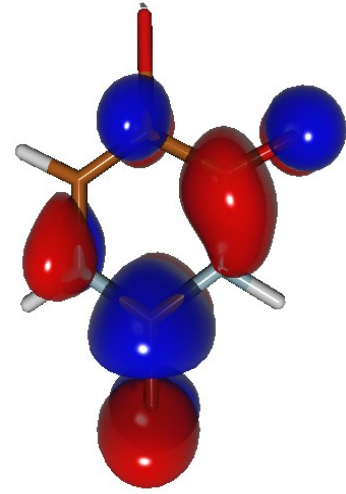

(c)

Figura 8.1: Orbitais SOMO/FOMO-CASCI/6-31G* associados aos estados (a) $\pi_{1}^{*}$, (b) $\sigma_{\mathrm{CBr}}^{*}$ e (c) $\pi_{2}^{*}$ do ânion 5 - $\mathrm{BrU}^{-}$, na geometria otimizada da molécula neutra. Os orbitais foram gerados com o isovalor 0.4.

reduzido, tanto no número de orbitais quanto no número de elétrons, e dessa forma a energia de correlação é subestimada, em módulo, e as energias dos estados estão também superestimadas em torno de $0.5 \sim 0.6 \mathrm{eV}$.

Superfícies de energia potencial (SEP) adiabáticas dos três estados do ânion foram levantadas com o mesmo nível de teoria em função da coordenada reativa definida como a comprimento da ligação C-Br (Fig. 8.2). As geometrias utilizadas para o levantamento das curvas foram parcialmente otimizadas, considerando a distância C-Br como fixa nos pontos mostrados no gráfico. Como estamos lidando com estados eletrônicos adiabáticos, o caráter das estruturas eletrônicas não se preservam, no geral. Ao invés disso, o caráter acaba sofrendo alterações essencialmente quando o pacote de ondas nuclear atravessa uma região de acoplamento ou um estado de transição. Na região de Franck-Condon da 5-BrU neutra os estados $\mathrm{D}_{0}, \mathrm{D}_{1}$ e $\mathrm{D}_{2}$ correspondem aos estados $\pi_{1}^{*}$ (ligado), $\sigma_{\mathrm{CBr}}^{*}$ e $\pi_{2}^{*}$ (ressonantes). Uma análise imediata da Fig. 8.2 nos leva a supor a existência de uma intersecção $\mathrm{D}_{2} / \mathrm{D}_{1}$ próximo a região de Franck-Condon do neutro $\left(R_{\mathrm{CBr}} \sim 1.9 \AA\right)$, particularmente próximo a $R_{\mathrm{CBr}} \sim 1.7 \AA$. Isso sugere que a ressonância $\pi_{2}^{*}$ pode decair via transição D2 $\rightarrow \mathrm{D}_{1} \mathrm{em}$ intervalos de tempo muito curtos (de unidades à poucas dezenas de fs), dependendo 


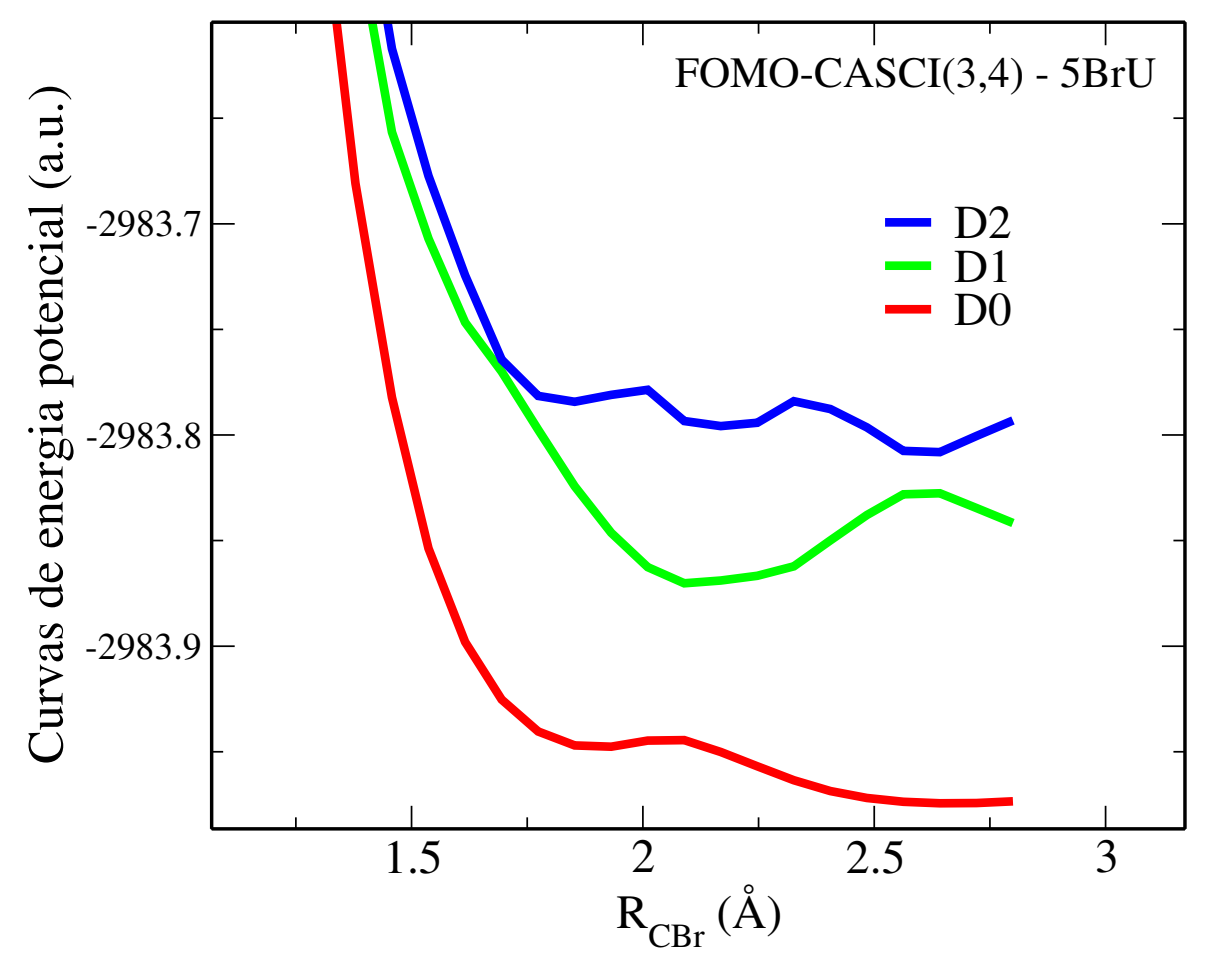

Figura 8.2: SEPs adiabáticas do estado fundamental $\mathrm{D}_{0}$ (vermelho) e dos dois primeiros estados excitados $\mathrm{D}_{1}$ (verde) e $\mathrm{D}_{2}$ (azul) em função da distância C-Br. As curvas foram levantadas no nível FOMO-CASCI $(3,4) / 6-31 \mathrm{G}^{*}$.

das condições iniciais. Sobre o decaimento $\mathrm{D}_{1} \rightarrow \mathrm{D}_{0}$, não foi possível identificar com clareza uma região de possível intersecção cônica nessa projeção das SEPs, indicando a necessidade da modificação de outros graus de liberdade para que o sistema a atinja. Entretanto, uma análise cuidadosa dos orbitais SOMOs ao longo das curvas mostra uma transferência de caráter $\sigma_{\mathrm{CBr}}^{*}$ do estado adiabático $\mathrm{D}_{1}$ para $\mathrm{D}_{0}$ a partir de $R_{\mathrm{CBr}} \sim 2.2 \AA$, na região onde o estado fundamental passa ser antiligante ao longo dessa ligação.

Vale lembrar que as energias das ressonâncias $E_{r}^{\pi_{2}^{*}}$ e $E_{r}^{\sigma_{\mathrm{CBr}}^{*}}$ não correspondem às energias de excitação do ânion, mas sim às energias dos estados excitados do ânion com relação ao estado fundamental do neutro. Os valores foram calculados em conjunto a estimativas da energia de ligação do ânion ligado (do inglês, vertical binding energy - VBE). Em outras palavras, estima-se a energia do estado ligado do ânion $\left(\pi_{1}^{*}\right)$ com relação ao estado fundamental do neutro, e a esse valor soma-se as energias de excitação FOMO-CASCI/6-31G*. Houve a necessidade de se trabalhar com dois níveis de teoria, pois o FOMO-CASCI descreve o estado $\pi_{1}^{*}$ como uma 
ressonância na geometria de equilíbrio. Após uma investigação metodológica e de funções de base, concluiu-se que a teoria que mais se aproximou das relações entre as energias dos ânions e do neutro S0 foi o método baseado em DFT $\omega$-PBE/aug-ccpVDZ usando o parâmetro de correção $\omega=0.4(\mathrm{VBE}=-0.30 \mathrm{eV})$.

Das 300 configurações geradas pela amostragem de Wigner, 21 foram selecionadas aleatoriamente para as simulações AIMS. Esse número aparentemente baixo é justificado a posteriori, e o argumento se baseia no número de TBFs geradas, que acaba por ser razoável no contexto de dinâmicas MQC não-adiabáticas (da ordem de $\sim 100)$. Cálculos das energias $E_{r}^{\pi_{2}^{*}}$ foram feitos com o intuito de obter um valor razoável para o parâmetro $\eta$ (equação 7.18). Na Fig. 8.3 apresento as distribuições $f_{l}$ para as 21 geometrias selecionadas, nos painéis à esquerda, e a soma normalizada, à direita, para $\eta=0.5,0.4,0.3,0.2$. O alargamento das distribuições com o aumento do valor $\eta$ é visível. Além disso, vemos que para distribuições finas $(\eta=0.2,0.3)$ ocorre o surgimento de algumas estruturas na distribuição da soma, o que poderia levar a estruturas com comportamentos similares na seção de choque de DEA. O valor utilizado foi 0.4 .

\subsection{Resultados da dinâmica}

A primeira parte da dinâmica AIMS foi realizada sem levar em conta o tempo de vida de autoionização. O tempo total de integração das equações de movimento foi definido como 390 fs, e na Fig. 8.4 disponho um painel esquemático útil para ilustrar como uma única condição inicial pode dar origem a várias TBFs ao longo da simulação, até o instante final. O número de TBFs ao final desse exemplo foi seis, e chamo a atenção para os últimos decaimentos das TBFs mostradas na parte superior do painel. O fato dos decaimentos não resultarem na divisão da TBF anterior, e sim apenas uma transferência da população para o estado eletrônico abaixo, mostra que as amplitudes das TBFs não indicadas são pequenas o suficiente para serem desprezadas. O valor de corte para desprezar uma TBF resultante de uma divisão foi $10^{-5}$, e a todo momento que uma TBF é desprezada as TBFs sobreviventes têm 


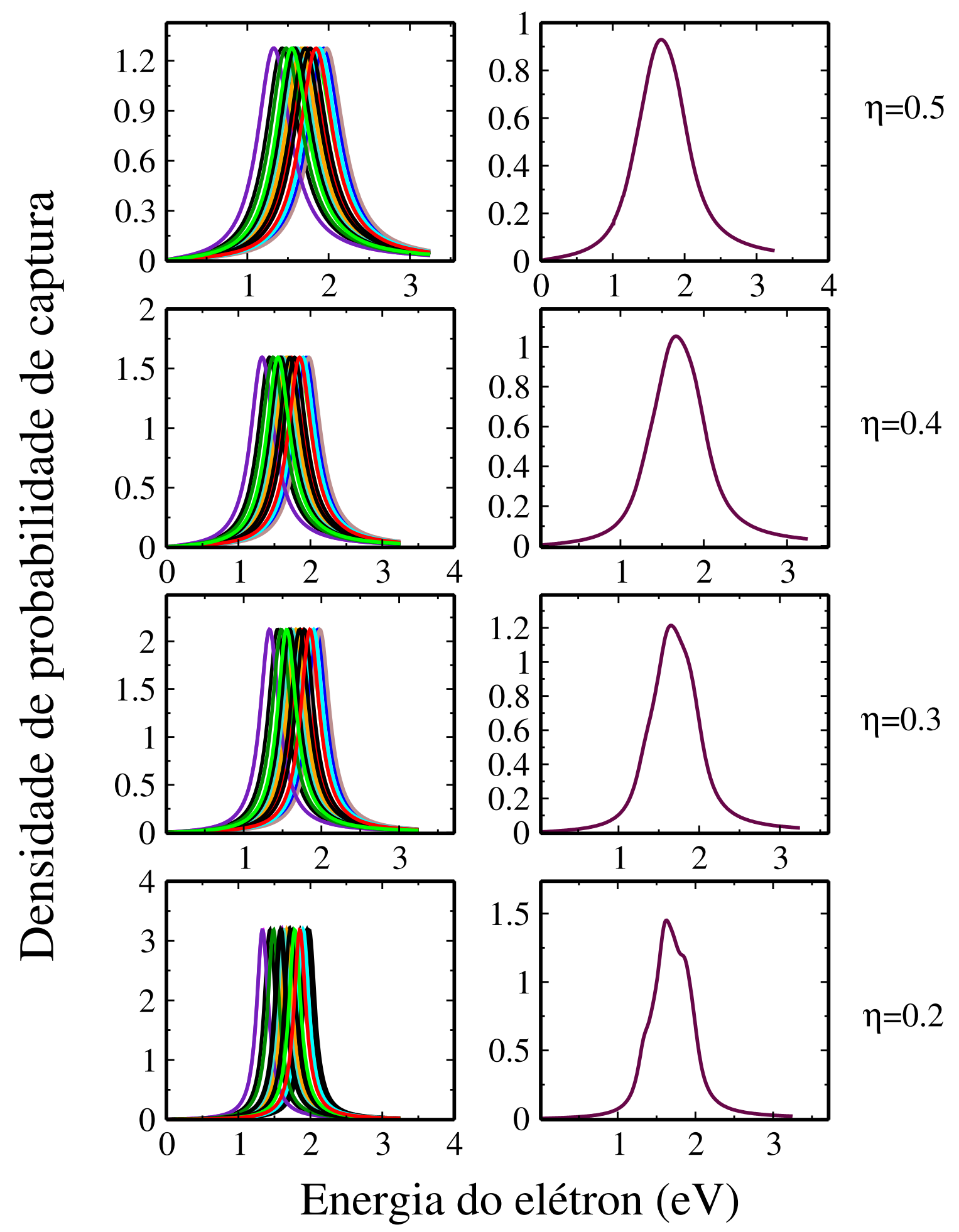

Figura 8.3: Painéis das distribuições Lorentzianas $f_{l}\left(\mathbf{R}_{0}^{j}, E\right)$ obtidas para as 21 configurações, à esquerda, e as respectivas somas normalizadas, à direita. Os valores do parâmetro $\eta$ estão indicados em cada caso.

suas amplitudes renormalizadas. Baseado apenas nos resultado dessa condição inicial, nota-se que as regiões de acoplamento são atingidas em tempos da ordem de poucas 
dezenas de fs.

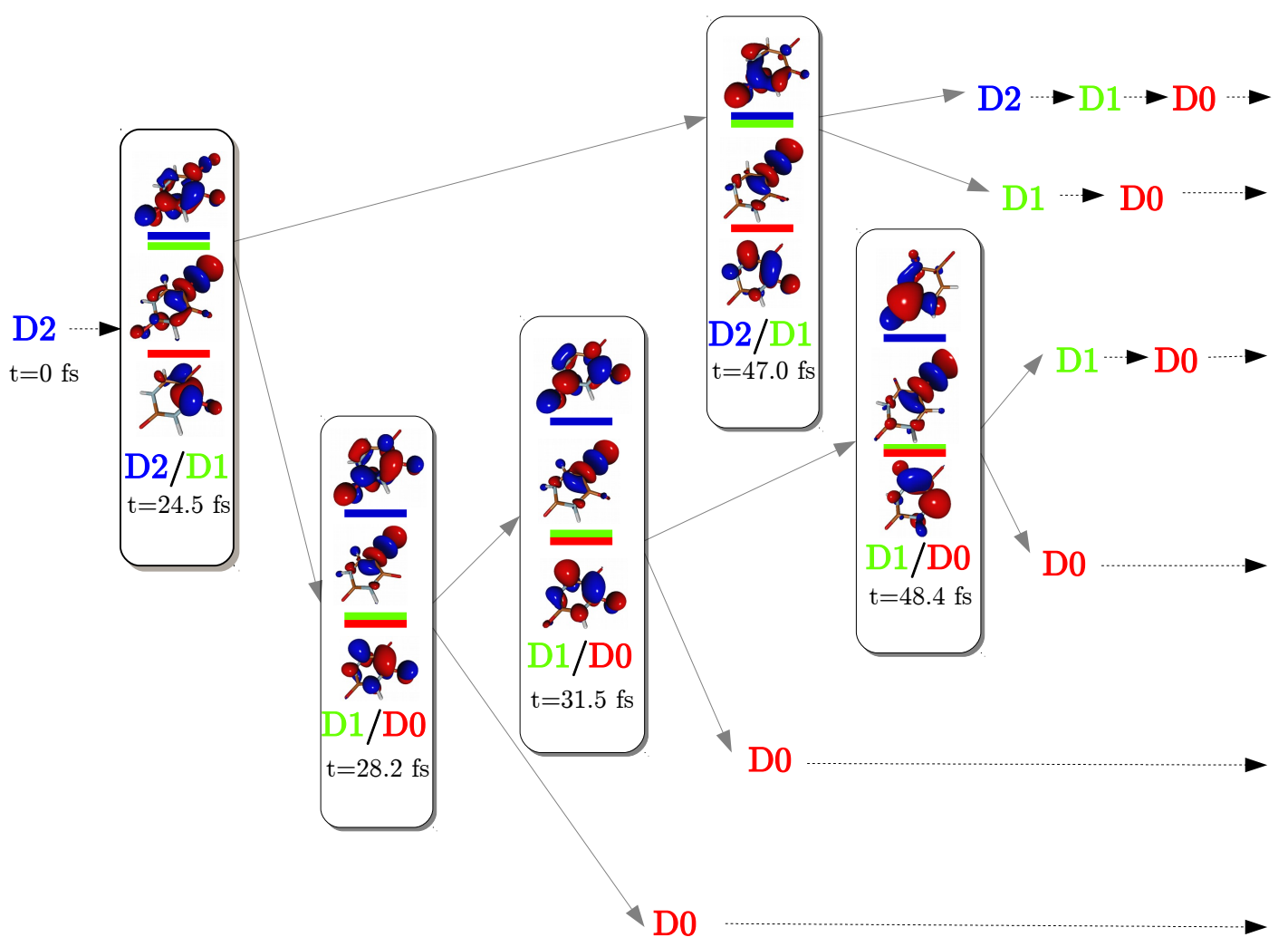

Figura 8.4: Painel esquemático da propagação e divisões (spawnings) da função de onda nuclear referente a uma única condição incial. Inicialmente $(t=0)$ a função de onda nuclear era dada por um único pacote de onda sobre o estado eletrônico $\mathrm{D}_{2}$ $\left(\pi_{2}^{*}\right)$. A primeira divisão da TBF ocorre em cerca de $t=24.5$ fs e corresponde a um decaimento $\mathrm{D}_{2} \rightarrow \mathrm{D}_{1}$ (acoplamento $\pi_{2}^{*} / \sigma_{\mathrm{CBr}}^{*}$ ). Seguindo adiante, podemos acompanhar duas TBFs percorrendo caminhos independentes e atingido regiões de diferentes acoplamentos. Nesse exemplo, há divisões em 28.2fs (acoplamento $\sigma_{\mathrm{CBr}}^{*} / \pi_{1}^{*}$ ), 32.5 fs (acoplamento $\sigma_{\mathrm{CBr}}^{*} / \pi_{1}^{*}$ ), 47.0fs (acoplamento $\pi_{2}^{*} / \sigma_{\mathrm{CBr}}^{*}$ ) and 48.4fs (acoplamento $\left.\sigma_{\mathrm{CBr}}^{*} / \pi_{1}^{*}\right)$.

O critério estabelecido para caracterizar a dissociação corresponde ao valor limiar $3.3 \AA$ para o comprimento da ligação, e três das seis TBFs resultantes da rodada mostrada na Fig. 8.4 apresentam eliminação de $\mathrm{Br}^{-}$. Todas as três dissociações mencionadas ocorrem uma vez que o pacote de onda já encontra-se no estado $D_{0}$.

Como mencionado acima, uma coleção de 21 condições iniciais foi selecionada, e ao final das 21 rodadas obtivemos 122 trajetórias - uma média de 5.81 TBFs por condição inicial. A população de TBFs, devidamente normalizada, foi estudada com a equação 7.13 e o resultado pode ser observado no gráfico da Fig. 8.5. Na figura, as 


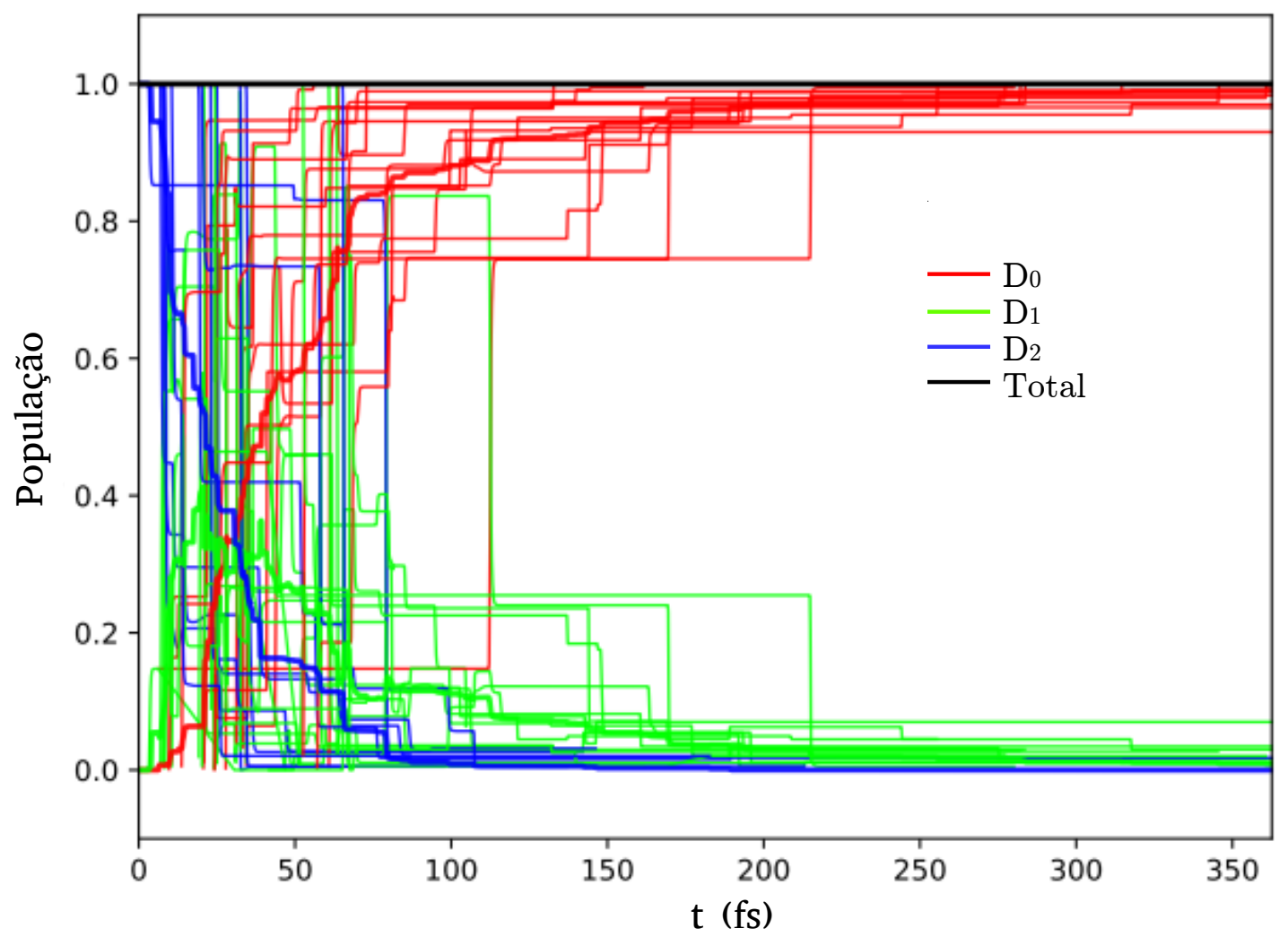

Figura 8.5: População $P_{I}(t)$ dos estados eletrônicos $I=0,1,2$ obtidos sobre as 122 TBFs originadas a partir de 21 condições iniciais. O ponto de partida das TBFs iniciais foi o estado $\mathrm{D}_{2}$ (curva azul), e pode-se observar a maneira como a população é transferida para os estados $\mathrm{D}_{1}$ (verde) e $\mathrm{D}_{0}$ (vermelho). As linhas mais finas representam a evolução das populações de cada condição inicial, enquanto que as linhas grossas (uma de cada cor) mostram a média obtida diretamente da equação 7.13.

linhas mais estreitas correspondem a diferentes condições iniciais, enquanto que as três linhas grossas correspondem a médias sobre todas elas. Com ajustes exponenciais, obteve-se um tempo de vida do estado $\mathrm{D}_{2}$, frente ao decaimento, de $\tau_{2}=38.7 \mathrm{fs}$, enquanto que o aumento da população em $\mathrm{D}_{0}$ ocorre em uma escala de tempo típica de $\tau_{0}=56.8 \mathrm{fs}$.

Explorando os resultados observamos que 76 das 122 trajetórias contemplam a eliminação de $\mathrm{Br}$ ou $\mathrm{Br}^{-}$, e interpretando o quadrado das amplitudes de cada uma delas como probabilidade, reportamos uma probabilidade de dissociação do Br neutro, ou (U-H) ${ }^{-}$de $26 \%$ contra $40 \%$ para o $\mathrm{Br}^{-}$. O gráfico da Fig. 8.6 apresenta o valor da coordenada reativa $R_{\mathrm{CBr}}$ de cada trajetória em função do tempo. É possível notar que a dissociação do halogênio não ocorre imediatamente após o decaimento para o 


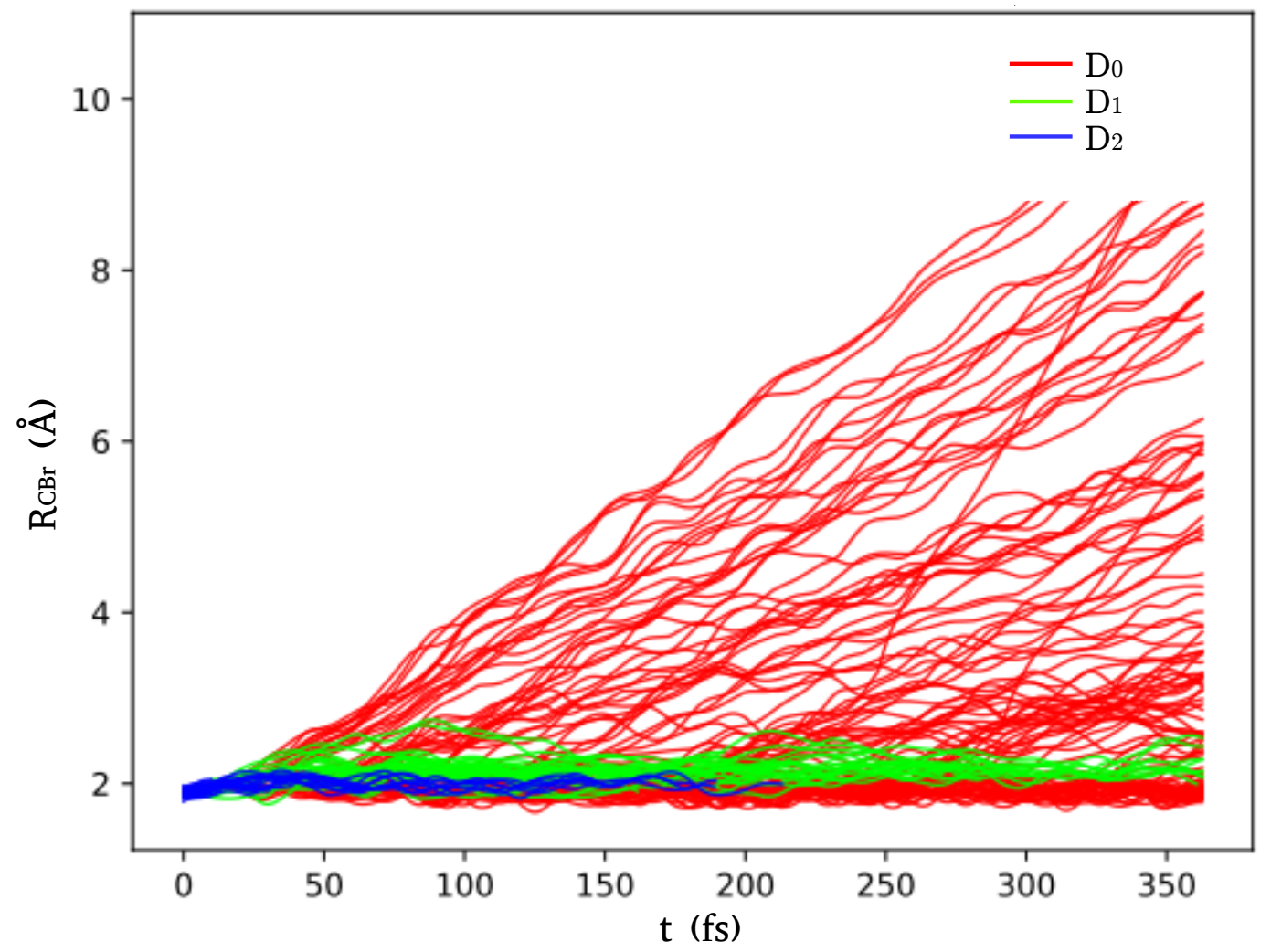

Figura 8.6: Análise dos valores da coordenada reativa $R_{\mathrm{CBr}}$ em função do tempo para cara trajetória. As cores indicam o cada estado eletrônico em que se encontram a TBF.

estado $D_{0}$. De fato, a interpretação é que parece não haver uma preferência para que a velocidade da coordenada reativa esteja significativamente ao longo da propria ligação no instante do decaimento. Isso ocasiona a formação do ânion ligado $\mathrm{D}_{0}$ quente, no sentido vibracional, que ruma à dissociação estocasticamente. Em outras palavra, uma vez que o decaimento para $\mathrm{D}_{0}$ acontece, a energia eletrônica que é transferida para os graus de liberdade vibracionais faz com que o ânion permaneça relaxando até, eventualmente, dissociar.

A análise seguinte é sobre a eliminação do hidrogênio (H-N1). Na Fig. 8.7 mostramos um gráfico equivalente ao da Fig. 8.6, porém agora lidamos com a distância da ligação N1-H como coordenada reativa. O caráter antiligante do estado $\sigma^{*}$ ao longo da ligação N1-H já foi discutido anteriormente. Segundo nossos resultados, predizemos uma probabilidade menor do que 3\% para a eliminação de hidrogênio do ânion $\pi_{2}^{*}$. A baixa probabilidade pode ser usada como um novo argumento a favor 


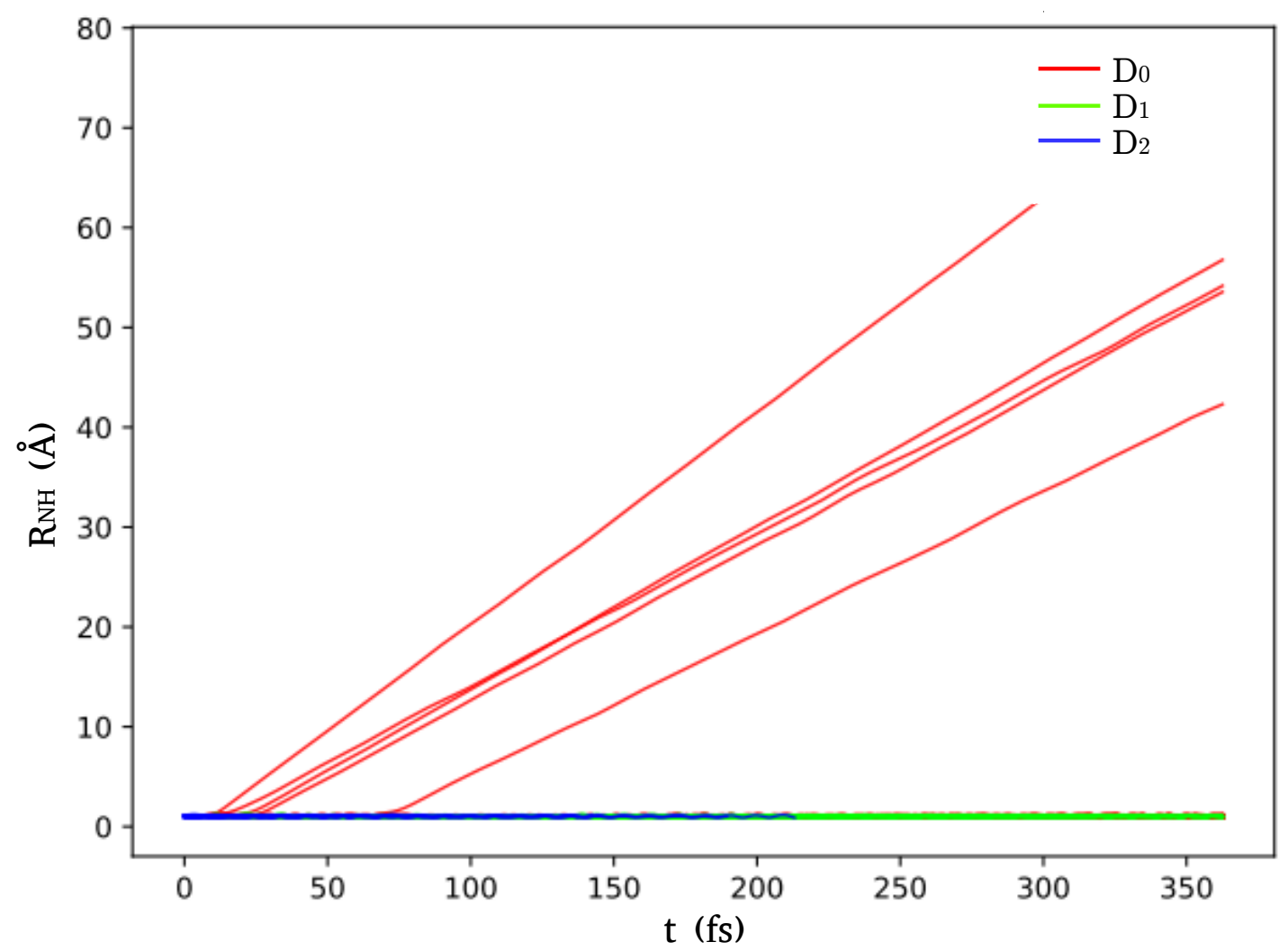

Figura 8.7: Análise dos valores da coordenada reativa $R_{\mathrm{N} 1 \mathrm{H}}$ em função do tempo para cara trajetória. As cores indicam o cada estado eletrônico em que se encontram a TBF.

da ausência do sinal.

Uma vez que as dinâmicas foram realizadas, passamos para a análise das probabilidades de sobrevidas das trajetórias frente a auto-ionização. Como detalhado no capítulo anterior, nosso modelo admite que a correção associada ao acoplamento com o contínuo seja feita em paralelo. Os cálculos de espalhamento auxiliares fornecem a a expressão para a aproximação local $\Gamma_{L}$, e os valores usados referem-se ao trabalho [9]. Na Fig. 8.8 estão dispostas as evoluções das energias das ressonâncias, assim como o $\Gamma_{L}$ para uma TBF. Nesse exmplo, o sistema foi rapidamente submetido a uma conversão interna ( $\sim 10 \mathrm{fs}) \pi_{2}^{*} \rightarrow \sigma_{\mathrm{CBr}}^{*}$, que por sua vez ruma rapidamente a dissociação. Naturalmente, as trajetórias que sofrem dissociações rápidas são as que mais contribuem para a seção de choque de DEA, devido aos valores relativamente baixos da integral de $\Gamma_{L}$ sobre seus valores positivos. Isso significa que apesar da Fig. 8.6 mostrar que as dissociações não acontecem necessariamente rápido, as trajetórias 
que resistem à conversão interna por mais tempo praticamente não sobrevivem à auto-ionização. Os valores das probabilidades de sobrevida das 122 trajetórias nes-
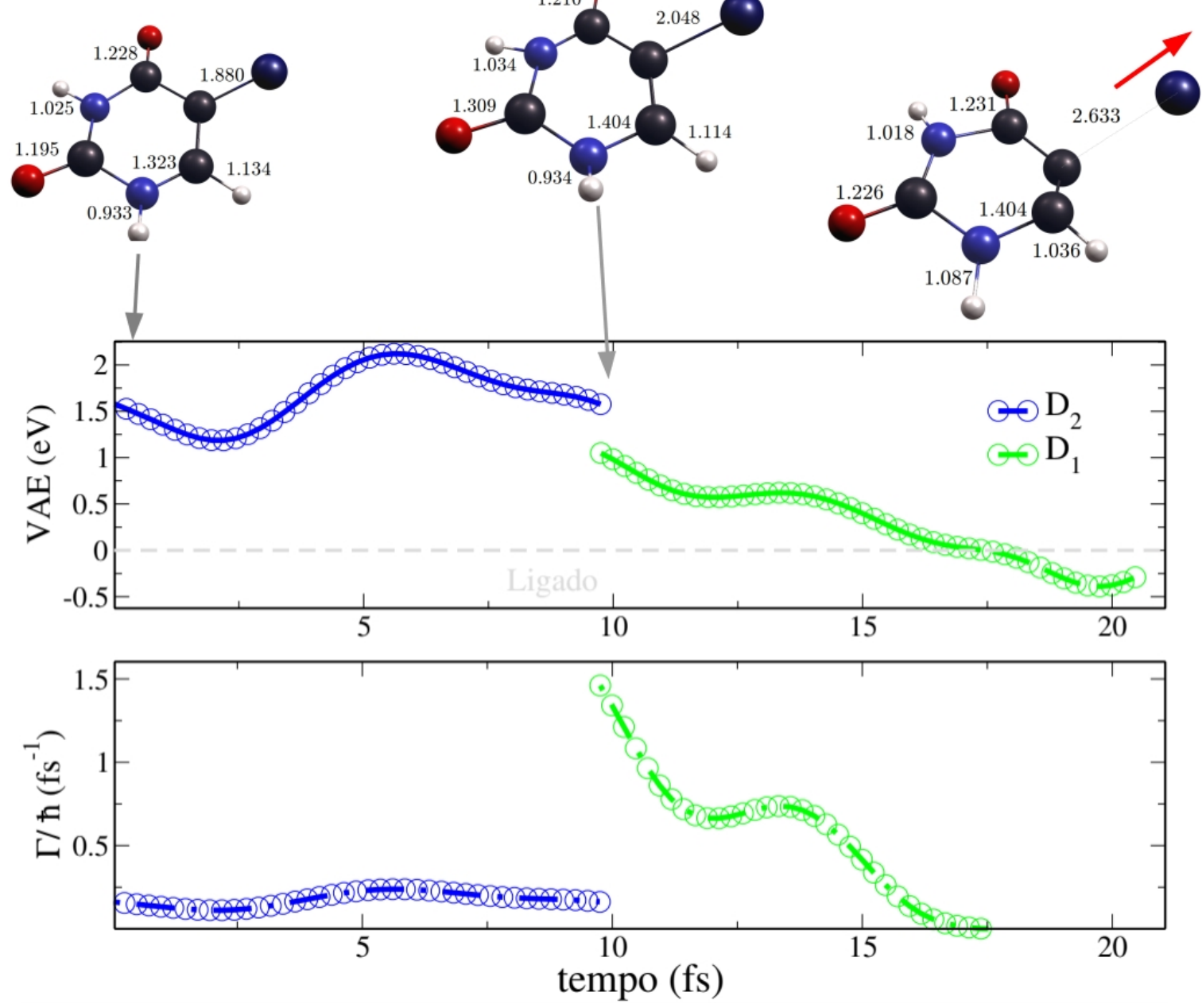

Figura 8.8: Evolução temporal das energias e larguras dos estados $\mathrm{D}_{1}$ e $\mathrm{D}_{2}$ ao longo da dinâmica de uma trajetória. As geometrias inicial, durante o acoplamento e a em $t=20$ fs estão dispostas na parte superior dos painéis. A linha tracejada cinza no painel superior representa a energia do estado fundamental do neutro, e fornece o instante em que o estado $\mathrm{D}_{2}$ passa a ser um estado ligado.

ses casos chegam a valores tão próximos de zero quanto $10^{-35}$, enquanto que para trajetórias que dissociam em poucas dezenas de fs esse valor pode chegar a $\sim 10^{-2}$.

As seções de choque de DEA foram calculadas através da equação 7.24 uma vez que todas as probabilidades de sobrevida foram avaliadas. As curvas obtidas estão dispostas na Fig. 8.9, e os resultados experimentais publicados por Abdoul-Carime et al.[11] estão mostrados para comparação. As medidas experimentais em questão são contagens de fragmentação aniônica em função do elétron incidente, e a comparação 
direta com seção de choque de DEA pode ser complicada, pois a correspondência entre as medidas depende de fatores como a intensidade do feixe incidente e densidade da amostra, por exemplo. Os dados experimentais foram escalonados em intensidade, apenas para facilitar a interpretação. De qualquer forma, as medidas apontam o fragmento $\mathrm{Br}^{-}$como o mais abundante no processo de DEA, sendo 5 vezes maior que seu fragmento complementar $(\mathrm{U}-\mathrm{H})^{-}$, equanto que os resultados do nosso modelo apontam para uma diferença de 3 a 4 vezes em magnitude. As energias dos picos nas curvas obtidas para $\sigma_{\text {DEA }}$ dos canais $\mathrm{Br}^{-}(1.42 \mathrm{eV})$ e Br neutro $(1.43 \mathrm{eV})$ estão em ótimo acordo com os reportados experimentalmente $(1.4 \mathrm{eV})$.

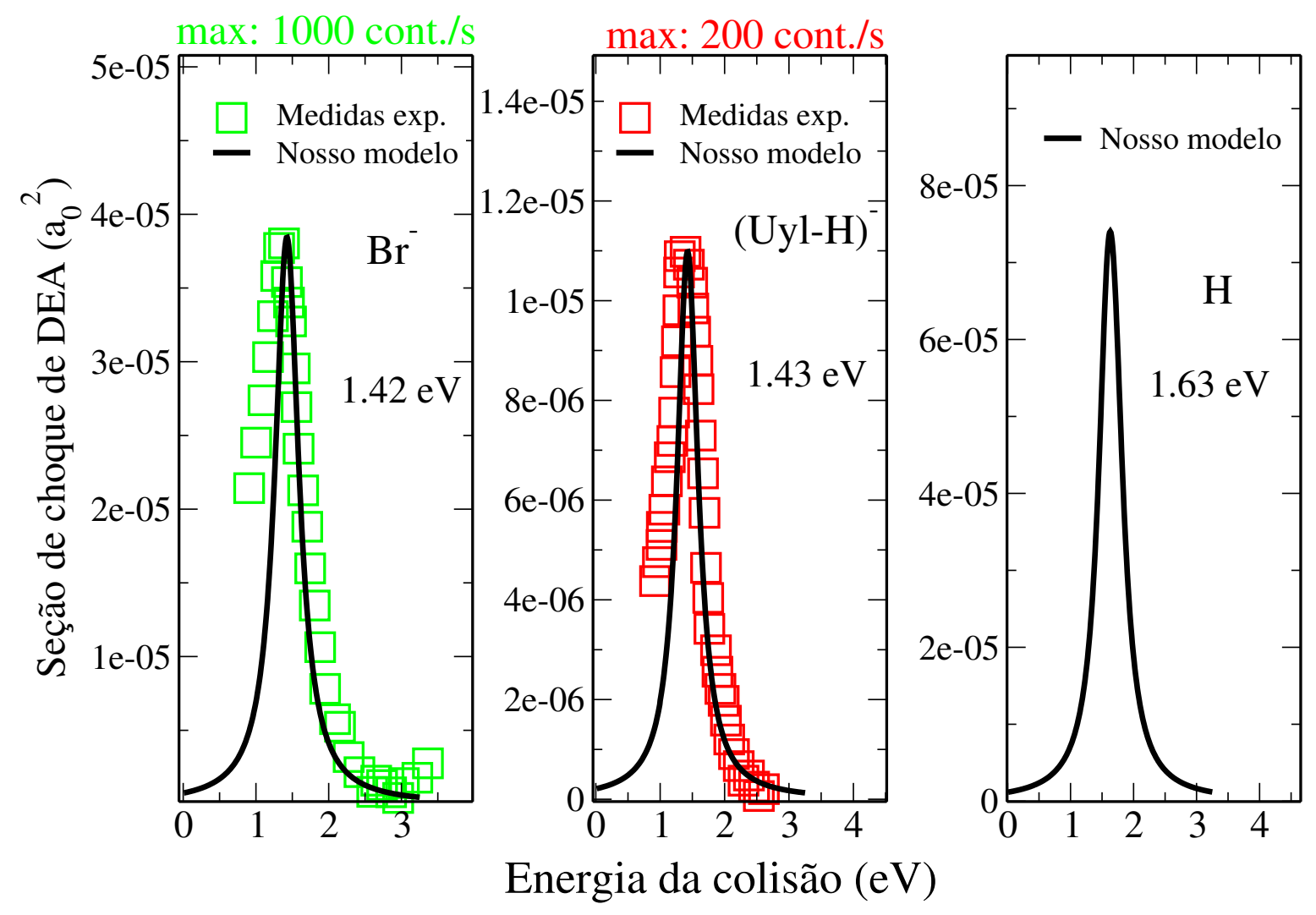

Figura 8.9: Seções de choque de DEA para os canais dissociativos $\mathrm{Br}^{-}$(à esquerda), $(\mathrm{U}-\mathrm{H})^{-}$(ao centro) e H (à direita). As curvas do nosso modelo foram obtidas da expressão 7.24. Os resultados experimentais[11] para a dissociação do $\mathrm{Br}^{-}$e (U-H) ${ }^{-}$ estão dispostos para comparação em seus respectivos painés.

Contudo, nosso modelo prevê uma seção de choque relativamente alta para eliminação de hidrogênio em $1.63 \mathrm{eV}$, contrariando todos os trabalhos experimentais sobre o sistema. Por outro lado, a análise feita anteriormente sobre as probabilidades de dissociação a partir das populações mostra um percentual menor que $<3 \%$ para 
dissociação de H sem levar em conta o tempo de vida de autoionização. Ou seja, a curva obtida não é razoável, e isso pode ser entendido através de dois fatores. O primeiro, e principal, é que a eliminação de hidrogênio requer a formação do ânion de caráter $\sigma_{\mathrm{NH}}^{*}$ a partir de algum instante da dinâmica. No nosso modelo, atribui-se ao estado eletrônico uma largura correspondente ao seu caráter adiabático (valor de $J$, que por sua vez pode assumir 2,1 ou 0 ), assumindo que uma vez estando em $\mathrm{D}_{1}$ a largura se relaciona com a energia de maneira análoga ao estado $\sigma_{\mathrm{CBr}}^{*}$. Porém, é razoável esperar que o ânion $\sigma_{\mathrm{NH}}^{*}$ possua larguras tipicamente maiores que as do ânion $\sigma_{\mathrm{CBr}}^{*}$, e como vimos uma grande sensibilidade da seção de choque de DEA com a probabilidade de sobrevida, isso faz com que a seção de choque para esse canal deva ser significativamente inferior à apresentada na Fig. 8.9. Além disso, um segundo fator diz respeito ao número de trajetórias simuladas. De fato, uma análise das TBFs responsáveis por essa seção de choque de DEA aponta 1 (uma) trajetória em específico como a maior protagonista nesse comportamento. A TBF a que me refiro foi submetida a um decaimento interno em unidades de fs e rapidamente rumou à dissociação do hidrogênio, e finalizou a simulação com uma população de 0.94, fazendo com que a seção de choque tenha esse comportamento inesperado. Uma grande amostragem de TBFs e seus respectivos tempos de vida certamente contribuiria para que esse tipo de evento seja cada vez menos relevantes, do ponto de vista estatístico. Apesar desse aspecto, a conclusão geral sobre o trabalho é positiva e promissora. As correspondências com os resultados experimentais são valiosas para trabalharmos em melhorias na descrição do problema. 


\section{Capítulo 9}

\section{Conclusões}

O trabalho foi dividido em três problemas e, apesar das principais análises e conclusões terem sido discutidas em cada um dos capítulos, aqui faço uma breve síntese das realizações.

A primeira parte do projeto foi o estudo dos ânions transientes da 5-OCNU e 5-SCNU, apontadas como possíveis novos candidatos a radiossensibilizadores. Primeiramente, o trabalho contribui de forma inédita para a investigação teórica de possíveis novos candidatos a radiossensibilizadores que foram pouco explorados ex-

perimentalmente. Juntamente com cálculos baseados em técnicas de estado ligado, as caracterizações das ressonâncias com técnicas de espalhamento, combinadas com estimativas de limiares de dissociação, formam um protocolo para o estudo de novos sistemas. Especificamente, obtivemos um espectro rico de estados para ambos sistemas, contemplando três ressonâncias de caráter $\pi^{*}$ sobre o anel e duas ressonâncias $\pi_{\mathrm{CN}}^{*}$ sobre os substituintes $\mathrm{XCN}(\mathrm{X}=\mathrm{O}, \mathrm{S})$, além da ressonância $\sigma_{S C N}^{*}$ no caso da 5SCNU. Uma conclusão interessante é que as ressonâncias $\pi^{*}$ localizadas sobre o anel não misturam consideravelmente com as ressonâncias localizadas sobre o grupo XCN, e enquanto os estados $\pi^{*}$ sobre o anel são muito similares nos dois casos, a ressonância localizada sobre o grupo XCN da 5-SCNU possui um caráter híbrido $\pi_{\mathrm{CN}, 1}^{*} / \sigma^{*}$, em contraposição à 5-OCNU.

A partir da análise do caráter dos orbitais virtuais responsáveis pela captura eletrônica em cada ressonância de forma observada, foi possível inferir reações dis- 
sociativas prováveis de serem observadas experimentalmente. Concluímos que a eliminação de H é uma reação provável no caso da 5-OCNU. Para a 5-SCNU, esse canal não é claro, uma vez que o orbital virtual antiligante ao longo da ligação NH possui um caráter híbrido $\sigma_{\mathrm{SCN}}^{*} / \sigma_{\mathrm{NH}}^{*}$. Para os canais de DEA envolvendo a eliminação dos substituintes XCN, observamos um comportamento oposto. O caráter das ressonâncias $\pi_{\mathrm{CN}, 1}^{*} / \sigma^{*}$ e $\sigma_{\mathrm{SCN}}^{*}$ devem promover de forma eficiente a quebra das ligações C5-S e S-C na 5-SCNU. Para a 5-OCNU, a ausência de uma ressonância antiligante com densidade significativa sobre o grupo OCN, além de observarmos pouca mistura $\sigma^{*}$ e $\pi_{\mathrm{CN}}^{*}$, nos faz concluir que esse processo é menos eficiente do que na 5-SCNU.

Uma vez que os mecanismos de DEA envolvendo acoplamentos DBS $/ \sigma_{\mathrm{NH}}^{*}$ possuem relevância questionável em solução aquosa, os nossos resultados concluem que a 5-SCNU deve ser um radiossensibilizador mais eficiente do que a 5-OCNU. Além disso, observamos que o espectro de TNIs da 5-SCNU e das 5-halouracilas são muito similares, com exceção das ressonâncias $\pi_{\mathrm{CN}}^{*}$. Como essas ressonâncias devem contribuir apreciativamente para a produção de espécies reativas, esperamos que a 5-SCNU deve ser um radiossensibilizador mais eficaz do que as halouracilas.

O trabalho Transient anion spectra of the potential radiosensitizers 5-cyanateuracil and 5- thiocyanateuracil foi publicado em forma de artigo na revista The Journal of Chemical Physics, vol. 147, 214310, em 2017[125].

A segunda parte do projeto diz respeito à investigação dos efeitos do solvente no processo de captura eletrônica pela uracila, timina e pelas 4 halouracilas 5 -XU $(\mathrm{X}=, \mathrm{F}, \mathrm{Cl}, \mathrm{Br}, \mathrm{I})$, sendo o caso da uracila o principal estudo sob o ponto de vista metodológico. A proposta de incluir moléculas de água no processo de espalhamento eletrônico, em composição com técnicas usuais de química quântica, permitiu verificar que, em geral, a estabilização sistemática das ressonâncias $\pi^{*}$ devido à influência das moléculas de água corrobora o que se sabia de trabalhos anteriores sobre sistemas pirimidínicos. Contudo, a maior contribuição do trabalho foi estabelecer uma metodologia que nos permitisse explorar de forma inovadora a distribuição térmica do efeito. No caso da timina e das halouracilas, essa metodologia foi simplesmente 
empregada para a realização de previsões. Os resultados estão em concordância com experimentos de DEA em agregados micro-solvatados de uracila, 5-FU e 5-BrU.

O trabalho Solvent effects on the $\pi^{*}$ shape resonances of uracil foi recentemente submetido para publicação.

Por último, apresentamos um protótipo para o tratamento teórico das dinâmicas de TNIs, baseado na interface do método AIMS com técnicas de espalhamento eletrônico, e abordou-se o problema da captura eletrônica dissociativa pelo estado $\pi_{2}^{*}$ da 5 -BrU. A propagação clássica dos núcleos sobre as SEP do ânion foi realizada da maneira usual, e o acoplamento com o contínuo foi introduzido em paralelo. A principal conclusão do estudo é a que apesar de todas as aproximações - locais, semi-locais, na técnica de estrutura eletrônica, entre outras - o nosso modelo se apresentou como uma boa alternativa para a descrição da seção de choque de DEA. Com exceção da seção de choque obtida para eliminação de hidrogênio, os canais dissociativos $\mathrm{Br}^{-}$ e $\mathrm{Uyl}^{-}$descritos pelo nosso modelo estão em notável acordo com medidas experimentais. Porém observamos que há a necessidade de realizar a simulação com um maior número de condições iniciais, a fim de estudarmos a convergência das curvas mostradas na Fig. 8.9, possivelmente eliminando o sinal de eliminação de hidrogênio.

Um outro objetivo do modelo é servir de referência/comparação para futuras abordagens mais sofisticadas. 


\section{Apêndice A}

\section{Separação e aproximação de}

\section{Born-Oppenheimer}

A equação de Schrödinger independente do tempo para um sistema molecular de $N$ elétrons e $M$ núcleos é

$$
\hat{\mathscr{H}} \Psi=E \Psi .
$$

Para a discussão dessa seção é conveniente ignorar os graus de liberdade de spin, tanto dos elétrons quanto dos núcleos. Portanto, na equação A.1 $\Psi=\Psi(\mathbf{r}, \mathbf{R})$ é a função de onda molecular, os vetores $\mathbf{r}$ e $\mathbf{R}$ colecionam os vetores posição dos elétrons e dos núcleos, respectivamente, e $\hat{\mathscr{H}}$ é o operador hamiltoniano do sistema, frequentemente chamado de hamiltoniano molecular. Em unidades atômicas $\left(m_{e}=\hbar=e\left(4 \pi \epsilon_{0}\right)^{-1}=\right.$ 1), o hamiltoniano molecular assume a expressão

$$
\begin{aligned}
\hat{\mathscr{H}}=-\sum_{\mu=1}^{M} \frac{1}{2 M_{\mu}} \nabla_{\mu}^{2}- & \frac{1}{2} \sum_{i=1}^{N} \nabla_{i}^{2}-\sum_{i=1}^{N} \sum_{\mu=1}^{M} \frac{Z_{\mu}}{\left|\mathbf{r}_{i}-\mathbf{R}_{\mu}\right|}+\sum_{i=1}^{N} \sum_{j<i}^{N} \frac{1}{\left|\mathbf{r}_{i}-\mathbf{r}_{j}\right|}+ \\
& +\sum_{\mu=1}^{M} \sum_{\nu<\mu}^{M} \frac{Z_{\mu} Z_{\nu}}{\left|\mathbf{R}_{\mu}-\mathbf{R}_{\nu}\right|}=\hat{T}_{N}+\hat{T}_{e}+\hat{V}_{N e}+\hat{V}_{e}+\hat{V}_{N}
\end{aligned}
$$

em que $M_{\mu}$ é a massa do $\mu$-ésimo núcleo, $\mathbf{r}_{i}$ e $\mathbf{R}_{\mu}$ são as posições do $i$-ésimo elétron e do $\mu$-ésimo núcleo, respectivamente. As quantidades $\left|\mathbf{r}_{i}-\mathbf{R}_{\mu}\right| \equiv R_{i \mu},\left|\mathbf{r}_{i}-\mathbf{r}_{j}\right| \equiv r_{i j}$ e $\left|\mathbf{R}_{\mu}-\mathbf{R}_{\nu}\right| \equiv R_{\mu \nu}$ são as posições relativas entre um elétron e um núcleo, entre dois elétrons e entre dois núcleos, respectivamente. O operador diferencial $\nabla_{i}^{2}$ corresponde 
às derivadas com relação as coordenadas do vetor $\mathbf{r}_{i}$, enquanto que o operador $\nabla_{\mu}^{2}$ corresponde às derivadas com relação as coordenadas do vetor $\mathbf{R}_{\mu}$. Daqui em diante, caso não esteja explicitado, a associação de elétrons com objetos de índices latinos e de núcleos com objetos de índices gregos ficará subentendida. Nessa nomenclatura $\hat{T}$ é o operador associado à energia cinética dos núcleos, $\hat{T}_{e}$ é o operador associado à energia cinética dos elétrons, $\hat{V}_{N e}$ é a energia potencial de interação núcleo-elétron, $\hat{V}_{e}$ é a interação elétron-elétron e $\hat{V}_{N}$ é a interação núcleo-núcleo, todos eles dispostos na expressão acima. O hamiltoniano molecular pode ser entendido como uma soma de um termo eletrônico $\hat{\mathscr{H}}_{\text {ele }}=\hat{T}_{e}+\hat{V}_{N e}+\hat{V}_{e}+\hat{V}_{N}$ e um termo nuclear $\hat{\mathscr{H}}_{n}=\hat{T}_{N}$ referente apenas à energia cinética dos núcleos. É interessante notar que apesar dos núcleos não serem particulas elementares não há nenhum termo relativo às particulas que os constituem no hamiltoniano molecular. Isso significa que estamos assumindo que os núcleos são objetos análogos a cargas pontuais massivas, consequentemente desprezando suas estruturas internas nesse nível de teoria. Tal aspecto pode ser encarado como razoável devido ao espectro de energias dos estados ligados associados às estruturas nucleares possuirem separações típicas muitas ordens de grandeza acima das estruturas eletrônicas e dos fenômenos interessantes para o trabalho.

A separação de Born-Oppenheimer[126] é usualmente considerada como um ponto de partida para se tratar quanticamente sistemas moleculares, e sua ideia central é propor uma função de onda que de uma certa forma desacopla o movimento dos núcleos e dos elétrons. A motivação associada a essa proposta se dá ao fato dos núcleos possuírem massas muito maiores que a dos elétrons. A inércia muito maior de cada núcleo, quando comparada ao elétron, origina uma diferença significativa entre seus movimentos no decorrer da dinâmica do sistema. Apesar de a argumentação formal e condições de validade da proposta serem muito mais complexas do que essa desigualdade[26, 27, 126], medidas espectroscópicas[127] justificam experimentalmente a ideia de movimentos nucleares e eletrônicos fisicamente desacoplados, de modo que elétrons se movem aproximadamente em um campo de núcleos fixos. Ma- 
tematicamente, escrevemos a separação na forma

$$
\Psi(\mathbf{r}, \mathbf{R})=\Phi(\mathbf{R}) \psi(\mathbf{r} \mid \mathbf{R})
$$

O produto A.3 nos diz que a função de onda do sistema é descrita diretamente por uma função de onda nuclear $\Phi$, que depende explícita e exclusivamente da posição dos núcleos, e de uma função de onda eletrônica $\psi$, que depende explicitamente da posição dos elétrons e parametricamente da posição dos núcleos. Procedimentos análogos são largamente empregados em tratamentos usuais de equações diferenciais parciais em que a separação de variáveis é conveniente[128, 129]. A equação A.1 pode ser então separada, de forma que a parte eletrônica toma a forma

$$
\hat{\mathscr{H}}_{\text {ele }} \psi(\mathbf{r} \mid \mathbf{R})=\epsilon \psi(\mathbf{r} \mid \mathbf{R})
$$

em que o auto-valor $\epsilon=\epsilon(\mathbf{R})$ é uma função das coordenadas nucleares devido a essa mesma dependência paramétrica das funções de onda eletrônicas. Uma vez que o hamiltoniano eletrônico é um operador hermiteano, a equação eletrônica pode no geral ser resolvida para uma família de funções $\psi_{m}(\mathbf{r} \mid \mathbf{R})$, com $m=0,1,2, \ldots$, cada qual associada a seu respectivo auto-valor real $\epsilon_{m}(\mathbf{R})$. A correspondência entre as funções de onda eletrônica e seus índices $m$ se dá usualmente em ordem crescente de energia. Isto é, $\psi_{0}(\mathbf{r} \mid \mathbf{R})$ está associada ao estado eletrônico fundamental e $\epsilon_{0}(\mathbf{R})$ sua respectiva energia. A partir de $m=1$ as funções e os auto-valores correspondem aos estados excitados. Vale a pena mencionar que as funções eletrônicas construídas de maneira que diagonalizam o operador $\hat{\mathscr{H}}_{\text {ele }}$ constituem o que é chamado de representação adiabática dos estados eletrônicos. Escolhendo as funções como sendo devidamente normalizadas, podemos trabalhar com a relação

$$
\int \psi_{n}^{*}(\mathbf{r} \mid \mathbf{R}) \psi_{m}(\mathbf{r} \mid \mathbf{R}) d \mathbf{r}=\left\langle\psi_{n} \mid \psi_{m}\right\rangle=\delta_{n m}
$$

em que a integral deve ser realizada no espaço multi-dimensional das coordenadas 
eletrônicas e o segundo termo representa o produto interno na notação de Dirac. De forma suscinta, a interpretação desse cenário é que podemos lidar com o problema eletrônico para uma dada configuração nuclear, cujas coordenadas assumem papéis de parâmetros fixos, implicando que a equação eletrônica independente do tempo pode ser resolvida para toda e cada geometria $\mathbf{R}$.

A existência do conjunto $\left\{\psi_{m}\right\}$, juntamente com a separação A.3, torna razoável construir a solução geral $\Psi$ como uma expansão to tipo

$$
\Psi(\mathbf{r}, \mathbf{R})=\sum_{m} \Phi_{m}(\mathbf{R}) \psi_{m}(\mathbf{r} \mid \mathbf{R})
$$

Essa expansão é conhecida como expansão de Born-Huang[130] e as funções $\Phi_{m}(\mathbf{R})$ são interpretadas como um conjunto enumerável de funções de onda nuclear, no sentido de A.3, e correspondem a coeficientes no sentido da expansão. Para determiná-los, substitui-se a expressão A.6 na equação A.1 e, com o uso de A.4, obtemos

$$
\sum_{m}\left(-\sum_{\mu=1}^{M} \frac{1}{2 M_{\mu}} \nabla_{\mu}^{2}+\left(\epsilon_{m}(\mathbf{R})-E\right)\right) \Phi_{m}(\mathbf{R}) \psi_{m}(\mathbf{r} \mid \mathbf{R})=0
$$

Projetando a equação A.7 sobre um estado eletrônico $\psi_{n}(\mathbf{r} \mid \mathbf{R})$, ou seja, multiplicandose ambos os lados pela função de onda eletrônica $\psi_{n}^{*}(\mathbf{r} \mid \mathbf{R})$ à esquerda e integrando-a sobre todas as coordenadas eletrônicas, obtemos ${ }^{1}$

$$
\begin{array}{r}
\left(-\sum_{\mu=1}^{M} \frac{1}{2 M_{\mu}} \nabla_{\mu}^{2}-\sum_{\mu=1}^{M} \frac{1}{M_{\mu}}\left(\nabla_{\mu}^{2}\right)_{n n}+\left(\epsilon_{n}(\mathbf{R})-E\right)\right) \Phi_{n}(\mathbf{R})= \\
\sum_{m \neq n} \sum_{\mu=1}^{M} \frac{1}{M_{\mu}}\left(\left(\nabla_{\mu}\right)_{n m} \cdot \nabla_{\mu}+\frac{\left(\nabla_{\mu}^{2}\right)_{n m}}{2}\right) \Phi_{n}(\mathbf{R}),
\end{array}
$$

onde os elementos $\left(\nabla_{\mu}\right)_{n m}$ e $\left(\nabla_{\mu}^{2}\right)_{n m}$ são definidos como

$$
\left(\nabla_{\mu}\right)_{n m} \equiv\left\langle\psi_{n}\left|\nabla_{\mu}\right| \psi_{m}\right\rangle=\int \psi_{n}^{*}(\mathbf{r} \mid \mathbf{R}) \nabla_{\mu} \psi_{m}(\mathbf{r} \mid \mathbf{R}) d \mathbf{r}
$$

\footnotetext{
${ }^{1}$ Também assumo que $\psi_{n}$ pode ser assumida real sem perda de generalidade, de forma que o elemento $\left(\nabla_{\mu}\right)_{n n}=0$ para todo $\mu$.
} 
e

$$
\left(\nabla_{\mu}^{2}\right)_{n m} \equiv\left\langle\psi_{n}\left|\nabla_{\mu}^{2}\right| \psi_{m}\right\rangle=\int \psi_{n}^{*}(\mathbf{r} \mid \mathbf{R}) \nabla_{\mu}^{2} \psi_{m}(\mathbf{r} \mid \mathbf{R}) d \mathbf{r}
$$

Os elementos de matriz $\left(\nabla_{\mu}\right)_{n m}$ e $\left(\nabla_{\mu}^{2}\right)_{n m}$ diagonais $(n=m)$ são chamados de termos de acoplamentos adiabáticos, enquanto que os elementos não diagonais $(n \neq m)$ são acoplamentos não adiabáticos.

A aproximação adiabática considera os termos de acoplamentos não adiabáticos como sendo desprezíveis, resultando na equação de movimento nuclear

$$
\left(-\sum_{\mu=1}^{M} \frac{1}{2 M_{\mu}} \nabla_{\mu}^{2}-\sum_{\mu=1}^{M} \frac{1}{M_{\mu}}\left(\nabla_{\mu}^{2}\right)_{n n}+\epsilon_{n}(\mathbf{R})\right) \Phi_{n}(\mathbf{R})=E \Phi_{n}(\mathbf{R}) .
$$

Essa aproximação define uma equação para o movimento nuclear vibracional a partir da solução para o problema eletrônico A.4, em que, a princípio, os núcleos foram considerados fixos. O operador entre parêntesis do membro esquerdo da equação pode ser interpretado como um hamiltoniano aproximado, ou efetivo, para o movimento dos núcleos. Tomando agora o limite de massa nuclear infinita, o último termo do hamiltoniano aproximado torna-se desprezível, definindo assim a aproximação de Born-Oppenheimer (BO),

$$
\frac{1}{M_{\mu}}\left(\nabla_{\mu}^{2}\right)_{n n} \sim 0
$$

que reduz a equação nuclear a

$$
\left(-\sum_{\mu=1}^{M} \frac{1}{2 M_{\mu}} \nabla_{\mu}^{2}+\epsilon_{n}(\mathbf{R})\right) \Phi_{n}^{(B O)}(\mathbf{R})=E \Phi_{n}^{(B O)}(\mathbf{R})
$$

\section{Validade da aproximação BO}

É possível demonstrar que os elementos de matriz A.9 e A.10 satisfazem, para $n \neq m$, a seguinte relação

$$
\left(\nabla_{\mu}^{2}\right)_{n m}=\left(\nabla_{\mu}\right)_{n m}^{2}+\nabla_{\mu} \cdot\left(\nabla_{\mu}\right)_{n m}
$$


Isso indica que o acoplamento não adiabático entre estados eletrônicos distintos depende essencialmente do elemento de matriz $\left(\nabla_{\mu}\right)_{n m}$, o qual é desprezado na aproximação adiabática. Por outro lado, esse termo está relacionado com a diferença de energia entre estados eletrônicos, podendo ser reescrito como[131, 132]

$$
\left(\nabla_{\mu}\right)_{n m}=\frac{\left\langle\psi_{n}\left|\nabla_{\mu} \hat{\mathscr{H}}_{\text {ele }}\right| \psi_{m}\right\rangle}{U_{n}(\mathbf{R})-U_{m}(\mathbf{R})}
$$

onde

$$
U_{n}(\mathbf{R}) \equiv \epsilon_{n}(\mathbf{R})-\sum_{\mu=1}^{M} \frac{1}{M_{\mu}}\left(\nabla_{\mu}^{2}\right)_{n n}
$$

O resultado acima significa que a aproximação adiabática e a aproximação de Born-Oppenheimer é uma boa aproximação em regiões onde os estados eletrônicos são energeticamente distantes, sendo tipicamente válida para estados fundamentais em torno da configuração nuclear de mínima energia. Entretanto, para estados excitados ou para o estado fundamental longe da configuração de mínima energia, a aproximação adiabática pode não ser satisfatória, fazendo com que a descrição do sistema necessite de métodos menos aproximados. 


\section{Apêndice B}

\section{Funções de onda multi-eletrônicas}

A separação de Born-Oppenheimer nos proporciona uma equação para o problema eletrônico A.4 que deve ser resolvida para um conjunto de $N$ elétrons indistinguíveis. Ao passo que nas primeiras seções do presente capítulo ignoramos o grau de liberdade de spin de todos os corpos do sistema, retomamos agora o spin na descrição dos elétrons. Baseados na teoria do orbital molecular[24, 27, 28], podemos contruir a função de onda de muitos elétrons a partir de funções de onda de um único elétron. Cada uma dessas funções pode ser construida como um produto entre a parte espacial e o termo de spin, definindo o que chamamos de spin-orbitais

$$
\chi\left(\mathbf{x}_{i}\right)=\phi\left(\mathbf{r}_{i}\right) \xi\left(S_{i}\right)
$$

em que o índice $i$ se refere ao $i$-ésimo elétron, $\phi\left(\mathbf{r}_{i}\right)$ a função de onda orbital e $\xi\left(S_{i}\right)$ é o termo de spin do spin-orbital. Aqui, a variável $\mathbf{x}_{i}=\left\{\mathbf{r}_{i}, S_{i}\right\}$ expressa uma forma compacta de denotar a posição e a variável de spin ao mesmo tempo. Genericamente a função $\xi$ pode assumir $2 s+1$ possíveis estados para uma partícula de spin $s$ e, no caso particular do elétron, que é um férmion de spin $1 / 2$, a função pode assumir apenas dois valores, associados às possíveis configurações up e down, para as quais usaremos a notação

$$
\xi\left(S_{i}\right)=\left\{\begin{array}{l}
\alpha(i), \uparrow \\
\beta(i), \downarrow
\end{array},\right.
$$


com

$$
\langle\alpha(i) \mid \alpha(i)\rangle=\langle\beta(i) \mid \beta(i)\rangle=1, \quad\langle\alpha(i) \mid \beta(i)\rangle=0 .
$$

A definição B.1 constrói um elemento de uma família $\left\{\chi_{i}\right\}$ de spin-orbitais associados a um único elétron. A partir disso, deve-se contruir uma função de onda eletrônica que respeite o princípio da exclusão de Pauli, uma vez que estamos tratando de férmions. O princípio da exclusão exige que a função de onda seja antissimétrica quando submetida à troca de dois elétrons de seus respectivos spin-orbitais. Uma proposta sistemática que respeita a antissimetria é a forma determinantal de Slater, em que a função de onda, devidamente normalizada, é escrita por um determinante de spin-orbitais

$$
\psi(\mathbf{x})=\frac{1}{\sqrt{N !}}\left|\begin{array}{ccc}
\chi_{1}\left(\mathbf{x}_{1}\right) & \cdots & \chi_{N}\left(\mathbf{x}_{1}\right) \\
\chi_{1}\left(\mathbf{x}_{2}\right) & \cdots & \chi_{N}\left(\mathbf{x}_{2}\right) \\
\vdots & \ddots & \vdots \\
\chi_{1}\left(\mathbf{x}_{N}\right) & \cdots & \chi_{N}\left(\mathbf{x}_{N}\right)
\end{array}\right|=\frac{1}{\sqrt{N !}} \mathscr{A}\left[\chi_{1}(1) \chi_{2}(2) \ldots \chi_{N}(N)\right]
$$

em que, a título de exemplo, $N$ elétrons dipostos em $N$ spin-orbitais constituem a função de onda multi-eletrônica $\psi$ e $\mathbf{x}$ coleciona todos os $\mathbf{x}_{i}$. Na expressão B.4 $\mathscr{A}$ representa um operador antissimetrizador, análogo ao determinante e, daqui pra frente, usaremos a forma mais compacta $\chi_{j}\left(\mathbf{x}_{i}\right) \equiv \chi_{j}(i)$ para denotar os spin-orbitais. Note que o princípio da exclusão de Pauli é imediatamente satisfeito pela forma determinantal devido à inversão de sinal quando a mesma é submetida à inversão de linhas. Além disso, construimos a função de onda com spin-orbitais linearmente independentes. Podemos, então, sempre escolhermos os orbitais $\phi$ 's ortonormais,

$$
\left\langle\phi_{j} \mid \phi_{k}\right\rangle=\int \phi_{j}^{*}\left(\mathbf{r}_{i}\right) \phi_{k}\left(\mathbf{r}_{i}\right) d \mathbf{r}_{i}=\delta_{j k} .
$$


Dessa forma, e usando B.3, a função de onda eletrônica definida através da B.4 fica devidamente normalizado,

$$
\langle\psi \mid \psi\rangle=\int \psi^{*}(\mathbf{x}) \psi(\mathbf{x}) d \mathbf{x}=1
$$

em que a integral deve ser realizada tanto nas coordenadas espaciais quanto nas variáveis de spin de todos os elétrons simultaneamente.

No caso geral, cada orbital molecular pode estar sendo ocupado por dois elétrons com diferentes estados de spin e, caso um número $K>N$ de orbitais esteja disponível, teremos spin-orbitais da forma

$$
\chi_{2 i-1}=\phi_{i} \alpha(i) \quad \text { e } \quad \chi_{2 i}=\phi_{i} \beta(i), \quad i=1,2, \ldots, K .
$$

Ou seja, um total de $2 K$ spin-orbitais distintos. Com isso em mãos, é possível construirmos um número enorme de diferentes determinantes. A saber, esse número é dado pelo binomial

$$
\left(\begin{array}{c}
2 K \\
N
\end{array}\right)=\frac{(2 K) !}{N !(2 K-N) !}
$$

A partir disso, resta determinar quais os orbitais moleculares tornam uma função do tipo B.4 uma solução de A.4. 


\section{Apêndice $\mathrm{C}$}

\section{O método Hartree-Fock e os métodos pós Hartree-Fock}

No método HF busca-se uma solução aproximada para o estado fundamental do problema eletrônico A.4 considerando uma solução monodeterminantal do tipo B.4 para o sistema de $N$ elétrons, onde os spin-orbitais são ortonormais. Para um dado estado eletrônico $|\psi\rangle$ qualquer, o funcional de energia $E[\psi]=\left\langle\psi\left|\hat{\mathscr{H}}_{\text {ele }}\right| \psi\right\rangle$ pode ser desenvolvido e reescrito na forma

$E[\psi]=\sum_{i}^{N}\left\langle\chi_{i}(q)\left|-\frac{1}{2} \nabla_{q}^{2}-\sum_{\mu=1}^{M} \frac{Z_{\mu}}{R_{q \mu}}\right| \chi_{i}(q)\right\rangle+\frac{1}{2} \sum_{i, j=1}^{N}\left\langle\chi_{i}(q)\left|\hat{\mathscr{J}}_{j}(q)-\hat{\mathscr{K}}_{j}(q)\right| \chi_{i}(q)\right\rangle$

em que $\hat{\mathscr{J}}_{k}(i)$ e $\hat{\mathscr{K}}_{k}(i)$ são, respectivamente, os operadores de Coulomb e exchange, cujas ações sobre um determinado spin-orbital estão definidas como

$$
\hat{\mathscr{J}}_{k}(i)\left|\chi_{j}(i)\right\rangle=\left[\int \chi_{k}^{*}(n) \frac{1}{r_{i n}} \chi_{k}(n) d \mathbf{x}_{n}\right]\left|\chi_{j}(i)\right\rangle
$$

e

$$
\hat{\mathscr{K}}_{k}(i)\left|\chi_{j}(i)\right\rangle=\left[\int \chi_{k}^{*}(n) \frac{1}{r_{i n}} \chi_{j}(n) d \mathbf{x}_{n}\right]\left|\chi_{k}(i)\right\rangle .
$$

Os índices indicados pelos parênteses indicam o espaço de coordenadas eletrônicas, espaciais e de spin, sobre o qual as integrais devem ser realizadas, sendo assim mudos nos elementos de matriz indicados.

Em seguida utiliza-se um procedimento variacional para minimizar o funcional 
C.1 em relação aos spin-orbitais moleculares. Para isso, usamos os multiplicadores de Lagrange com o vínculo associado à ortogonalidade dos spin-orbitais. Após uma manipulação algébrica e considerações sobre a diagonalizabilidade dos operadores envolvidos, a condição de mínimo nos fornece um conjunto de equações conhecidas como equações de HF, dadas por

$$
\hat{F}(i)\left|\chi_{j}(i)\right\rangle=\varepsilon_{j}\left|\chi_{j}(i)\right\rangle
$$

Nesse conjuto de equações, o operador $\hat{F}(i)$ é o operador de Fock dado por

$$
\hat{F}(i) \equiv \hat{h}(i)+\sum_{k=1}^{N}\left(\hat{\mathscr{J}}_{k}(i)-\hat{\mathscr{K}}_{k}(i)\right)
$$

As equações C.4 para $j=1,2, \ldots$ são conhecidas como equações canônicas de HF e determinam os spin-orbitais moleculares que minimizam o funcional de energia eletrônica, com os auto-valores $\varepsilon$ 's estando associados às energias de cada orbital. Entretanto, o operador de Fock atuando num determinado estado depende explicitamente dos outros estados, o que faz com que o sistema de equações seja não linear. Por esse motivo o sistema é resolvido através de um processo iterativo, conhecido com ciclo de auto-consistência, ou SCF (Self-Consistent Field). Nesse procedimento, inicialmente são gerados spin-orbitais arbitrariamente. Em seguida a equação C.4 é montada e resolvida, gerando assim um novo conjunto de spin-orbitais. O procedimento se repete até que o conjunto de orbitais, e o funcional de energia eletrônica, atinjam uma convergência pré-estabelecida.

Além de seu uso para caracterização de estruturas eletrônicas de estados fundamentais ligados, o método HF também foi usado no contexto do problema de espalhamento eletrônico. Ele foi utilizado para descrever a estrutura eletrônica do alvo, gerando orbitais moleculares ocupados e virtuais que posteriormente foram usados na contrução do espaço de configurações, assunto que será discutido na próxima seção. Por ora, vale ressaltar que os estados fundamentais das espécies neutras das moléculas estudadas são sistemas de camada fechada (número par de elétrons), e as- 
sim a implementação do método HF pode ser desenvolvida como segue. Em sistemas de camada fechada cada orbital está duplamente ocupado com eletróns cujos estados de spin são opostos. Nessa abordagem, chamada de HF restrito (do inglês Restricted Hartree-Fock - RHF), as equações canônicas de HF podem ser simplificadas de modo a serem expressas em termos dos orbitais moleculares

$$
\hat{F}(i)\left|\phi_{j}(i)\right\rangle=\varepsilon_{j}\left|\phi_{j}(i)\right\rangle, \quad j=1,2, \ldots, \frac{N}{2}
$$

onde o operador de Fock é dado por

$$
\hat{F}(i) \equiv \hat{h}(i)+\sum_{k=1}^{N / 2}\left(2 \hat{\mathscr{J}}_{k}(i)-\hat{\mathscr{K}}_{k}(i)\right)
$$

e os operadores de Coulomb e exchange agora dados também em termos de suas respectivas atuações sobre os orbitais moleculares;

$$
\hat{\mathscr{J}}_{k}(i)\left|\phi_{j}(i)\right\rangle=\left[\int \phi_{k}^{*}\left(\mathbf{r}_{n}\right) \frac{1}{r_{i n}} \phi_{k}\left(\mathbf{r}_{n}\right) d \mathbf{r}_{n}\right]\left|\phi_{j}(i)\right\rangle
$$

$\mathrm{e}$

$$
\hat{\mathscr{K}}_{k}(i)\left|\phi_{j}(i)\right\rangle=\left[\int \phi_{k}^{*}\left(\mathbf{r}_{n}\right) \frac{1}{r_{i n}} \phi_{j}\left(\mathbf{r}_{n}\right) d \mathbf{r}_{n}\right]\left|\phi_{k}(i)\right\rangle .
$$

Essas expressões são equivalentes às expressões gerais definidas anteriormente, com a diferença de que agora todos os operadores dizem respeito apenas à parte espacial dos spin-orbitais. Realiza-se assim os ciclos SCF até a convergência dos orbitais moleculares.

Sistemas de camadas fechadas estão no geral associados a moléculas neutras. Porém, em muitas situações estaremos interessados na descrição da estrutura eletrônica de ânions, que são tipicamente sistemas de camada aberta. Tipicamente, sistemas de camada aberta possuem um número $N$ ímpar de elétrons, em que existem $n_{\alpha}$ elétrons cujo estado de spin é $\alpha$ e $n_{\beta}$ elétrons cujo estado de spin é $\beta$. O método para resolver o problema eletrônico pelo método Hartree-Fock é chamado de método Hartree-Fock Não-Restrito (do inglês Unrestricted Hartree-Fock - UHF). Uma das implementações 
de HF não-restritos é a proposta por Pople-Nesbet[133], o qual o Hamiltoniano gera um funcional de energia eletrônico expresso na forma

$$
\begin{aligned}
E[\psi] & =\sum_{q=1}^{n_{\alpha}}\left\langle\chi_{q}^{\alpha}(i)|\hat{h}(i)| \chi_{q}^{\alpha}(i)\right\rangle+\frac{1}{2} \sum_{q, l=1}^{n_{\alpha}}\left\langle\chi_{q}^{\alpha}(i)\left|\hat{\mathscr{J}}_{l}^{\alpha}(i)-\hat{\mathscr{K}}_{l}^{\alpha}(i)\right| \chi_{q}^{\alpha}(i)\right\rangle+ \\
& +\sum_{q=1}^{n_{\beta}}\left\langle\chi_{q}^{\beta}(i)|\hat{h}(i)| \chi_{q}^{\beta}(i)\right\rangle+\frac{1}{2} \sum_{q, l=1}^{n_{\beta}}\left\langle\chi_{q}^{\beta}(i)\left|\hat{\mathscr{J}}_{l}^{\beta}(i)-\hat{\mathscr{K}}_{l}^{\beta}(i)\right| \chi_{q}^{\beta}(i)\right\rangle+ \\
& +\frac{1}{2} \sum_{q, l=1}^{n_{\alpha}, n_{\beta}}\left\langle\chi_{q}^{\alpha}(i)\left|\hat{\mathscr{J}}_{l}^{\beta}(i)\right| \chi_{q}^{\alpha}(i)\right\rangle+\frac{1}{2} \sum_{q, l=1}^{n_{\beta}, n_{\alpha}}\left\langle\chi_{q}^{\beta}(i)\left|\hat{\mathscr{J}}_{l}^{\alpha}(i)\right| \chi_{q}^{\beta}(i)\right\rangle, \quad \text { C. }
\end{aligned}
$$

onde $\chi_{q}^{\alpha}(i)$ representa o spin-orbital $\phi_{q}^{\alpha}\left(\mathbf{r}_{i}\right) \alpha(i)$, enquanto $\chi_{q}^{\beta}$ estão associados aos spin-orbitais $\phi_{q}\left(\mathbf{r}_{i}\right) \beta(i)$. Os operadores $\hat{\mathscr{J}}_{l}^{\xi}$ e $\hat{\mathscr{K}}_{l}^{\xi}$, para $\xi=\alpha, \beta$, são agora particularmente adaptados de maneira que

$$
\hat{\mathscr{J}}_{q}^{\xi}(i)\left|\chi_{l}^{\xi^{\prime}}(i)\right\rangle=\left[\int \chi_{q}^{* \xi}(n) \frac{1}{r_{i n}} \chi_{q}^{\xi}(n) d \mathbf{x}_{n}\right]\left|\chi_{l}^{\xi^{\prime}}(i)\right\rangle
$$

$\mathrm{e}$

$$
\hat{\mathscr{K}}_{q}^{\xi}(i)\left|\chi_{l}^{\xi^{\prime}}(i)\right\rangle=\left[\int \chi_{q}^{* \xi}(n) \frac{1}{r_{i n}} \chi_{l}^{\xi^{\prime}}(n) d \mathbf{x}_{n}\right]\left|\chi_{q}^{\xi}(i)\right\rangle .
$$

O procedimento novamente consiste então em minimizar o funcional C.10 com os vínculos de ortonormalidade $\left\langle\chi_{q}^{\xi} \mid \chi_{l}^{\xi^{\prime}}\right\rangle=\delta_{q l} \delta_{\xi \xi^{\prime}}$. Aqui a minimização também é feita com o uso dos multiplicadores de Lagrange e, de maneira equivalente ao caso geral, obtém-se os seguintes dois conjuntos de equações de auto-valores e auto-estados, decompostos para cada estado de spin,

$$
\hat{\mathscr{F}}^{\alpha}(i)\left|\chi_{q}^{\alpha}(i)\right\rangle=\varepsilon_{q}^{\alpha}\left|\chi_{q}^{\alpha}(i)\right\rangle \Rightarrow \hat{\mathscr{F}}^{\alpha}(i)\left|\phi_{q}^{\alpha}(i)\right\rangle=\varepsilon_{q}^{\alpha}\left|\phi_{q}^{\alpha}(i)\right\rangle
$$

e

$$
\hat{\mathscr{F}}^{\beta}(i)\left|\chi_{q}^{\beta}(i)\right\rangle=\varepsilon_{q}^{\beta}\left|\chi_{q}^{\beta}(i)\right\rangle \Rightarrow \hat{\mathscr{F}}^{\beta}(i)\left|\phi_{q}^{\beta}(i)\right\rangle=\varepsilon_{q}^{\beta}\left|\phi_{q}^{\beta}(i)\right\rangle,
$$

em que as últimas igualdades de cada um diz respeito apenas à parte espacial dos spin-orbitais. Dessa vez os operadores de Fock adaptados para cada projeção de spin 
é escrito como

$$
\hat{\mathscr{F}}^{\alpha}(i)=\hat{h}(i)+\sum_{l=1}^{n_{\alpha}}\left(\hat{\mathscr{J}}_{l}^{\alpha}(i)-\hat{\mathscr{K}}_{l}^{\alpha}(i)\right)+\sum_{l=1}^{n_{\beta}} \hat{\mathscr{J}}_{l}^{\beta}(i)
$$

e

$$
\hat{\mathscr{F}}^{\beta}(i)=\hat{h}(i)+\sum_{l=1}^{n_{\beta}}\left(\hat{\mathscr{J}}_{l}^{\beta}(i)-\hat{\mathscr{K}}_{l}^{\beta}(i)\right)+\sum_{l=1}^{n_{\alpha}} \hat{\mathscr{J}}_{l}^{\alpha}(i) .
$$

Como no caso anterior, os operadores de Fock dependem explicitamente de um conjunto de spin-orbitais, o que faz com que os sistemas C.13 e C.14 sejam nãolineares. Ciclos auto-consistente SCFs são então realizados a partir de dois conjuntos de orbitais iniciais; um conjunto associado a cada projeção de spin. Como as soluções são distintas, o método UHF é chamado também de método de spin polarizado. Devemos notar que, uma vez que $n_{\alpha}$ e $n_{\beta}$ são números diferentes, a função de onda $\psi$, uma vez convergida, não é necessariamente um auto-estado do operador $\hat{S}^{2}$. Portanto propriedades espectroscópicas devem ser analisadas com cautela.

\section{O Método de Hartree-Fock Roothaan}

A teoria de Hartree-Fock Roothaan para o estudo do problema eletrônico serve como uma maneira prática de se resolver as equações de HF. A ideia se baseia em outro aspecto da teoria do orbital molecular, no qual os orbitais moleculares podem ser descritos como combinações lineares de orbitais atômicos (do inglês linear combination of atomic orbitals - LCAO). Na prática, isso significa construir a priori um conjunto finito de $n$ orbitais atômicos $\left\{\varphi_{\mu}\right\}$ normalizados (porém não necessariamente ortogonais), definindo uma base para expandir os orbitais moleculares,

$$
\left|\phi_{i}\right\rangle=\sum_{\mu=1}^{n} C_{i \mu}\left|\varphi_{\mu}\right\rangle
$$

As expansões C.17 podem ser sintetizadas com uma formulação matricial,

$$
\bar{\phi}=\mathbf{C} \bar{\varphi}
$$


onde definimos as matrizes

$$
\bar{\phi}=\left[\begin{array}{c}
\left|\phi_{1}\right\rangle \\
\vdots \\
\left|\phi_{N}\right\rangle
\end{array}\right], \bar{\varphi}=\left[\begin{array}{c}
\left|\varphi_{1}\right\rangle \\
\vdots \\
\left|\varphi_{N}\right\rangle
\end{array}\right] \text { e } \mathbf{C}=\left[\begin{array}{ccc}
C_{11} & \cdots & C_{1 n} \\
C_{21} & \cdots & C_{2 n} \\
\vdots & \ddots & \vdots \\
C_{N 1} & \cdots & C_{N n}
\end{array}\right]
$$

Substituindo a expansão C.17 em nas equações canônicas de HF, e multiplicando à esquerda por $\left\langle\varphi_{\nu}\right|$, obtemos um sistema de equações para os coeficientes $C$ 's que da forma matricial é escrita como

$$
\mathbf{F C}=\mathbf{S C} \bar{\varepsilon}
$$

Nessa expressão, a matriz $\bar{\varepsilon}$ é diagonal cujos elementos são os auto valores das equações de HF, do tipo $(\bar{\varepsilon})_{i j}=\varepsilon_{i} \delta_{i j}$. F, por sua vez, é a resolução matricial do operador de Fock na base dos orbitais atômicos propostos, cujos elementos são dados por $(\mathbf{F})_{\mu \nu} \equiv F_{\mu \nu}=\left\langle\varphi_{\mu}|\hat{\mathscr{F}}| \varphi_{\nu}\right\rangle$. Para os casos RHF, o operador de Fock em questão corresponde à equação C.7, enquanto que em casos UHF lidamos com os dois casos C.15 e C.16 para cada projeção. Finalmente, a matriz $\mathbf{S}$ coleciona elementros de overlap entre estados da base, de forma que $(\mathbf{S})_{\mu \nu} \equiv S_{\mu \nu}=\left\langle\varphi_{\mu} \mid \varphi_{\nu}\right\rangle$.

A equação (2.61) pode ser reescrita na forma:

$$
(\mathbf{F}-\varepsilon \mathbf{S}) \mathbf{C}=0
$$

que representa um conjunto de equações conhecidas como equações de Hartree-Fock Roothaan:

$$
\sum_{\mu=1}^{n}\left(F_{\nu \mu}-\varepsilon_{i} S_{\nu \mu}\right) C_{\mu i}=0
$$

para $i=1,2, \ldots, N$ e $\nu=1,2, \ldots, n$. Os auto-valores das equações de Hartree-Fock Roothaan são, portanto, raízes da equação secular,

$$
\operatorname{det}|\mathbf{F}-\varepsilon \mathbf{S}|=0
$$


Os termos $F_{\nu \mu}$ associados ao operador de Fock podem ser escritos como:

$$
F_{\mu \nu}=h_{\mu \nu}+\sum_{\rho, \lambda} P_{\rho \lambda}\left(\langle\mu \nu \mid \rho \lambda\rangle-\frac{1}{2}\langle\mu \lambda \mid \rho \nu\rangle\right)
$$

em que $h_{\mu \nu}=\left\langle\varphi_{\mu}|\hat{h}| \varphi_{\nu}\right\rangle$, e:

$$
\begin{gathered}
P_{\rho \lambda}=2 \sum_{i=1}^{N} C_{\rho i}^{*} C_{\lambda i} \\
\langle\mu \nu \mid \rho \lambda\rangle=\iint \varphi_{\mu}\left(\mathbf{r}_{i}\right) \varphi_{\nu}\left(\mathbf{r}_{j}\right) \frac{1}{r_{i j}} \varphi_{\rho}\left(\mathbf{r}_{i}\right) \varphi_{\lambda}\left(\mathbf{r}_{j}\right) d \mathbf{r}_{i} d \mathbf{r}_{j} \\
\langle\mu \lambda \mid \rho \nu\rangle=\iint \varphi_{\mu}\left(\mathbf{r}_{i}\right) \varphi_{\lambda}\left(\mathbf{r}_{j}\right) \frac{1}{r_{i j}} \varphi_{\rho}\left(\mathbf{r}_{i}\right) \varphi_{\nu}\left(\mathbf{r}_{j}\right) d \mathbf{r}_{i} d \mathbf{r}_{j}
\end{gathered}
$$

A equação (2.66) é então resolvida de maneira auto-consitente, com um ciclo SCF sujo critério de convergência foi pré-estabelecido. Os orbitais atômicos utilizados na expansão (2.55) são chamados funções base, e suas características serão discutidas adiante.

\section{Métodos pós HF}

O método HF é um método relativamente simples para a caracterização de estruturas eletrônicas. Porém, uma solução monodeterminantal da forma como o método foi construído não fornece a energia eletrônica exata do problema A.4, pois não contempla energia de correção eletrônica. Os métodos pós HF são métodos ab initio que partem da solução HF e tentam estimar a energia de correlação eletrônica, melhorando a energia obtida com o método HF usual. Um dos métodos mais populares é o método MP2 (Møller-Plesset second order perturbation theory)[27, 31], onde a correlação eletrônica é incluída de forma perturbativa, onde é empregada a teoria de perturbação de segunda ordem usual da mecânica quântica. Uma outra classe de métodos pós HF são os baseados na interação de configurações (configurational interaction - CI)[27], nos quais parte-se da solução HF para construir a solução do problema eletrônico como uma expansão de determinantes que contemplam excitações eletrônicas de orbitais ocupados HF para orbitais virtuais HF, 


\section{Apêndice D}

\section{Teoria do Funcional da Densidade}

Nesse apêndice apresento uma descrição modesta do DFT, buscando mostrar alguns aspectos matemáticos da teoria. Apesar de haver muitas referências sobre o tema, disponibilizo um novo material para consulta e referência.

Parte-se de uma expressão para a densidade eletrônica em termos de um sistema de partículas independentes, cada qual representada por uma função de partícula única $\psi_{i}$, expressa da forma

$$
\rho(\mathbf{r})=\sum_{i=1}^{N}\left|\psi_{i}(\mathbf{r})\right|^{2}
$$

Para que haja estabilidade variacional, essas funções satisfazem um conjunto de equações conhecidas como equações de Kohn-Shan (KS), dadas pela forma

$$
\left(-\frac{1}{2} \nabla^{2}+v^{K S}[\rho]\right) \psi_{i}^{K S}=\hat{h}^{K S} \psi_{i}^{K S}=\varepsilon_{i} \psi_{i}^{K S}
$$

onde as funções $\psi_{i}^{K S}$ são assim conhecidos por orbitais de Kohn-Shan, e

$$
v^{K S}[\rho]=v(\mathbf{r})+\int \frac{\rho(\mathbf{r})}{\left|\mathbf{r}-\mathbf{r}^{\prime}\right|} d \mathbf{r}^{\prime}+v_{x c}[\rho]
$$

e a partir delas podemos definir a função de onda eletrônica através de um determinante equivalente à B.4. Na equação D.3, o termo $v(\mathbf{r})$ é o potencial externo (tipicamente a interação elétron-núcleo) e $v_{x c}[\rho]$ diz respeito ao potencial de correlação e troca, conectado ao termo de energia de correlação e troca $E_{x c}$ atraves da 
relação

$$
v_{x c}[\rho]=\frac{\delta E_{x c}}{\delta \rho}
$$

Para sistemas de camada fechada, ou sistemas de spin compensado[28], a função de onda eletrônica do estado fundamental é construída com um determinante específico, mas com o uso de $N / 2$ orbitais, de forma que cada orbital está duplamente ocupado com elétrons em diferentes estados de spin, e satisfazem as equações D.2 para $i=$ $1,2, \ldots, \frac{N}{2}$. A densidade eletrônica é, nesse caso,

$$
\rho(\mathbf{r})=\sum_{i=1}^{N / 2} 2\left|\psi_{i}^{K S}(\mathbf{r})\right|^{2}
$$

e a energia eletrônica pode ser calculada da seguinte maneira

$$
E[\rho]=\sum_{i=1}^{N / 2} 2 \varepsilon_{i}-\frac{1}{2} \iint \frac{\rho(\mathbf{r}) \rho\left(\mathbf{r}^{\prime}\right)}{\left|\mathbf{r}-\mathbf{r}^{\prime}\right|} \mathrm{d} \mathbf{r} \mathrm{d} \mathbf{r}^{\prime}+\int \rho(\mathbf{r})\left\{\epsilon_{x c}(\rho(\mathbf{r}))-v_{x c}(\rho(\mathbf{r}))\right\} \mathrm{d} \mathbf{r}, \quad \text { (D.6) }
$$

que é a expressão da energia escrita em termos dos auto-valores das equações de KS. Ao longo de muitos anos, diversos funcionais foram propostos para descrever o termo de correlação e troca da equação D.6. 


\section{Apêndice E}

\section{DFT: Modelos para o termo de correlação e troca e funcionais híbridos}

Ao longo de muitos anos, diversos funcionais foram propostos para descrever o termo de correlação e troca da equação D.6. Nesse contexto, descreveremos duas aproximações para o termo de correlação e troca conhecidas como Local Spin Density Approximation - LSDA - e Generalized Gradient Approximation - GGA. Na aproximação de densidade de spin local (LSDA), aproxima-se a energia de correlação de troca no ponto $\mathbf{r}$ como a energia de correlação e troca de um gás de elétrons homogêneo de densidade $\rho(\mathbf{r})$. Nessa aproximação supõe-se que a densidade eletrônica varie lentamente nas vizinhanças do ponto r. Assim,

$$
\begin{aligned}
E_{x c}\left[\rho^{\alpha}, \rho^{\beta}\right] & \simeq E_{x c}^{L S D A}\left[\rho^{\alpha}, \rho^{\beta}\right]=\int\left(\epsilon_{x}\left(\rho^{\alpha}(\mathbf{r})\right)+\epsilon_{c}\left(\rho^{\alpha}(\mathbf{r})\right)\right) \rho^{\alpha}(\mathbf{r}) \mathrm{d} \mathbf{r} \\
& +\int\left(\epsilon_{x}\left(\rho^{\beta}(\mathbf{r})\right)+\epsilon_{c}\left(\rho^{\beta}(\mathbf{r})\right)\right) \rho^{\beta}(\mathbf{r}) \mathrm{d} \mathbf{r},
\end{aligned}
$$

onde $\alpha$ e $\beta$ denotam os diferentes estados de spin. Podemos, de outra forma e também sinteticamente, escrever o termo $E_{x c}^{L S D A}\left[\rho^{\alpha}, \rho^{\beta}\right]$ como uma soma de dois termos:

$$
E_{x c}^{L S D A}\left[\rho^{\alpha}, \rho^{\beta}\right]=E_{x}^{L S D A}\left[\rho^{\alpha}, \rho^{\beta}\right]+E_{c}^{L S D A}\left[\rho^{\alpha}, \rho^{\beta}\right]
$$


em que

$$
E_{x}^{L S D A}\left[\rho^{\alpha}, \rho^{\beta}\right]=\int\left(\epsilon_{x}\left(\rho^{\alpha}(\mathbf{r})\right) \rho^{\alpha}(\mathbf{r})+\epsilon_{x}\left(\rho^{\beta}(\mathbf{r})\right) \rho^{\beta}(\mathbf{r})\right) \mathrm{d} \mathbf{r}
$$

e

$$
E_{c}^{L S D A}\left[\rho^{\alpha}, \rho^{\beta}\right]=\int\left(\epsilon_{c}\left(\rho^{\alpha}(\mathbf{r})\right) \rho^{\alpha}(\mathbf{r})+\epsilon_{c}\left(\rho^{\beta}(\mathbf{r})\right) \rho^{\beta}(\mathbf{r})\right) \mathrm{d} \mathbf{r}
$$

Na aproximação LSDA, uma expressão analítica para o termo E.3 referente à energia de troca foi proposta diretamente da teoria quântica para gases de elétrons homogêneos,

$$
E_{x}^{L S D A}\left[\rho^{\alpha}, \rho^{\beta}\right]=2^{1 / 3} C_{x} \int\left\{\left(\rho^{\alpha}(\mathbf{r})\right)^{4 / 3}+\left(\rho^{\beta}(\mathbf{r})\right)^{4 / 3}\right\} \mathrm{d} \mathbf{r}
$$

onde

$$
C_{x}=\frac{3}{4}\left(\frac{3}{\pi}\right)^{1 / 3}
$$

Por outro lado, como não se obtém analiticamente uma expressão para o termo E.4, existem diversas propostas parametrizadas que foram sendo calibradas ao longo dos anos. Alguns trabalhos sobre propostas e parametrizações para os termos de correlação podem ser encontradas na literatura.

A aproximação (GGA) pode ser entendida como um refinamento da aproximação LSDA, onde se considera o termo de correlação e troca como uma função do gradiente da densidade eletrônica no ponto r. Entende-se esse aproximação como uma correção à LSDA pois em sistemas físicos, no geral, a densidade eletrônica não varia lentamente entre um determinado ponto e sua vizinhança. O funcional assume a seguinte fórmula:

$$
E_{x c}^{G G A}[\rho]=\int f(\rho(\mathbf{r}), \nabla \rho(\mathbf{r})) \mathrm{d} \mathbf{r}
$$

Assim como na equação E.2, esse termo pode ser entendido como uma contribuição de dois termos,

$$
E_{x c}^{G G A}[\rho]=E_{x}^{G G A}[\rho]+E_{c}^{G G A}[\rho] .
$$


Para o termo de troca, obteve-se uma expressão analítica dada por

$$
E_{x}^{G G A}[\rho]=-\frac{3}{4}\left(\frac{3}{\pi}\right)^{1 / 3} \int(\rho(\mathbf{r}))^{4 / 3} F(s(\mathbf{r})) \mathrm{d} \mathbf{r}
$$

onde $F(s(\mathbf{r}))$ é uma função cuja variável $s(\mathbf{r})$ indica a não-homogeneidade local da densidade eletrônica, e é dada por

$$
s(\mathbf{r})=\frac{|\nabla \rho(\mathbf{r})|}{2 k_{F} \rho(\mathbf{r})}
$$

em que $k_{F}=\left(3 \pi^{2} \rho\right)^{1 / 3}$. Note-se que, para $F(s(\mathbf{r}))=1$, obtemos um funcional de troca da mesma forma que o considerado na aproximação LSDA. Entretanto, muitas formas para a função $F$ foram propostas e diferentes funcionais de troca GGA foram criados. Analogamente à aproximação LSDA, não há uma expressão analítica para o termo de correlação eletrônica $E_{c}^{G G A}[\rho]$, e muitos trabalhos referentes às propostas e parametrizações podem ser encontrados na literatura.

A partir das aproximações LSDA e GGA, alguns funcionais foram construídos considerando combinações entre os funcionais de correlação e troca da teoria do funcional da densidade (DFT) com o termo de troca (exchange) da teoria Hartree-Fock. Esse funcionais foram batizados de funcionais híbridos, e o B3LYP (Beck, 3-parameter, Lee-Yang-Parr)[37] é um dos mais usados atualmente no estudo de propriedades eletrônicas de macromoléculas de interesse biológico, pois descreve de maneira satisfatória muitas medidas experimentais e possui baixo custo computacional. O funcional B3LYP é dado pela seguinte combinação de funcionais

$$
\begin{gathered}
E_{x c}^{B 3 L Y P}[\rho]=E_{x}^{L S D A}[\rho]+a_{0}\left(E_{x}^{H F}[\rho]-E_{x}^{L S D A}[\rho]\right)+ \\
a_{x}\left(E_{x}^{G G A}[\rho]-E_{x}^{L S D A}[\rho]\right)+a_{c}\left(E_{c}^{G G A}[\rho]-E_{c}^{L S D A}[\rho]\right),
\end{gathered}
$$

em que os parâmetros possuem os valores $a_{0}=0.20, a_{x}=0.72$ e $a_{c}=0.81$. 


\section{Apêndice F}

\section{Quadratura utilizada nas integrais dos cálculos de espalhamento}

Os cálculos numéricos implementados no código SMC utilizam a quadratura de Gauss-Legendre para calcular as integrais em coordenadas esféricas no espaço $k$. A determinação da quadratura adotada para resolver as integrais referentes aos elementos de matriz do operador $V G_{P}^{(+)} V$ na expressão de trabalho 3.22 foi baseada em cálculos preliminares dos sistemas 5-OCNU e 5-SCNU (ver capítulo 4).

Na Fig. F.1 mostramos a seção de choque da simetria $A^{\prime \prime}$ da 5-SCNU plana, na aproximação estático-troca. Uma das curvas (em vermelho) mostra o resultado obtido com a quadratura radial sendo construída com 32 pontos antes de um valor fixo $k_{\text {MAX }}=1.6$ mais 32 pontos a partir desse valor, sendo que para cada ponto da quadratura radial há uma quadratura angular de $32 \times 32$ pontos. A outra curva (em verde) mostra o mesmo resultado com uma quadratura maior; 48 pontos antes de $k_{\text {MAX }}$ mais 48 pontos a partir desse valor, sendo que para cada ponto da quadratura radial há uma quadratura angular de $48 \times 48$ pontos. Vemos que ambas as quadraturas se mostram razoavelmente equivalentes para descrever o primeiro pico na seção de choque, que se encontra em torno de $1.3 \mathrm{eV}$. Entretanto, para os segundos e terceiros picos há uma divergência significativa na descrição. A saber, ao aumentar a quadratura o distanciamento entre as ressonâncias diminui cerca de $0.4 \mathrm{eV}$, que é razoavelmente comparável à precisão usual do método.

O grande problema da última quadratura é que a mesma demanda um custo com- 


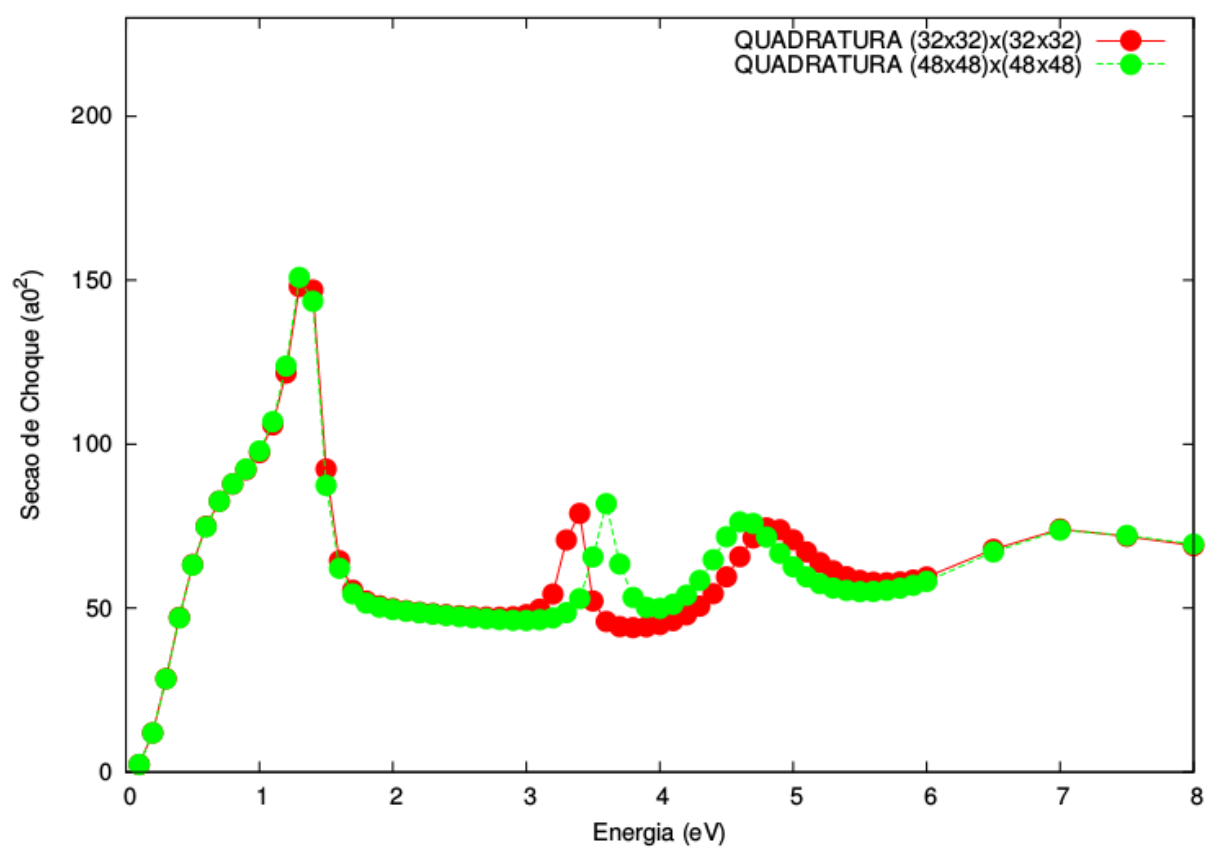

Figura F.1: Seção de choque integral da componente $A^{\prime \prime}$ da 5-SCNU plana, na aproximação ET. A curva vermelha foi obtida com a quadratura de $32+32$ pontos radiais com $32 \times 32$ pontos angulares para cada ponto radial,já a curva verde foi obtida com a quadratura de $48+48$ pontos radiais com $48 \times 48$ pontos angulares para cada ponto radial.

putacional muito grande, estimulando a busca por quadraturas alternativas. Nossa investigação se deu acerca de estabelecer a menor quadratura que reproduz o cálculo com a quadratura $(48+48) \times(48 \times 48)$. A menor quadratura encontrada foi um conjunto descrito da seguinte forma. Constroi-se a quadratura radial com $32+32$ pontos. Os 32 pontos radiais antes de $k_{\text {MAX }}$ são fixados a uma quadratura angular de $32 \times 32$ pontos. Dentre os 32 pontos radiais seguintes, os 24 primeiros possuem uma quadratura angular $48 \times 48$ enquanto que os últimos 8 possuem uma quadratura angular $32 \times 32$. Na Fig. F.2 as curvas com a quadratura finalmente estabelecida e a quadratura $(48+48) \times(48 \times 48)$ estão sobrepostas, mostrando o acordo dispendiosamente investigado. Essa quadratura foi utilizada em todos os cálculos de espalhamento subsequentes. 


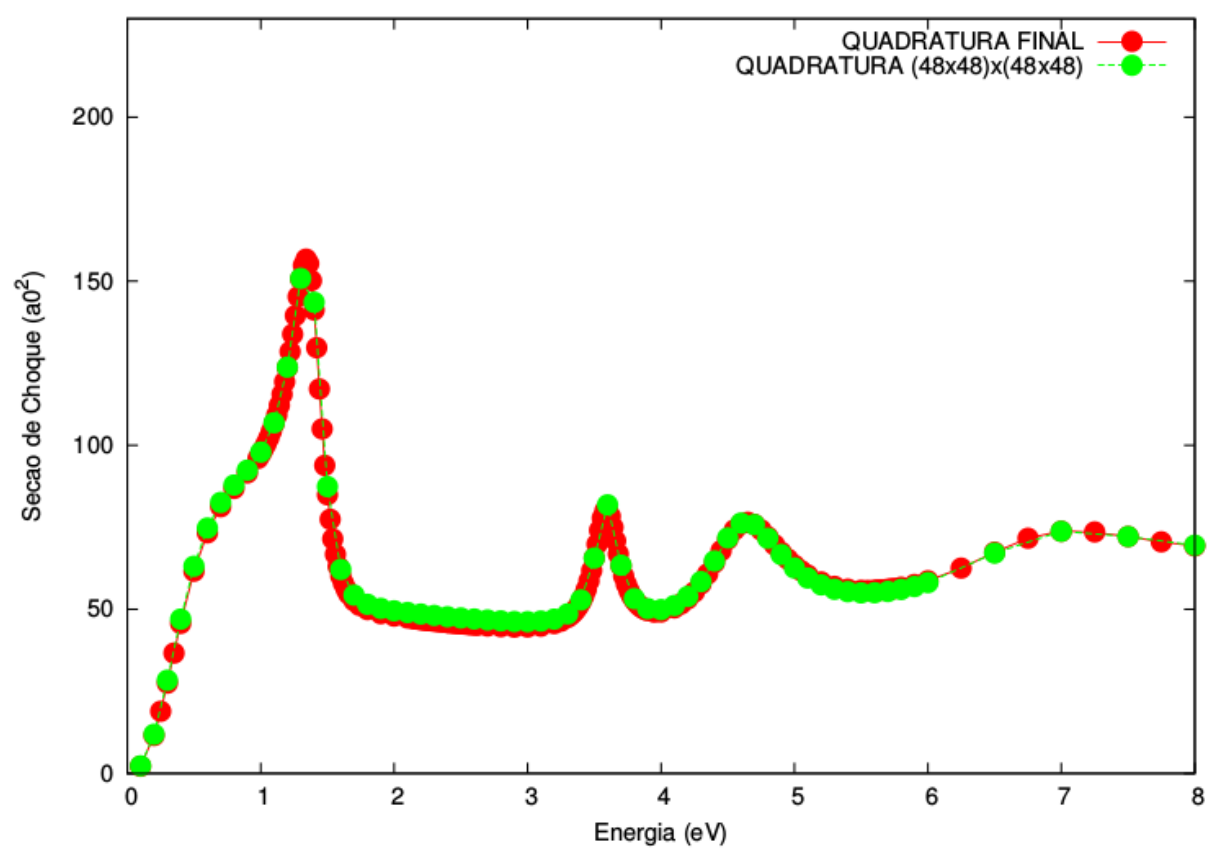

Figura F.2: Seção de choque integral da componente $A^{\prime \prime}$ da 5-SCNU plana, na aproximação ET. A curva vermelha foi obtida com a quadratura de $32+32$ pontos radiais com $32 \times 32$ pontos angulares para cada ponto radial, já a curva verde foi obtida com a quadratura de $32+8$ pontos radiais com $32 \times 32$ pontos angulares para cada um desses pontos radiais mais 24 pontos radiais com $48 \times 48$ pontos angulares para cada um desses pontos radiais. 


\section{Referências Bibliográficas}

[1] L. Chomicz, M. Zdrowowicz, F. Kasprzykowski, J. Rak, A. Buonaugurio, Y. Wang, and K. H. Bowen. How to find out whether a 5 -substituted uracil could be a potential DNA radiosensitizer. Journal of Physical Chemistry Letters, 4:2853-2857, 2013.

[2] J. S. dos Santos, R. F. da Costa, and M. T. do N. Varella. Low-energy electron collisions with glycine. The Journal of Chemical Physics, 136:084307, 2012.

[3] E. M. de Oliveira, S. d'A. Sanchez, M. H. F. Bettega, A. P. P. Natalense, M. A. P. Lima, and M. T. do N. Varella. Shape resonance spectra of lignin subunits. Physical Review A, 86(2):020701, 2012.

[4] F. Kossoski, M. H. F. Bettega, and M. T. do N. Varella. Shape resonance spectra of uracil, 5-fluorouracil, and 5-chlorouracil. The Journal of Chemical Physics, 140:024317, 2014.

[5] C. Winstead, V. McKoy, and S. D'Almeida Sanchez. Interaction of low-energy electrons with the pyrimidine bases and nucleosides of DNA. Journal of Chemical Physics, $127(8), 2007$.

[6] S. Tonzani and C. H. Greene. Low-energy electron scattering from DNA and RNA bases: Shape resonances and radiation damage. The Journal of Chemical Physics, $124(5), 2006$.

[7] A. Dora, J. Tennyson, L. Bryjko, and T. Van Mourik. R-matrix calculation of lowenergy electron collisions with uracil. The Journal of Chemical Physics, 130(16), 2009.

[8] F. A. Gianturco, F. Sebastianelli, R. R. Lucchese, I. Baccarelli, and N. Sanna. Ringbreaking electron attachment to uracil: Following bond dissociations via evolving resonances. The Journal of Chemical Physics, 128(17):1, 2008.

[9] F. Kossoski and M. T. do N. Varella. Negative ion states of 5-bromouracil and 5iodouracil. Physical Chemistry Chemical Physics, 17:17271, 2015.

[10] T. J. Martínez. Insights for light-driven molecular devices from ab initio multiple spawning excited-state dynamics of organic and biological chromophores. Accounts of Chemical Research, 39(2):119, 2006. 
[11] H. Abdoul-Carime, M. A. Huels, F. Brüning, E. Illenberger, and L. Sanche. Dissociative electron attachment to gas-phase 5-bromouracil. The Journal of Chemical Physics, 113(7):2517, 2000.

[12] C. J. Joachain. Quantum Collision Theory. North Holland, 1975.

[13] M. Joiner and A van der Kogel. Basic Clinic Radiobiology. London, Hodder Arnold, 2009.

[14] E. Alizadeh, T. M. Orlando, and L. Sanche. Biomolecular Damage Induced by Ionizing Radiation: The Direct and Indirect Effects of Low-Energy Electrons on DNA. Annual Review of Physical Chemistry, 66:379-398, 2015.

[15] E. Alizadeh and L. Sanche. Precursors of solvated electrons in radiobiological physics and chemistry. Chemical Reviews, 112(11):5578-5602, 2012.

[16] C. Wang, T. Luo, and Q. Lu. On the lifetimes and physical nature of incompletely relaxed electrons in liquid water. Physical Chemistry Chemical Physics, 10(30):44634470, 2008.

[17] B. Boudaïffa, P. Cloutier, D. Hunting, M. a Huels, and L. Sanche. Resonant formation of DNA strand breaks by low-energy (3 to $20 \mathrm{eV}$ ) electrons. Science (New York, N.Y.), 287(5458):1658-1660, 2000.

[18] L. Sanche. Biological chemistry: Beyond radical thinking. Nature, 461:358, 2009.

[19] I. Baccarelli, I. Bald, F. A. Gianturco, E. Illenberger, and J. Kopyra. Electron-induced damage of DNA and its components: Experiments and theoretical models. Physics Reports, 508(1-2):1-44, 2011.

[20] C. Wang, J. Nguyen, and Q. Lu. Bond breaks of nucleotides by dissociative electron transfer of nonequilibrium prehydrated electrons: A new molecular mechanism for reductive DNA damage. Journal of the American Chemical Society, 131(32):1132011322, 2009.

[21] M. A. Yandell, S. B. King, and D. M. Neumark. Time-resolved radiation chemistry: Photoelectron imaging of transient negative ions of nucleobases. Journal of the American Chemical Society, 135:2128-2131, 2013.

[22] S. B. King, M. A. Yandell, and D. M. Neumark. Time-resolved photoelectron imaging of the iodide-thymine and iodide-uracil binary cluster systems. Faraday Discussions, 163:59-72, 2013.

[23] S. Zamenhof, R. de Giovanni, and S. Greer. Induced gene unstabilization. Nature (London), 181:827, 1958.

[24] A. Szabo and N. S. Ostlund. Modern Quantum Chemistry: Introduction to Advanced Electronic Structure Theory. Dover Publications, Inc., 1996. 
[25] L. Pauling and E. B. Wilson Jr. Introduction to Quantum Mechanics with Applications to Chemistry. Mcgraw Hill, 1935.

[26] G. Herzberg and K. P. Huber. Molecular Spectra and Molecular Structure. 1956.

[27] J. D. M. Vianna, A. Fazzio, and S. Canuto. Teoria Quântica de Moléculas e Sólidos. Livraria da Física, 2004.

[28] N. H. Morgon and K. Coutinho. Métodos de Química Teórica e Modelagem Molecular. Livraria da Física, 2007.

[29] F. Jensen. Introduction to Computational Chemistry. Wiley, 2007.

[30] E. Runge and E. K. U. Gross. Density-Functional Theory for Time-Dependent Systems. Physical Review Letters, 52:997, 1984.

[31] C. Møller and M. S. Plesset. Note on an Approximation Treatment for Many-Electron Systems. Phys. Rev., 46:618, 1934.

[32] P. Slavíček and T. J. Martínez. Ab initio floating occupation molecular orbitalcomplete active space configuration interaction: An efficient approximation to CASSCF. The Journal of Chemical Physics, 132(23):1, 2010.

[33] X. Li, M. D. Sevilla, and L. Sanche. DFT Investigation of Dehalogenation of Adenine - Halouracil Base Pairs upon Low-Energy Electron Attachment. Journal of the American Chemical Society, 125(9):8916, 2003.

[34] H. Chen, P. Yang, H. Chen, C. Kao, and L. Liao. DFT reinvestigation of DNA strand breaks induced by electron attachment. The Journal of Physical Chemistry $B, 118: 11137,2014$.

[35] M. J. Gillan, D. Alfè, and A. Michaelides. Perspective: How good is DFT for water? The Journal of Chemical Physics, 144(13):130901, 2016.

[36] J. Gu, J. Wang, and J. Leszczynski. Low Energy Electron Attachment to the Adenosine Site of DNA. The Journal of Physical Chemistry B, 115(49):14831, 2011.

[37] A. D Becke. A new mixing of Hartree-Fock and local density-functional theories. The Journal of Chemical Physics, 98(2):1372, 1993.

[38] T. Yanai, D. P. Tew, and N. C. Handy. Chem. Phys. Lett., 51:393, 2004.

[39] J. D. Chai and M. Head-Gordon. Long-range corrected hybrid density functionals with damped atom-atom dispersion corrections. Physical Chemistry Chemical Physics, 10(44):6615, 2008.

[40] C. Adamo and V. Barone. Toward reliable density functional methods without adjustable parameters: The PBE0 model. The Journal of Chemical Physics, 110(13):6158, 1999. 
[41] Y. Zhao and D. G. Truhlar. Density functionals with broad applicability in chemistry. Accounts of Chemical Research, 41(2):157, 2008.

[42] Y. Zhao and D. G. Truhlar. The M06 suite of density functionals for main group thermochemistry, thermochemical kinetics, noncovalent interactions, excited states, and transition elements: Two new functionals and systematic testing of four M06class functionals and 12 other function. Theoretical Chemistry Accounts, 120:215, 2008 .

[43] W. W. Schmidt, K. K. Baldridge, J. A. Boatz, S. T. Elbert, M. S. Gordon, J. H. Jensen, S. Koseki, N. Matsunaga, K. A. Nguyen, S. Su, T. L. Windus, M. Dupuis, and J. A. Montgomery. General atomic and molecular electronic structure system. J. Comput. Chem., 14:1347, 1993.

[44] M. J. Frisch et al. Gaussian, inc. Wallingford CT, 2009.

[45] I. S. Ufimtsev and T. J. Martínez. Quantum chemistry on graphical processing units. 1. Strategies for two-electron integral evaluation. Journal of Chemical Theory and Computation, 4(2):222, 2008.

[46] I. S. Ufimtsev and T. J. Martinez. Quantum chemistry on graphical processing units. 2. direct self-consistent-field implementation. Journal of Chemical Theory and Computation, 5(4):1004, 2009.

[47] I. S. Ufimtsev and T. J. Martinez. Quantum chemistry on graphical processing units. 3. Analytical energy gradients, geometry optimization, and first principles molecular dynamics. Journal of Chemical Theory and Computation, 5(10):2619, 2009.

[48] K. Takatsuka and V. McKoy. Extension of the Schwinger variational principle beyond the static-exchange approximation. Physical Review A, 24(5):2473-2480, 1981.

[49] K. Takatsuka and V. McKoy. Theory of electronically inelastic scattering of electrons by molecules. Physical Review A, 30(4):1734-1740, 1984.

[50] R. F. da Costa, M. T. do N. Varella, M. H. F. Bettega, and M. A. P. Lima. Recent advances in the application of the Schwinger multichannel method with pseudopotentials to electron-molecule collisions. Eur. Phys. J. D, 69:159, 2015.

[51] M. A.P. Lima and V. McKoy. Aspects of the Schwinger multichannel variational formulation. Physical Review A, 38(1):501, 1988.

[52] M. H. F. Bettega, L. G. Ferreira, and M. A. P. Lima. Local-Density Norm-Conserving Pseudopotentials. Physical Review A, 47(2):1111, 1993.

[53] G. B. Bachelet, D. R. Hamann, and M. Schluter. Pseutopotentials that work: From H to Pu. Physical Review B, 26(8):4199, 1982. 
[54] T. H. Dunning. Gaussian basis functions for use in molecular calculations. Contraction of (12s9p) atomic basis sets for the second row atoms. Chemical Physics Letters, $7(1970): 423,1970$.

[55] M. A. P. Lima, L. M. Brescansin, A. J.R. da Silva, C. Winstead, and V. McKoy. Applications of the Schwinger multichannel method to electron-molecule collisions. Physical Review A, 41(1):327, 1990.

[56] F. Kossoski and M. H F Bettega. Low-energy electron scattering from the azaderivatives of pyrrole, furan, and thiophene. The Journal of Chemical Physics, 138(2013), 2013.

[57] C. W. Bauschlicher. The construction of modified virtual orbitals (MVO's) which are suited for configuration interaction calculations. The Journal of Chemical Physics, $72(1980): 880,1980$.

[58] S. W. Staley and J. T. Strnad. Calculation of the Energies of pi* Negative Ion Resonance States by the Use of Koopmans' Theorem. The Journal of Physical Chemistry, page 116, 1994.

[59] J Kopyra, H. Abdoul-Carime, F. Kossoski, and M. T. do N. Varella. Electron driven reactions in sulphur containing analogues of uracil: the case of 2-thiouracil. Physical Chemistry Chemical Physics, 16:25054, 2014.

[60] A. V. Marenich, C. J. Cramer, and D. G. Truhlar. Universal Solvation Model Based on Solute Electron Density and on a Continuum Model of the Solvent Defined by the Bulk Dielectric Constant and Atomic Surface Tensions. The Journal of Physical Chemistry B, 113(18):6378, 2009.

[61] C. P. Kelly, C. J. Cramer, and D. G. Truhlar. Aqueous Solvation Free Energies of Ions and Ion - Water Clusters Based on an Accurate Value for the Absolute Aqueous Solvation Free Energy of the Proton. The Journal of Physical Chemistry B, page 16066, 2006.

[62] H. M. Cezar, S. Canuto, and K. Coutinho. DICE A Monte Carlo program for molecular liquid simulation. University of São Paulo, 2018.

[63] L. Onsager. Electric moments of molecules in liquids. Journal of the American Chemical Society, 58(8):1486, 1936.

[64] J. G. Kirkwood. On the theory of dielectric polarization. The Journal of Chemical Physics, 4(9):592, 1936.

[65] O. Tapia and O. Goscinski. Self consistent Reaction Field Theory of Solvent Effects. Molecular Physics, 29(6):1653, 1975. 
[66] J. Rivail and D. Rinaldi. A Quantum Chemical Approach to Dielectric Solvent Effects in Molecular Liquids. Chemical Physics, 18(1-2):233, 1976.

[67] A. Nitzan. Chemical Dynamics in Condensed Phases: Relaxation, Transfer, and Reactions in Condensed Molecular Systems. Oxford Graduate Texts. OUP Oxford, 2013.

[68] S. Canuto. Solvation Effects on Molecules and Biomolecules: Computational Methods and Applications. Springer Verlag, 2008.

[69] J. Tomasi, B. Mennucci, and R. Cammi. Quantum Mechanical Continuum Solvation Models. Chemical Reviews, 105(8):2999, 2005.

[70] M. P. Allen and D. J. Tildesley. Computer Simulation of Liquids. Oxford Science Publ. Clarendon Press, 1989.

[71] D. Frenkel and B. Smit. Understanding Molecular Simulation: From Algorithms to Applications. Academic Press, 2002.

[72] W. L. Jorgensen, D. S. Maxwell, and J. Tirado-Rives. Development and Testing of the OPLS All-Atom Force Field on Conformational Energetics and Properties of Organic Liquids. Journal of the American Chemical Society, 118(45), 1996.

[73] W. D. Cornell, P. Cieplak, C. I. Bayly, I. R. Gould, K. M. Merz, D. M. Ferguson, D. C. Spellmeyer, T. Fox, J. W. Caldwell, and P. A. Kollman. A second generation force field for the simulation of proteins, nucleic acids, and organic molecules. Journal of the American Chemical Society, 117(19):5179, 1995.

[74] C. M. Breneman and K. B. Wiberg. Determining atom-centered monopoles from molecular electrostatic potentials. the need for high sampling density in formamide conformational analysis. Journal of Computational Chemistry, 11(3):361, 1990.

[75] H. J. C. Berendsen, J. R. Grigera, and T. P. Straatsma. The missing term in effective pair potentials. The Journal of Physical Chemistry, 91(24):6269, 1987.

[76] V. Vinš, D. Celný, B. Planková, T. Němec, M. Duška, and J. Hrubý. Molecular Simulations of the Vapor-Liquid Phase Interfaces of Pure Water Modeled with the SPC/E and the TIP4P/2005 Molecular Models. 114(02136), 2016.

[77] H. C. Georg, K. Coutinho, and S. Canuto. Solvent effects on the UV-visible absorption spectrum of benzophenone in water: A combined Monte Carlo quantum mechanics study including solute polarization. The Journal of Chemical Physics, 126:34507, 2007.

[78] S. Canuto, K. Coutinho, and D. Trzesniak. New developments in Monte Carlo/quantum mechanics methodology. The solvatochromism of $\beta$-carotene in different solvents. Advances in Quantum Chemistry, 41:161, 2002. 
[79] K. Coutinho, H. C. Georg, T. L. Fonseca, V. Ludwig, and S. Canuto. An efficient statistically converged average configuration for solvent effects. Chemical Physics Letters, 437:148-152, 2007.

[80] F. A. Gianturco, D. G. Thompson, and A. Jain. Electron-scattering from polyatomic molecules using a single-center-expansion formulation. In Computational Methods for Electron-Molecule Collisions, pages 75-118. Springer, 1995.

[81] F. Blanco and G. García. Screening corrections for calculation of electron scattering differential cross sections from polyatomic molecules. Physics Letters A, 330(3-4):230, 2004.

[82] T. N. Rescigno, C. W. McCurdy, A. E. Orel, and B. H. Lengsfield. The complex kohn variational method. In Computational Methods for Electron-Molecule Collisions, pages 1-44. Springer, 1995.

[83] J. Tennyson. Electron-molecule collision calculations using the r-matrix method. Physics Reports, 491(2-3):29, 2010.

[84] T. C. Jagau, K. B. Bravaya, and A. I. Krylov. Extending quantum chemistry of bound states to electronic resonances. Annual review of physical chemistry, 68, 2017.

[85] J. D. Gorfinkiel and S. Ptasinska. Electron scattering from molecules and molecular aggregates of biological relevance. Journal of Physics B: Atomic, Molecular and Optical Physics, 50(18):182001, 2017.

[86] T. C. Freitas, M. A. P. Lima, S. Canuto, and M. H. F. Bettega. Physical Review A, 80:062710, 2009.

[87] S. Caprasecca, J. D. Gorfinkiel, D. Bouchiha, and L. G. Caron. Journal of Physics B, 42:095205, 2009.

[88] T. C. Freitas, K. Coutinho, M. T. do N. Varella, M. A. P. Lima, S. Canuto, and M. H. F. Bettega. The Journal of Chemical Physics, 138:174307, 2013.

[89] E. M. de Oliveira, T. C. Freitas, K. Coutinho, M. T. do N. Varella, S. Canuto, M. A. P. Lima, and M. H. F. Bettega. (Communication) The Journal of Chemical Physics, 141:051105, 2014.

[90] M. Smyth, J. Kohanoff, and I. Fabrikant. Electron-induced hydrogen loss in uracil in a water cluster environment. The Journal of Chemical Physics, 140(18):184313, 2014 .

[91] A. Sieradzka and J. D. Gorfinkiel. Theoretical study of resonance formation in microhydrated molecules. i. pyridine- $(\mathrm{H} 2 \mathrm{O}) \mathrm{n}, \mathrm{n}=1,2,3,5$. The Journal of Chemical Physics, 147(3):034302, 2017. 
[92] A. Sieradzka and J. D. Gorfinkiel. Theoretical study of resonance formation in microhydrated molecules. ii. thymine- $(\mathrm{H} 2 \mathrm{O}) \mathrm{n}, \mathrm{n}=1,2,3,5$. The Journal of Chemical Physics, 147(3):034303, 2017.

[93] P. Schyman and A. Laaksonen. On the effect of low-energy electron induced dna strand break in aqueous solution: A theoretical study indicating guanine as a weak link in dna. Journal of the American Chemical Society, 130(37):12254, 2008.

[94] M. Smyth and J. Kohanoff. Excess electron interactions with solvated DNA nucleotides: Strand breaks possible at room temperature. Journal of the American Chemical Society, 134(22):9122, 2012.

[95] L. M. Cornetta, K. Coutinho, S. Canuto, and M. T. do N. Varella. Free energy barrier for dissociation of the guanosine monophosphate anion in water. The European Physical Journal D, 70:176, 2016.

[96] M. McAllister, N. Kazemigazestane, L. T. Henry, B. Gu, I. Fabrikant, G. A. Tribello, and J. Kohanoff. Solvation Effects on Dissociative Electron Attachment to Thymine. The Journal of Physical Chemistry B, 123(7):1537, 2019.

[97] M. Neustetter, J. Aysina, F. F. da Silva, and S. Denifl. The Effect of Solvation on Electron Attachment to Pure and Hydrated Pyrimidine Clusters. Angewandte Chemie - International Edition, 54(31):9124, 2015.

[98] J. Kocisek, A. Pysanenko, M. Fárník, and J. Fedor. Microhydration prevents fragmentation of uracil and thymine by low-energy electrons. The Journal of Physical Chemistry Letters, 7(17):3401, 2016.

[99] J. Poštulka, P. Slavíček, J. Fedor, M. Fárník, and J. Kočišek. Energy Transfer in Microhydrated Uracil, 5-Fluorouracil, and 5-Bromouracil. Journal of Physical Chemistry B, 121:8965, 2017.

[100] J. Berdys, P. Skurski, and J. Simons. Damage to model dna fragments by $0.25-1.0$ ev electrons attached to a thymine $\pi^{*}$ orbital. The Journal of Physical Chemistry B, 108(18):5800, 2004.

[101] M. Smyth and J. Kohanoff. Excess electron localization in solvated dna bases. Physical Review Letters, 106(23):238108, 2011.

[102] J. Gu, J. Leszczynski, and H. F. Schaefer. Interactions of electrons with bare and hydrated biomolecules: From nucleic acid bases to DNA segments. Chemical Reviews, 112:5603, 2012.

[103] F. Kossoski, J. Kopyra, and M. T. do N. Varella. Anion states and fragmentation of 2-chloroadenine upon low-energy electron collisions. Physical Chemistry Chemical Physics, 17(43):28958, 2015. 
[104] F. Kossoski and M. T. do N. Varella. How does methylation suppress the electroninduced decomposition of 1-methyl-nitroimidazoles? The Journal of Chemical Physics, 147(16):164310, 2017.

[105] D. Nachtigallovaí, A. J. A. Aquino, J. J. Szymczak, M. Barbatti, P. Hobza, and H. Lischka. Nonadiabatic dynamics of uracil: Population split among different decay mechanisms. The Journal of Physical Chemistry A, 115:5247-5255, 2011.

[106] S. Yamazaki and T. Taketsugu. Nonradiative deactivation mechanisms of uracil, thymine, and 5-fluorouracil: A comparative ab initio study. The Journal of Physical Chemistry A, 116:491, 2012.

[107] C. Bistafa, H. C. Georg, and S. Canuto. Combining ab initio multiconfigurational and Free Energy Gradient methods to study the $\pi-\pi^{*}$ excited state structure and properties of uracil in water. Computational and Theoretical Chemistry, 1040-1041:312, 2014.

[108] P. L. Gertitschke and W. Domcke. Time-dependent wave-packet description of dissociative electron attachment. Physical Review A, 47(2):1031, 1993.

[109] SA Pshenichnyuk, IA Pshenichnyuk, EP Nafikova, and NL Asfandiarov. Dissociative electron attachment in selected haloalkanes. Rapid Communications in Mass Spectrometry: An International Journal Devoted to the Rapid Dissemination of Upto-the-Minute Research in Mass Spectrometry, 20(7):1097, 2006.

[110] D. A. Horke, Q. Li, L. Blancafort, and J. R. R. Verlet. Nature Chemistry, 5:711, 2013.

[111] A. M. Scheer, K. Aflatooni, G. A. Gallup, and P. D. Burrow. Bond Breaking and Temporary Anion States in Uracil and Halouracils: Implications for the DNA Bases. Physical Review Letters, 92(6):3, 2004.

[112] R. Abouaf and H. Dunet. Structures in dissociative electron attachment cross-sections in thymine, uracil and halouracils. European Physical Journal D, 35:405, 2005.

[113] W. L. Jorgensen and P. Schyman. Treatment of halogen bonding in the OPLS-AA force field: Application to potent anti-HIV agents. Journal of Chemical Theory and Computation, 8(10):3895, 2012.

[114] J. Quenneville, M. Ben-Nun, and T. J Martínez. Photochemistry from first principles - advances and future prospects. Journal of Photochemistry and Photobiology A: Chemistry, 144:229, 2001.

[115] H. R. Hudock, B. G. Levine, A. L. Thompson, H. Satzger, D. Townsend, N. Gador, S. Ullrich, A. Stolow, and T. J. Martínez. The Journal of Physical Chemistry A, 111:8500, 2007. 
[116] A. M. Virshup, C. Punwong, T. V. Pogorelov, B. A. Lindquist, C. Ko, and T. J Martİnez. Photodynamics in Complex Environments: Ab InitioMultiple Spawning Quantum Mechanical/Molecular Mechanical Dynamics $\{\backslash$ dag $\}$. The Journal of Physical Chemistry B, 113(11):3280, 2009.

[117] A. L. Thompson, C. Punwong, and T. J. Martínez. Optimization of width parameters for quantum dynamics with frozen Gaussian basis sets. Chemical Physics, 370(1-3):70, 2010 .

[118] F. Kossoski, M. T.do N. Varella, and M. Barbatti. On-the-fly dynamics simulations of transient anions. The Journal of Chemical Physics, 151(22):224104, 2019.

[119] R. Crespo-Otero and M. Barbatti. Recent Advances and Perspectives on Nonadiabatic Mixed Quantum-Classical Dynamics. Chemical Reviews, 118(15):7026, 2018.

[120] T. F. O'Malley. Theory of dissociative attachment. Physical Review, 150:14, 1966.

[121] W. Domcke. Theory of resonance and threshold effects in electron-molecule collisions: The projection-operator approach. Physics Reports, 208(2):97, 1991.

[122] E. P. Wigner. On the behavior of cross sections near thresholds. Physical Review, 73:1002, 1948.

[123] H. Abdoul-Carime, M. A. Huels, E. Illenberger, and L. Sanche. Formation of negative ions from gas phase halo-uracils by low-energy $(0-18 \mathrm{eV})$ electron impact. International Journal of Mass Spectrometry, 228:703, 2003.

[124] R. Abouaf, J. Pommier, and H. Dunet. Negative ions in thymine and 5-bromouracil produced by low energy electrons. International Journal of Mass Spectrometry, 226:397, 2003.

[125] L. M. Cornetta, F. Kossoski, and M. T.Do N. Varella. Transient anion spectra of the potential radiosensitizers 5-cyanateuracil and 5-thiocyanateuracil. The Journal of Chemical Physics, 147(21), 2017.

[126] M. Born and R. Oppenheimer. Zur Quantentheorie der Molekeln. Annalen der Physik, 84(20):457, 1927.

[127] G. Herzberg and B. L. Crawford. Infrared and Raman Spectra of Polyatomic Molecules. The Journal of Physical Chemistry, 50(3):288-288, 1946.

[128] E. Butkov. Mathematical Physics. Addison-Wesley, 1968.

[129] H. J. Weber and G. B. Arfken. Essential Mathematical Methods for Physicists. Elsevier Science, 2003.

[130] M. Born and K. Huang. Dynamical Theory of Crystal Lattices. Oxford classic texts in the physical sciences. Clarendon Press, 1988. 
[131] H. Hellmann. Einführung in die Quantenchemie. Deutsche, Leipzig, 1937.

[132] R. P. Feynman. Forces in molecules. Physical Review, 56(4):340-343, 1939.

[133] J. A. Pople and R. K. Nesbet. Self-consistent orbitals for radicals. The Journal of Chemical Physics, 22(3):571, 1954. 